\title{
Utilização de Medidas de Previsibilidade em Sinais de Voz para Discriminação de Patologias de Laringe
}

\section{Paulo Rogério Scalassara}

\author{
Tese apresentada à Escola de Engenha- \\ ria de São Carlos da Universidade de São \\ Paulo, como parte dos requisitos para ob- \\ tenção do título de Doutor em Engenharia \\ Elétrica \\ ORIENTADOR: Prof. Dr. José Carlos Pereira \\ ÁREA DE CONCENTRAÇÃO: Processamento Digital de Sinais
}


AUTORIZO A REPRODUÇÃO E DIVULGAÇÃO TOTAL OU PARCIAL DESTE TRABALHO, POR QUALQUER MEIO CONVENCIONAL OU ELETRÓNICO, PARA FINS DE ESTUDO E PESQUISA, DESDE QUE CITADA A FONTE.

Ficha catalográfica preparada pela Seção de Tratam ento da Inform ação do Serviço de Biblioteca - EESC/USP

Scalassara, Paulo Rogério

utilização de medidas de previsibilidade em sinais de voz para discriminação de patologias de laringe / Faulo Rogério Scalassara; orientador José Carlos Pereira. -Sāo Carlos, 2009 .

Tese (Doutorado-Programa de Pós-Graduação em Engenharia Blétrica e Área de Concentração em Processamento Digital de Sinais) -- Escola de Engenharia de são Carlos da Universidade de São Paulo, 2009.

1. Voz. 2. Previsibilidade. 3. Entropia. 4. Potência de previsão. 5. Patologia. 6. Nódulo. 7. Edema de Reinke. 8. Análise de componentes previsiveis. I. Titulo. 
FOLHA DE JULGAMENTO

Candidato: Engenheiro PAULO ROGERIO SCALASSARA.

Tese defendida e jułgada em 10/11/2009 perante a Comissão Julgadora:
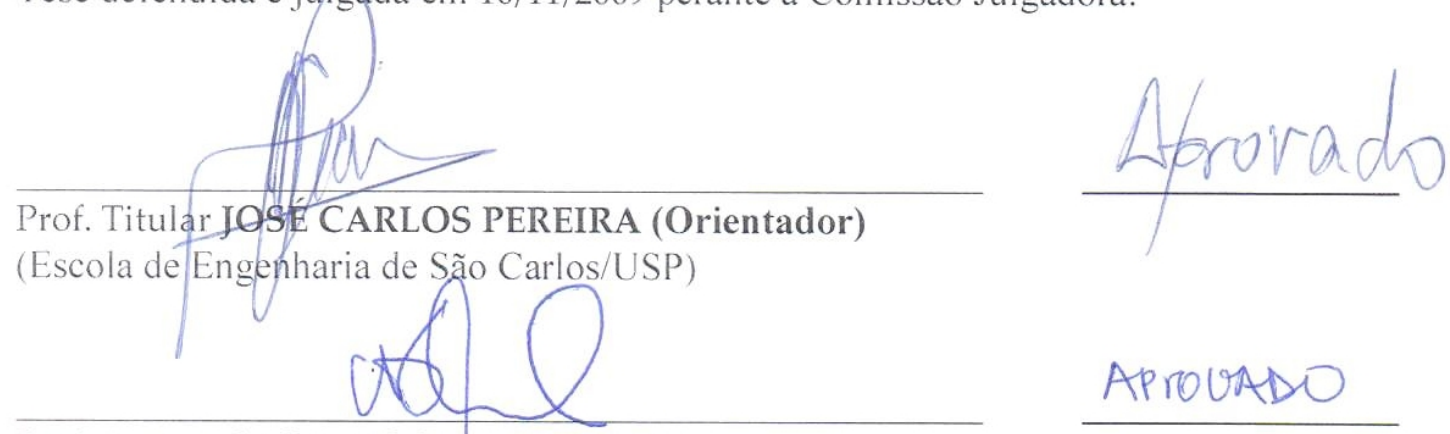

APROUADO

Prof. Associado CARLOS DIAS MACIEL

(Escola de Engenharia de São Carlos/USP)
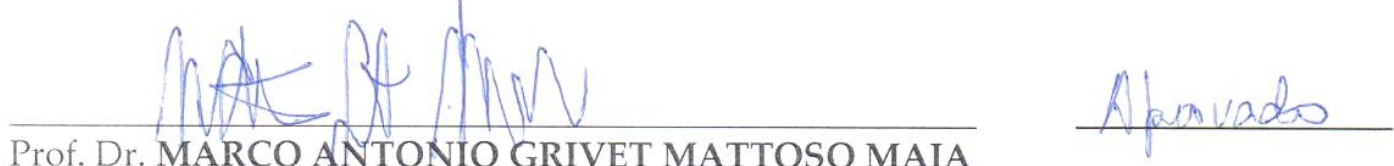

(Pontificia Uniyersidade)Católica/PUC/Campus do Rio de Janeiro)

Prof. Tifutar FRANCISCO JAVIER RAMIREZ FERNANDEZ

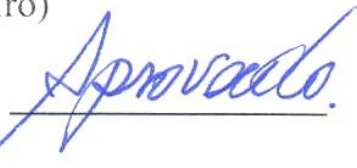

(Escola Politécnica/USP)

If. barrallt.

Prof. Associado APARECIDO AUGUSTO DE CARVALHO

(Universidade Estadual Paulista "Julio de Mesquita Filho"/UNESP/Campus de Ilha Solteira)

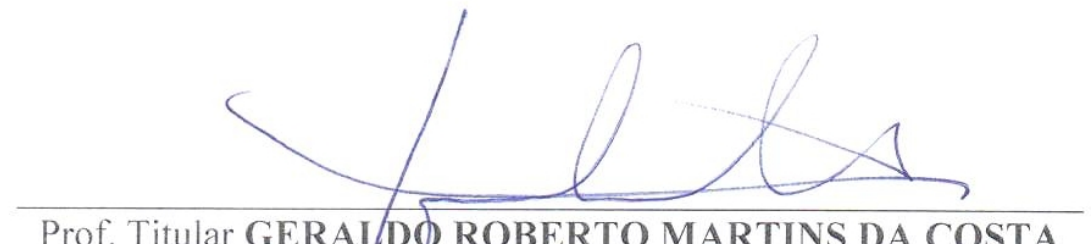

Prof. Titular GERAL/D $\phi$ ROBERTO MARTINS DA COSTA

Coordenador do Progranna/de Pós-Graduação em Engenharia Elétrica e Presidente da Comissão de Pós-Graduação 
Dedicatória

Dedico este trabalho à minha esposa Melissa e ao filhote Tomás. 
Eu gostaria de agradecer, inicialmente, a Deus, pela iluminação muito necessária no desenvolvimento deste trabalho. Também, por ter me capacitado a vencer a "inércia de não fazer nada" e a nunca desistir quando as coisas ficavam difíceis.

Logo em seguida, um agradecimento muito especial a minha esposa Melissa, pois ela suportou todas as dificuldades junto comigo, dividindo o "peso do fardo" a ser carregado. Além disso, perdeu muitas horas da minha companhia quando tive que "por a mão na massa".

Também, aos meus pais por sempre me incentivarem a continuar e a pensar no futuro. E, claro, por me ensinarem a estudar!

Agradeço aos meus orientadores, profs. Pereira e Maciel, por me auxiliarem, discutirem os problemas, terem paciência e ajudarem no desenvolvimento deste trabalho. As conversas e conselhos foram imprescindíveis.

Obrigado também às fonoaudiólogas Eugenia e Jamille por terem analisado tantas vozes quantas foram necessárias para os estudos e por terem me ajudado com a parte fisiológica "da coisa".

Um agradecimento também ao pessoal do LPS e do LIM, por terem contribuído com discussões, materiais e muitas risadas.

Agradeço, também, a todos que me ajudaram durante minha estada em Iowa City. Aos profs. Karnell e Titze por discutirem sobre análise de voz, a fonoaudióloga Abby por coletar diversos sinais e ao prof. Diego Moreira pelas discussões matemáticas, as quais ajudaram muito a ver os problemas por outra perspectiva.

Por fim, um agradecimento especial à Fapesp por ter me financiado este tempo todo com duas bolsas, as quais foram essenciais para uma melhor qualidade de vida neste período. 
"É muito difícil fazer previsões,

especialmente sobre o futuro."

Niels Bohr (1885-1962) 


\section{Sumário}

$\begin{array}{ll}\text { Lista de Figuras } & \text { xv }\end{array}$

$\begin{array}{ll}\text { Lista de Tabelas } & \text { xxi }\end{array}$

Lista de Símbolos $\quad$ xxiii

$\begin{array}{ll}\text { Lista de Siglas } & \text { xxix } \\ & \end{array}$

Resumo $\quad$ xxxi

Abstract $\quad$ xxxiii

1 Introdução 1

2 Análise de Voz $\quad 7$

2.1 Sistema Vocálico . . . . . . . . . . . . . . . . . . . . . . . . . 9

2.1.1 Modelos do Sistema Vocálico . . . . . . . . . . . . . . . . . . . . . 12

2.1.2 Características dos Sinais de Voz . . . . . . . . . . . . . 16

2.2 Patologias da Laringe . . . . . . . . . . . . . . . . . . . . . . . . . 19

2.2.1 Nódulo nas Pregas Vocais _ . . . . . . . . . . . . . . . . . 20

2.2.2 Edema de Reinke . . . . . . . . . . . . . . . . . . . . . . . . 21

2.2 .3 Avaliação das Patologias . . . . . . . . . . . . . . . . . . 22

2.3 Estudos dos Sinais de Voz . . . . . . . . . . . . . . . . . 25

2.3 .1 Histórico . . . . . . . . . . . . . . . . . 26

2.3 .2 Análise Acústica . . . . . . . . . . . . . . . . . . . . . . 27

2.3.3 Classificadores e Outros Métodos . . . . . . . . . . . . . . . . . 32

2.3.4 Métodos Não-Lineares e Probabilísticos . . . . . . . . . . . . . . . . 39

3 Estudos de Previsibilidade 43

3.1 Introdução ao Método . . . . . . . . . . . . . . . . . . . . 46

3.2 Medidas de Previsibilidade . . . . . . . . . . . . . . . . . . . . . . . . 47 
$3.2 .1 \quad$ Entropia . . . . . . . . . . . . . . . . . . . . 48

3.2.2 Características da Curva de Entropia . . . . . . . . . . . . . . . 50

3.2.3 Potência de Previsão . . . . . . . . . . . . . . . . . . . . . . . . . . . 54

3.3 Análise de Componentes Previsíveis . . . . . . . . . . . . . . . . . . 58

4 Sinais e Modelos de Previsão de Voz

4.1 Sinais de $\operatorname{Voz} \ldots \ldots \ldots \ldots$. . . . . . . . . . . . . . . 65

4.2 Modelos de Previsão dos Sinais . . . . . . . . . . . . . . . . . . . . . . . 74

4.2.1 Modelo Autorregressivo . . . . . . . . . . . . . . . . . . . . . . . . . 74

4.2.2 Modelo de Decomposição por Wavelets . . . . . . . . . . . . . . . . . 81

4.2.3 Análise da Representação Multidimensional da Voz . . . . . . . . . . 95

5 Algoritmos $\quad 105$

5.1 Estimativa da Entropia . . . . . . . . . . . . . . . . . . . . . 105

5.1.1 Método da Discretização da Entropia Diferencial . . . . . . . . . . . . 108

5.1.2 Método do Passo de Quantização Constante . . . . . . . . . . . . . . 114

5.1.3 Método da Equalização do Histograma . . . . . . . . . . . . . . . . 123

5.1 .4 Entropia de Blocos . . . . . . . . . . . . . . . . . . . . . 128

5.2 Estimativa da Potência de Previsão . . . . . . . . . . . . . . . . . . 136

5.2 .1 PP com Modelo AR . . . . . . . . . . . . . . . . . . . . 136

5.2.2 PP com Modelo Baseado em Decomposição por Wavelets . . . . . . . 140

5.3 Algoritmo de Análise de Componentes Previsíveis . . . . . . . . . . . . . . . 144

5.3.1 PrCA e Sinais Temporais . . . . . . . . . . . . . . . . . . . 146

5.3.2 PrCA e Representações Tridimensionais . . . . . . . . . . . . . . . . 151

6 Ensaios e Resultados $\quad 157$

6.1 Ensaios de Medidas de Entropia . . . . . . . . . . . . . . . . 157

6.1 .1 Curvas de Entropia . . . . . . . . . . . . . . . . . . . . 162

6.2 Ensaios de Potência de Previsão . . . . . . . . . . . . . . . . . . . . . . 165

6.2 .1 Modelagem AR . . . . . . . . . . . . . . . . . 165

6.2.2 Modelagem Baseada em Decomposição por Wavelets . . . . . . . . 168

6.3 Ensaios de $\operatorname{PrCA} \ldots \ldots \ldots 171$

6.3.1 Análise Temporal usando Modelo AR . . . . . . . . . . . . . . . . . . 171

6.3.2 Análise Temporal usando Modelo Wavelet . . . . . . . . . . . . . . . 173

6.3.3 Análise da Representação Tridimensional . . . . . . . . . . . . . . . . 177

7 Discussão e Conclusões 181 
7.1 Discussão dos Métodos e Resultados . . . . . . . . . . . . . . . . . . . . 181

$7.1 .1 \quad$ Entropia . . . . . . . . . . . . . . . . . . 183

7.1.2 Potência de Previsão . . . . . . . . . . . . . . . . . . . . . 185

7.1.3 Análise de Componentes Previsíveis . . . . . . . . . . . . 188

7.2 Contribuição Científica . . . . . . . . . . . . . . . . . . . . . . . . . 190

7.3 Conclusões Gerais . . . . . . . . . . . . . . . . . . . . . . . . . . . . . . . . 194

7.4 Próximos Passos . . . . . . . . . . . . . . . . . . . . . . 197

$\begin{array}{ll}\text { Referências Bibliográficas } & 199\end{array}$

$\begin{array}{ll}\text { Apêndice A - Simulador de Sinais de Voz } & 219\end{array}$

Apêndice B - Erro da Entropia Relativa pelo Deslocamento da PDF 225

Apêndice C - Entropia de Distribuições Gaussianas $\quad 227$

C.1 Entropia de Shannon de uma Distribuição Gaussiana . . . . . . . . . . . . . 227

C.2 Entropia Relativa entre duas Distribuições Gaussianas . . . . . . . . . . . 229 


\section{Lista de Figuras}

FIGURA 1.1 Comparação de MSE de estimativa de sinal com baixo nível de ruído 3

FIGURA 1.2 Comparação de MSE de estimativa de sinal com alto nível de ruído . 3

FIGURA 2.1 Imagens das fases aberta e fechada das pregas vocais $\ldots \ldots \ldots$

FIGURA 2.2 Esquemático da formação do trato vocal . . . . . . . . . . . . . . . 10

FIGURA 2.3 Esquemático da formação anatômica da laringe . . . . . . . . . . . . 11

FIGURA 2.4 Esquemático da formação histológica de uma prega vocal . . . . . . 12

FIGURA 2.5 Esquemático do sistema fonte-filtro $\ldots \ldots \ldots$

FIGURA 2.6 Ilustração do espectro de potências dos sinais da produção da voz . . 14

FIGURA 2.7 Esquemático do modelo matemático linear da produção de voz . . . . 15

FIGURA 2.8 Exemplo de sinal de voz masculino e sua PSD $\ldots \ldots \ldots$

FIGURA 2.9 Exemplo de resíduo de sinal de voz $\ldots \ldots \ldots \ldots$

FIGURA 2.10 Imagens de pregas vocais com nódulos $\ldots \ldots$. . . . . . . . . . 20

FIGURA 2.11 Imagens de pregas vocais com edemas de Reinke . . . . . . . . . . . 21

FIGURA 2.12 Ilustrações de jitter e shimmer da voz . . . . . . . . . . . . . 30

FIGURA 3.1 Estrutura interna do sistema e transição de seus estados . . . . . . . . . 45

FIGURA 3.2 Comportamento típico da curva de crescimento da entropia . . . . . . 52

FIGURA 3.3 Derivadas da curva de crescimento de entropia $\ldots \ldots$. . . . . . . 53

FIGURA 3.4 Representação tridimensional de um sinal senoidal com ruído . . . . 61 
FIGURA 4.1 Exemplo de sinal de voz não pré-processado $\ldots$. . . . . . . . . . . 67

FIGURA 4.2 Ilustração da escolha do trecho de sinal a ser analisado . . . . . . . . 68

FIGURA 4.3 Exemplos de vozes dos grupos analisados . . . . . . . . . . . . . 70

FIGURA 4.4 Exemplos de representações tridimensionais dos sinais patológicos 71

FIGURA 4.5 Gráficos dos valores dos parâmetros acústicos dos sinais de voz . . 73

FIGURA 4.6 PSD de um sinal de voz e estimativas por pólos do modelo AR . . . . 79

FIGURA 4.7 Ilustração da estimativa de um sinal de voz usando AR(26) . . . . . . 80

FIGURA 4.8 Banco de filtros para análise e síntese de um sinal . . . . . . . . . . 83

FIGURA 4.9 Bancos de filtros de duas bandas . . . . . . . . . . . . . . . . . 84

FIGURA 4.10 Exemplo das formas de onda do banco de filtros de duas bandas . . . 84

FIGURA 4.11 Exemplo da decomposição de um sinal por banda oitava de dois estágios 86

FIGURA 4.12 Exemplo das contrações e expansões da função wavelet . . . . . . . 87

FIGURA 4.13 Relação entre a compressão-expansão das wavelets e a largura de banda 87

FIGURA 4.14 Ilustração do cruzamento das bandas de freqüência das wavelets . . 88

FIGURA 4.15 Exemplos de funções de escala da família Daubechies . . . . . . . . 89

FIGURA 4.16 Exemplos de funções wavelet da família Daubechies . . . . . . . . . 89

FIGURA 4.17 Resolução de tempo e freqüência de acordo com a largura da wavelet 91

FIGURA 4.18 Ilustração da decomposição wavelet usada como modelo . . . . . . 92

FIGURA 4.19 Ilustração da estimativa de um sinal de voz usando modelo wavelet 94

FIGURA 4.20 Comparação dos erros de estimativa usando os dois modelos propostos 96

FIGURA 4.21 Seleção do primeiro mínimo local da curva da informação mútua . . 98

FIGURA 4.22 Representação bidimensional de um sinal de voz . . . . . . . . . . 98

FIGURA 4.23 Representação tridimensional de um sinal de voz . . . . . . . . . . . 99

FIGURA 4.24 Comparação entre representações tridimensionais de sinais simulados 100

FIGURA 4.25 Estimativa da representação 3D usando modelo AR multidimensional 102

FIGURA 4.26 Erro de estimativa da representação tridimensional . . . . . . . . . 103 
FIGURA 5.1 Sinal do exemplo do método da discretização da entropia diferencial . 109

FIGURA 5.2 Entropia usando o primeiro método para variação de SNR . . . . . . 110

FIGURA 5.3 Entropia usando o primeiro método para variação de jitter . . . . . . 111

FIGURA 5.4 Entropia usando o primeiro método para variação de shimmer . . . . 111

FIGURA 5.5 Comparação de histogramas de ruído com diferentes variâncias . . . 114

FIGURA 5.6 Ilustração da escolha do passo de quantização . . . . . . . . . . . . 116

FIGURA 5.7 Comparação da entropia teórica e estimada de Gaussiana . . . . . . . 116

FIGURA 5.8 Entropia usando o segundo método para variação de SNR . . . . . 117

FIGURA 5.9 Entropia usando o segundo método para variação de jitter . . . . . 118

FIGURA 5.10 Entropia usando o segundo método para variação de shimmer . . . 118

FIGURA 5.11 Erro de previsão do sinal de voz com AR(10) . . . . . . . . . . . . . 119

FIGURA 5.12 Ilustração do alinhamento dos histogramas . . . . . . . . . . . . . 120

FIGURA 5.13 Comparação da entropia relativa teórica e estimada de Gaussianas . 121

FIGURA 5.14 Nova comparação da entropia relativa teórica e estimada . . . . . . 122

FIGURA 5.15 Ilustração do algoritmo da equalização do histograma . . . . . . . . . 124

FIGURA 5.16 Ilustração do uso do algoritmo do terceiro método . . . . . . . . . 126

FIGURA 5.17 Entropia usando o terceiro método para variação de SNR . . . . . . 126

FIGURA 5.18 Entropia usando o terceiro método para variação de jitter . . . . . . 127

FIGURA 5.19 Entropia usando o terceiro método para variação de shimmer . . . . . 127

FIGURA 5.20 Curva de entropia de bloco de um sinal binário de período 5 . . . . 129

FIGURA 5.21 Curva de entropia de bloco de um sinal real de período 5 . . . . . . 130

FIGURA 5.22 Curva de entropia de bloco de um sinal binário aleatório . . . . . . 131

FIGURA 5.23 Curva de entropia de bloco de um sinal real aleatório . . . . . . . . . 131

FIGURA 5.24 Ilustração da utilização de menor quantidade de faixas de amplitude 133

FIGURA 5.25 Ilustração do número de possibilidades para sinal real . . . . . . . . . 133

FIGURA 5.26 Curvas de crescimento da entropia para sinais senoidais com ruído . . 134 
FIGURA 5.27 Curva de crescimento da entropia de bloco do sinal de voz . . . . . . 135

FIGURA 5.28 Curva de convergência da entropia de Shannon do sinal de voz . . . . 135

FIGURA 5.29 Sinais e PDFs envolvidos no algoritmo de PP com modelo AR . . . . 137

FIGURA 5.30 Valores de PP com modelo AR(26) e variação de SNR . . . . . . . . 138

FIGURA 5.31 Valores de PP com modelo AR(26) e variação de jitter . . . . . . . . . 139

FIGURA 5.32 Valores de PP com modelo AR(26) e variação de shimmer . . . . . 139

FIGURA 5.33 PDFs dos erros de previsão de sinais simulados usando AR . . . . . . 140

FIGURA 5.34 Exemplo de estimativa da PP com modelo de decomposição wavelet . 142

FIGURA 5.35 Valores de PP com modelo wavelet e variação de SNR . . . . . . . . 143

FIGURA 5.36 Valores de PP com modelo wavelet e variação de jitter . . . . . . . . 143

FIGURA 5.37 Valores de PP com modelo wavelet e variação de shimmer . . . . . . 145

FIGURA 5.38 PDFs dos erros de previsão de sinais simulados usando wavelets . . . 145

FIGURA 5.39 Exemplo de PrCA de um sinal simulado . . . . . . . . . . . . . . . . 147

FIGURA 5.40 Representação das variâncias de erro normalizadas com ordem 26 148

FIGURA 5.41 Representação dos componentes previsíveis com ordem 26 . . . . . . 148

FIGURA 5.42 Reconstruções do sinal simulado . . . . . . . . . . . . . . . . . . 149

FIGURA 5.43 Valores de PP com PrCA com AR(26) e variação de SNR . . . . . . 149

FIGURA 5.44 Valores de PP com PrCA com AR(26) e variação de jitter . . . . . . 150

FIGURA 5.45 Valores de PP com PrCA com AR(26) e variação de shimmer . . . 150

FIGURA 5.46 Valores de PP com PrCA com wavelets e variação de SNR . . . . . . 151

FIGURA 5.47 Valores de PP com PrCA com wavelets e variação de jitter . . . . . . 151

FIGURA 5.48 Valores de PP com PrCA com wavelets e variação de shimmer . . . . 152

FIGURA 5.49 Exemplo de PrCA de representação tridimensional . . . . . . . . 154

FIGURA 5.50 Sinais temporais relacionados com as representações tridimensionais 155

FIGURA 5.51 PP de PrCA de representação tridimensional e variação de SNR . . 155

FIGURA 5.52 PP de PrCA de representação tridimensional e variação de jitter . . 156 
FIGURA 5.53 PP de PrCA de representação tridimensional e variação de shimmer . 156

FIGURA 6.1 Resultados do ensaio de medidas de entropia de Shannon . . . . . . . 159

FIGURA 6.2 Resultados do ensaio de medidas de entropia para os grupos . . . . 159

FIGURA 6.3 Exemplos de sinais de voz dos grupos estudados e suas PDFs . . . 160

FIGURA 6.4 Resultados do ensaio de medidas de entropia relativa . . . . . . . . . 161

FIGURA 6.5 Resultados do ensaio de medidas de entropia relativa dos grupos . . . 162

FIGURA 6.6 Curva de crescimento da entropia para os sinais saudáveis . . . . . . 163

FIGURA 6.7 Curva de crescimento da entropia para os sinais de nódulo $\ldots$. . . . 163

FIGURA 6.8 Curva de crescimento da entropia para os sinais de edema $\ldots . . \ldots 164$

FIGURA 6.9 Relação da variação da curva e período de pitch . . . . . . . . . . . . . 164

FIGURA 6.10 Exemplos de erros de previsão de vozes com AR(26) . . . . . . . . 166

FIGURA 6.11 Resultados de PP usando AR(26) para os sinais de voz . . . . . . . 167

FIGURA 6.12 Resultados consolidados de PP usando AR(26) para os grupos . . . . 168

FIGURA 6.13 Exemplos de erros de previsão de vozes com wavelets . . . . . . . 169

FIGURA 6.14 Resultados de PP usando modelo wavelet para os sinais de voz . . . . 170

FIGURA 6.15 Resultados consolidados de PP usando modelo wavelet . . . . . . . . 171

FIGURA 6.16 Resultados de PP para PrCA com AR(26) direto nos sinais de voz . . 172

FIGURA 6.17 Resultados consolidados de PP para PrCA com AR(26) direto . . . . 173

FIGURA 6.18 Resultados de PP para PrCA com wavelets direto nos sinais de voz $\quad 174$

FIGURA 6.19 Resultados consolidados de PP para PrCA com wavelets direto . . . . 174

FIGURA 6.20 PDFs dos erros de previsão por PrCA e os modelos usados . . . . . . 176

FIGURA 6.21 PPs para PrCA das representações tridimensionais . . . . . . . . . . 177

FIGURA 6.22 PPs consolidados para PrCA das representações tridimensionais . 178

FIGURA 6.23 PP médios para PrCA das representações tridimensionais . . . . . . . 179

FIGURA 6.24 PPs médios consolidados de PrCA das representações tridimensionais 179 
FIGURA 7.1 Diferenciação das curvas de convergência da entropia . . . . . . . . . 192

FIGURA 7.2 Diferença de comportamento das curvas de convergência da entropia 193

FIGURA A.1 Trecho de sinal de voz usado para criar sinais simulados . . . . . . 220

FIGURA A.2 Variação do nível de ruído dos sinais simulados . . . . . . . . . . . . 222

FIGURA A.3 Exemplos de variação dos parâmetros do simulador . . . . . . . . . . 223

FIGURA A.4 Outro exemplo de sinal de voz feminino . . . . . . . . . . . . . . . 224

FIGURA A.5 Sinal de nódulo e sua representação tridimensional . . . . . . . . . . 224 


\section{Lista de Tabelas}

TABELA 4.1 Valores dos parâmetros acústicos dos sinais de voz . . . . . . . . 72

TABELA 5.1 Entropia pelo método de discretização da entropia diferencial . . . 109

TABELA 5.2 Entropia Relativa pelo método de discretização da entropia diferencial 112

TABELA 5.3 Entropia pelo método do passo de quantização constante . . . . . . . 115

TABELA 5.4 Entropia relativa pelo método do passo de quantização constante . . 119

TABELA 5.5 Algoritmo da entropia usando método da equalização do histograma. 123

TABELA 5.6 Entropia relativa pelo método de equalização do histograma . . . . . 125

TABELA 5.7 Algoritmo da estimativa da entropia de bloco. . . . . . . . . . . . . 129

TABELA 5.8 Algoritmo de estimativa da PP com modelo AR . . . . . . . . . . 136

TABELA 5.9 Algoritmo de PP usando modelo baseado em decomposição wavelet . 141

TABELA 5.10 Algoritmo de PrCA e reconstrução de sinais temporais . . . . . . . 146

TABELA 5.11 Algoritmo de PrCA da representação tridimensional . . . . . . . . 152

TABELA A.1 Algoritmo usado para gerar sinais simulados de voz . . . . . . . . 221 


\section{Lista de Símbolos}

$U(z) \quad$ Transformada $Z$ do sinal de fonte vocálica ou não-vocálica .............. 14

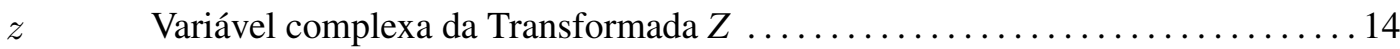

$E(z) \quad$ Transformada $Z$ do sinal do gerador de trem de impulsos $\ldots \ldots \ldots \ldots \ldots \ldots 14$

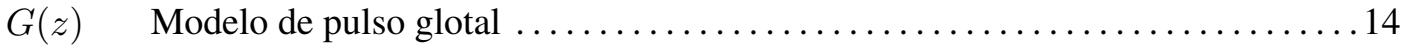

Av Ganho de variação da pressão do pulmão para sons vocálicos $\ldots \ldots \ldots \ldots \ldots 14$

An Ganho de variação da pressão do pulmão para sons não-vocálicos $\ldots \ldots \ldots \ldots 14$

$S(z) \quad$ Transformada $Z$ do sinal de voz resultante do modelo matemático $\ldots \ldots \ldots \ldots 14$

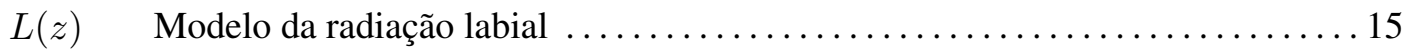

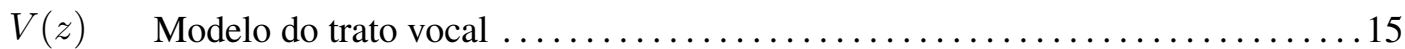

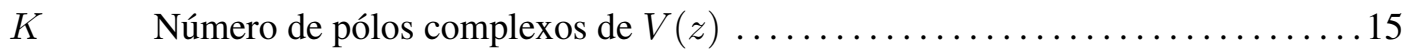

$M_{p} \quad$ Número de pólos do sinal de voz do modelo matemático $\ldots \ldots \ldots \ldots \ldots \ldots 16$

$m \quad$ Constante do número de pólos do sinal de voz do modelo matemático . . . . . 16

$a_{i} \quad$ Coeficientes do modelo resultante do sinal de voz $\ldots \ldots \ldots \ldots \ldots \ldots \ldots \ldots$

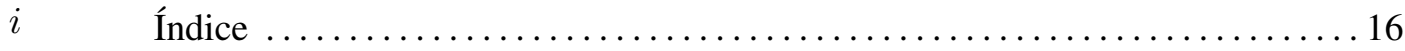

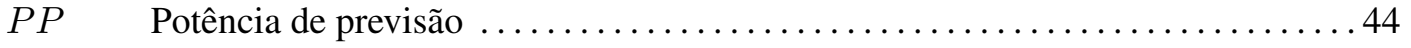

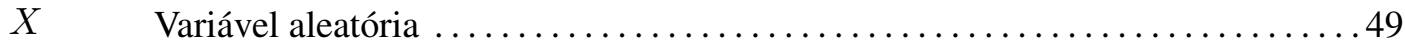

$H(X) \quad$ Entropia de Shannon da variável aleatória discreta $X \ldots \ldots \ldots \ldots \ldots . \ldots 49$

$\mathcal{X} \quad$ Alfabeto de eventos da variável aleatória $X \ldots \ldots \ldots \ldots \ldots . \ldots . \ldots . \ldots 49$

$p_{X}(x) \quad$ Função de densidade de probabilidade da variável aleatória $X \ldots \ldots \ldots \ldots . .49$

$H_{D}(X)$ Entropia diferencial de Shannon da variável aleatória contínua $X \ldots \ldots \ldots .49$

$H_{\alpha}(X)$ Entropia de Rényi da variável aleatória discreta $X \ldots \ldots \ldots \ldots \ldots \ldots . \ldots 49$

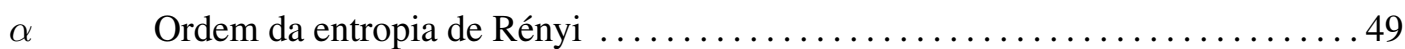

$q_{X}(x) \quad$ Outra função de densidade de probabilidade da variável aleatória $X \ldots \ldots \ldots 5$

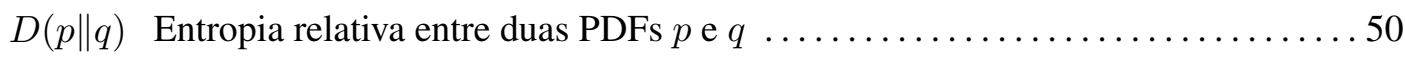

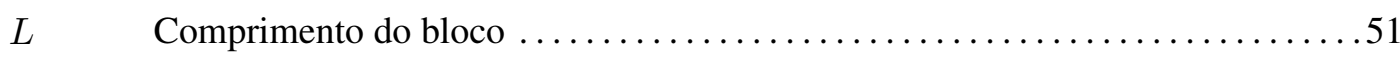


$p\left(x^{L}\right) \quad$ Função de densidade de probabilidade dos blocos de comprimento $L \ldots \ldots . .51$

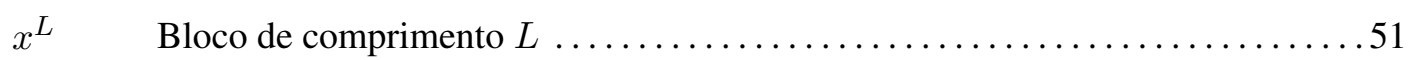

$H_{B}(L)$ Entropia de bloco em função do comprimento $L \ldots \ldots \ldots \ldots \ldots \ldots \ldots \ldots \ldots$

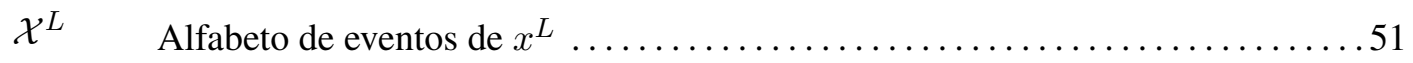

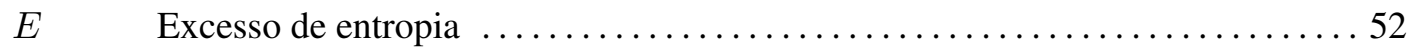

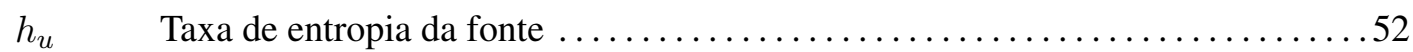

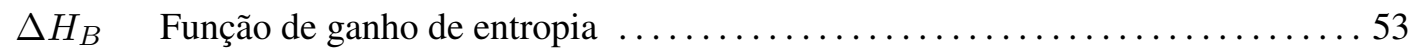

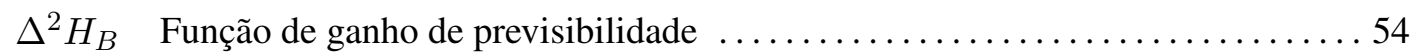

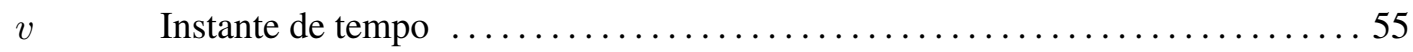

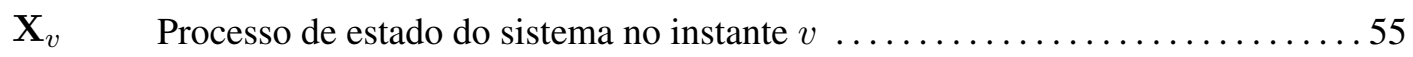

$M \quad$ Dimensão do vetor de estado do sistema ou decimação dos filtros wavelet . . ...55

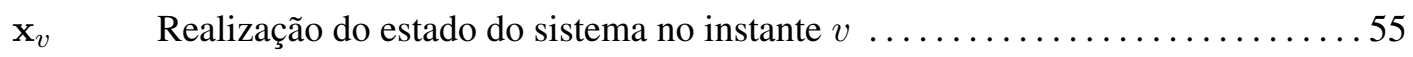

$\hat{\mathbf{x}}_{v} \quad$ Realização da previsão do estado do sistema no instante $v \ldots \ldots \ldots \ldots \ldots 55$

$\mathbf{e}_{v} \quad$ Realização do erro de previsão do estado do sistema $\ldots \ldots \ldots \ldots \ldots \ldots \ldots$

$\mathbf{E}_{v} \quad$ Processo de erro de previsão do estado do sistema $\ldots \ldots \ldots \ldots \ldots \ldots \ldots \ldots 5$

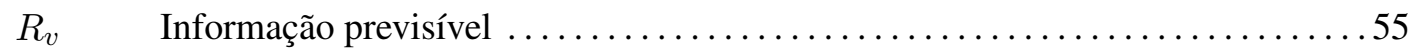

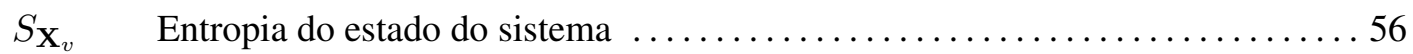

$S_{\mathbf{E}_{v}} \quad$ Entropia do erro de previsão do estado do sistema $\ldots \ldots \ldots \ldots \ldots \ldots \ldots \ldots \ldots \ldots \ldots \ldots$

$\gamma_{k} \quad$ Variância de erro normalizada do $k$-ésimo componente previsível $\ldots \ldots \ldots \ldots 59$

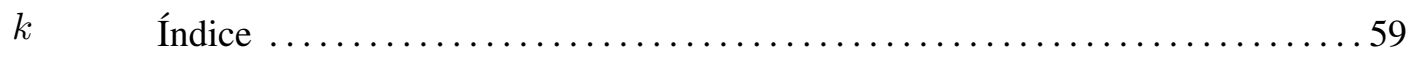

$\mathbf{q}_{v}^{k} \quad k$-ésimo autovetor da solução da análise de componentes previsíveis .......59

$\mathbf{C}_{o} \quad$ Matriz de covariância do estado do sistema $\ldots \ldots \ldots \ldots \ldots \ldots \ldots . \ldots . \ldots . \ldots 59$

$\mathbf{C}_{e} \quad$ Matriz de covariância do erro de previsão do estado do sistema $\ldots \ldots \ldots \ldots . \ldots 59$

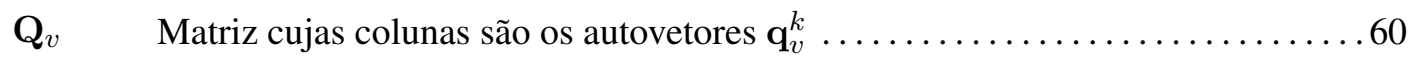

$\mathbf{p}_{v}^{k} \quad k$-ésimo componente previsível $\ldots \ldots \ldots \ldots \ldots \ldots \ldots \ldots \ldots \ldots \ldots \ldots \ldots \ldots \ldots \ldots \ldots \ldots \ldots$

$\mathbf{P}_{v} \quad$ Matriz cujas colunas são os componentes previsíveis $\mathbf{p}_{v}^{k} \ldots \ldots \ldots \ldots \ldots 60$

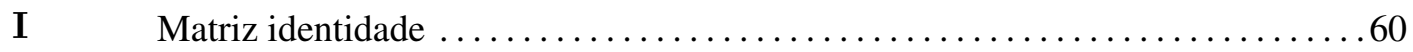

$\boldsymbol{\Gamma}_{v} \quad$ Matriz diagonal cujos elementos são as variâncias de erro normalizadas . . . .66 60

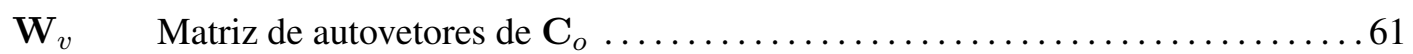

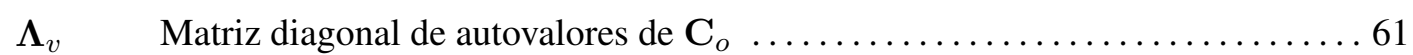

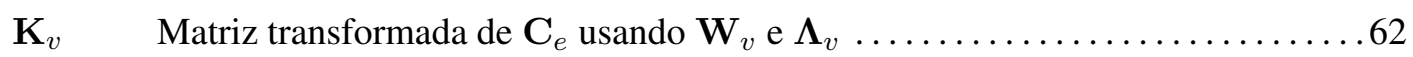

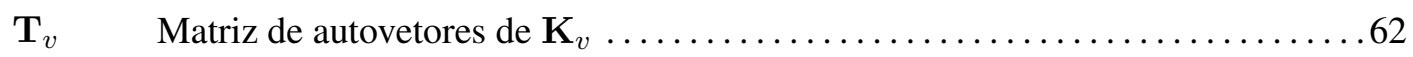

$\boldsymbol{\Delta}_{v} \quad$ Matriz diagonal de autovalores de $\mathbf{K}_{v} \ldots \ldots \ldots \ldots \ldots \ldots \ldots \ldots \ldots \ldots \ldots \ldots \ldots \ldots$ 


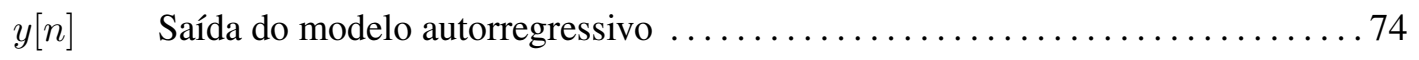

$x[n] \quad$ Entrada do modelo autorregressivo $\ldots \ldots \ldots \ldots \ldots \ldots \ldots \ldots \ldots \ldots \ldots \ldots$

$n \quad$ Índice da amostra de um sinal digital $\ldots \ldots \ldots \ldots \ldots \ldots \ldots \ldots \ldots$

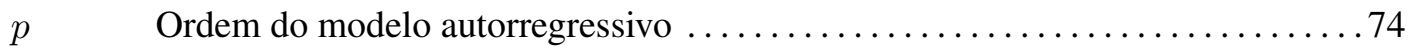

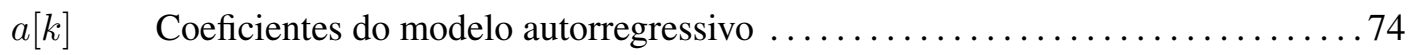

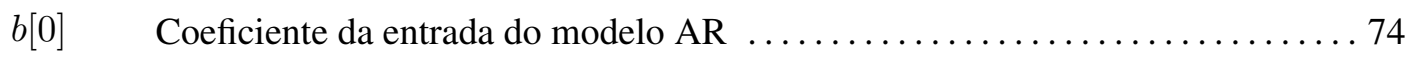

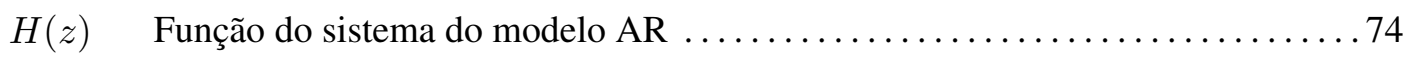

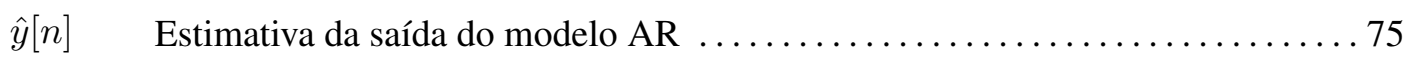

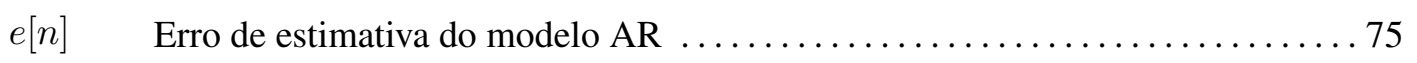

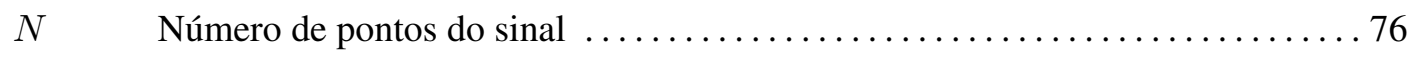

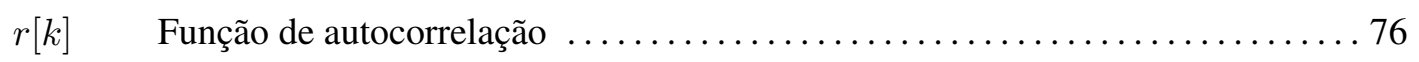

$\mathbf{Y}_{p} \quad$ Matriz de versões atrasadas do sinal usada no método da autocorrelação . .... 76

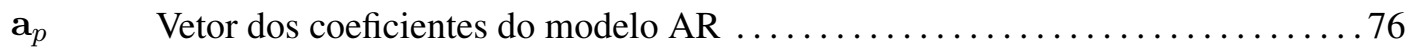

$\mathbf{y}_{1} \quad$ Vetor do sinal a partir do segundo ponto, usado no método da autocorrelação .. 76

$z_{k} \quad k$-ésimo pólo do modelo AR .............................. 78

$f_{k} \quad$ Freqüência do $k$-ésimo pólo do modelo AR $\ldots \ldots \ldots \ldots \ldots \ldots \ldots \ldots$

$\theta_{k} \quad$ Ângulo do $k$-ésimo pólo do modelo AR $\ldots \ldots \ldots \ldots \ldots \ldots \ldots \ldots$

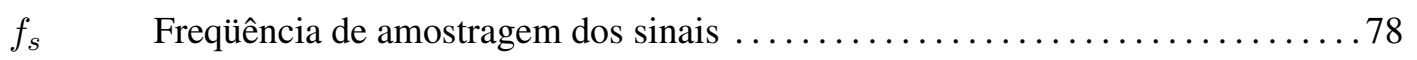

$H_{k}(z) \quad$ Transformada $Z$ do $k$-ésimo filtro de análise da DWT $\ldots \ldots \ldots \ldots \ldots$

$G_{k}(z) \quad$ Transformada $Z$ do $k$-ésimo filtro de síntese da DWT $\ldots \ldots \ldots \ldots \ldots \ldots . \ldots 3$

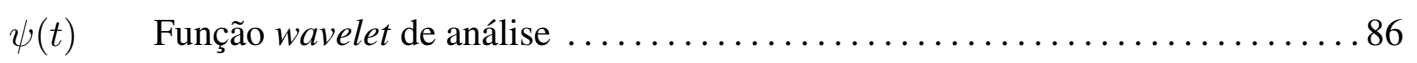

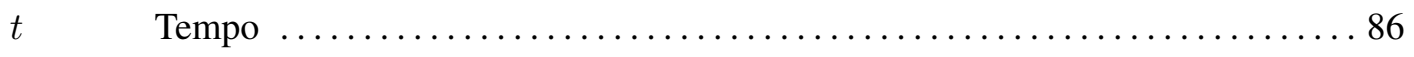

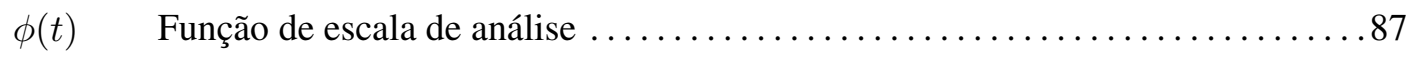

$h_{k}(n) \quad$ Resposta impulsiva do $k$-ésimo filtro de análise da DWT $\ldots \ldots \ldots \ldots \ldots \ldots 88$

$g_{k}(n) \quad$ Resposta impulsiva do $k$-ésimo filtro de síntese da DWT $\ldots \ldots \ldots \ldots \ldots \ldots 8$

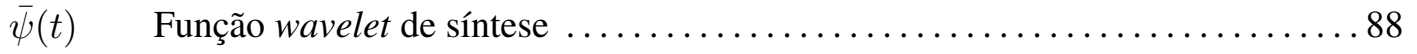

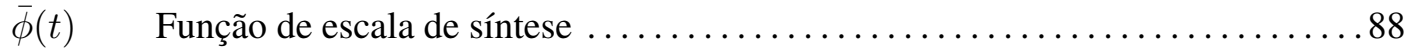

$\psi_{u, s}(t) \quad$ Função wavelet deslocada de $u$ e escalada de $s \ldots \ldots \ldots \ldots . \ldots . \ldots . \ldots . \ldots . \ldots 9$

$u \quad$ Fator de deslocamento da função wavelet ......................... 89

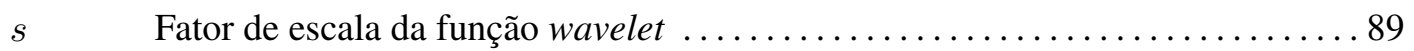

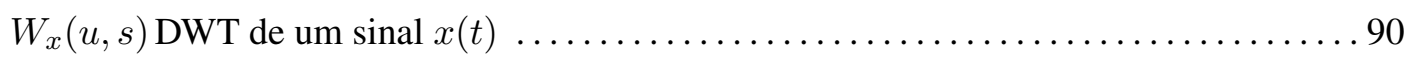

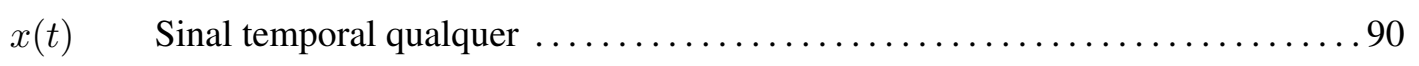

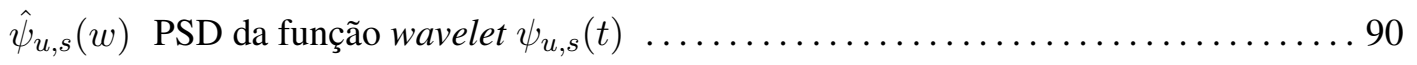




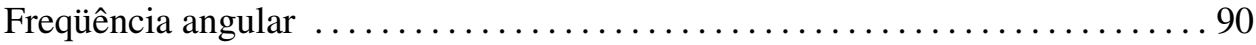

$c A_{i} \quad$ Coeficiente de aproximação da DWT no nível $i \ldots \ldots \ldots \ldots \ldots \ldots$. . . . . .

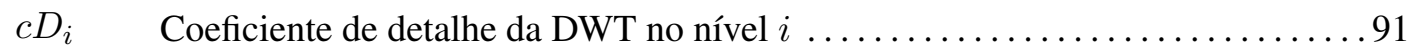

$A_{i} \quad$ Aproximação reconstruída da DWT no nível $i \ldots \ldots \ldots \ldots . \ldots . \ldots . \ldots . \ldots . \ldots$

$D_{i} \quad$ Detalhe reconstruído da DWT no nível $i \ldots \ldots \ldots \ldots \ldots \ldots$

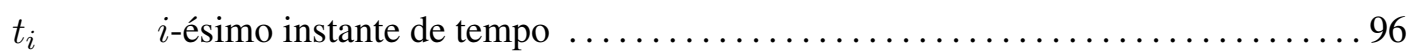

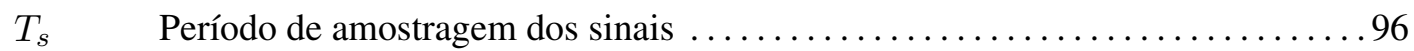

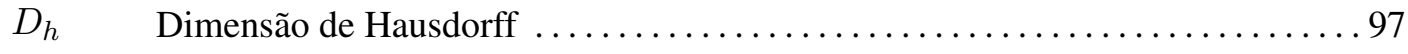

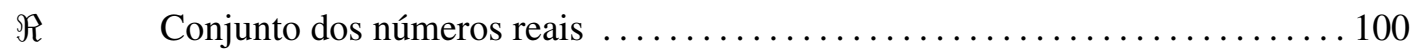

$\epsilon_{v} \quad$ Vetores aleatórios descorrelacionados do modelo AR multidimensional ..... 101

w Vetor de termos de intersecção do modelo AR multidimensional . .......... 101

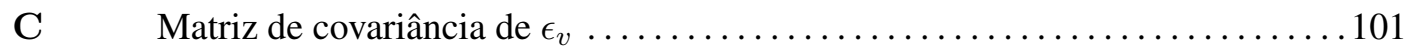

$\mathbf{A}_{k} \quad k$-ésima matriz de coeficientes do modelo AR multidimensional $\ldots \ldots \ldots \ldots 101$

I Número de células do histograma nas estimativas da entropia $\ldots \ldots \ldots \ldots \ldots 108$

$p_{i} \quad$ Probabilidade de cada célula $i$ nas estimativas da entropia $\ldots \ldots \ldots \ldots \ldots 108$

$k_{i} \quad$ Número de ocorrências de cada célula $i$ nas estimativas da entropia $\ldots \ldots \ldots 108$

$\Delta x \quad$ Largura das células nas estimativas da entropia $\ldots \ldots \ldots \ldots \ldots \ldots \ldots$

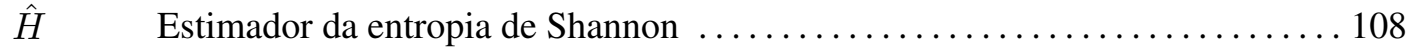

$\mu \quad$ Média de uma distribuição de probabilidades .......................... 109

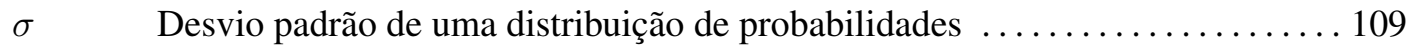

e $\quad$ Número de Euler, cujo valor (com somente três casas decimais) é 2, $718 \ldots \ldots 109$

$\hat{H}_{h} \quad$ Estimativa da entropia de Shannon usando o histograma ............... 110

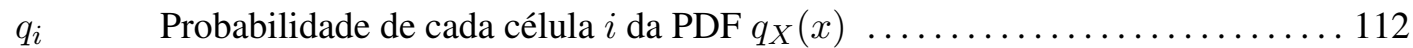

$k_{p i} \quad$ Número de ocorrências de cada célula $i$ em $p_{X}(x) \ldots \ldots \ldots \ldots \ldots \ldots \ldots \ldots \ldots \ldots$

$k_{q i} \quad$ Número de ocorrências de cada célula $i$ em $q_{X}(x) \ldots \ldots \ldots \ldots \ldots \ldots \ldots \ldots \ldots$

$q \quad$ Passo de quantização usado na estimativa da entropia $\ldots \ldots \ldots \ldots \ldots \ldots . \ldots 114$

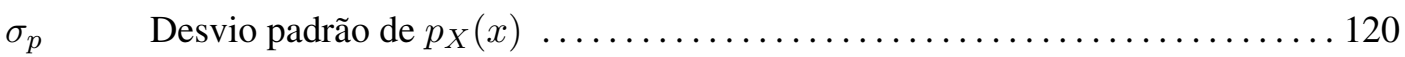

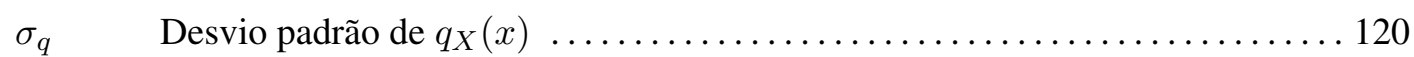

$\hat{p}\left(x^{L}\right) \quad$ Estimativa da distribuição de probabilidade de $x^{L} \ldots \ldots \ldots \ldots \ldots \ldots \ldots \ldots \ldots$

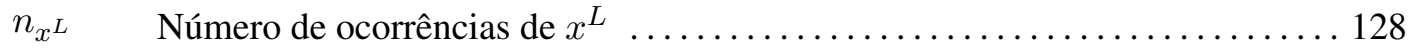

$\hat{H}_{B}(L)$ Estimativa da entropia de bloco em função do comprimento $L \ldots \ldots \ldots \ldots 128$ 


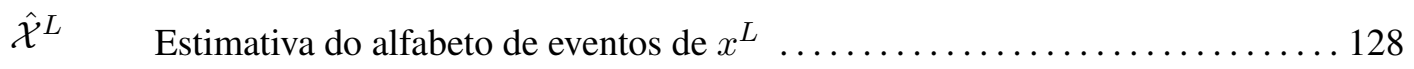

$A_{d} \quad$ Amplitude relativa do ruído usado no simulador de vozes . ................ 219

$J \quad$ Percentual decimal do jitter usado no simulador de vozes . ..............219

Sh Percentual decimal do shimmer usado no simulador de vozes ...........219

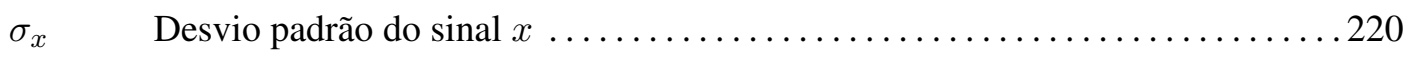

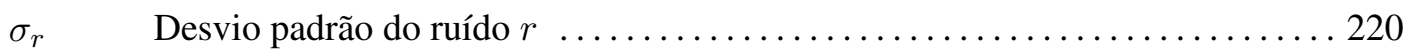




\section{Lista de Siglas}

HRV Variabilidade de batimento cardíaco ..........................

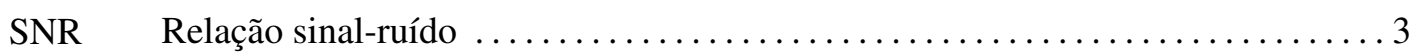

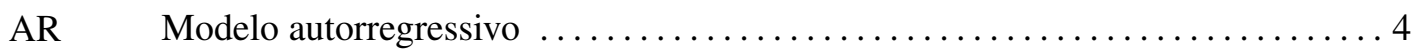

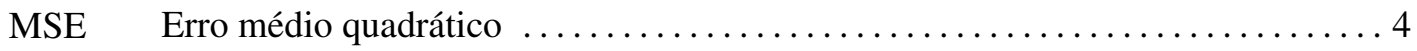

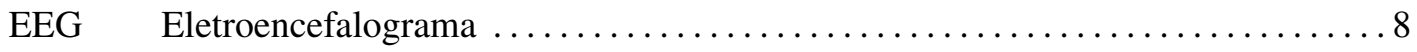

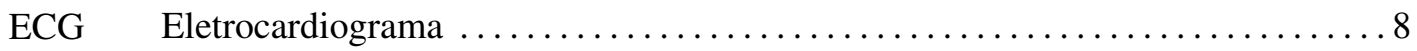

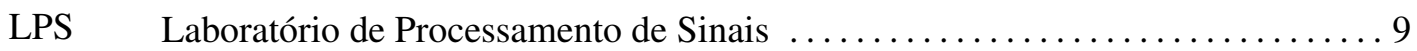

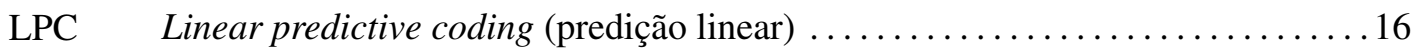

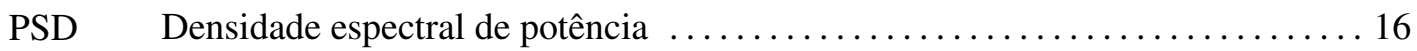

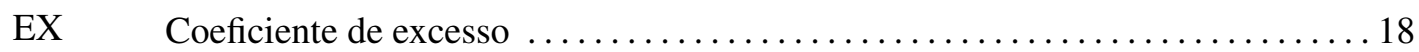

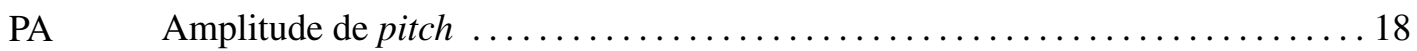

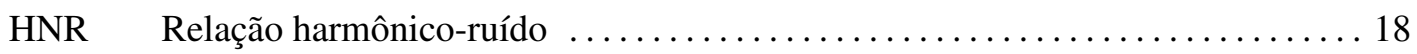

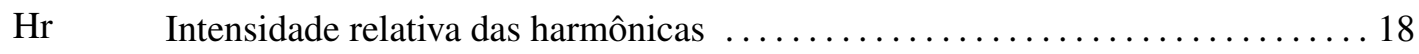

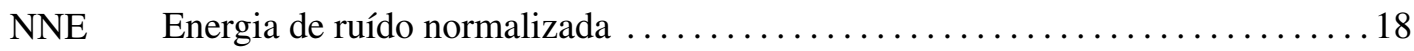

GRBAS Escala de avaliação da qualidade vocal internacional $\ldots \ldots \ldots \ldots \ldots \ldots \ldots . \ldots 25$

RASAT Escala de avaliação da qualidade vocal brasileira $\ldots \ldots \ldots \ldots \ldots \ldots \ldots \ldots 25$

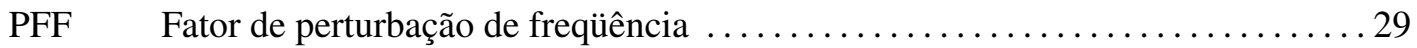

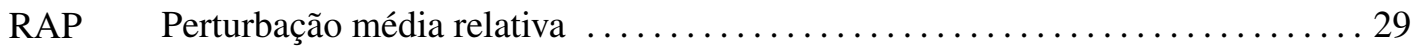

APQ Quociente de perturbação de amplitude $\ldots \ldots \ldots \ldots \ldots \ldots \ldots \ldots \ldots \ldots \ldots \ldots . \ldots \ldots$

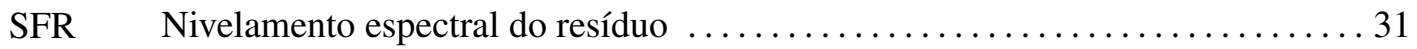

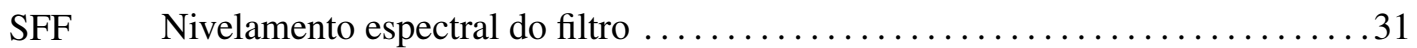

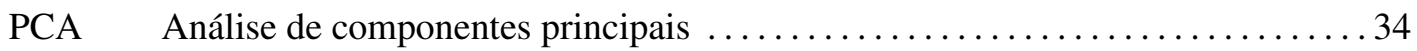

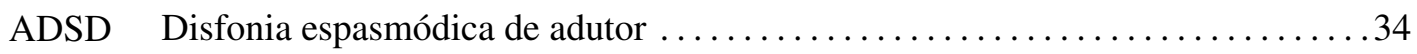

HMM Modelo oculto de Markov .................................. 35

LFPC Coeficientes de potência com freqüência logarítmica $\ldots \ldots \ldots \ldots \ldots \ldots \ldots$ 
LPCC Coeficientes cepstrais de predição linear ......................... 36

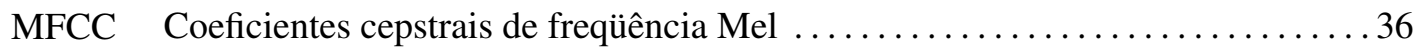

MLE Método de estimativa de máxima verossimilhança $\ldots \ldots \ldots \ldots \ldots \ldots \ldots . \ldots . \ldots 36$

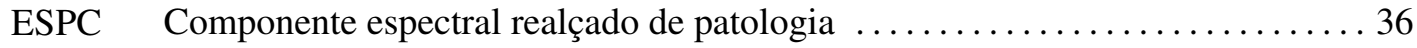

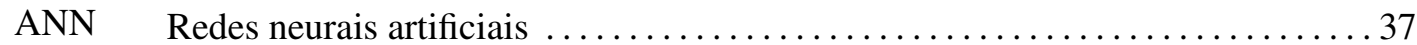

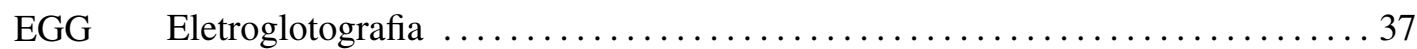

RBH Tipo de índice de qualidade vocal ............................. 38

PHCC Coeficientes cepstrais harmônicos perceptuais ......................... 38

WPD Decomposição wavelet packet ................................ 38

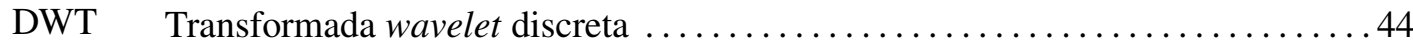

LS-SVM Máquinas de vetores de suporte com mínimos quadrados ............... 44

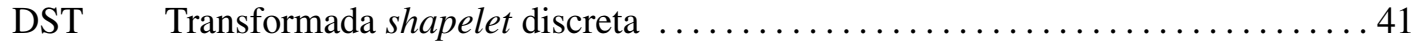

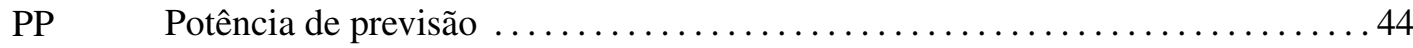

PrCA Análise de componentes previsíveis ........................... 44

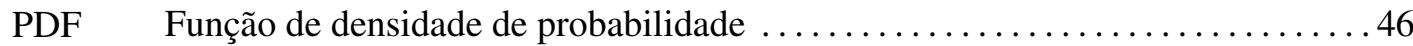

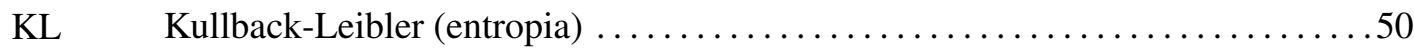

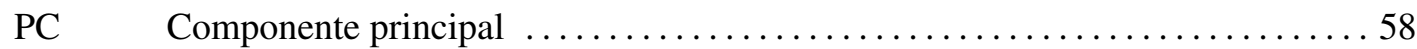

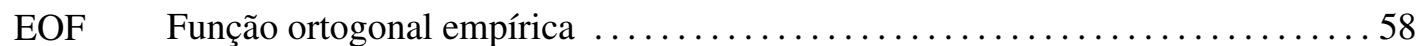

EESC Escola de Engenharia de São Carlos ................................66

USP Universidade de São Paulo . . . . . . . . . . . . . . . . . . . . . . . . . . . . . 66

WAVE Waveform audio format, um tipo de codificação de áudio sem perdas . .......66 66

WSS Estacionaridade em sentido amplo .......................... 67

ARMA Modelo autorregressivo e média móvel $\ldots \ldots \ldots \ldots \ldots \ldots \ldots \ldots \ldots \ldots \ldots . \ldots 74$

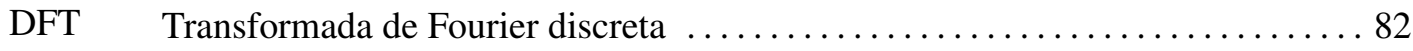

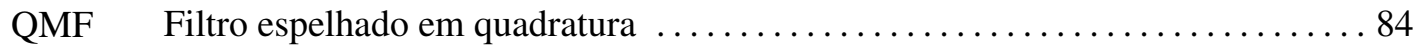

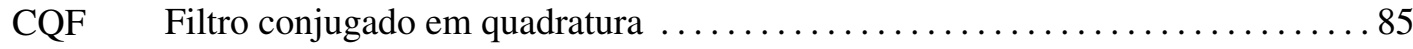

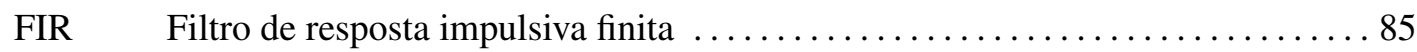

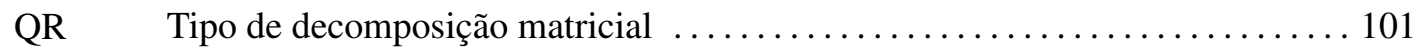

IEEE Instituto de Engenheiros Eletricistas e Eletrônicos ..................... 190 


\section{Resumo}

SCALASSARA, P. R. Utilização de Medidas de Previsibilidade em Sinais de Voz para Discriminação de Patologias de Laringe. 2009. 267 f. Tese (Doutorado). Escola de Engenharia de São Carlos, Universidade de São Paulo, São Carlos, 2009.

Este trabalho apresenta um estudo inicial da aplicação de medidas de previsibilidade em sinais de voz. O objetivo é desenvolver métodos que sejam capazes de diferenciar sinais saudáveis e patológicos, inclusive separar patologias. Para isso, tenta-se medir a variação da incerteza e previsibilidade entre os sinais de voz dos grupos analisados. Algumas patologias de laringe, como nódulo e edema de Reinke, usadas neste estudo, causam modificações nos sinais de voz devido a mudanças na estrutura e funcionalidade do trato e pregas vocais. Nos casos patológicos, tem-se, principalmente, aumento de perturbações de frequiência e amplitude, adição de ruído e supressão de componentes harmônicos de alta freqüência da voz. Por causa disso, observa-se perda da estrutura quase-periódica dos sinais, aumentando-se a incerteza do sistema vocal e, portanto, diminuição de sua previsibilidade. Para avaliar essas mudanças, usam-se medidas de entropia de Shannon e entropia relativa entre os sinais saudáveis e patológicos. Além dessas, tem-se a potência de previsão (PP), a qual é uma medida baseada na entropia relativa entre o sinal de voz e seu erro de previsão obtido por um modelo. Inicialmente, optou-se pelo modelo autorregressivo (AR), consagrado em análise de voz, porém, devido a resultados não satisfatórios, apresentou-se um modelo baseado em decomposições por wavelets. Outra ferramenta utilizada foi a chamada análise de componentes previsíveis (PrCA), a qual realiza uma decomposição dos sinais em componentes ordenados por sua previsibilidade, sendo possível reconstruí-los usando somente os componentes mais previsíveis. Também, com essa técnica, analisaram-se representações tridimensionais dos sinais de voz em um espaço cujas coordenadas são dadas por versões atrasadas dos próprios sinais. Os algoritmos desenvolvidos foram 
testados com o auxílio de sinais de voz simulados, os quais possuíam variações de nível de ruído e perturbações de amplitude e frequiência. Com isso, foi possível detectar erros e solucionar problemas com os métodos. Após a avaliação dos algoritmos, estimou-se os valores de entropia dos sinais de voz, a entropia relativa entre os sinais saudáveis e os sinais dos grupos analisados, além de se calcular a PP usando o modelo AR e o modelo por wavelets. Por fim, utilizou-se a PrCA para obtenção de versões mais previsíveis dos sinais, então, calculando-se a PP para esses casos usando essa versão como previsão dos sinais. Aplicou-se, também, a PrCA para as representações tridimensionais dos sinais usando um modelamento AR multidimensional para obtenção de previsões. Com os ensaios de entropia dos sinais de voz, não foi possível diferenciar os grupos, mas com os resultados de entropia relativa, conseguiu-se distinguir eficientemente os sinais patológicos dos saudáveis. Porém, essa medida não possui muita aplicação prática, isso pois é necessário um banco de vozes diagnosticadas para servir de comparação. Nos ensaios de PP usando modelo AR, também não foi possível diferenciar os grupos, no entanto, com o modelo wavelet, os sinais saudáveis apresentaram significativamente maior previsibilidade do que os patológicos, mas, mesmo assim, não se conseguiu diferenciar as patologias. Com a PrCA, utilizando-se ambos os modelos, foi possível diferenciar os grupos patológicos do saudável, porém, frente ao modelo AR, os sinais saudáveis apresentaram menor previsibilidade. Isso demonstra que a previsibilidade depende do modelo usado para a análise, assim, as patologias da laringe podem diminuir ou aumentar a capacidade de previsão dos sinais de voz conforme o modelo usado. Com a avaliação dos resultados de PrCA das representações tridimensionais, tem-se comportamento semelhante ao obtido pela análise direta nos sinais de voz com o modelo AR, entretanto, essa forma de representação dos dados mostrase promissora em estudos futuros. Com esses ensaios, concluiu-se que este estudo foi muito útil para um maior conhecimento da dinâmica da produção vocal e que as medidas de previsibilidade são interessantes para avaliação de patologias da laringe, em especial, a presença de nódulo nas pregas vocais e edema de Reinke, pelo menos nestes estudos iniciais e usando os sinais de voz disponíveis. Mais estudos ainda são necessários, entretanto essa forma de análise já apresenta bons resultados, os quais podem ser aplicados para auxiliar o diagnóstico de disfonias por profissionais da saúde.

Palavras-chaves: voz, previsibilidade, entropia, potência de previsão, patologia, nódulo, edema de Reinke, análise de componentes previsíveis. 


\section{Abstract}

SCALASSARA, P. R. Application of Predictability Measures to Voice Signals for Larynx Pathology Differentiation. 2009. 267 p. Thesis (Doctoral). Escola de Engenharia de São Carlos, Universidade de São Paulo, São Carlos, 2009.

This thesis presents initial studies of the application of predictability measures to voice signal analysis. Its aim is to develop methods that are capable of differentiating healthy and pathological signals, also amongst pathologies. In order to do that, we perform an attempt to measure the uncertainty and predictability variations of the signals from the analyzed groups. Some larynx pathologies, such as nodule and Reinke's edema, that are used in this study, cause changes to the voice signals due to structure and functionality modifications of the vocal tract and folds. The main modifications are higher amplitude and frequency perturbations, noise addition, and supression of high frequency harmonic components. Because of that, the signals lose some of their almost periodic structure, the vocal system's uncertainty increases and, therefore, the predictability decreases. We use several measures to evaluate these changes, such as Shannon's entropy and relative entropy between healthy and pathological signals. In addition, we use the predictive power (PP), that is based on the relative entropy between the voice signal and its prediction error given by a model. Firstly, we used the autoregressive model (AR), common for voice analysis, however, due to unsatisfactory results, we presented a model based on wavelet decomposition. We also took advantage of another tool, called predictable component analysis (PrCA), it performs a signal decomposition in components that are ordered by their predictability. Then it is possible to reconstruct the signals using only their most predictable components. Using this technique, we analyzed a kind of tridimensional representation of the voice signals in a space with coordinates given by delayed versions of the signals. We tested the developed algorithms with the aid of simulated voice signals, which had variations of noise 
level and amplitude and frequency perturbations. By means of that, it was possible to detect errors and solve method problems. After the algorithms evaluation, we estimated the entropy of the voice signals and the relative entropy between the healthy signals and all the signals. In addition, we estimated the PP using the AR and wavelet based models. After that, we used the PrCA in order to obtain more predictable versions of the signals and then, estimated the PP using this version as the signals' prediction. Also, we applied the PrCA to the signals' tridimensional representations using a multidimensional AR model as a predictor. Using the voice entropy results, we could not distinguish between the analyzed groups, but with the relative entropy values, the healthy and pathological signals were differentiated efficiently. In spite of that, this measure has no practical application, because a diagnosed voice database is necessary as a basis of comparison. For the PP with AR modeling, no distinction between the groups is observed, but with the wavelet modeling, the healthy signals showed significantly higher predictability than the pathological ones, however the pathologies were differentiated. Using the PrCA with both models, the pathological and healthy groups were distinguished, but for the AR model, the healthy signals presented smaller predictability. This shows that the predictability depends on the analysis model, thus the larynx pathologies can decrease or increase the prediction capacity of the voice signals according to the used model. The results of PrCA of the tridimensional representations show similar behavior of the ones from direct PrCA signal analisys with the AR model. Despite of these results, this form of data representation seems to be promising for future studies. Considering these results, we concluded that this study was very useful to acquire a better understanding of the dynamics of voice production and that the predictability measures are interesting for the evaluation of larynx pathologies, especially presence of nodule in the vocal folds and Reinke's edema, at least for this initial study using the available signals. More studies are still necessary, but this analysis method already presents good results, which can be applied to aid pathology diagnosis by health professionals.

Keywords: voice, predictability, entropy, predictive power, pathology, nodule, Reinke's edema, predictable component analysis. 


\section{Capítulo 1}

\section{Introdução}

O uso de previsões pela humanidade tem raízes no passado remoto. Atualmente, são essenciais em diversas áreas do conhecimento, sendo usadas como base para tomadas de decisão e criação de estratégias. Entretanto, essas previsões só possuem valor quando são obtidas para a aplicação desejada, com métodos desenvolvidos em conjunto por usuários e analistas, os quais definirão o contexto e os objetivos dessa aplicação (Pinson, 2006).

Em um contexto científico, uma previsão é uma informação a respeito de algum evento que acontecerá em condições específicas. Com base na capacidade de se testar as previsões é que são definidas teorias científicas, caso essas não sejam condizentes com as observações práticas, uma dada teoria é rejeitada. Geralmente, utilizam-se modelos matemáticos para descrever o comportamento de algum fenômeno, utilizando-o para fazer previsões.

Na história da ciência, muitos exemplos que contribuem para essa discussão podem ser apresentados. Alguns mostram previsões que não se concretizaram, como o experimento de Michelson-Morley realizado em 1887 com o intuito de provar a existência do éter (suposta substância existente no universo na qual as ondas eletromagnéticas se propagavam). Esse experimento fracassou, mostrando que as previsões feitas com base nessa hipótese eram falsas, então, abriu-se caminho para se provar a inexistência do éter (Michelson e Morley, 1887). Outro exemplo é a experiência da influência da gravidade sobre a luz, realizada por Arthur Stanley Eddington em 1919 na ocasião de um eclipse solar. Esta confirmou as previsões feitas por Einstein usando sua Teoria da Relatividade, a qual afirmava que a luz de uma estrela distante seria influenciada pela gravidade do Sol ao passar em sua vizinhança (Einstein et al., 2005). 
Atualmente, quando se fala em previsibilidade, logo se pensa em previsão do tempo. Essa idéia não se distancia da noção de previsibilidade utilizada nesta pesquisa. Isso, pois, desde os trabalhos iniciados por Lorenz (1963), considerações sobre a dinâmica caótica dos sistemas atmosféricos começaram a ser levados em conta na previsão do tempo e clima. Dessa forma, a complexidade dos sistemas e o avanço da computação, permitiram (e exigiram) o uso de modelos mais elaborados para fazer a previsão de eventos.

Trabalhos mais recentes como Renwick e Wallace (1995), Déqué (1998), Schneider e Griffies (1999), DelSole e Chang (2003) e DelSole e Tippett (2007) começaram a apresentar uma nova abordagem para a análise de previsibilidade de sistemas. Princípios de teoria da informação, como medidas de entropia, foram acrescentados aos métodos tradicionais para aumentar o alcance das previsões, obtendo resultados muito bons (Schneider e Griffies, 1999).

Assim, ao utilizar métodos estocásticos e medidas universais, essas técnicas passaram a ser aplicáveis a diversos tipos de sistemas e não somente ao clima. Um dos conceitos errôneos de previsibilidade é a idéia da previsão ser somente sobre eventos futuros, sendo que informações de previsibilidade de eventos passados também são interessantes. Como exemplo, pode-se pensar em um sinal coletado de um sistema de controle automatizado, uma análise de previsibilidade desse sinal pode indicar instantes onde o sistema esteve sobrecarregado, pois seu comportamento foi menos previsível por causa da variação da carga.

Com essa noção de aplicabilidade, pode-se considerar a utilização desse método em sistemas biológicos, nos quais os sinais dependem da dinâmica do sistema e possuem características estocásticas. Como exemplo, em Cai et al. (2001), apresenta-se um estudo de previsibilidade aplicada em variabilidade de batimento cardíaco (HRV - Heart Rate Variability), procurando um índice para medir danos no coração após um infarto do miocárdio. Assim, utilizando-se esse tipo de medida, foram obtidos resultados que contribuíram para o entendimento do comportamento da HRV dos pacientes.

Seguindo a mesma linha, pode-se considerar o sistema de produção da fala humana. Diversas patologias que ocorrem na laringe como, por exemplo, presença de nódulos por esforço demasiado, modificam a dinâmica do sistema de produção de voz, gerando pequenas variações em parâmetros acústicos do trato vocal. Essas variações podem ser percebidas por uma análise do sinal de voz a partir de técnicas que meçam sua variação de previsibilidade.

Para ilustrar essa análise de sinais de voz, apresenta-se um sinal de voz saudável ao qual foi adicionado ruído branco em dois diferentes níveis conforme as Figuras 1.1 e 1.2. Na pri- 
meira, tem-se relação sinal-ruído (SNR - signal-to-noise ratio) de aproximadamente $28 d B$ e, na segunda, $18 d B$. Como o nível de ruído é maior no segundo sinal, este é mais imprevisível. Conforme será apresentado nos capítulos seguintes, a presença de ruído no sinal de voz é um indicativo de patologias.

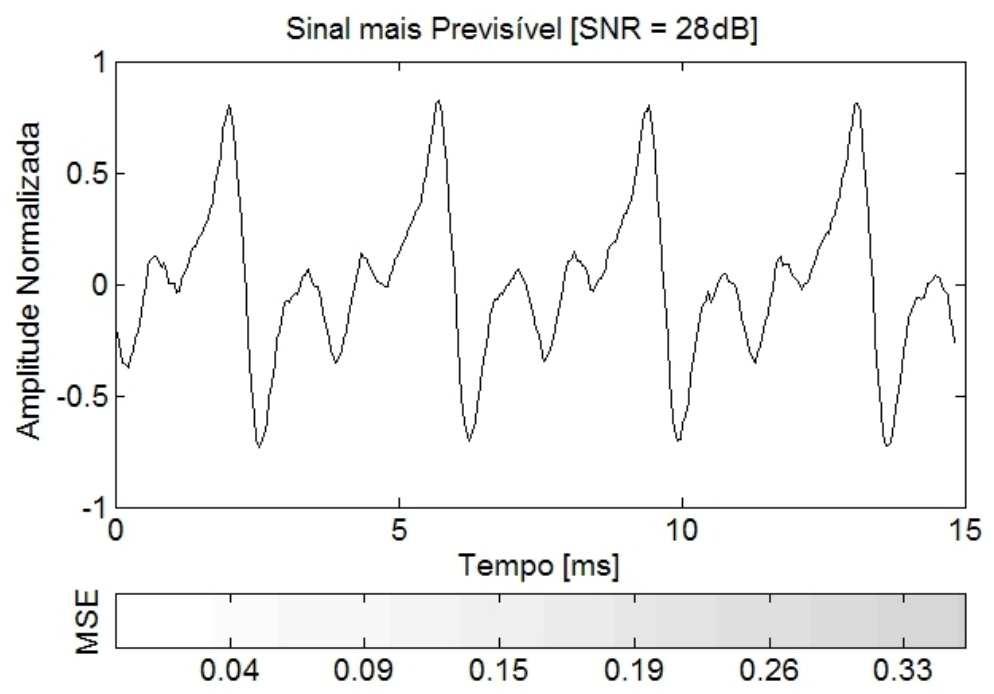

Figura 1.1: Sinal de voz com nível de ruído branco em torno de $28 d B$, sendo mais previsível. A barra em tons de cinza indica o MSE da estimativa do sinal usando AR(5) conforme o sinal progride no tempo.

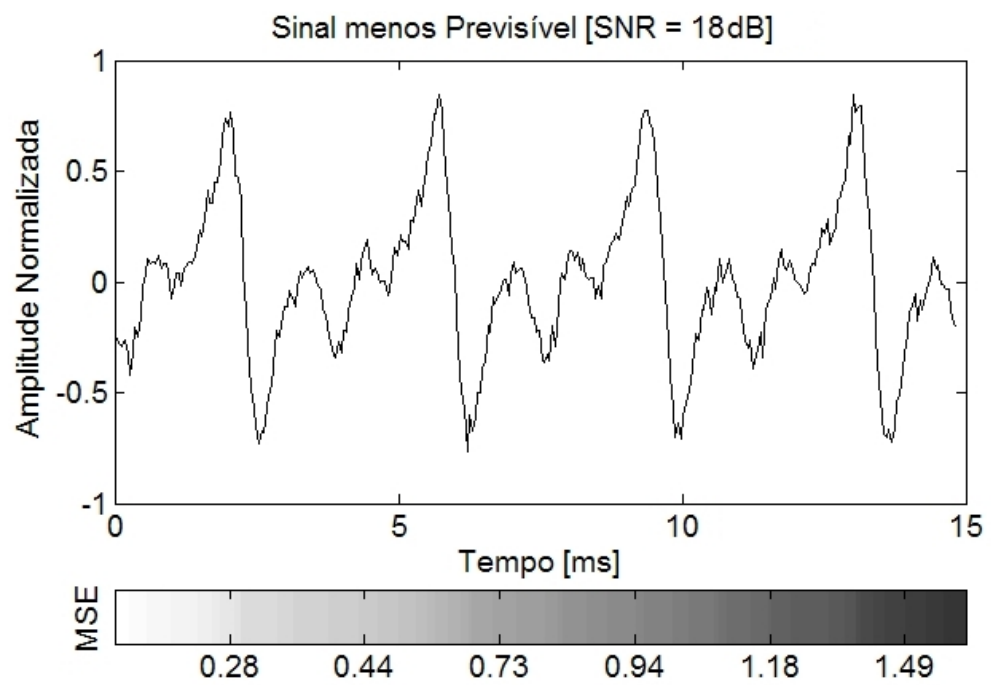

Figura 1.2: Sinal de voz com nível de ruído branco em torno de $18 d B$, sendo menos previsível. A barra em tons de cinza indica o MSE da estimativa do sinal usando AR(5) conforme o sinal progride no tempo.

Como uma forma de obtenção de previsões dos sinais, usa-se um modelo autorregressivo de quinta ordem $\mathrm{AR}(5)$, o qual resulta em um erro de estimativa. Calcula-se o valor do erro médio quadrático (MSE - mean squared error) conforme o sinal progride temporalmente, indicando- 
se esse valor com uma barra de níveis de cinza logo abaixo das figuras. O MSE é uma medida simples de previsibilidade muito usada (DelSole, 2004). Como se pode ver, o segundo sinal, que é menos previsível devido ao ruído, apresenta maiores níveis de MSE.

Após essa breve introdução, pode-se delinear a tese a ser desenvolvida. Faz-se a suposição de que as medidas de previsibilidade, especificamente, entropia, potência de previsão, tanto estimada diretamente com o auxílio de um modelo ou por meio da análise de componentes previsíveis; possuem a capacidade de diferenciar sinais de voz saudáveis e patológicos. Supõem-se que, pelo menos, sejam capazes de auxiliar outros métodos nessa tarefa.

Este estudo de previsibilidade é realizado com a abordagem de que a dinâmica interna do sistema de produção de voz seja desconhecida, ou seja, não se sabe como é a sua estrutura interna nem a transição de seus estados. Dessa forma, buscam-se as informações do sistema através de estimativas das características estatísticas dos sinais de voz gerados por ele, como as distribuições de probabilidade. Assim, objetiva-se analisar as diferenças de comportamento da dinâmica dos sistemas saudável e patológicos usando as medidas de previsibilidade para fornecer informações sobre propriedades como regularidade, redundância e complexidade dos sinais de voz.

Mais especificamente, tem-se como objetivos, consolidar um banco de dados com vozes saudáveis e patológicas, sendo estas últimas de nódulo nas pregas vocais e edema de Reinke; desenvolver um algoritmo para estimativa não-paramétrica da entropia de Shannon e da entropia relativa entre dois sinais; desenvolver, também, algoritmos para estimativa de potência de previsão e análise de componentes previsíveis; validar esses algoritmos usando sinais simulados de voz; e, por fim, avaliar o desempenho desses métodos para a diferenciação dos sinais de voz do banco de dados.

De forma resumida, pode-se apresentar os resultados obtidos e a conclusão deste estudo. Pode-se mostrar que a potência de previsão pode realmente ser usada para a diferenciação dos sinais saudáveis e patológicos, mas não conseguiram diferenciar os sinais patológicos entre si. Já a entropia de Shannon dos sinais não foi capaz dessa separação, entretanto, com a entropia relativa entre os sinais dos grupos foi possível a diferenciação. Mostra-se a capacidade da análise de componentes previsível em reconstruir sinais somente com suas partes mais previsíveis, ou seja, retirar a parte estocástica das vozes e permitir uma melhor observação de sua parte determinística, o que melhora a diferenciação desses sinais.

Mostra-se que a previsibilidade dos sinais depende do modelo usado para a obtenção das 
previsões, e que o modelo proposto de decomposição por wavelets foi eficaz em caracterizar os sinais saudáveis como mais previsíveis do que os patológicos.

Mostra-se também a dificuldade em estimar a entropia de blocos de sinais com valores reais, mas, apresenta-se a relação das variações da freqüência fundamental das vozes com a curva de convergência da entropia. Essa característica é promissora para o uso como parâmetro de análise de voz.

Esta tese está dividida da seguinte forma: inicialmente, no capítulo Análise de Voz, faz-se uma introdução do estudo de sinais de voz, apresentando-se alguns aspectos relevantes do sistema vocálico, especificamente um de seus modelos matemáticos e características dos sinais de voz. Comenta-se também sobre duas patologias da laringe: presença de nódulo nas pregas vocais e edema de Reinke, pois foram os sinais patológicos usados neste estudo. Por fim, mostra-se uma visão resumida e objetiva da atual condição das técnicas usadas em processamento de voz para detecção de patologias.

No capítulo seguinte, Estudos de Previsibilidade, detalha-se o método de previsibilidade, apresentando algumas medidas de previsão como a entropia, a qual caracteriza a incerteza do sistema, e potência de previsão, que se baseia em medidas de entropia relativa. Além disso, mostram-se características das curvas de crescimento de entropia de blocos. Finaliza-se o capítulo, explicando a análise de componentes previsíveis.

Em seguida, em Sinais e Modelos de Previsão de Voz, inicia-se com considerações a respeito dos sinais de voz utilizados no estudo, sua aquisição e pré-processamento. Depois, comentam-se sobre os modelos usados para previsão dos sinais: autorregressivo, um modelo baseado em decomposição por wavelets e o modelo AR multidimensional usado para prover previsões da representação tridimensional dos sinais de voz.

Em Algoritmos, apresentam-se, simplificadamente, algoritmos para a estimativa da entropia de sinais usando três métodos diferentes: primeiro, discretização da entropia diferencial; segundo, passo de quantização constante, e terceiro, equalização do histograma. Discutem-se os problemas para a estimativa da entropia de blocos usada para gerar as curvas de crescimento de entropia. Em seguida, mostram-se os algoritmos para cálculo da potência de previsão usando o modelo autorregressivo e o baseado em decomposição por wavelets. Finaliza-se o capítulo mostrando o algoritmo para análise de componentes previsíveis, tanto diretamente aplicada aos sinais temporais quanto a representação tridimensional. Todo o capítulo é ilustrado com ensaios usando sinais simulados. 
No capítulo seguinte, Ensaios e Resultados, apresentam-se os ensaios feitos com sinais de voz para as medidas de entropia, entropia relativa e curvas de entropia. Mostram-se, também, os resultados de potência de previsão para os dois modelos usados neste estudo. Por fim, apresentam-se os ensaios com análise de componentes previsíveis para os sinais temporais, novamente com dois modelos propostos, e para a representação tridimensional usando modelo AR multidimensional.

No último capítulo, Discussão e Conclusões, apresentam-se discussões a respeito dos resultados obtidos com todos os ensaios anteriores, comparando os métodos usados e a aplicabilidade em análise de voz. Comenta-se, também, a contribuição científica do estudo enfatizando as publicações em congressos e periódicos. Finaliza-se o texto, apresentando as conclusões obtidas e os próximos passos a serem dados para continuar o trabalho.

Após as Referências Bibliográficas, apresentam-se três apêndices. No primeiro, Apêndice A, discutem-se alguns detalhes do simulador de sinais de voz usado neste trabalho. Já no Apêndice B, demonstra-se o erro da adição de um deslocamento na estimativa da distribuição de probabilidades para o cálculo da entropia relativa, conforme comentado no Capítulo 5. No Apêndice C, demonstram-se as entropias de Shannon e relativa para distibuições Gaussianas, formulações usadas também no Capítulo 5. 


\section{Capítulo 2}

\section{Análise de Voz}

Neste capítulo, discute-se alguns princípios de análise de voz, iniciando com uma breve apresentação do sistema de produção vocálico e um dos mais usados modelos matemáticos, Seção 2.1. Em seguida, mostram-se algumas características dos sinais de voz que são usadas para realizar as análises. Já na Seção 2.2, comenta-se um pouco sobre as disfunções desse sistema, principalmente a presença de nódulos nas pregas vocais e o edema de Reinke, discutem-se, também, algumas formas de avaliação de patologias da laringe.

Após essa revisão teórica, na Seção 2.3, apresentam-se alguns dos métodos mais comuns utilizados para processamento de sinais de voz. Esses métodos são aplicados na detecção de patologias de laringe pelo estudo de mudanças nos sinais dos pacientes quando comparados com sinais de pessoas saudáveis. Apresentam-se diversos estudos, buscando identificar o atual estado da arte. Inicia-se com um breve histórico dos trabalhos realizados nessa área a partir do século XVIII, passando para a análise acústica e técnicas de classificação de sinais.

O conceito principal para a análise de sinais de voz é que esta é dependente da estrutura do sistema vocálico, assim, qualquer distúrbio que ocorra na laringe é refletido no sinal. Geralmente, isso ocorre na forma de variações de características do sinal como mudanças no pitch ${ }^{1}$ e amplitude ou acréscimo de ruído (Davis, 1979). Os métodos clássicos se baseiam na análise dessas perturbações acústicas ou também pelo uso de medidas no espectro de potência do sinal.

Além do estudo das medidas de perturbação dos sinais de voz, outros métodos de processamento de sinais são empregados na análise de distúrbios do sistema vocálico. Pode-se citar

\footnotetext{
${ }^{1} \mathrm{O}$ pitch, de forma geral e resumida, é o nome dado a freqüência fundamental do sinal de voz, sendo também a propriedade do sinal que caracteriza se a voz é mais grave ou aguda.
} 
o uso de redes neurais para classificação de patologias (Rosa, 1998), análise usando transformada wavelet (Fonseca et al., 2007), cepstrum (Awan e Roy, 2005) e filtragem inversa usando predição linear (Rosa et al., 2000).

Outros métodos lineares são apresentados na literatura, entretanto é interessante ressaltar a atual importância dos modelos não-lineares, os quais consideram que a produção da voz possui componentes de caos (Titze et al., 1993). Assim, utilizam-se ferramentas como reconstrução em espaço de fase (Dajer et al., 2005), dimensão de correlação, expoentes de Lyapunov (Nicollas et al., 2008), seção de Poicaré e análise de fractais (Baken, 1990).

Nos últimos anos, começou-se a aplicar medidas de teoria da informação em diversos tipos de sinais. Valores de entropia, informação mútua e entropia relativa entre dois sinais apresentam dados a respeito da incerteza de um sinal ou, também, da sua complexidade. Como a presença de patologias em diversos sistemas do corpo resulta em mudanças nessas características dos sinais coletados, o uso das medidas mencionadas contribuem para o estudo e diagnóstico de doenças.

Dessa forma, estudos recentes usam essas medidas para estudar sinais biológicos, como variabilidade de batimento cardíaco (Lake et al., 2002), análise do efeito de anestesias em sinais de EEG (eletroencefalograma) (Sleigh et al., 2001), ou para detecção de epilepsia (Kannathal et al., 2005). Outro exemplo é a aplicação de entropia de Renyi em sinais de espalhamento de ultra-som para caracterização de tecidos (Smolíková et al., 2004). Para finalizar este capítulo, comenta-se mais sobre esses recentes estudos usando métodos não-lineares.

Na mesma linha desses estudos, surgiram alguns tipos de análises baseada em medidas probabilísticas de incerteza dos sinais e também de previsibilidade de um sistema. Essas técnicas podem ser aplicadas a sinais biológicos considerando que modificações na dinâmica de funcionamento do organismo resultam na diminuição da previsibilidade dos sinais coletados. Um exemplo é apresentado em Cai et al. (2001), conforme mencionado no Capítulo 1, o qual analisa a variabilidade de batimentos cardíacos de pessoas que sofreram ataques cardíacos usando a previsibilidade dos sinais de ECG (eletrocardiograma).

Alguns desses métodos utilizam medidas de entropia para estimar a previsibilidade de sistemas, entretanto, essa técnica foi desenvolvida originalmente para estudar o clima e fazer previsões do tempo (Schneider e Griffies, 1999). Mais sobre esses métodos probabilísticos serão apresentados no final deste capítulo, porém, mais atenção será dada no Capítulo 3. 
Assim, antes de se apresentar alguns dos mais relevantes e recentes estudos de análise de voz, inicia-se com alguns detalhes do sistema vocálico, características dos sinais de voz e patologias da laringe.

\subsection{Sistema Vocálico}

Os diferentes sons de fala emitidos pelos seres humanos são produzidos por uma combinação de diversos órgãos, entre eles estão as pregas vocais, a língua e os lábios. Na maioria desses sons, as vibrações do ar quando passam pela garganta, boca e nariz servem como os movimentos para iniciar as ondas acústicas. Esse conjunto de órgãos é chamado de trato vocal supraglótico, o qual começa nas pregas vocais e termina na boca, formando um câmara de ressonância complexa (Ladefoged, 1995).

Os implulsos que iniciam o movimento do ar no trato vocal, também chamados de pulsos glotais, são causados pela ação das pregas vocais no ar que é forçado para fora do pulmão pelo músculos respiratórios. Quando as pregas estão juntas, a pressão cresce sob elas; se a pressão for suficientemente grande, as pregas se abrem e o ar é liberado. Essa liberação abrupta do ar serve como um impulso no ar do trato vocal, iniciando uma vibração.

As Figuras 2.1 (a) e (b) apresentam fotos obtidas por videolaringoscopia de pregas vocais saudáveis nas posições abertas e fechadas respectivamente. Essas imagens fazem parte de um banco de dados do Laboratório de Processamento de Sinais (LPS) conforme será apresentado no Capítulo 4. Na figura, indicam-se os seguintes componentes da laringe: glote, pregas vocais, cartilagem aritenóide e epiglote.

Para ilustrar a posição anatômica dos componentes do trato vocal, apresenta-se a Figura 2.2, modificada de Tortora e Grabowski (2002), a qual mostra um esquemático do sistema respiratório. Considerando a glote (ou espaço glótico) como referência, o trato vocal pode ser dividido em duas partes: supraglótica e infraglótica. A primeira é composta pela cavidade nasal, faringe e laringe (pregas vocais) e, a segunda, pela traquéia e os brônquios. Os pulmões não são considerados parte do trato vocal, mas sim parte do trato respiratório. A Figura 2.3, modificada de Netter (1997), apresenta mais alguns detalhes da laringe, mostrando as visões anterior e posterior com seus principais componentes. 


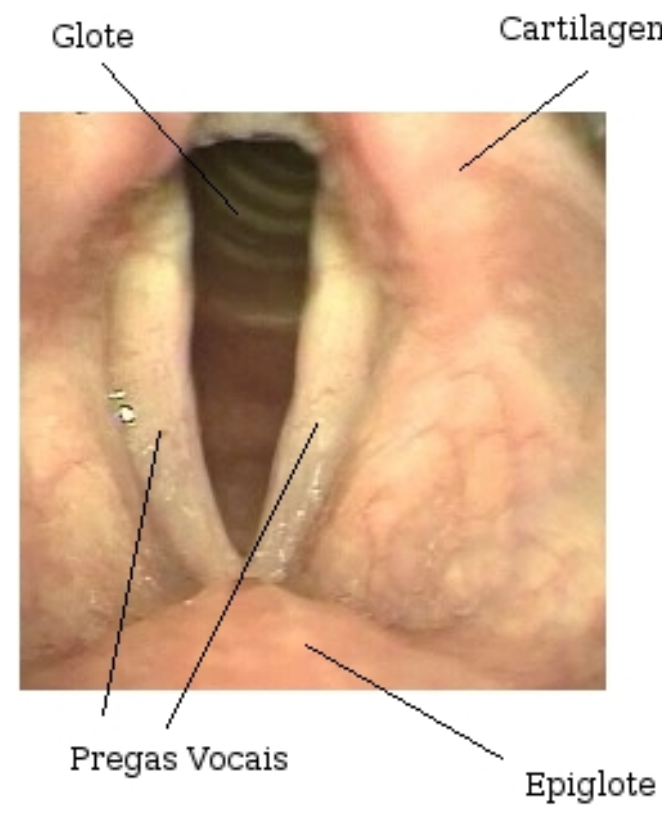

(a)

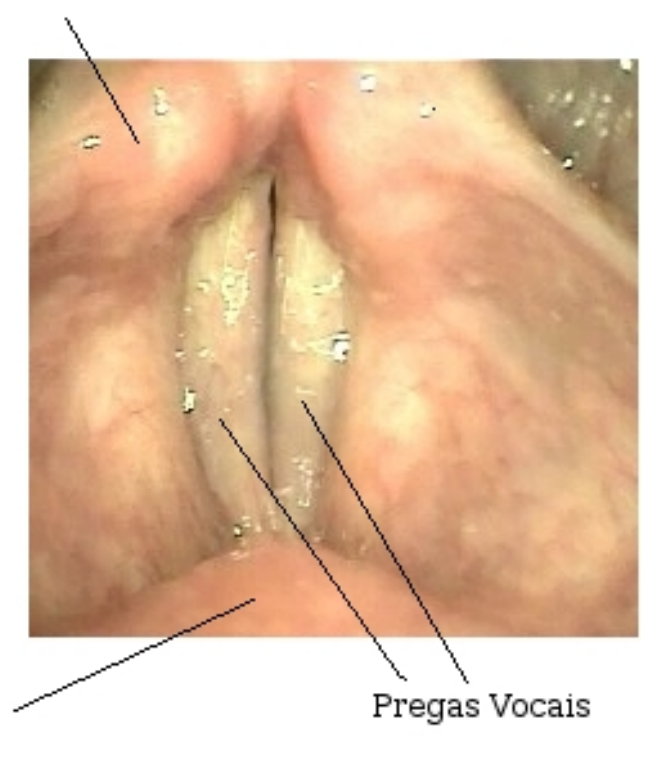

(b)

Figura 2.1: Imagens de videolaringoscopia das pregas vocais. (a) Fase aberta das pregas, quando ocorre a passagem de ar dos pulmões para a boca, iniciando uma vibração acústica no trato vocal. (b) Fase fechada das pregas, evita-se a passagem de ar dos pulmões para a boca.

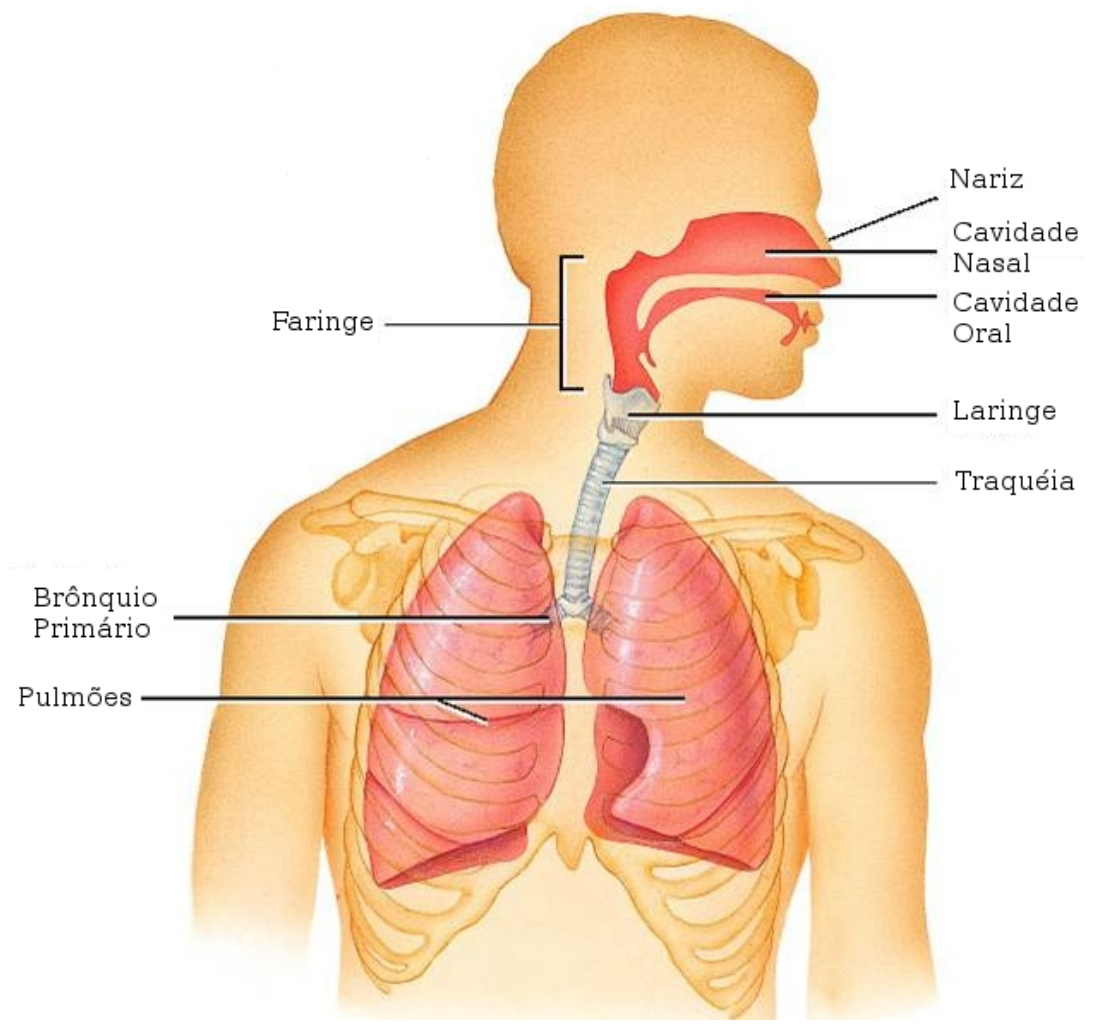

Figura 2.2: Esquemático da formação do trato vocal, divido em duas partes: supraglótico, composto pela cavidade nasal, faringe e laringe (pregas vocais), e infraglótico, composto pela traquéia e brônquios. Os pulmões são considerados como parte do trato respiratório apesar de sua função na produção vocal. Imagem modificada de Tortora e Grabowski (2002). 


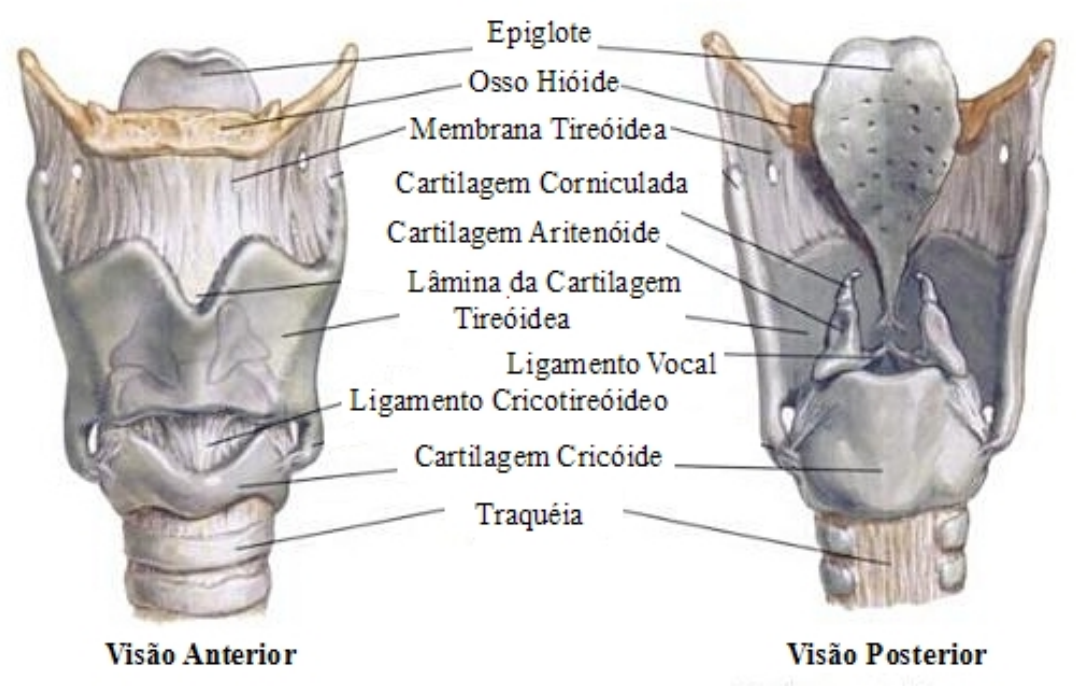

Figura 2.3: Esquemático da formação anatômica da laringe, visões anterior e posterior com indicações dos principais componentes. Imagem modificada de Netter (1997).

Devido a sua importância na geração dos pulsos glotais, apresentam-se mais algumas informações a respeito das pregas vocais. As pregas estão localizadas em posição horizontal dentro da laringe e são compostas por duas estruturas multilaminadas: a mucosa e o músculo vocal, as quais são constituídas por camadas com propriedades mecânicas distintas. A mucosa é divida em duas: epitélio e lâmina própria (Dajer, 2006). A Figura 2.4, modificada de Hirano e Sato (1993), apresenta um esquemático que ilustra essa composição.

Pode-se dividir essas camadas de outra forma conforme sua estrutura e propriedades mecânicas como proposto pelo modelo cobertura-corpo (do termo em inglês cover-body) (Hirano e Kakita, 1985; Dajer, 2006). Divide-se em três grupos: cobertura, transição e corpo. A cobertura é composta pelo epitélio e a camada superficial da lâmina própria, também chamada de espaço de Reinke. O epitélio, que é formado por tecido escamoso e estratificado, tem a função de cobrir e manter a forma da prega vocal. O espaço de Reike é a camada que mais vibra durante a fala, pois é formado por tecido gelatinoso e flexível, o que permite um alto deslocamento dessa camada.

A transição é composta pelas camadas intermediária e profunda da lâmina própria, a primeira é formada por várias fibras elásticas, tendo densidade maior que a camada superficial. A camada profunda é mais rígida com maior quantidade de fibras de colágeno e menor de fibras elásticas quanto mais próximo do corpo da prega vocal. O corpo é composto pelo músculo vocal, o qual é formado por fibras elásticas, de colágeno e musculares. Algumas das fibras da camada profunda da lâmina própria se inserem na camada do músculo (Gray et al., 1993). 


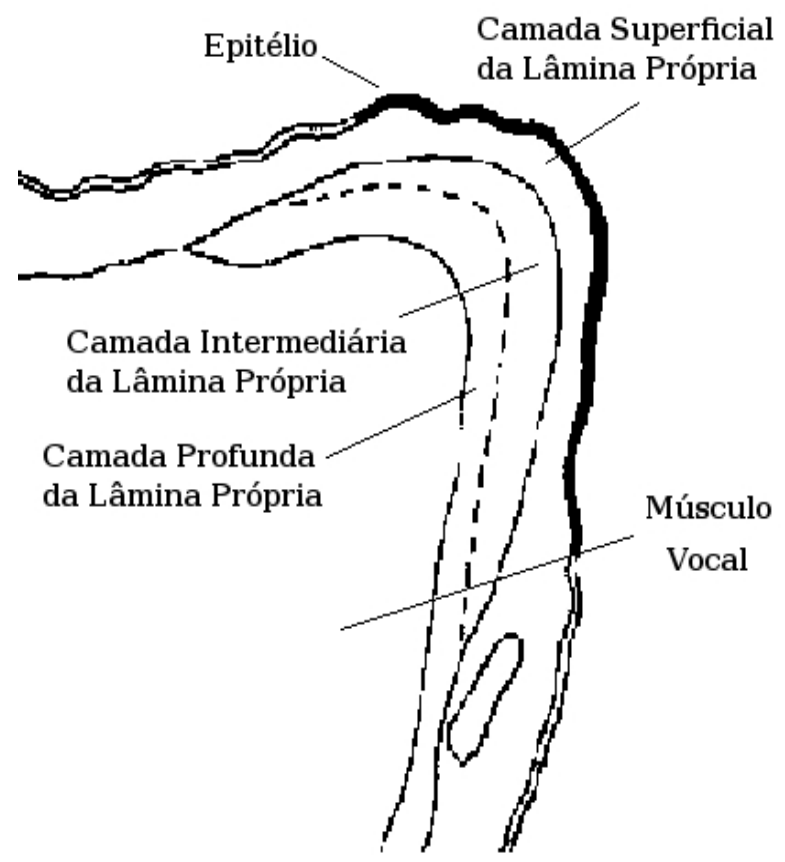

Figura 2.4: Esquemático da formação histológica de uma prega vocal. Apresentam-se o epitélio, as camadas da lâmina própria (superficial, intermediária e profunda) e o músculo vocal. Figura modificada de Hirano e Sato (1993).

Após essas considerações anatômicas, histológicas e funcionais do sistema vocálico, faz-se necessário apresentar um modelo para transpor essas características biológicas para conceitos matemáticos. Esse procedimento é o tópico da próxima seção.

\subsubsection{Modelos do Sistema Vocálico}

Os sons produzidos pelos seres humanos podem ser classificados em três classes distintas conforme o seu modo de excitação: vocálicos, não-vocálicos (fricativos) e plosivos. Os sons vocálicos são produzidos quando se força o ar através da glote com a tensão das pregas vocais ajustada para vibrar como uma oscilação relaxada, assim, produzem-se pulsos quaseperiódicos ${ }^{2}$ de ar no trato vocal. Os sons fricativos são formados por uma constrição em algum ponto do trato vocal, normalmente na boca, fazendo o ar dos pulmões passar com velocidade suficiente para gerar turbulência, então, cria-se uma fonte de ruído de banda larga no trato. Por fim, os sons plosivos são resultantes de um fechamento do trato, geralmente na boca, criando um aumento de pressão, o qual gera o som quando liberado (Rabiner e Schafer, 1978).

\footnotetext{
${ }^{2}$ A característica de quase-periodicidade de uma seqüência de pulsos pode ser entendida como uma variação aleatória dos períodos de repetição dos pulsos. Essa definição é derivada do termo em inglês almost periodic.
} 
As diferenças nas vibrações do ar no trato vocal são dependentes da forma do trato, sendo determinadas, principalmente, pelos movimentos da língua, lábios e palato. Para cada configuração, mudam-se as frequiências de ressonância do trato vocal, também chamadas de frequiências formantes do sinal. Essas formantes são características que apresentam variações de pessoa para pessoa, tanto na freqüência central quanto na largura de banda (Rosa, 1998).

O trato vocal inferior, como visto anteriormente ser constituído pelo pulmão, brônquios e traquéia, também pode ser chamado de sistema subglotal. Esse sistema é o responsável por fornecer a energia para a geração da fala, assim, é considerado a fonte do sistema vocálico. Por sua vez, o trato vocal superior é considerado o filtro, pois o sinal gerado pelo sistema subglotal tem sua banda de freqüências modificada pela seletividade do trato superior (Dajer, 2006; Rabiner e Schafer, 1978). Dessa forma, o sistema vocálico pode ser entendido como um conjunto fonte-filtro conforme ilustrado na Figura 2.5 de acordo com Dajer (2006).

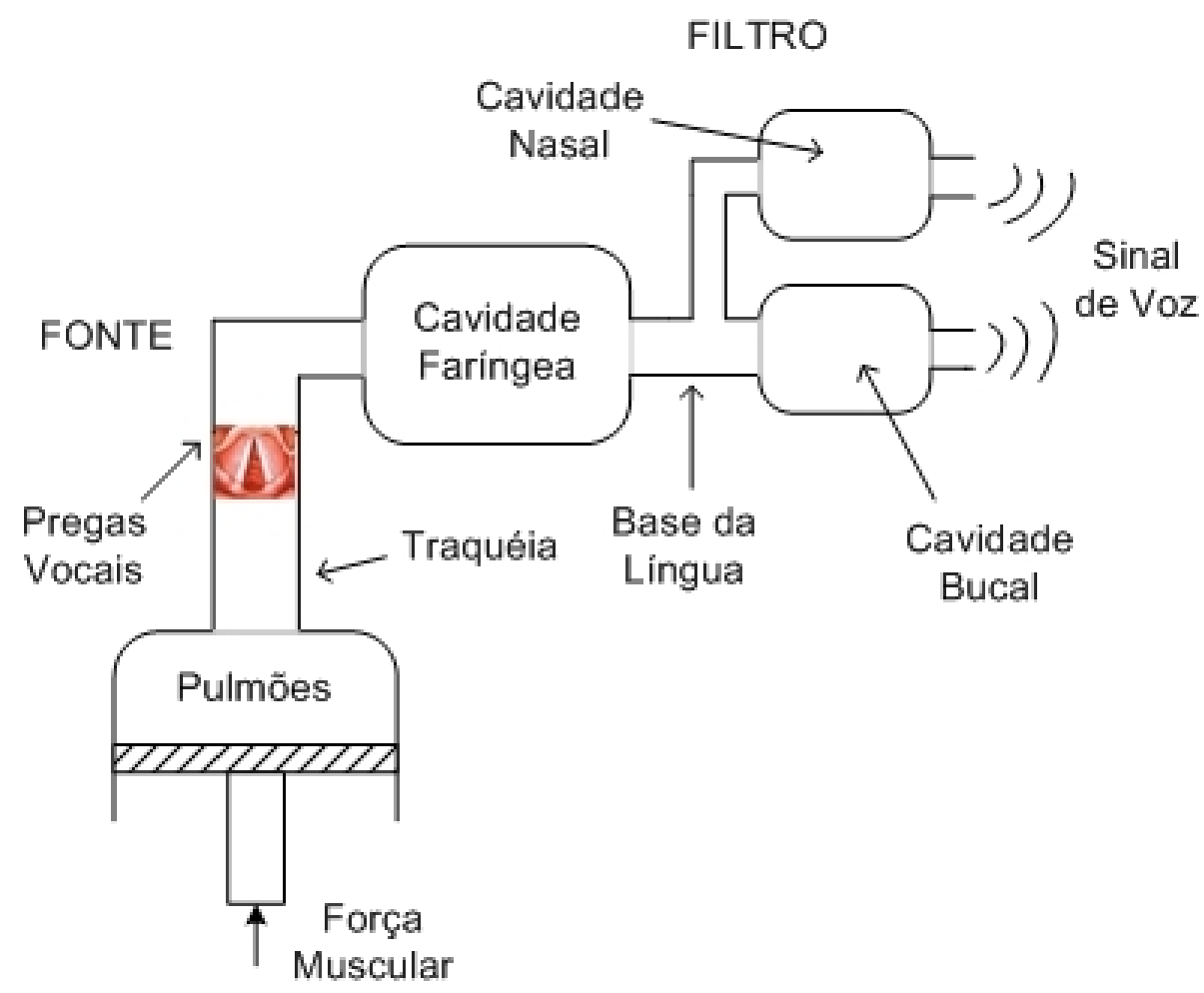

Figura 2.5: Esquemático do sistema fonte-filtro, o qual é uma interpretação do sistema vocálico. O sistema subglotal é considerado a fonte de energia para a geração de som e o trato vocal é comparado com um filtro, pois modifica a banda de frequiências do sinal gerado na fonte.

O som gerado pela fonte desse sistema apresenta amplitude muito baixa, portanto ainda não pode ser caracterizado como o som ouvido quando alguém fala. A Figura 2.6 (a) ilustra o comportamento do espectro de potências desse sinal gerado pelas pregas vocais, mostrando 
o decréscimo da potência com o aumento da freqüência. A parte (b) mostra a resposta de frequiência do trato vocal, a qual modifica os pulsos glotais, filtrando e amplificando esse sinal. A parte (c) ilustra a resposta da radiação dos lábios, que também filtra o sinal após o trato vocal. Por fim, a parte (d) mostra o espectro de potências do sinal resultante, agora considerado como a voz. Essa figura baseia-se em uma ilustração de Levin e Edgerton (1999).

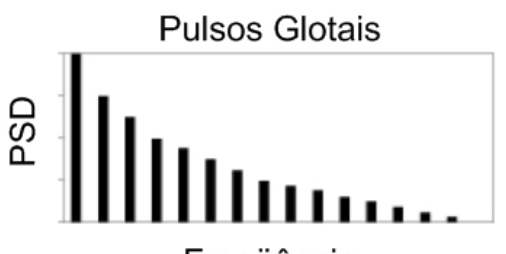

(a)

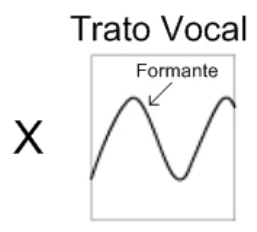

(b)

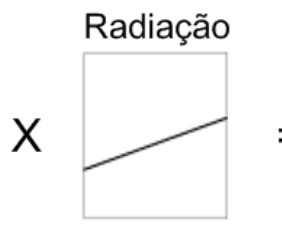

(c)

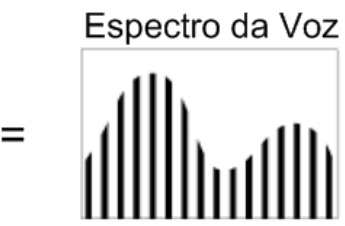

(d)

Figura 2.6: Ilustração do espectro de potências dos sinais envolvidos na produção da voz. (a) Espectro do pulso glotal gerado pelo sistema subglotal usando as pregas vocais. (b) Resposta em frequiência do filtro equivalente do trato vocal. (c) Resposta em freqüência da característica de radiação dos lábios. (d) Espectro do sinal de voz resultante.

Um modelo matemático para o sistema vocálico começou a ser proposto em Fant (1959), apresentando um modelo linear da produção de sinais de voz, posteriormente melhorado em Flanagan (1972). Esse modelo é composto por três filtros acústicos, sendo uma de suas vantagens a separabilidade dos filtros na geração dos sinais de voz. A construção desse modelo baseia-se na teoria de tubos acústicos, em medidas de formas de onda de velocidade volumétrica e pressão acústica, em dados de raios-X e em resultados de síntese de sons vocálicos usando circuitos elétricos (Davis, 1979; Rabiner e Schafer, 1978).

A Figura 2.7 apresenta um esquemático desse modelo para a geração de sons vocálicos e não-vocálicos. A diferença está no sinal $U(z)$ que pode ser formado pelo gerador de ruído para sons não-vocálicos, ou pelo trem de impulsos, $E(z)$, para sons vocálicos. No segundo caso, o sinal $E(z)$ é filtrado pelo modelo do pulso glotal, ou seja, $U(z)=A_{v} G(z) E(z)$. $A_{v}$ e $A_{n}$ são valores de ganho que consideram os efeitos de variação da pressão exercida pelo pulmão (Rosa, 1998). Essa figura se baseia em ilustração semelhante em Rabiner e Schafer (1978).

Conforme o modelo da Figura 2.7, sendo um sinal vocálico discreto no tempo $s[n]$, com transformada $Z$ igual a $S(z)$, pode-se descrever esse sinal pela Equação (2.1).

$$
S(z)=L(z) V(z) G(z) E(z)
$$




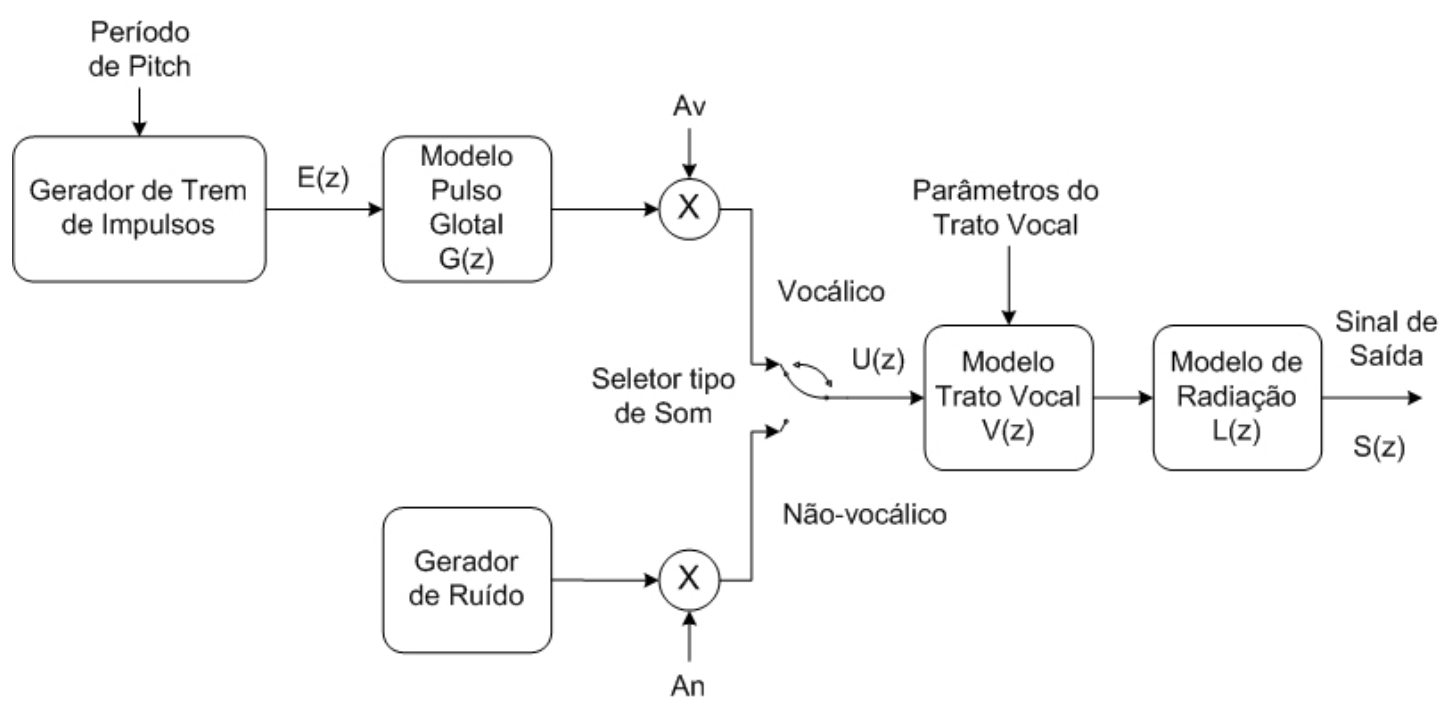

Figura 2.7: Esquemático do modelo matemático linear da produção de sons vocálicos e nãovocálicos. Para sons vocálicos, utiliza-se o gerador de trem de pulsos, cujo sinal gerado tem $E(z)$ como transformada $Z$, o qual é moldado pelo pulso glotal, com resposta em freqüência igual a $G(z)$. Esse sinal é amplificado pelo ganho $A_{v}$. Para sons não-vocálicos, utiliza-se o gerador de ruído amplificado pelo ganho $A_{n}$. Os dois tipos de sinal são filtrados pelo modelo do trato vocal, $V(z)$, cujos parâmetros variam conforme a pessoa, e pelo modelo de radiação labial, $L(z)$. O sinal gerado tem espectro de potências dado por $S(z)$.

Tem-se que $L(z)$ é o modelo da radiação labial, $V(z)$ é o modelo do trato vocal, $G(z)$ é o modelo do pulso glotal e $E(z)$ é a excitação, a qual é um trem de impulsos gerado pelo sistema subglotal. O componente $G(z) E(z)$ é equivalente ao espectro mostrado na Figura 2.6 (a).

De forma simplificada, cada um dos componentes do modelo é apresentado a seguir. Nesse modelo, o pulmão, que biologicamente auxilia na definição da queda de pressão necessária para excitar um escoamento de ar através da laringe, é substituído por um trem de impulsos unitários espaçados pelo período de pitch do som a ser gerado. A laringe é substituída pelo filtro $G(z)$ que transforma a excitação em sinal glotal. Esse modelo do pulso glotal, $G(z)$, é representado por um modelo do tipo tudo-pólo (Hayes, 1996), o qual é baseado nas formas de onda fisiológicas observadas na prática (Davis, 1979).

O modelo do trato vocal é usado para anexar as características de ressonância acústica dos espaços de ar contidos entre a glote e os lábios, baseando-se em uma aproximação do trato vocal por tubos acústicos. Esse filtro $V(z)$ pode ser modelado por um pequeno número de pólos complexos, $K$. O modelo de radiação labial representa a transformação, nos lábios, do sinal proveniente da glote em uma onda de pressão sonora. O filtro $L(z)$ é obtido considerando uma situação análoga à vibração de um conjunto de pistões em uma placa infinita (Davis, 
1979). De acordo com Davis (1979), esse modelo pode ser simplificado conforme os resultados apresentados em Markel (1972). Assim, a transformada $Z$ do sinal de saída é apresentada na Equação (2.2), sendo $M_{p}=2 K+m, a_{i}$ são constantes reais e, geralmente, $m \leq 6$.

$$
S(z)=\frac{\sigma}{\sum_{i=0}^{M_{p}} a_{i} z^{-i}} E(z)
$$

Dessa forma, a produção de um sinal vocálico pode ser modelada por um filtro tudo-pólo excitado por um trem de impulsos. Esse modelo é muito interessante, pois possibilita o uso de várias ferramentas de análise como LPC (Linear Predictive Coding), o qual é uma aplicação de modelos autorregressivos. Uma forma muito usada de análise é o sinal residual do filtro LPC inverso, conforme apresentado em (Rosa, 1998; Rosa et al., 2000).

Na próxima subseção, apresentam-se algumas características dos sinais de voz que, junto com o modelo recém definido, serão usados para a análise de previsibilidade.

\subsubsection{Características dos Sinais de Voz}

Em análises acústicas com o objetivo de caracterização de patologias, os sons vocálicos são mais usados, pois, quando coletados com pitch e intensidade confortáveis para a pessoa que os pronunciam, esse tipo de sinal carrega mais informações da estrutura da laringe do que os sons não-vocálicos (plosivos e fricativos) (Kiliç et al., 2004).

Um exemplo de sinal de voz saudável é apresentado na Figura 2.8, o qual é uma amostra masculina de vogal "a" sustentada retirada do banco de dados do LPS. A parte (a) da figura mostra um trecho com amplitude normalizada (valores entre -1 e 1) de duração de $40 \mathrm{~ms}$. Pode-se ver a repetição de períodos relacionados com os pulsos glotais e a presença de diversos componentes harmônicos. Para melhor visualização desses componentes, a densidade espectral de potência (PSD - Power Spectral Density) do sinal original (com $1 s$ de duração) é apresentada na parte (b). Percebe-se que até aproximadamente 2,5 $\mathrm{kHz}$, existem diversos componentes bem definidos de freqüência, a partir desse ponto, a magnitude de potência é menor do que $-50 d B$, caracterizando alta concentração de ruído e pouca informação.

De acordo com Davis (1979), existem muitos métodos usados para avaliar a condição da laringe, entre eles: laringoscopia, estroboscopia, videolaringoscopia como será apresentado 


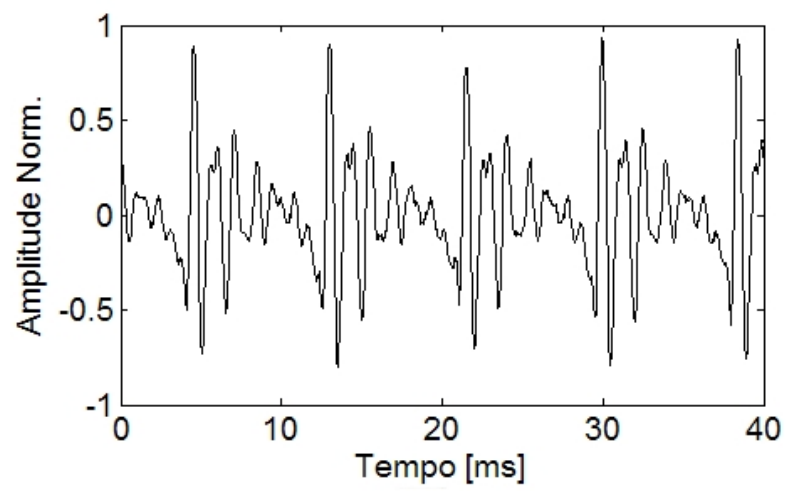

(a)

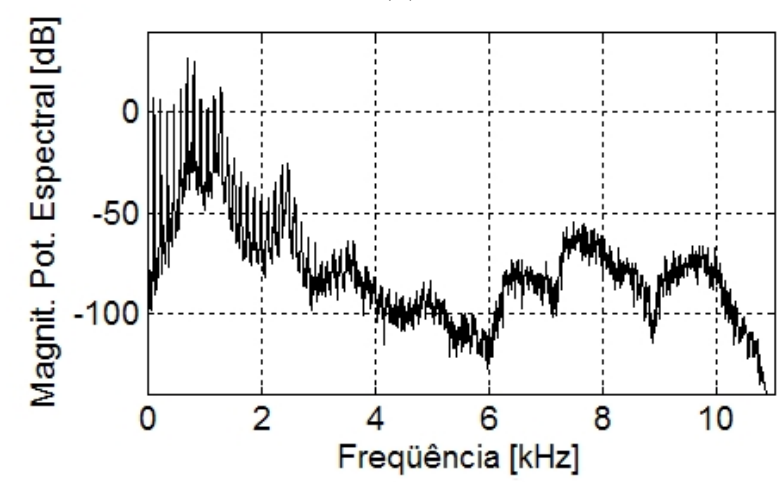

(b)

Figura 2.8: Exemplo de sinal masculino de voz retirado do banco de dados do LPS. (a) Trecho de $40 \mathrm{~ms}$ do sinal com aplitude normalizada. (b) PSD do sinal original mostrando os componentes harmônicos, sendo a grande parte da informação do sinal presente até $2,5 \mathrm{kHz}$, o resto possui magnitude menor do que $-50 d B$.

mais a frente. Entretanto, desde meados da década de 1960 (Lieberman, 1963), uma técnica que se tornou bastante popular é a análise acústica do sinal de voz, isso por ser um método não-invasivo e com resultados rápidos.

Essa técnica utiliza a análise de alguns parâmetros acústicos dos sinais para a avaliação da laringe. Pode-se dividir esses parâmetros em dois tipos, aqueles obtidos do sinal temporal e os que são obtidos do espectro de potência dos sinais. Esses parâmetros serão melhor explorados na seção 2.3.2. Entretanto, pode-se citar duas medidas do primeiro tipo (domínio do tempo): as perturbações de frequiência fundamental (pitch) e de amplitude do sinal, chamados de jitter e shimmer respectivamente (Andrade et al., 2002).

Além dessas medidas obtidas do sinal de voz no domínio do tempo, pode-se extrair outros parâmetros do sinal residual da análise LPC (Davis, 1979). O resíduo, como mencionado anteriormente, é obtido através da filtragem inversa do sinal de voz, a qual objetiva retirar os efeitos do trato vocal, ou seja, busca obter uma aproximação do trem de impulsos da fonte 
(Rosa et al., 2000). Assim, o sinal residual é uma estimativa de uma função periódica que exibe picos fortes no início de cada período (corresponde ao pitch) e ruídos quase-periódicos entre os picos. A Figura 2.9 apresenta o resíduo do sinal de voz da Figura 2.8 (a) usando LPC de ordem 5. Percebe-se os picos referentes ao período de pitch do sinal original.

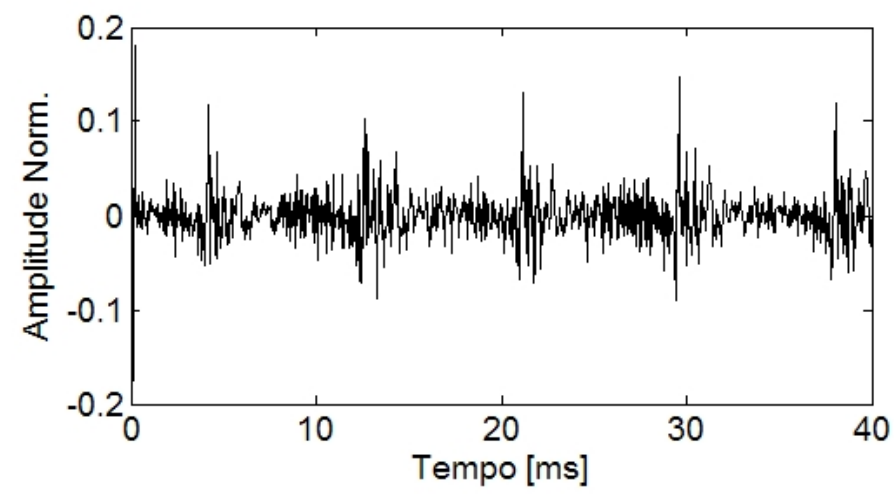

Figura 2.9: Resíduo do sinal de voz masculino de vogal "a" sustentada da Figura 2.8 (a) usando LPC de ordem 5.

Dois parâmetros interessantes que usam o sinal residual são o coeficiente de excesso (EX) e a amplitude de pitch (PA). O primeiro utiliza medidas estatísticas da distribuição de probabilidade do resíduo para verificar variações em seu formato quando comparada com uma distribuição Gaussiana. O PA é uma medida normalizada da amplitude do pico do período de pitch retirado da função de autocorrelação do sinal residual. Esse parâmetro é elevado (próximo a unidade) para sinais com períodos bem definidos como sons vocálicos (Davis, 1979; Rosa, 1998).

Por sua vez, as medidas obtidas do espectro de potência visam caracterizar o descréscimo da média espectral e a distribuição de energia do espectro (Davis, 1979). Outros desses parâmetros buscam medir a quantidade de ruído presente no espectro da voz. Isso, pois em casos patológicos, o fechamento incompleto da glote ou vibração assíncrona das pregas vocais pode adicionar componentes de ruído no espectro. Pode-se citar a relação harmônico-ruído (HNR Harmonic Noise Ratio), intensidade relativa das harmônicas (Hr) e energia de ruído normalizada (NNE - Normalized Noise Energy) (Dajer, 2006).

Conforme mencionado, esses parâmetros são muito usados para caracterizar patologias da laringe. Na próxima seção, apresentam-se alguns detalhes sobre as duas patologias cujos sinais foram usados neste estudo: presença de nódulo nas pregas vocais e edema de Reinke. 


\subsection{Patologias da Laringe}

Uma boa classificação para patologias da laringe (disfonias) é apresentada em Behlau (2001), a qual é realizada de acordo com a etiologia do sintoma, ou seja, ou seja, com base nas causas da doença. Assim, consideram-se três tipos de disfonias: funcional, organofuncional e orgânica.

Normalmente, as disfonias funcionais são o resultado de uso abusivo da voz, caracterizamse por alterações na emissão da voz. Também podem ser decorrentes de inadaptações vocais e alterações psicogênicas. As difonias organofuncionais também são causadas por problemas funcionais, entretanto já apresentam lesões orgânicas secundárias. Geralmente, estão relacionadas a diagnósticos tardios de disfonias funcionais. Algumas das disfonias organofuncionais mais comuns são: presença de nódulos ou pólipos nas pregas vocais e edema de Reinke. Por último, as disfonias orgânicas apresentam alterações anatômicas e podem possuir causas independentes do uso da voz (Branco e Romariz, 2006; Behlau, 2001).

As patologias da laringe, de acordo com Davis (1979), geralmente produzem mudanças assimétricas nas pregas vocais, isso resulta em diferentes tipos de vibrações, também ocorrem mudanças nas características de massa, elasticidade e tensão das pregas. Além disso, problemas com os músculos respiratórios, como paralisia, pode ocasionar pressão subglotal insuficiente, mudando as vibrações das pregas vocais. Dessa forma, o sinal resultante é afetado pela patologia da laringe, podendo ser usado para medir esses desvios.

Algumas doenças podem causar uma dinâmica anormal do sistema vocal, entretanto não são caracterizadas como aleatórias, pois seguem alguns padrões. Porém, algumas vezes, apresentam resultados altamente imprevisíveis (Bélair, 1995). Considerando essas informações, pode-se utilizar os parâmetros apresentados anteriormente para se medir essa previsibilidade. Conforme Uloza et al. (2005), análises desses parâmetros já têm sido usadas para auxiliar o diagnóstico de diversas patologias.

Em Rosa et al. (2000), apresenta-se um lista das patologias mais comuns do sistema vocal, sendo elas: carcinoma, cisto, edema, edema de Reinke, engrossamento das pregas vocais, granuloma, laringite crônica, úlcera de contato, paralisia, pólipo e nódulo. Neste estudo, utilizamse sinais de voz apenas de pacientes com nódulo e edema de Reinke nas pregas vocais. Essas duas patologias serão sucintamente descritas a seguir. 


\subsubsection{Nódulo nas Pregas Vocais}

Um nódulo é definido como uma pequena lesão que ocorre nos dois lados das pregas vocais (bilateral), desenvolve-se na região anterior das pregas, na metade da área de maior vibração glótica, sendo, geralmente, decorrente de abuso vocal (Behlau, 2001). A lesão, normalmente imóvel durante a fonação, localiza-se na camada superficial da lâmina própria. Histologicamente, consiste de tecido edematoso e fibras colágenas. Tem-se vascularização dilatada e, em casos mais avançados, hialinização e fibrose, aumentando-se a rigidez do tecido (Behlau, 2001; Wallis, 2004).

A Figura 2.10 apresenta duas imagens, obtidas por videolaringoscopia, de nódulo nas pregas vocais. A parte (a), modificada de Dedivitis e Barros (2002), está em um estágio inicial e, a parte (b), modificada de Behlau (2001), em estágio mais avançado.

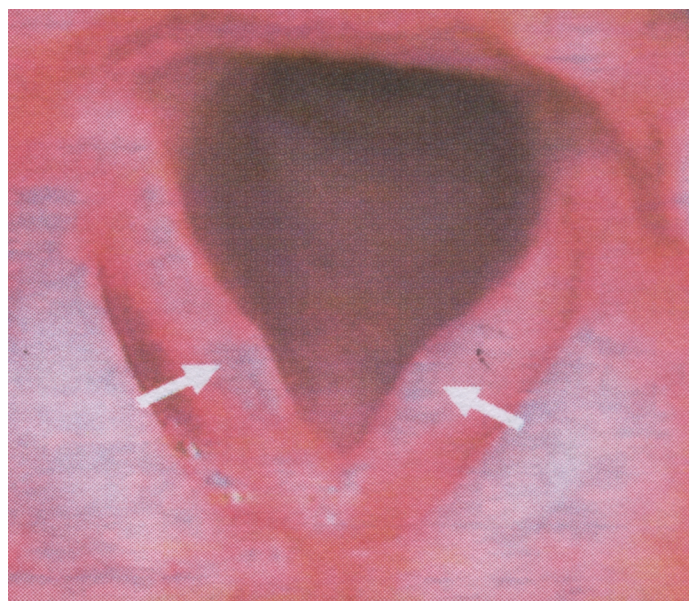

(a)

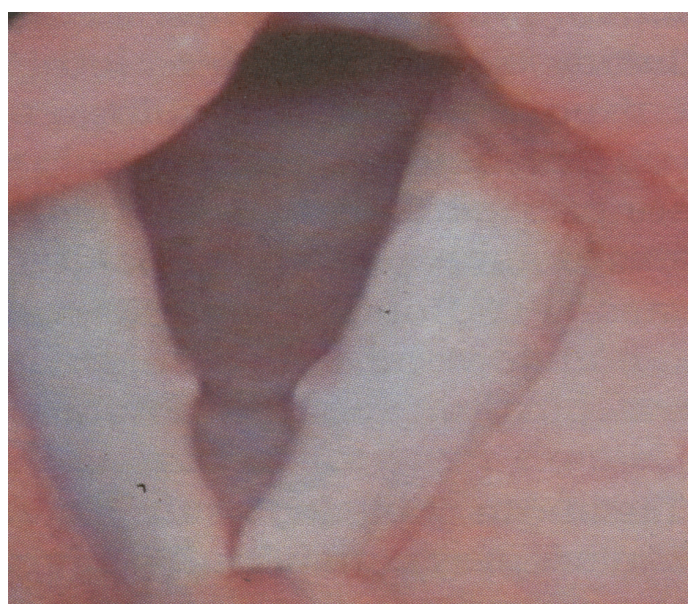

(b)

Figura 2.10: Imagens de videolaringoscopia mostrando pregas vocais com nódulos. Em (a), os nódulos são menores e indicados por setas. Em (b), os nódulos são maiores.

A incidência de nódulos vocais é maior em mulheres, normalmente em ocupações que requeiram uso freqüente da voz. Um dos efeitos da patologia é a hiperfunção vocal (Holmberg, 2003), o que acontece devido à tensão muscular desregulada na laringe e ao desbalanço das forças aerodinâmicas. A produção da voz é realizada em condições ruins, as pregas vocais ficam muito enrijecidas, geralmente em conjunto com alta pressão do ar subglotal e velocidade de fechamento das pregas. Por causa da presença dos nódulos, é possível que a glote não se feche completamente, aumentando a turbulência do ar através dela, assim, dificultando a fala. Caso a pessoa, para melhorar a fala, aumente a força com a qual expele o ar, pode-se causar mais trauma na região (Holmberg, 2001). 
Vozes de pessoas com nódulos apresentam qualidade vocal reduzida e soprosidade com vários graus de ruído turbulento. Frequentemente, a voz apresenta irregularidades como rouquidão e instabilidade (Hammarberg, 1998). O fechamento incompleto das pregas vocais, vazamento de ar glotal e vibração assimétrica (devido à alteração biomecânica) tornam-se responsáveis por mudanças na frequiência de pitch, no volume do fluxo de ar e reduções na amplitude da onda mucosa das pregas vocais (Hugh-Munier et al., 1997). Portanto, tem-se maiores valores de jitter e shimmer.

\subsubsection{Edema de Reinke}

O edema de Reinke é uma patologia benigna da laringe, a qual ocorre na camada superficial da lâmina própria. Ele pode ocorrer em ambas as pregas vocais ou somente de um lado, principalmente em estágios iniciais. Ocorre um acúmulo de fluido na parte mucosa do espaço de Reinke, o qual faz com que a cobertura da prega vocal fique menos rígida e vibre como uma estrutura mais massiva (Hirano, 1981b).

A Figura 2.11 apresenta duas imagens, obtidas por videolaringoscopia, de pregas vocais com edema de Reinke. A parte (a) foi modificada de Dedivitis e Barros (2002) e, a parte (b), de Behlau (2001). Em ambas as fotos, percebe-se o inchaço das pregas.

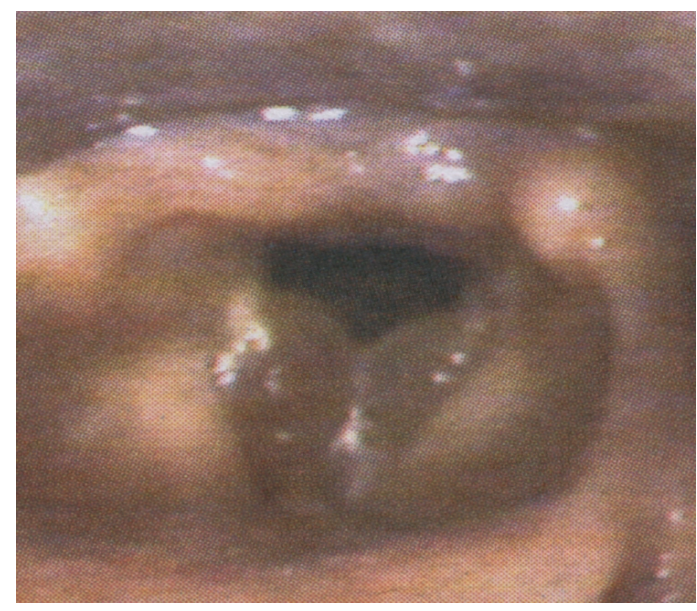

(a)

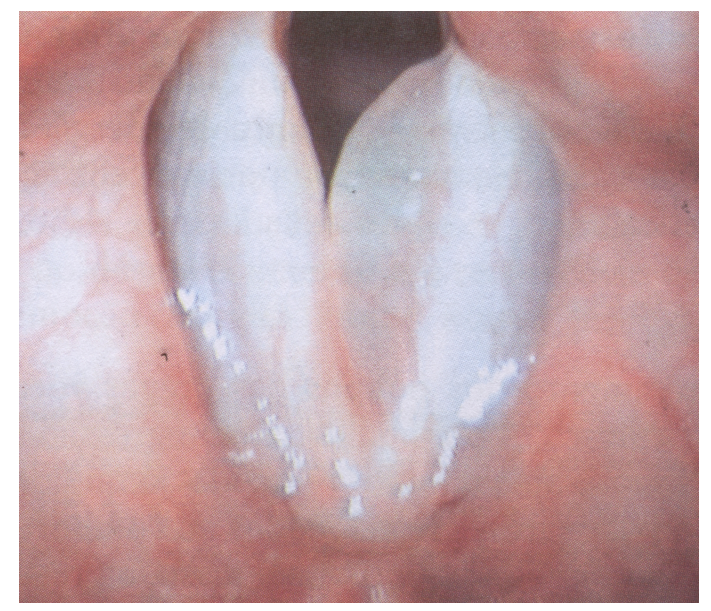

(b)

Figura 2.11: Imagens de laringoscopia mostrando pregas vocais com edemas de Reinke.

Normalmente, o edema de Reinke se desenvolve a partir de uma irritação crônica das pregas vocais, a qual modifica a permeabilidade capilar dos tecidos. Além do aumento do fluido no espaço de Reinke, também aumenta-se o sangue na região. Essa patologia pode estar associada a um excessivo e longo uso de cigarro combinado com extenso uso da voz (Yates e 
Dedo, 1984). De acordo com Kleinsasser (1982), refluxo gastroesofágico ou outra irritação persistente podem ser considerados fatores de contribuição para o desenvolvimento do edema. Entretanto, não se sabe se condições alérgicas ou medicamentos também contribuem (Lumpkin et al., 1990).

O edema de Reinke se desenvolve gradualmente e, inicialmente, o paciente só percebe uma diminuição do pitch da voz. Após isso, a voz se torna mais áspera e é necessário um aumento do esforço para falar. Assim, as pessoas que sofrem dessa patologia somente procuram um especialista quando ocorrem grandes mudanças na qualidade vocal.

O edema de Reinke, quando analisado por estroboscópio, apresenta movimentos de onda da mucosa maiores que o normal e espaço glotal posterior alargado (Courey et al., 1996). Lumpkin et al. (1990) descrevem que a vibração das pregas vocais parecem ser assimétricas, irregulares e aperiódicas.

Em seguida, comenta-se um pouco sobre as formas de avaliação das patologias de laringe do ponto de vista da fonoaudiologia. Isso quer dizer, apresentam-se os métodos invasivos e a avaliação perceptivo-auditiva.

\subsubsection{Avaliação das Patologias}

A avaliação vocal é um tema de constante estudo na área de fonoaudiologia. A forma mais comum de avaliação é a perceptivo-auditiva, a qual utiliza o ouvido humano como instrumento de inspeção. Além dessa abordagem, existem alguns exames usados em conjunto com essa avaliação para o diagnóstico de distúrbios da laringe.

O exame de laringe mais comum é a laringoscopia, podendo-se citar a laringoscopia indireta, realizada com o auxílio de espelhos específicos, a telelaringoscopia e nasofibrolaringoscopia, as quais utilizam um aparelho para filmar a laringe. A diferença entre esses dois últimos tipos é que o primeiro usa um dispositivo rígido e, o segundo, flexível (fibras ópticas). Esse dispositivo flexível é inserido pelo nariz resultando em imagens menos precisas, entretanto com menos desconforto para o paciente (Dedivitis e Barros, 2002).

A laringoscopia é classificada como um método de visualização que tem por objetivo fazer um diagnóstico etiológico das doenças, avaliar o estágio de evolução, monitorar e realizar o prognóstico. A laringoscopia foi desenvolvida na segunda metade do século XIX mas, a partir da década de 1980, tornou-se conhecida como videolaringoscopia, devido à gravação em vídeo 
das imagens observadas. A laringoscopia rígida passou a ser utilizada em 1960, usando um tipo de telescópio que permite a visualização da laringe quando colocado próximo a epiglote.

As vantagens da laringoscopia indireta são a simplicidade e baixo custo dos aparelhos, mas os resultados dependem da interpretação do avaliador. Além disso, nem todos ao pacientes podem ser analisados devido a configurações anatômicas desfavoráveis ou falta de colaboração, especialmente em crianças. A lagingoscopia flexível tem a vantagem de uma melhor visualização de algumas partes do sistema, apesar de menor precisão, sem a necessidade de tração lingual. Entretanto, o aparelho possui alto custo, tem campo de visão limitado e imagem com menos detalhes. Já na telelaringoscopia, é necessária a tração da língua, limitando a avaliação funcional, e requerindo anestésico local na maioria dos casos.

Os métodos apresentados não são muito eficientes para descrição da função fonotória, devido a alta frequiência de vibração das cordas vocais. Os casos pobremente avaliados precisavam de exames radiográficos ou laringoscopia direta, a qual é um método invasivo, mas eficiente. Assim, no final do século XIX, foi desenvolvido o exame com estroboscópio, permitindo a observação das vibrações das pregas. Entretanto, o equipamento utilizado possui alto custo. Além disso, para cerca de um terço dos pacientes, o exame de laringoestroboscopia é insatisfatório por diversos fatores, desde a má vontade até a presença de grandes lesões com efeito de massa, como pólipos.

Na década de 1970, passou-se a utilizar a ultrasonografia para examinar a laringe, sendo um método alternativo a estroboscopia para análise dos movimentos das pregas vocais. A vantagem é que o método é totalmente não-invasivo, possui tempo de exame curto e custo relativamente baixo. Porém, os resultados não se comparam aos dos outros métodos.

Na década de 1990, com o uso de sistemas de alta velocidade de fotografia, desenvolveu-se a videoquimografia, a qual utiliza imagens ópticas com lagingoscopia e analisa características vibratórias de uma dada região. Essa técnica é usada como auxiliar da estroboscopia, pois não proporciona uma visão tão completa.

Além desses métodos, destacam-se outros como a tomografia computadorizada e a ressonância magnética, os quais fornecem imagens precisas de alterações estruturais e patológicas da laringe. Também, pode-se citar a eletromiografia laríngea, muito usada para avaliar o estado neurológico da musculatura da laringe. Esse método utiliza a observação dos potencias de ação gerada pelas unidades motoras da musculatura laríngea para avaliar a integridade do sistema motor no diagnóstico de doenças neurológicas. 


\section{Avaliação Perceptivo-Auditiva}

O tratamento de problemas da laringe se inicia com uma avaliação otorrinolaringológica que pode utilizar alguns dos métodos anteriores, entretanto, uma forma de acompanhar o diagnóstico e a evolução da doença é a avaliação vocal perceptivo-auditiva. Essa se divide em duas partes: anamnese e avaliação do comportamento vocal. A anamnese é um detalhamento do histórico do paciente em forma de questionário.

A avaliação vocal é subjetiva, pois depende da experiência do avaliador na classificação da voz. A avaliação é feita observando a qualidade vocal, a qual é um termo usado para definir um conjunto de características vocais, um tipo de voz. Os principais tipos de voz são: rouca, a qual é a mais comum em disfonias; áspera; soprosa; tensa, que é aquela que possui som comprimido; pastosa, que é uma voz sem precisão articulatória; fluida; normal; astênica; fraca; entre outras (Dedivitis e Barros, 2002).

Pode-se definir a rouquidão como irregularidade vibratória da mucosa das pregas vocais durante a fonação causada por uma fenda glótica maior ou igual a $0,5 \mathrm{~mm}^{2}$ (Isshiki, 1980; Dajer, 2006). Além disso, provoca ruído de baixa freqüência mascarando harmônicos inferiores (Hammarberg, 2000; Dajer, 2006). Já a aspereza, pode ser definida como uma característica associada à rigidez da mucosa provocada por certa irregularidade vibratória dependendo da presença de fenda ou outras alterações na laringe (Dajer, 2006). De acordo com Pinho e Pontes (2002), a soprosidade corresponde à presença de ruído de fundo, audível e cujo correlato fisiológico mais freqüente é a presença de fenda glótica ou em casos com extrema rigidez de mucosa, mesmo sem fenda. A voz astênica está relacionada a hipofunção das pregas vocais e pouca energia na emissão.

Além da classificação do tipo de voz, faz-se a quantificação usando uma escala. Alguns estudos foram feitos a esse respeito como a classificação de Isshiki, a qual classifica a rouquidão com respeito a quatro fatores: R-áspera, B-soprosa, A-astênica e Nnormal. Além disso, aplica-se uma pontuação de 0 a 3 para, respectivamente, normal, leve, moderado e extremo (Lieberman e Blumstein, 1988). Takahashi e Koite realizaram estudos usando medidas de freqüência fundamental e perturbações de frequiência e amplitude dos sinais de voz chegando a conclusões similares (Hirano, 1981a). 
Porém, a escala mais usada é a GRBAS, foi desenvolvida pelo Comitê para Teste de Função Fonatória da Sociedade Japonesa de Logopedistas e Foniatras (Committee for Phonatory Function Tests of the Japan Society of Logopedics and Phoniatrics) (Hirano, 1981a). Essa escala utiliza cinco itens para avaliação, o primeiro avalia a grau global da disfonia ou anormalidade da voz, refere-se ao G (grade) do nome da escala. Os outros quatro itens se referem a diferentes aspectos de anormalidades vocais: $\mathrm{R}$ de aspereza (roughness), B de soprosidade (breathiness), A de astenia (asteny) e S de tensão (strain). Junto dessa classificação, usa-se uma segunda escala numérica de 0 a 3 para indicar o grau de disfunção vocal, sendo 0 para voz normal, 1 para leve, 2 para moderado e 3 para extremo. No Brasil, a GRBAS foi adaptada para RASAT, Escala de Avaliação Perceptiva da Fonte Glótica (Pinho e Pontes, 2002; Dajer et al., 2005).

Além da análise da qualidade vocal, algumas outras características da voz podem ser usadas na avaliação perceptiva-auditiva. Pode-se citar: ressonância, a qual está ligada a forma das estruturas adjacentes à laringe; tempo máximo de fonação, que busca medir a capacidade de controle da expiração do ar e eficiência do fechamento glótico; ataque vocal, a qual é a análise do início da emissão do som; pitch, para avaliação da classificação da voz como grave ou aguda; intensidade, se as vozes são fracas ou fortes; articulação e pronúncia; ritmo e velocidade; e resistência vocal, que é capacidade de falar por determinado período. Também, a dinâmica respiratória, pois alterações vocais podem se originar de hábitos respiratórios incorretos, alterações anatômicas e/ou funcionais (Dedivitis e Barros, 2002).

Após a discussão do sistema vocálico e caracteríticas dos sinais de voz, além de detalhes e avaliação de patologias, apresentam-se alguns estudos recentes de análise de voz.

\subsection{Estudos dos Sinais de Voz}

Nesta seção, apresentam-se alguns trabalhos recentes que usam métodos de análise de sinais de voz para avaliação de patologias ou sua classificação. Inicia-se com um breve histórico desse tipo de estudo, passando para as técnicas clássicas, finalizando com a abordagem não-linear e probabilística. 


\subsubsection{Histórico}

Pode-se dizer que os primeiros estudos dos sinais de voz foram iniciados na segunda metade do século XVIII com Wolfgang Ritter Von Kempelen, que tentou construir uma máquina que reproduzisse sons de voz humana. A máquina era composta por uma câmara pressurizada que simulava os pulmões, uma peça metálica vibratória para representar as pregas vocais e um tubo de couro flexível para simular o trato vocal (Flanagan, 1972). Pela manipulação do tubo, produziam-se sons bem semelhantes a vogais. Para produção de sons plosivos, Von Kempelen adaptou um tipo de língua e lábios móveis. O benefício desse dispositivo foi o de chamar a atenção dos cientistas da época para o trato vocal como o responsável pela articulação acústica humana. Além de estimular o estudo da fisiologia da produção de voz (Schroeder, 1999).

Ainda no final do século XVIII, Christian G. Kratzenstein criou tubos de ressonância para sintetizar os sons vocálicos, de forma parecida a instrumentos musicais. Também com tubos, W. Willis, no início do século XIX, mostrou a relação entre os sons vocálicos e a geometria do trato vocal. O físico Charles Wheatstone continuou o desenvolvimento dessa teoria mostrando que somente alguns dos componentes da fonte estimulavam o trato vocal (Flanagan, 1972). Posteriormente, verificou-se que, na verdade, eram alguns dos componentes da transformada de Fourier do sinal fonte que estimulavam o trato.

Com base nisso, Hermann Von Helmholtz propôs uma teoria sobre sons vocálicos em meados do século XIX, dizendo que o trato vocal age como o filtro acústico amplificando as harmônicas da fonte de ar vinda da epiglote que forem próximas da freqüência de ressonância do filtro. Paralelamente, L. Hermann desenvolveu algo equivalente no domínio do tempo, usando o ponto de vista de oscilações amortecidas geradas pela fonte de ar. A relação entre as teorias foi mostrada por Rayleigh pelo uso da transformada de Fourier. Já no começo do século XX, novos estudos foram feitos por C. Stumpf, O. Russel e R. Paget, em trabalhos separados, usando análises espectrais, aprofundando o conhecimento das freqüências formantes (Schroeder, 1999).

Após esses estudos, e devido a avanços em dispositivos de análise, como o espectrógrafo acústico; as pesquisas seguintes buscaram uma relação entre a dinâmica da articulação vocal e o sinal acústico de voz. Assim, no final da década de 1960 e começo 
da década de 1970, B. Atal e M. Schroeder, seguidos por J. Markel, desenvolveram a técnica chamada predição linear (LPC) baseada em um modelo para os sinais de voz formado somente por pólos (Atal e Schroeder, 1967; Markel, 1972). Com o LPC, foi possível fazer análises dos formantes sem os problemas dos métodos anteriores, sendo usado em muitos dos sistemas de análises e síntese de voz do século XX.

Um outro avanço foi a introdução da minimização do erro usando as propriedades auditivas humanas o que permitiu melhoria na transmissão de voz (Schroeder et al., 1979). Essas técnicas são conhecidas atualmente como métodos clássicos de análise de sinais de voz e serão detalhados na próxima subseção.

\subsubsection{Análise Acústica}

Um complemento para a análise perceptivo-auditiva, também não-invasiva, são as técnicas de análise acústica. Essas são muito utilizadas como auxílio aos profissionais da saúde, pois não requerem equipamentos caros, somente computador e microfone, e provêm resultados úteis para aplicação clínica. Porém, alguns dos parâmetros avaliados ainda têm resultados preliminares ou são de difícil avaliação, sendo necessários mais estudos e treinos (Behlau, 2001). Nesta seção, comentam-se alguns dos parâmetros e métodos usados nessas análises.

Esses métodos baseiam-se na extração de parâmetros dos sinais de voz (ou resíduo) ou espectro de potência (Rabiner e Schafer, 2007). Esses parâmetros são obtidos para sinais de pessoas com laringes saudáveis e patológicas, então, os valores são confrontados e testes estatísticos realizados para verificar a separação dos grupos.

Para realizar a análise acústica, faz-se necessário gravar amostras de voz do paciente para avaliação digital por software. Entretanto, como a variação da voz captada é determinada por uma série de fatores, como visto na Subseção 2.1.1, a utilização do sinal é limitada, assim alguns tipos de processamento ou técnicas são usados. Pode-se usar um microfone de contato pré-traqueal para diminuir a influência do trato vocal, entretanto, não se sabe o quanto essa influência é diminuída, além de se acrescentarem efeitos de filtro por causa dos tecidos ao redor do ponto de contato (Hirano, 1981a). 
Dois métodos tentam obter um sinal livre das influências do trato vocal e radiação labial usando modelos do sistema de produção de voz. O primeiro busca obter a onda glotal, também conhecida como onda de velocidade volumétrica glotal, por meio de filtragem inversa de um modelo físico linear. Porém, faz-se necessário a determinação precisa dos formatos e larguras de banda do sinal de saída. Outra forma utiliza um modelo matemático de predição linear da produção de voz, conforme apresentado na Subseção 2.1.2.

Usa-se filtragem inversa com o objetivo de retirar as influências do trato vocal, da radiação labial e da contribuição espectral da forma glotal. O sinal obtido é chamado de resíduo e apesar de não ser equivalente a um sinal real do sistema de produção vocal, pode ser mais facilmente obtido que no modelo físico e possui muitas aplicações no cálculo de outros parâmetros físicos.

Normalmente, utilizam-se dois tipos de gravação de sinais de voz para análise: a parte estacionária de vogais sustentadas ou transições de partes de fonação corrente. No primeiro tipo, o qual é o padrão em análises acústicas, tem-se a vantagem da facilidade em se retirar os efeitos do trato vocal. Por outro lado, utilizando o segundo tipo, algumas patologias são mais facilmente identificadas, mas não há padronização no método de seleção de amostras.

Conforme apresentado em Davis (1979), a análise acústica baseia-se na idéia de que o sinal vocal produzido é um reflexo de distúrbios da laringe, podendo ser usado para medir esses distúrbios. Patologias orgânicas geralmente produzem mudanças assimétricas na massa, elasticidade e tensão das pregas vocais, causando vibrações irregulares. Além disso, problemas nos músculos respiratórios causam pressão subglotal insuficiente resultando em mudanças nas forças aerodinâmicas, que agem nas pregas e no padrão de vibração. Essas irregularidades se propagam pela faringe, cavidades nasais e boca influenciando o sinal resultante.

Os sintomas acústicos mais comuns causados por patologias da laringe são mudanças na frequiência fundamental, intensidade vocal e qualidade vocal. De acordo com Behlau (2001), os parâmetros mais usados para análise são jitter, shimmer e medidas de ruído, além do estudo do espectro de potência do sinal. 
Os métodos de análise acústica clássicos baseiam-se na fonte do sinal e no método. A fonte pode ser de dois tipos: sinal direito, ou seja, a pressão acústica irradiada pela boca; ou indireto, obtido por filtragem inversa de um modelo físico ou matemático como apresentado anteriormente. Assim, definida a fonte, considera-se o método, o qual pode ser análise no domínio do tempo ou da frequiência (Davis, 1979).

\section{Parâmetros do Domínio do Tempo}

Os principais parâmetros obtidos dos sinais temporais são: jitter e shimmer, os quais, como já visto, são medidas de perturbação de período (ou pitch) e amplitude dos sinais respectivamente. De forma mais detalhada, o jitter pode ser definido como a média das variações de cada período de um sinal de voz (Lieberman, 1963), como mostra a Figura 2.12 (a). O shimmer, de forma semelhante, é definido como a média das variações de amplitude de sucessivos períodos de pitch de um sinal (Koike, 1969), conforme ilustrado na Figura 2.12 (b).

Alterações de jitter estão relacionadas a presença de lesões de massa ou doenças neurológicas e psicológicas. O jitter é associado ao aspecto perceptivo de aspereza (Andrade et al., 2002). Em Lieberman (1963), mostrou-se que os valores obtidos para sinais patológicos eram maiores que nos sinais saudáveis. Esse parâmetro possui várias formas de cálculo, uma das mais antigas é o fator de perturbação de frequiência (PFF), o qual busca as perturbações maiores do que $0,5 \mathrm{~ms}$. Outra forma é a perturbação média relativa (RAP), a qual utiliza médias móveis entre os períodos para melhorar os resultados. Essa medida foi apresentada em Koike (1973) usando a consideração de que os sons vocálicos estáveis normalmente exibem mudanças lentas e suaves no período de pitch. Nesse trabalho, concluiu-se que a RAP das vozes patológicas têm valores diferentes daquelas de vozes saudáveis, especialmente para pacientes com neoplasmas e paralisia unilateral.

Já as alterações de shimmer ocorrem, principalmente, por patologias que apresentam lesões de massa nas pregas vocais, como nódulos, pólipos, edemas e carcinomas. Assim, o aspecto de rouquidão da voz está relacionado com esse parâmetro (Andrade et al., 2002). A forma mais comum de cálculo é pelo quociente de perturbação de 


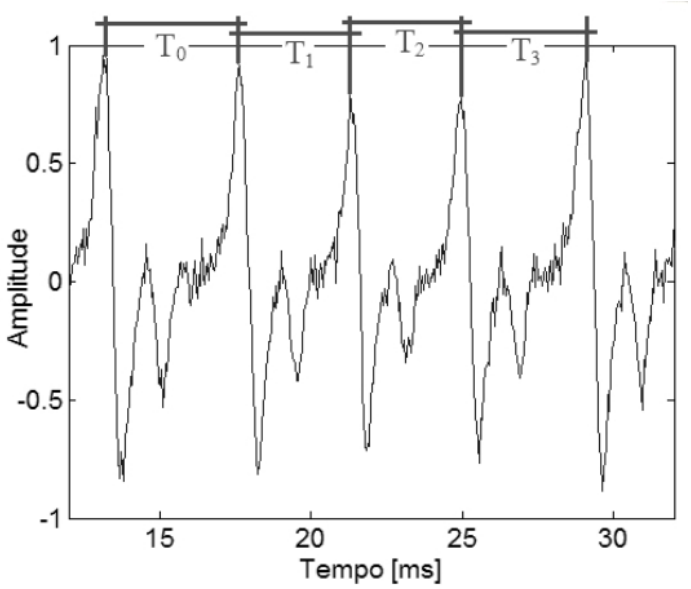

(a)

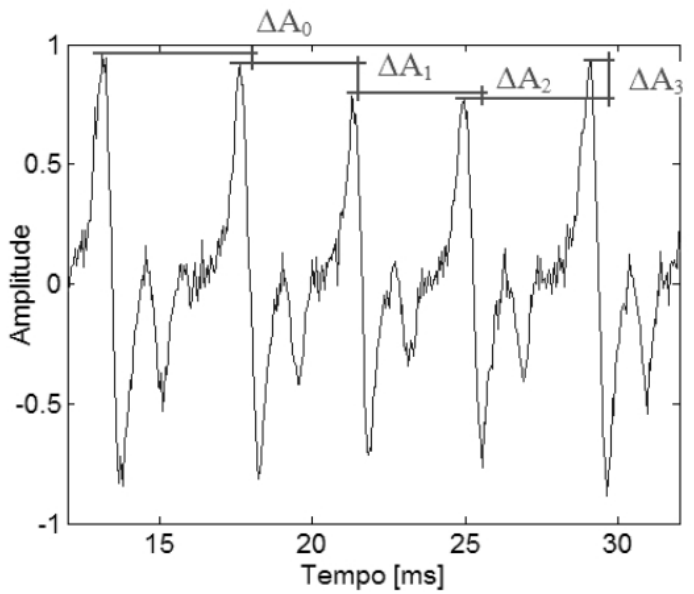

(b)

Figura 2.12: Ilustrações das perturbações de período (jitter) em (a), e perturbações de amplitude (shimmer) em (b). Ambas os sinais são obtidos usando o simulador de voz apresentado no Apêndice A.

amplitude (APQ), o qual utiliza uma janela móvel de cinco períodos para melhorar o resultado. Em Davis (1979), concluiu-se que as medidas de perturbação obtêm melhores resultados quando são realizadas no sinal residual do que no sinal acústico.

O uso do jitter e shimmer mostrou-se interessante no estudo de eficiência do tratamento de paralisia unilateral apresentado em Zhang et al. (2005a). Já em Feijó (2004), mostrou-se a aplicação desses parâmetros para investigar a presença de sintomas disfônicos em pacientes com esclerose múltipla, através de comparações com dados de pessoas normais.

De forma semelhante, Wolfe et al. (2002) mostraram diferenças entre medidas de perturbação acústica de pessoas com problemas vocais após atividades aeróbicas e de pessoas saudáveis. Em Niedzielska (2005), análises de medidas acústicas foram usadas para estudar a nasalidade em pacientes com rinite alérgica e outros problemas.

Além desses dois parâmetros de perturbação; no domínio do tempo, tem-se o coeficiente de excesso e a amplitude de pitch, os quais são relacionados ao nível de ruído do sinal (Andrade et al., 2002). O coeficiente de excesso tem por base o uso da relação sinal-ruído do sinal residual para discriminação de sinais saudáveis e patológicos (Santos et al., 2005; Davis, 1979). O sinal residual patológico apresenta maior quantidade de ruído, assim sua distribuição de probabilidade é mais baixa e larga do que de sinais normais, sendo que ambos podem ser aproximadas por curvas Gaussianas. Assim, o 
EX é uma medida da forma dessas distribuições, sendo, positivo se a distribuição for maior e mais estreita do que uma Gaussiana e negativo no caso oposto. Conforme Davis (1979), numerosas medidas apontam uma correlação entre EX e o SNR do sinal residual.

A amplitude de pitch é outro parâmetro estimado com base no sinal residual. O PA é o valor do pico do período de pitch da função de autocorrelação do sinal residual (Santos et al., 2005). O PA é normalizado de 0 a 1, sendo alto para sons vocálicos, devido à natureza periódica destes; valor intermediário para sons fricativos sonoros, os quais usam as fontes da laringe, e nulo para fricativos não-sonoros, os quais são aperiódicos. Nos sons vocálicos, o PA pode ser considerado uma medida de vocalização. Em vozes normais, a simetria dos movimentos das pregas vocais resultam em alta periodicidade do som e, conseqüentemente, alto PA.

\section{Parâmetros do Domínio da Freqüência}

De acordo com Davis (1979), muitos estudos mostram que existem diferenças entre o espectro de vozes patológicas e saudáveis. As harmônicas de alta freqüência de vogais patológicas são mais atenuadas. Além dessas atenuações, componentes de ruído espectral são adicionados, os quais, provavelmente, são originados de fluxo de ar turbulento no trato vocal, o que seria resultado do fechamento glotal incompleto ou vibrações irregulares das pregas vocais. Essas são características da rouquidão, um sintoma comum de muitas patologias da laringe.

Os parâmetros acústicos mais comuns obtidos do domínio da frequiência são nivelamento espectral do resíduo (SFR - spectral flatness of the residue signal), nivelamento espectral do filtro (SFF - spectral flatness of the residue inverse filter), relação harmônico-ruído e energia normalizada de ruído.

O método para cálculo do nivelamento espectral foi desenvolvido em Gray e Markel (1974), sendo definido como a razão, em decibéis, da média geométrica do espectro por sua média aritmética. O nivelamento espectral avalia o quão plana é a envoltória do espectro em relação à referência de zero decibéis. Conforme Santos et al. (2005), a voz ruidosa possui maiores componentes nas altas freqüências, portanto possui com- 
portamento espectral mais plano do que as vozes saudáveis. Quando o som se torna mais ruidoso, como em vozes patológicas, a estrutura harmônica se torna menos significativa e o SFR também aumenta. De acordo com Davis (1979), o SFF é uma medida de mascaramento, causado pelo ruído, das amplitudes das freqüências formantes e da largura da banda. Da mesma forma, o SFR é uma medida de mascaramento das amplitudes das harmônicas da freqüência fundamental pelo ruído.

O HNR é uma medida que relaciona os componentes harmônicos com o ruído. Essa medida, desenvolvida em Yumoto et al. (1982), busca avaliar o grau de rouquidão de sinais de vogais sustentadas. Isso é realizado pela observação da quantidade de estrutura harmônica do espectro que é substituída por ruído (Araújo et al., 2002). Os resultados obtidos nesse trabalho estavam de acordo com inspeções visuais do espectro dos sinais. No cálculo do HNR, usa-se a energia da uma média da onda sonora para se estimar a parte harmônica do sinal e a energia média da diferença entre a onda média e os períodos individuais do trecho em análise para estimar o ruído.

O NNE é um índice acústico usado para estimar ruído devido ao fechamento ineficiente da glote (Araújo et al., 2002). Calcula-se o NNE pela utilização de um método de filtragem adaptativa em pente no domínio da frequiência, o qual foi proposto em Kasuya et al. (1986). Nesse trabalho, os experimentos com sinais de várias patologias apontaram eficiência do NNE para detecção de carcinoma, paralisia e nódulos nas pregas vocais.

Após a apresentação desses parâmetros, serão comentados alguns resultados obtidos com diversos métodos na próxima subseção. Além disso, mostram-se alguns trabalhos que utilizaram esses e outros parâmetros para tentar separar sinais saudáveis e patológicos.

\subsubsection{Classificadores e Outros Métodos}

A partir dessas técnicas clássicas, diversos métodos de processamento digital começaram a ser aplicados em sinais de voz, objetivando detecção e classificação de patologias, compressão e transmissão de áudio, além de outras aplicações. 
Entre esses, destaca-se o uso de cepstrum, essa técnica considera o modelo de produção de voz proposto na Subseção 2.1.1 (Deng e O’Shaughnessy, 2003). Assim, calculando-se o logaritmo do espectro, transformam-se os componentes multiplicativos do modelo em soma, dessa forma, podem-se aplicar diversos outros métodos para processamento dos sinais. Essa técnica também é conhecida como processamento homomórfico (Oppenheim e Schafer, 1989; Rabiner e Schafer, 2007).

Com o uso desse método, Noll (1966) propôs uma forma de estimativa de pitch. Além disso, outros parâmetros acústicos podem ser extraídos por cepstrum para uso em aplicações de reconhecimento de voz (Deng e O'Shaughnessy, 2003).

O filtro inverso e sinal residual, conforme apresentado anteriormente, são amplamente utilizados para avaliação de patologias e análise de sinais vocais. Além dos trabalhos de B. Atal, M. Schroeder e J. Markel apresentados na Seção 2.3, pode-se citar Davis (1975), o qual utiliza o sinal residual para o cálculo de parâmetros acústicos, usando-os para classificação de sinais de pessoas saudáveis e com distúrbios de laringe, obtendo sucesso acima de 70\%, o que, na época, foi um grande estímulo para o uso do LPC em análise de voz. Também, nesse mesmo ano, Koike e Markel (1975) publicaram um estudo do uso da filtragem inversa para detecção de patologias.

Em seguida, Deller e Anderson (1980) analisaram a posição dos zeros do filtro inverso de diversos segmentos de sinais simulados de voz e fizeram um estudo de classificadores no plano $Z$, detectando vários distúrbios nas simulações. Em Wong et al. (1979), filtragem inversa dos sinais de voz é realizada usando uma abordagem de mínimos quadrados, com isso, conseguiu-se reduzir alguns ruídos e distorções de gravação, além de se obter resultados com boa resolução para a onda de velocidade volumétrica glotal, tanto no momento da abertura quanto no fechamento glotal.

Já no domínio da freqüência, muitas análises são feitas usando o espectrograma dos sinais de voz para a estimativa de parâmetros espectrais, como apresentado anteriormente. Entre os principais usos está o estudo dos formantes da voz para avaliar as características da voz, como apresentado em Lieberman e Blumstein (1988).

Desde a década de 1970, com o aumento do poder computacional, vários trabalhos foram feitos usando análise de espectro de potência, podendo-se citar Berouti et al. (1979), que apresentaram uma técnica para realce de sinais de voz corrompidos por 
ruído. E também Boll (1979), que usa o método de subtração espectral para diminuir ruídos de sinais de voz.

Em O'Leidhin e Murphy (2005), algumas medidas obtidas da PSD, como a amplitude do primeiro harmônico e razões das amplitudes de harmônicos, são usados para avaliar sinais simulados de voz com variações de jitter, shimmer e nível de ruído. Os resultados com sinais reais foram bons indicativos do nível de ruído presente.

Em Gomez et al. (2005), parâmetros obtidos do espectro de potência dos sinais de voz, junto com HNR e outras medidas foram classificadas por um algoritmo de agrupamento k-means junto com análise de componentes principais (PCA - principal component analysis) para determinar a dimensão ótima dos conjuntos de parâmetros. O classificador apresentou resultados interessantes mostrando a capacidade de classificação dos parâmetros.

Em Linville (2002), a análise espectral é usada para estudar diferenças entre vozes de pessoas com idades diferentes. Os resultados indicaram que jovens e mulheres idosas apresentam características espectrais associadas a voz soprosa. Para homens, os resultados foram semelhantes a outros obtidos com uso de laringoscopia. Sergeant e Welch (2008) apresentam um estudo semelhante para avaliar mudanças nas vozes de crianças conforme a idade. Em crianças mais velhas, a energia espectral abaixo de $5,75 \mathrm{kHz}$ era maior do que em crianças mais novas.

Em Cannito et al. (2005), amplitudes da primeira e segunda harmônicas mais as amplitudes dos três formantes principais são usados como parâmetros para diferenciar vozes saudáveis e vozes de pessoas com disfonia espasmódica de adutor (ADSD adductor spasmodic dysphonia). As análises foram feitas em vogais "a" e "i" de voz corrente. Os resultados de combinações dos parâmetros, especialmente da vogal "a", foram bem correlacionados com casos da patologia. Além disso, algumas combinações tiveram boa correlação com análises perceptuais de soprosidade e aspereza.

Em Silva e Joaquim (2008) apresenta-se um método para redução de ruídos em sinais de fala contínua objetivando análises de parâmetros acústicos. O método se baseia em filtragem de Kalman e subtração espectral, resultando em sinais com baixa quantidade de ruídos. 
Em Awan e Roy (2005), vozes patológicas com diversas características: soprosa, rouca e áspera, e vozes saudáveis foram analisadas usando vários parâmetros acústicos. Além disso, esses sinais passaram por testes perceptivos. Usou-se análise discriminante com um modelo de cinco parâmetros para classificação das vozes obtendo acertos da ordem de $75 \%$ na validação cruzada. Entre os parâmetros, estavam características do cepstrum, shimmer e razão entre energia espectral de baixa e alta frequiência. Com isso, foi possível realizar previsões sobre as classificações de sinais.

Eadie e Doyle (2005) publicaram um trabalho sobre classificação de vozes normais e patológicas utilizando análise perceptivo-auditiva e medidas acústicas obtidas do espectro de potência, HNR, PA, SNR e SFR. Os resultados de classificação obtiveram quase $100 \%$ de acertos quando cruzados os dois tipos de análise.

Para classificação de patologias, um dos métodos bastante utilizados é o classificador baseado nos modelos ocultos de Markov (HMM - hidden Markov models). Um exemplo é apresentado em Dibazar et al. (2006), nesse trabalho características dos sinais são aplicados no classificador HMM obtendo bons resultados na classificação de cinco patologias. Também, foi proposto o uso de rótulos múltiplos para as amostras, o que melhorou o resultado.

Em um modelo HMM, o sistema em estudo é considerado um processo Markoviano, ou seja, aquele no qual a distribuição de probabilidade do estado atual é condicionalmente independente do caminho dos estados passados (Cohen, 1998). Esse processo é chamado oculto porque seus parâmetros são desconhecidos, buscando-se descobri-los pela análise dos parâmetros observáveis do sistema. Esse modelo é muito usado em processamento de sinais de voz para classificação e reconhecimento de fonemas, patologias e locutores (Rabiner, 1989). Além disso, usa-se para estudo de sinais de EEG e seqüências de proteínas (Cohen, 1998).

De forma semelhante à classificação de patologias, Nwe et al. (2003) utilizaram um classificador HMM para diferenciar emoções em sinais de voz. O método proposto utiliza os coeficientes de potência com frequiência logarítmica (LFPC - log frequency power coefficients) obtidos do espectro de potência para representar os sinais e usar no classificador. Os resultados apresentaram acerto médio de $78 \%$, o que foi melhor do que resultados obtidos com parâmetros mais comuns como os coeficientes cepstrais 
de predição linear (LPCC - linear prediction cepstral coefficients) e os coeficientes cepstrais de freqüência Mel (MFCC - Mel frequency cepstral coefficients).

Ceballos e Hansen (1996) apresentam um estudo de classificação de vozes saudáveis e de pessoas com câncer nas pregas vocais. Para isso, utilizam o método de estimativa iterativa de máxima verossimilhança (MLE - maximum likelihood estimation). Obtém-se o chamado componente espectral realçado de patologia (ESPC - enhanced spectral pathology component), o qual varia adequadamente quando se analisam sinais normais e patológicos. Outras quantidades, derivadas dessa, também são medidas significativas de patologias. A classificação é realizada pela técnica de HMM. O ESPC é parametrizado usando coeficientes de um banco de filtros de frequiência MEL. Com esses parâmetros, para a classificação dos sinais usados, foram obtidos sucessos acima de $88 \%$.

Em Wallen e Hansen (1996), o objetivo do estudo é avaliar a qualidade vocal em casos de alta probabilidade de patologia. A técnica apresentada combina medidas de qualidade que avaliam características da excitação e trato vocal como jitter, shimmer e pico cepstral principal. Essas características são aplicadas em um classificador HMM obtendo uma separação entre vozes saudáveis e patológicas com mais de $85 \%$ de sucesso.

Já em Halavati et al. (2007), é apresentado um algoritmo que usa uma descrição fuzzy do espectro de potência de fonemas para fazer reconhecimento. Isso é feito usando um algoritmo genético para analisar os parâmetros. Os resultados foram comparados com outros obtidos usando HMM, com parâmetros MFCC, sendo melhor em sinais de ambientes ruidosos.

A técnica de HMM pode ser usada em conjunto com outros métodos como realizado em Chen e Parsa (2007). Nesse trabalho, um modelamento Bayesiano foi usado para mapear características de padrões de intensidade de sinais de voz em notas qualitativas para serem usadas no classificador HMM. Foram obtidos altos índices de acertos nas previsões de qualidade vocal dos sinais analisados. A teoria Bayesiana considera as probabilidades como medidas de incerteza, assim, utilizando probabilidades condicionais, podem-se atualizar as probabilidades dos eventos quando novas informações ficam disponíveis. 
Com base nessa teoria, Granato e Pereira (2004); Granato (2005) apresentam um método para classificação de vozes normais e patológicas, sendo, essas últimas, de quatro tipos: edema, fenda, nódulo e pólipo. Para isso, foram obtidas 38 medidas acústicas e, como resultado, percentuais de acerto na classificação com o uso desses parâmetros. Utilizando análises univariadas, chegou-se a 90\% de acerto na classificação, mas nas análises multivariadas com combinações dos parâmetros, foi obtido somente $10 \%$ de acertos para os sinais analisados. Assim, esse método se caracterizou como uma potencial ferramenta para auxílio de profissionais da saúde, porém o tempo de processamento foi muito elevado.

De forma semelhante à teoria Bayesiana para classificação de dados, o uso de redes neurais artificiais (ANN - artificial neural networks) baseia-se em novas informações a respeito do sistema para avaliar os dados em estudo. Assim, as relações entre as entradas e saídas são determinadas através de um processo de aprendizagem, ou seja, a rede se comporta como um sistema adaptativo. As aplicações são amplas, desde previsão de séries temporais e separação de sinais até reconhecimento de padrões e classificação.

Em processamento de voz, as redes neurais são muito usadas para reconhecimento de voz, fonemas ou locutor (Katagiri, 2000). Também podem ser utilizadas em classificação de patologias usando características dos sinais para análise na rede. Um exemplo é Rosa et al. (1998), uma rede neural é usada para classificar diversas patologias da laringe utilizando sete parâmetros acústicos: jitter, shimmer, EX, PA, SFF, SFR, e SNR. PCA é utilizada para reduzir a dimensão do sistema e acelerar o processamento. Os resultados da classificação foram corretos em mais de 60\% dos casos (em média), mas a discriminação entre vozes normais e patológicas foi bem superior.

Em Ritchings et al. (2002), a qualidade vocal de pacientes com câncer de laringe é analisada por uma rede neural usando uma combinação de parâmetros obtidos do espectro de potência dos sinais de EGG (eletroglotografia). Os resultados de classificação são comparados com a análise perceptiva de um profissional chegando a $92 \%$ de acerto.

O uso de redes neurais continua bem atual, sendo um exemplo Linder et al. (2008). Nesse trabalho, uma ANN foi usada para classificar vozes disfônicas de acordo com 
uma escala perceptivo-auditiva chamada índice RBH (aspereza, soprosidade, rouquidão - roughness, breathiness, hoarsness) baseada na GRBAS. Foram obtidos resutados com $80 \%$ de acerto na classificação de voz saudável ou rouca.

Os estudos apresentados anteriormente de classificação de patologias avaliam diversos tipos de características dos sinais para os classificar. Entre eles, estão os parâmetros acústicos como jitter, shimmer, SNR, coeficientes do espectro dos sinais, como MFCC ou coeficientes cepstrais harmônicos perceptuais (PHCC - perceptual harmonic cepstrum coefficients), e coeficientes da análise LPC (Rosa et al., 2000).

Trabalhos recentes têm usado coeficientes obtidos de análises wavelet dos sinais, um exemplo é Crovato e Schuck (2007). Nesse trabalho, analisaram-se cinco grupos de sinais de vozes patológicas: laringite crônica, disfonia degenerativa, paralisa, edemas e nódulos, mais um grupo de controle saudável. Algumas características dos sinais são extraídas usando decomposição wavelet packet (WPD - Wavelet Packet Decomposition) e classificadas usando redes neurais, obtendo sucesso de mais de $87 \%$ na classificação dos sinais.

De forma semelhante, em Fonseca et al. (2007), utiliza-se decomposição por transformada wavelet discreta (DWT - Discrete Wavelet Transform), usando família de filtros Daubechies com ordem 20, para analisar sinais de voz saudáveis e de pessoas com nódulo nas cordas vocais. Os sinais decompostos são aplicados em um filtro LPC e os coeficientes usados em um classificador LS-SVM (máquinas de vetores de suporte com mínimos quadrados - least squares support vector machine). Os resultados obtidos da classificação apresentam acertos acima de 90\%. Em Guido et al. (2006), mostra-se que a DWT usando Daubechies (ordem 20), classificação SVM também, obteve o melhor resultado quando comparado com outras combinações de famílias e ordens dos filtros.

Em Guido et al. (2005), diversas famílias de wavelets são usadas para extração de parâmetros de vozes patológicas, sendo elas Haar, Daubechies, Coiflets, Symmlets e Spikelets. Os resultados foram promissores para a aplicação em classificação de patologias, especialmente a separação de casos saudáveis e patológicos. Além disso, calcula-se a dimensão fractal dos sinais, utilizando-se a consideração de existência de componentes não-lineares na produção da voz, como comentado a seguir. 


\subsubsection{Métodos Não-Lineares e Probabilísticos}

Pesquisas iniciadas na década de 1980 apresentaram evidências de caos na vibração das cordas vocais (Titze et al., 1993; Hawkshaw et al., 1997), ou seja, a produção da voz pode ser modelada como um sistema com realimentação, onde pequenas mudanças podem resultar em grandes efeitos (Titze, 2004, 2007). A teoria do caos foi sendo desenvolvida em todo o século XX, apesar do termo "caos" ter sido cunhado por James Yorke em 1975. Na década de 1960, Edward Lorenz, quando estudava previsão metereológica, descreveu a sensibilidade das condições iniciais (Lorenz, 1963), a qual é uma das características de sistemas caóticos. Assim, iniciaram-se os estudos da teoria do caos.

Esse fenômeno é observado em diversas áreas, como em sistemas determinísticos que, apesar de previsíveis a curto prazo, tornam-se imprevisíveis a longo prazo (Crutchfield et al., 1986). Muitos exemplos de aplicações dessa teoria são apresentados em Stewart (1990). Apesar de ser uma teoria aplicável somente a sistemas determinísticos, algumas extrapolações são feitas utilizando uma abordagem de sistemas estocásticos. Um exemplo de análise de voz usando essa abordagem é apresentado em Kumar e Mullick (1996), utilizam-se expoentes de Lyapunov, dimensão de correlação e entropia de segunda ordem. Observações são feitas no espaço de fase dos sinais de voz utilizando os expoentes de Lyapunov. Pode-se distinguir entre trajetórias de sinais que possuam comportamento periódico ou quase-periódico.

Steinecke e Herzel (1995) apresentam um estudo usando um modelo de duas massas para as vibrações das cordas vocais. Com a análise de espaço de fase, mostrou-se a relação entre um desbalanço das tensões das pregas vocais e o surgimento de caos pelo aparecimento de bifurcação. Discute-se a relação entre esse comportamento e a observação de patologias, em especial, paralisia laríngea.

Em Dajer et al. (2005), uma análise qualitativa de sinais de voz saudáveis é realizada usando o espaço de fase reconstruído junto com análise de parâmetros acústicos tradicionais: jitter, shimmer, EX e PA. Apresentam-se correlações entre as variações dos parâmetros e seus reflexos no espaço de fase. Com isso, mostra-se que ferramentas não-lineares podem ser usadas para realizar análise de sinais de voz. Um estudo mais completo é apresentado em Dajer (2006). 
Jiang e Zhang (2002) realizam uma análise em sinais de voz pertencentes a dois grupos: pacientes com laringes saudáveis e outros com pólipos nas pregas vocais. Estima-se a dimensão de correlação dos sinais, mostrando que o sistema vocálico apresenta característica dinâmica de baixa ordem, portanto, que o sistema apresenta baixa complexidade. Assim, concluiu-se que as vozes patológicas apresentam mais complexidade, ou seja, dimensão de correlação estatisticamente maior do que para os sinais saudáveis.

Também utilizando dimensão de correlação, Narayanan e Alwan (1995) apresentam um estudo com amostras de voz de consoantes fricativas, obtendo baixa dimensão de correlação para 59\% dos sinais que se adequaram aos limites de estacionaridade. Também, possuíam máximo expoente de Lyapunov positivo, indicando presença de caos.

Em Zhang et al. (2005b), métodos não-lineares, especificamente dimensão de correlação, são comparados com métodos de perturbação de sinais de voz, como análise de jitter e shimmer. Mostrou-se que os primeiros são eficientes para casos caóticos, enquanto os outros não são. Os métodos de perturbação só são eficientes para sinais quase-periódicos. A dimensão de correlação apresenta análise mais estável para amostras quase-periódicas com poucos pontos, baixa taxa de amostragem e alto nível de ruído.

Boshoff e Grotepass (1991) apresentam um estudo usando dimensão fractal em sinais de voz fricativa. Diversas amostras foram analisadas e, com base nos valores obtidos, concluiu-se que se pode aplicar esse método (em conjunto com outros) para separar fricativas vocais e não-vocais.

A dimensão fractal também é usada em Accardo et al. (1992) como uma ferramenta para separar vozes normais de outras de pessoas com disartria. Essa patologia é um tipo de desordem motora da fala resultante de um distúrbio no controle muscular dos mecanismos da fala. Seus principais sinais são fraqueza, paralisia e falta de coordenação (Murdoch, 1997; Mac-Kay et al., 2003). O estudo foi realizado com oito pessoas, sendo quatro do grupo de controle. Elas leram um texto com cem palavras, trechos adequados eram selecionados e divididos em 160 amostras. Com o uso da medida de dimensão fractal, foi possível separar completamente essas amostras. 
Em Hertrich et al. (1997), apresenta-se um estudo usando dimensão fractal de vogais sustentadas objetivando separar pacientes saudáveis de outros com disfunções neurológicas, especificamente mal de Parkinson e atrofia cerebelar. As análises eram feitas com os sinais de voz e com os EGG. Os valores de dimensão fractal do EGG de pacientes patológicos foram maiores, em média, do que os de pacientes do grupo de controle. Assim, mostrou-se que essa ferramenta é útil para classificação desse tipo de patologia. A análise dos sinais acústicos foi muito dependente do tipo de vogal usada.

Em Guido et al. (2008), apresenta-se uma nova ferramenta chamada transformada shapelet discreta (DST - Discrete Shapelet Transform), a qual, apesar de se basear na DWT, que é uma transformação linear, utiliza medidas de dimensão fractal para analisar as formas dos sinais estudados. Essa técnica foi desenvolvida para buscar padrões em sinais de voz, especialmente para reconhecimento de voz, mostrando-se eficiente em testes preliminares.

Da mesma forma que em Dajer et al. (2005); Dajer (2006), outros trabalhos utilizaram ferramentas muito comuns de sistemas dinâmicos e caóticos em sistemas estocásticos. Entre alguns métodos, pode-se citar a reconstrução em espaço de fase e outras medidas emprestadas de teoria da informação como entropia, informação mútua e medidas de previsibilidade.

Em Birgmeier et al. (1997), uma técnica baseada em medidas de informação mútua é apresentada para realizar previsões de sinais de voz. Essa medida relaciona a informação compartilhada entre dois sinais, além disso, pode ser interpretada como um limite superior de ganho de previsão do sistema, o qual é uma medida de desempenho do método. Como esperado, a capacidade de previsão diminui conforme se aumenta o intervalo de tempo da previsão. Com base nos testes apresentados, concluiu-se que o uso dos métodos probabilísticos contribuiu para uma melhor análise dos sinais podendo ser usado para extrapolar trechos maiores do sinal. Essa função é aplicável em diversas situações como restauração de partes perdidas de transmissões de áudio.

Outra medida muito usada é a entropia. Em Aghazadeh et al. (2007), usa-se entropia aproximada para análise de sinais de voz. Esse tipo de entropia foi apresentada em Pincus (1991), como uma forma de quantificar regularidade e complexidade dos sinais. Assim, como o uso de DWT para extrair características de similaridade dos 
sinais, em Aghazadeh et al. (2007), a entropia aproximada é utilizada como parâmetro na classificação dos sinais, com o uso de um algoritmo fuzzy k-means. Os sinais de voz usados pertenciam aos seguintes grupos: saudáveis e patológicos, sendo que este último incluía pacientes com cistos, pólipos e laringite traumática. O método apresentado foi eficiente para separar os casos patológicos dos saudáveis, pois, para o grupo patológico, os sinais possuíam maior entropia.

Essas medidas de teoria da informação se mostram muito promissoras para a análise de sinais de voz. Assim, após essa revisão do sistema vocálico e suas características, como o seu modelo matemático e sinais de voz, apresenta-se o método da previsibilidade no próximo capítulo, o qual usa essas medidas para quantificar as diferenças entre sinais patológicos e saudáveis. 


\section{Capítulo 3}

\section{Estudos de Previsibilidade}

Neste capítulo, apresenta-se o método de previsibilidade, o qual é a base deste estudo e que será usado na análise de sinais de voz, tanto saudáveis como patológicos. Inicialmente, faz-se uma revisão de algumas medidas de previsibilidade de sinais, principalmente a entropia, mostrando algumas características interessantes como as curvas de entropia e suas propriedades. Apresenta-se a potência de previsão e, para finalizar, o método da análise de componentes previsíveis, o qual visa decompor sistemas em suas direções mais previsíveis, eliminando elementos com baixa contribuição para a previsibilidade do sistema.

Diversos trabalhos foram feitos usando medidas de informação e previsibilidade aplicados em sinais fisiológicos. Um exemplo é o índice de previsibilidade da variabilidade do batimento cardíaco apresentado em Cai et al. (2001), com o qual foi possível diferenciar os pacientes devido à natureza periódica, caótica ou aleatórios ${ }^{3}$ dos sinais de ECG. Nos casos normais, os sinais são caóticos e em pessoas que sofreram ataques cardíacos, nos primeiros seis meses, os sinais são aleatórios.

Apesar de bons resultados em estudos com sinais fisiológicos, as análises de previsibilidade, inicialmente, foram desenvolvidas para melhorar a qualidade das previsões do clima. Desde Lorenz (1963), as técnicas usadas nos estudos de clima começaram a considerar modelos baseados em sistemas dinâmicos, inclusive caóticos.

\footnotetext{
${ }^{3}$ Sinais com natureza periódica são aqueles formados por repetições de trechos iguais ou muito parecidos, como os sinais de vogais sustentadas, sendo previsíveis por um longo tempo. Os sinais caóticos são aqueles que são previsíveis somente para instantes próximos do atual e os sinais aleatórios são aqueles que não são previsíveis mesmo em curto tempo (Cai et al., 2001).
} 
Um dos primeiros trabalhos a apresentar, de forma concisa e organizada, essa técnica foi Schneider e Griffies (1999). Introduziu-se uma medida chamada potência de previsão (PP), a qual se baseia em medidas de entropia do sinal e de seu erro de previsão. Também, apresenta-se a análise de componentes previsíveis (PrCA - predictable component analysis), a qual, de forma semelhante à PCA, decompõe um sistema em componentes descorrelacionados ordenados conforme sua potência de previsão. Um estudo mais detalhado da PrCA é apresentado em DelSole e Tippett (2007).

Ainda em Schneider e Griffies (1999), aplica-se a teoria de previsibilidade em um problema simulado de variabilidade das temperaturas da parte norte do oceano Atlântico por várias décadas, apresentando bons resultados. Também, mostra-se que o modelo AR pode ser usado facilmente como modelo de previsão em conjunto com a técnica. Isso torna o método atrativo para aplicações de voz por causa da eficiência do AR em modelar esse tipo de sistema.

Em DelSole e Chang (2003), apresenta-se uma comparação entre PrCA, análise de correlação canônica e modelos autorregressivos. Utiliza-se uma grandeza chamada variância de erro normalizada, a qual está relacionada à PP. Mostra-se que a PrCA é uma generalização da análise de correlação canônica para qualquer tipo de modelo usado para as previsões do sistema.

Em DelSole (2004), apresentam-se mais detalhes da teoria de previsibilidade. Basicamente, mostram-se as relações entre PrCA e as medidas: informação previsível, entropia relativa e informação mútua. Apresentam-se suas características, vantagens e desvantagens, comparando com Schneider e Griffies (1999). A seqüência desse estudo, DelSole (2005), mostra as implicações do uso de previsões imperfeitas nessa teoria. Em Tippett e Chang (2003), apresentam-se considerações a respeito de dinâmicas estocásticas lineares.

Outras abordagens podem ser usadas, um exemplo é Yao et al. (2004), onde se apresenta uma medida de previsão chamada entropia de previsão. Usa-se esse tipo de entropia para analisar o espaço de fase ${ }^{4}$ de sinais e melhorá-los.

\footnotetext{
${ }^{4} \mathrm{O}$ espaço de fase de um sinal aqui é definido como uma representação desse sinal em um espaço cujas coordenadas são formadas por versões atrasadas do próprio sinal, conforme Broomhead e King (1986).
} 
Já em Kleeman (2002), medidas baseadas em entropia relativa são usadas para prever condições de sistemas de clima. Apresenta-se uma decomposição em dispersão e componentes do sinal. Num trabalho seguinte, Kleeman (2007), a previsibilidade é analisada do ponto de vista bayesiano, com aplicações em previsão do tempo.

Por fim, Crutchfield e Feldman (2003) fazem uma análise da convergência da entropia para processos estocásticos estacionários. Mostram-se curvas do crescimento da entropia, ganho de entropia e ganho de previsibilidade,${ }^{5}$ obtidos das estimativas de entropia. Essas teorias são aplicáveis a vários tipos de sinais. Fez-se a consideração de que a estrutura interna do sistema e a transição de seus estados, ou seja, sua dinâmica interna, são desconhecidas. Assim, é necessário estudar o sistema como um processo e analisar as probabilidades observadas, como mostra a Figura 3.1, modificada de Crutchfield e Feldman (2003). As medidas mencionadas são calculadas a partir das funções de densidade de probabilidade do processo.

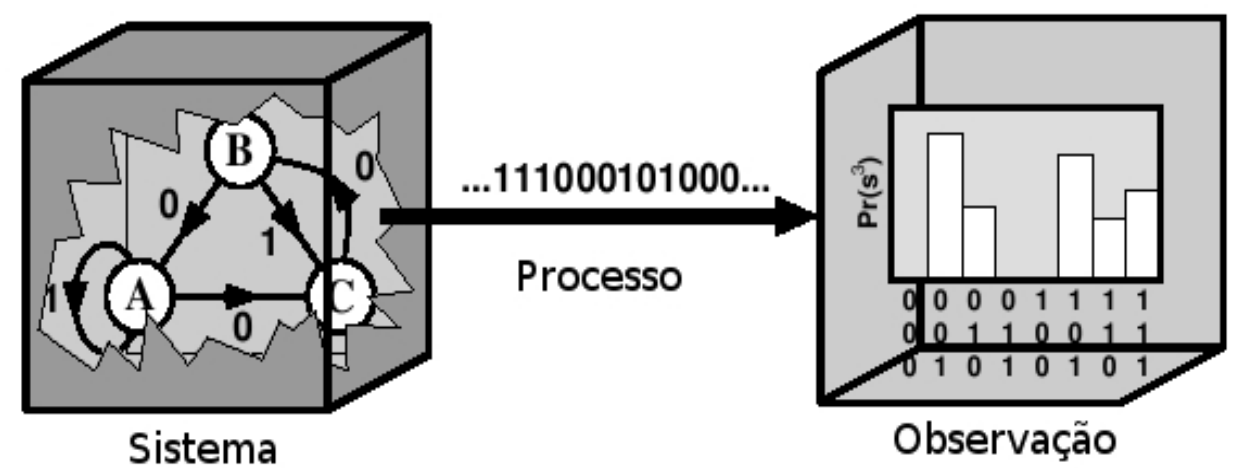

Figura 3.1: Estrutura interna do sistema e transição de seus estados desconhecidos. Consideração feita sobre o sistema em estudo conforme Crutchfield e Feldman (2003), utilizam-se medidas do processo observável para análise.

Assim, o uso do método de previsibilidade possibilita uma nova abordagem em análise de sinais de voz. Como apresentado, essa técnica possui características interessantes para serem usados em sistemas fisiológicos. Então, considerando a abordagem apresentada em Crutchfield e Feldman (2003), realiza-se a análise de patologias de laringe olhando-se para as características dos sinais vocais, usando as medidas de previsibilidade para a obtenção de informações.

\footnotetext{
${ }^{5}$ As curvas de crescimento de entropia, suas derivadas e características serão apresentadas na Subseção 3.2.2.
} 


\subsection{Introdução ao Método}

Previsibilidade pode ser definida como o estudo da extensão da previsão de eventos. Os princípios da teoria de previsibilidade, atualmente conhecida pela famosa "previsão do tempo", começou a ser proposta na década de 1960 nos trabalhos Lorenz (1963) e Epstein (1969).

Nessa abordagem, o modelo de previsão é considerado determinístico, ou seja, as equações que o regem são conhecidas completamente. Entretanto, as condições iniciais do sistema não são conhecidas, sendo melhor representadas por uma função de densidade de probabilidade (PDF - probability densisty function) (DelSole, 2004).

Outra forma de se entender a previsibilidade é como uma propriedade da diferença de duas distribuições de probabilidade: uma formada pelos dados atuais do sistema, geralmente obtida por valores de observações passadas; e a segunda, formada pelas previsões de tempos posteriores. O nível de previsibilidade depende de quão melhor as previsões são em relação a estimativas baseadas somente na distribuição atual (DelSole, 2004).

Em Lorenz (1975), foram apresentados dois tipos de previsibilidade, os quais foram nomeados: estudos de primeiro e segundo tipo. Conforme descrito em DelSole (2004); Schneider e Griffies (1999), a previsibilidade de primeiro tipo se refere a mudanças nas estatísticas do sistema quando se considera um tempo fixo, ou seja, como estará o sistema após algum tempo pré-determinado. Um exemplo desse tipo é a previsão do tempo para o dia seguinte. Nesse tipo, estuda-se como incertezas nas condições iniciais afetam as previsões de tempos futuros. A previsibilidade de segundo tipo se refere a mudanças nas estatísticas do sistema por variações na condições de contorno. No caso de previsões de clima, um exemplo seria o aumento da concentração de gases que causam o efeito estufa.

Para análise de sinais de voz, usou-se somente a previsibilidade de primeiro tipo. Para esses tipos de estudo, são necessárias duas coisas: um modelo para se obter as previsões e uma forma de medida para quantificação (Schneider e Griffies, 1999; DelSole e Chang, 2003). Os modelos usados variam muito, pois dependem do tipo de sistema em estudo. No caso de previsão do tempo, atualmente, utilizam-se os modelos 
gerais de circulação, os quais usam informações sobre a temperatura da superfície do mar (Schneider e Griffies, 1999). Comuns, também, são os modelos obtidos diretamente de dados observados ou mesmo usando valores passados do sistema, como é o caso dos modelos AR. Com respeito à quantificação da previsibilidade, existem diversas medidas que podem ser usadas, como o erro médio quadrático, a entropia ou a potência de previsão. Esse será o tópico da próxima seção.

\subsection{Medidas de Previsibilidade}

Conforme apresentado em DelSole (2004), existem muitas medidas de previsibilidade, entre elas: o erro médio quadrático, análise de variância, teste estatístico de Kuiper ou de Kolmogorov-Smirnov, entre outros.

Uma das medidas mais usadas é o erro médio quadrático de um modelo de previsão. O MSE aumenta proporcionalmente ao tempo de previsão. Aproxima-se, de forma assintótica, a um valor de saturação, o qual é comparável à diferença média quadrática entre dois valores quaisquer retirados aleatoriamente da distribuição do sistema (DelSole, 2004).

Assim, o sistema é dito imprevisível quando os erros são comparáveis a esse valor, porque a previsão não é melhor do que um valor qualquer observado anteriormente. Portanto, o processo em questão é considerado previsível se o erro do modelo for menor que o erro da média. Utilizando esse método, diversos avanços foram realizados em estudos de previsão do tempo (Schneider e Griffies, 1999).

Apesar da simplicidade de estimativa, o MSE possui alguns problemas. Primeiro, essa medida é somente um momento de uma distribuição conjunta, provendo, então, menos informação do que uma distribuição, que é a descrição mais completa de uma previsão. Segundo, o MSE depende das coordenadas nas quais os dados estão representados (DelSole, 2004), ou seja, em algumas aplicações, não se pode usar o MSE ou se faz necessário análises mais rigorosas dos resultados obidos.

Em seguida, apresentam-se características da entropia, a qual é uma medida de incerteza de um sistema que pode ser usada para caracterizar sua previsibilidade. 


\subsubsection{Entropia}

A entropia é uma grandeza que é usada para medir a incerteza de um sistema de informações. Essa medida foi apresentada dessa forma pela primeira vez em Shannon (1948), a partir de então se tornou uma das ferramentas mais importantes de teoria da informação.

Um trabalho interessante que mostra o uso de medidas de entropia é Pincus (1991), o qual apresenta uma modificação da entropia clássica sendo chamada de entropia aproximada. Mostra-se que a entropia de um sinal pode ser relacionado à complexidade $^{6}$ do sistema gerador. Pincus e Goldberger (1994) também apresentam uma relação entre a entropia e a regularidade dos sinais com uma aplicação em análise de sinais fisiológicos, especialmente ECG.

Um outro exemplo, o qual é relacionado ao sistema vocálico, é apresentado em Moore et al. (2006). Esse trabalho mostra a entropia aproximada aplicada na análise de padrões espectrais de sinais de voz. Concluiu-se que essa entropia é uma medida confiável de qualidade vocal em pacientes com câncer nas pregas vocais. Já em Richman e Moorman (2000), apresenta-se a entropia amostral, a qual é destinada a pequenos e ruidosos conjuntos de dados, como os sinais obtidos do sistema cardiovascular.

É importante citar também a contribuição de Kolmogorov (1965), o qual definiu a chamada entropia (ou complexidade) de Kolmogorov que mede a complexidade algorítmica de um dado objeto, como uma seqüência de números. Essa grandeza é dada pelo comprimento do menor programa de computador que consegue descrever a seqüência (Cover e Thomas, 1991).

$\mathrm{Na}$ verdade, as idéias por trás dessa medida foram publicadas quase simultaneamente em Solomonoff (1960) e Chaitin (1966), sendo que G. Chaitin também apresentou alguns estudos provando matematicamente a complexidade de Kolmogorov (Cover e Thomas, 1991). O problema é que não é possível calcular diretamente essa grandeza, somente obter um limite de seu valor (Wyner e Foster, 2003).

\footnotetext{
${ }^{6}$ O termo complexidade tem diversos significados na ciência de forma geral. Neste trabalho, considera-se complexidade como uma característica de sistemas que produzem sinais complicados, ou seja, sinais que possuam muitas informações e que são de difícil modelagem.
} 
A entropia, originalmente definida como medida de informação por Shannon, é dada pela Equação (3.1) para uma variável aleatória discreta $X$, conforme Cover e Thomas (1991).

$$
H(X)=-\sum_{x \in \mathcal{X}} p_{X}(x) \log _{2} p_{X}(x)
$$

Nessa formulação, considera-se que o alfabeto de eventos da variável $X$ é $\mathcal{X}$, sendo $p_{X}(x)$ a PDF associada a essa variável. O logaritmo possui base 2, assim, a entropia é expressa em bits, sendo a base neperiana, tem-se unidade em nats. Considera-se $0 \log _{2} 0=0$. Uma extrapolação dessa entropia para variáveis aleatórias contínuas é conhecida como entropia diferencial $^{7}$ (Cover e Thomas, 1991; Kullback, 1968).

Uma generalização da entropia de Shannon é a entropia de Rényi, a qual foi definida em Rényi (1960), Equação 3.3. Quando $\alpha$ tende à unidade, a entropia de Rényi tende para a entropia de Shannon, por isso ela é considerada uma generalização. Neste estudo, por questões de simplicidade, usaram-se somente a entropia de Shannon e entropia relativa, entretanto, informações mais detalhadas sobre a entropia de Rényi podem ser encontradas em Zyczkowski (2003).

$$
H_{\alpha}(X)=\frac{1}{1-\alpha} \log _{2}\left(\sum_{x \in \mathcal{X}} p(x)^{\alpha}\right)
$$

As medidas de entropia estão intimamente relacionadas a previsibilidade de sinais, podendo ser usadas para avaliar a capacidade de previsão de um sistema. Em Schneider e Griffies (1999), essa característica é usada para construir um parâmetro chamado potência de previsão, como será visto na Subseção 3.2.3, o qual é calculado usando medidas de entropia. Uma das formas de cálculo utiliza a entropia relativa entre dois sinais, a qual possui algumas vantagens conforme Kleeman (2002).

\footnotetext{
${ }^{7}$ A entropia diferencial é dada pela Equação (3.2), sendo $X$ uma variável aleatória contínua com PDF $p_{X}(x)$.

$$
H_{D}(X)=-\int_{-\infty}^{\infty} p_{X}(x) \log p_{X}(x) d x
$$

Para essa formulação, considera-se que o conjunto suporte de $X$ abrange a faixa $[-\infty, \infty]$ (Cover e Thomas, 1991). Essa entropia é muito similiar a entropia da uma variável discreta, entretanto existem algumas diferenças, sendo uma das principais, o fato dessa medida poder resultar em valores negativos ao contrário da versão para variáveis discretas. No Apêndice C, apresenta-se a derivação da entropia diferencial de uma distribuição Gaussiana.
} 
Outra medida, relacionada a entropia de Shannon, é a entropia relativa, também conhecida como entropia Kullback-Leibler (KL). Esta pode ser interpretada como uma medida da dificuldade de se discrimar duas distribuições de probabilidade (DelSole, 2004). A definição da entropia relativa de duas PDFs, $p_{X}(x)$ e $q_{X}(x)$, de uma variável aleatória discreta $X$ é dada pela Equação (3.4), sendo $\mathcal{X}$ o alfabeto de eventos dessa variável.

$$
D\left(p_{X} \| q_{X}\right)=\sum_{x \in \mathcal{X}} p_{X}(x) \log _{2} \frac{p_{X}(x)}{q_{X}(x)}
$$

A entropia KL também possui uma versão diferencial, extrapolada para aplicações que envolvam variáveis aleatórias contínuas ${ }^{8}$ (Cover e Thomas, 1991).

A entropia KL é, às vezes, chamada de divergência KL. Apesar de apresentar algumas características de uma divergência (distância) entre distribuições de probabilidade, como ser sempre positiva e igual a zero quando $p(x)=q(x)$, essa medida não é realmente uma distância. Isso porque $D\left(p_{X} \| q_{X}\right)$ é diferente de $D\left(q_{X} \| p_{X}\right)$, ou seja, não satisfaz a desigualdade triangular (Cover e Thomas, 1991), o que é um requisito para ser considerada uma métrica.

Na próxima subseção, apresentam-se algumas propriedades das curvas de entropia de blocos, como a taxa de entropia.

\subsubsection{Características da Curva de Entropia}

Em Crutchfield e Feldman (2003), apresentam-se diversas características das curvas obtidas com a entropia de blocos, como a taxa de entropia, a qual pode ser relacionada a complexidade do sistema. Em Porta et al. (2001), tem-se um estudo usando medidas de entropia e taxa de entropia para caracterizar o sistema cardiovascular humano, realizando análises de complexidade da variabilidade do batimento cardíaco.

\footnotetext{
${ }^{8} \mathrm{~A}$ versão diferencial da entropia relativa entre duas PDFs, $p_{X}(x)$ e $q_{X}(x)$, é dada pela Equação (3.5), sendo que a variável aleatória $X$ é contínua.

$$
D\left(p_{X} \| q_{X}\right)=\int_{-\infty}^{\infty} p_{X}(x) \log \frac{p_{X}(x)}{q_{X}(x)} d x
$$

Novamente, considera-se que o conjunto suporte de $X$ abrange a faixa $[-\infty, \infty]$. As propriedades dessa entropia são iguais a da versão discreta. No Apêndice $C$, apresenta-se a derivação da entropia relativa diferencial entre duas distribuições Gaussianas de mesma média e desvios padrões diferentes.
} 
Com base na curva de crescimento de entropia, pode-se obter informações do sistema a partir das assíntotas, tanto da curva como de suas derivadas. Considerando-se as análises realizadas, Crutchfield e Feldman (2003) chegam a conclusão que a dinâmica de um sistema pode ter regularidades ocultas em suas medidas, a qual pode ser confundida com aleatoriedade. Assim, também pode ser relacionada com a previsibilidade do sistema. Os níveis de convergência da entropia são ferramentas para estudar a estrutura do sistema, analisando as medidas obtidas do fluxo de dados do processo, como mostrou a Figura 3.1.

Para se obter a taxa de entropia é necessário estimar a curva de crescimento da entropia em função do comprimento $(L)$ de blocos de símbolos consecutivos, também conhecida como entropia de bloco. A entropia de Shannon de uma sequiência de comprimento $L$ é dada pela Equação (3.6), sendo que $x^{L}$ denota um bloco de $L>0$ símbolos consecutivos, $p\left(x^{L}\right)$ é a distribuição de probabilidades desse bloco e $\mathcal{X}^{L}$ é o alfabeto de eventos de $x^{L}$.

$$
H_{B}(L)=-\sum_{x^{L} \in \mathcal{X}^{L}} p\left(x^{L}\right) \log _{2} p\left(x^{L}\right)
$$

Apesar de sua aparente simplicidade, essa soma deve ser executada sobre todas os blocos possíveis de $L$ símbolos consecutivos. Esse procedimento é bem complicado quando o processo em análise não é binário ou, mesmo assim, quando muitas combinações forem possíveis, pois seu número cresce exponencialmente com $L$. Portanto, se esse número não for limitado pelo sistema, a estimativa da entropia de bloco para grandes valores de $L$ é impossível.

A entropia de bloco, para sinais estacionários, é uma função não-decrescente de $L$, a qual pode ser usada para analisar alguns aspectos do sistema. Para sinais estacionários, garante-se a existência de uma assíntota dessa curva após a estabilização do crescimento. Primeiramente, $H_{B}(0)=0$, pois não existe incerteza para uma seqüência nula. Com o alfabeto finito $\mathcal{X}$, a capacidade do canal de dados é $\log _{2}|\mathcal{X}|$, a qual é a máxima taxa de entropia possível (Crutchfield e Feldman, 2003).

A Figura 3.2 apresenta o comportamento típico da curva de crescimento da entropia de bloco, mostra-se também a assíntota da curva (linha tracejada). A partir da assíntota 
apresentada na Figura 3.2, obtém-se duas medidas: a taxa de entropia da fonte, $h_{u}$, e o excesso de entropia, $E$. A primeira medida é definida como a taxa de crescimento da entropia quando $L$ tende ao infinito, como mostra a Equação (3.7) em bits/símbolo.

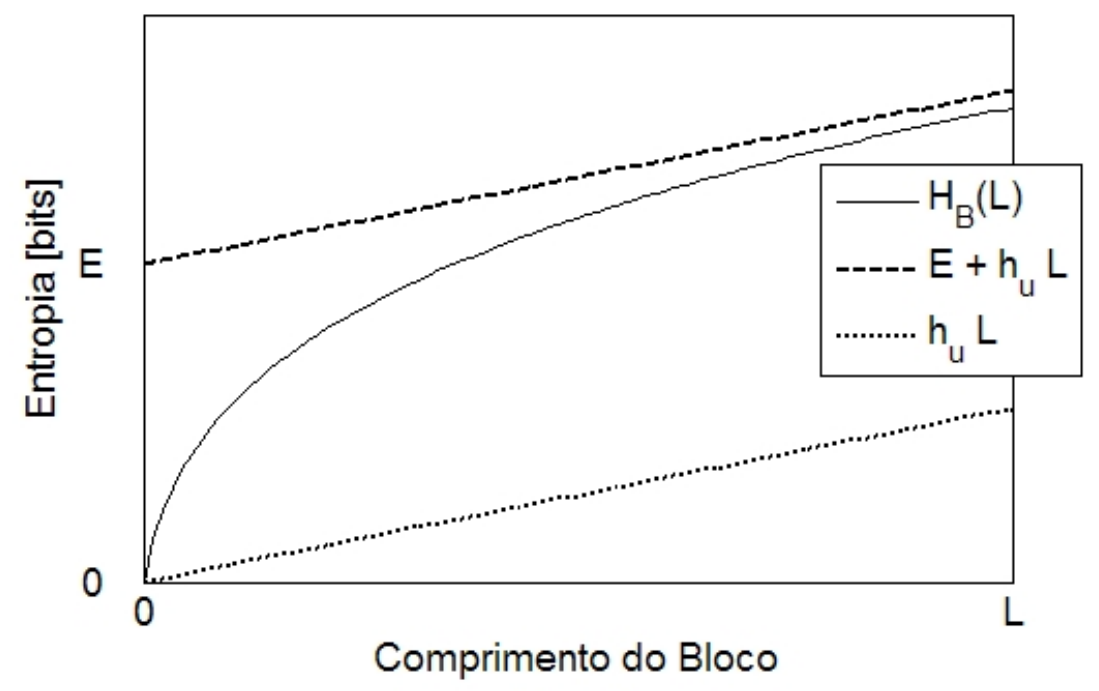

Figura 3.2: Comportamento típico da curva de crescimento da entropia de bloco $H_{B}(L)$. Em linha tracejada, tem-se a assíntota da curva de entropia.

$$
h_{u}=\lim _{L \rightarrow \infty} \frac{H_{B}(L)}{L}
$$

De acordo com Crutchfield e Feldman (2003), para longos comprimentos de bloco, $h_{u}$ pode ser entendido como a quantidade de aleatoriedade que continua sendo observada nas medidas após todas as correlações e estruturas serem consideradas. Portanto, pode ser visto a codificação binária ótima da sequiência; então quanto maior o $h_{u}$, menos a seqüência pode ser comprimida devido à aleatoriedade.

Por outro lado, o excesso de entropia pode ser interpretado como a redundância intrínseca da fonte de dados, a qual está relacionada a estrutura do processo. A definição dessa grandeza é apresentada pela Equação (3.8).

$$
E=\lim _{L \rightarrow \infty}\left[H_{B}(L)-h_{u} L\right]
$$

A Figura 3.2 ilustra a obtenção dessas duas grandezas a partir da assíntota da curva de crescimento da entropia de bloco, reta essa que pode ser escrita como $E+h_{u} L$. Assim, o excesso de entropia é o valor da assíntota para $L=0$ e a taxa de entropia 
da fonte é a inclinação dessa reta. Também nessa figura, mostra-se uma outra reta (em linha pontilhada), dada por $h_{u} L$, a qual é a aproximação em versão sem memória da fonte, conforme Crutchfield e Feldman (2003).

Conforme explorado em Crutchfield e Feldman (2003) e em outros trabalhos como Bialek et al. (2001), a maneira como a entropia de blocos converge para sua assíntota revela características do sistema, especialmente sobre a estrutura e memória. Essas características podem ser obtidas a partir das derivadas discretas da curva de entropia. As Figuras 3.3 (a) e (b) apresentam a primeira e segunda derivadas da curva de entropia.

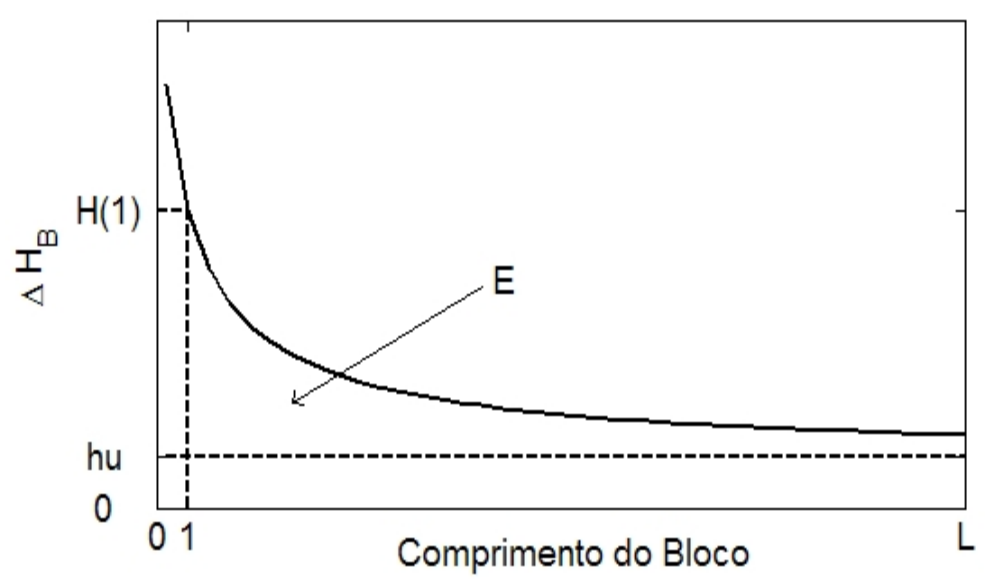

(a)

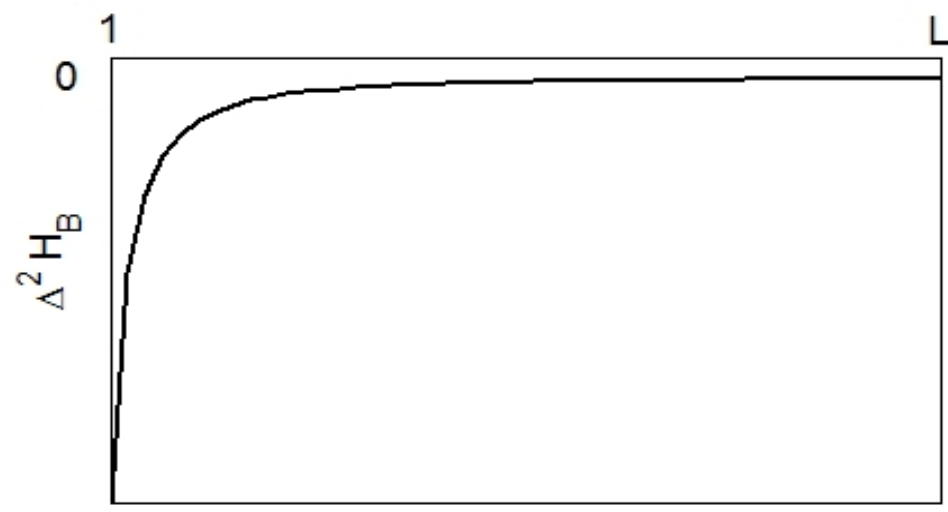

Comprimento do Bloco

(b)

Figura 3.3: (a) Primeira derivada da curva de crescimento de entropia $\left(\Delta H_{B}\right)$ da Figura 3.2. (b) Segunda derivada da curva de crescimento de entropia $\left(\Delta^{2} H_{B}\right)$.

A primeira derivada da curva de entropia é chamada de ganho de entropia e sua assíntota possui o valor da taxa de entropia da fonte, $h_{u}$. A segunda derivada é chamada de ganho de previsibilidade porque $\Delta H_{B}$ pode ser interpretada como uma estimativa 
da falta de previsibilidade da fonte, assim sua variação representa a perda dessa característica. A curva de $\Delta^{2} H_{B}$ tem como assíntota o zero.

Outras informações podem ser obtidas dessas curvas pelo cálculo da área entre as curvas e suas assíntotas como mostrado em Crutchfield e Feldman (2003). Usando como base a Figura 3.2, pode-se obter uma quantidade chamada informação transiente, a qual é estimada como a área entre a curva de crescimento da entropia de bloco e sua assíntota. Essa é uma medida de quão difícil é sincronizar com a fonte do processo. Essa característica auxilia a análise da fonte, pois estar sincronizado significa estar em uma condição de conhecimento do sistema que se pode prever as saídas do processo com uma taxa de erro igual a $h_{u}$.

De forma semelhante, a área entre a curva de ganho de entropia, Figura 3.3 (a), e sua assíntota, $h_{u}$, é igual ao excesso de entropia, E. Essa medida, como já mencionado, pode ser interpretada como a redundância intrínseca da fonta e pode auxiliar a caracterizar a complexidade do sistema. Por fim, a área entre a curva de ganho de previsibilidade da Figura 3.3 (b) resulta na previsibilidade total, a qual é também relacionada a redundância, mas, especialmente, à previsibilidade do sistema.

Essas propriedades obtidas da curva de crescimento da entropia e suas derivadas apresentam bons resultados teóricos como apresentam Crutchfield e Feldman (2003), especialmente quando analisadas para processos binários (ou processos Markovianos) com alfabeto limitado. Entretanto, a estimativa prática considerando um processo com valores reais, como sinais de voz, torna-se inviável devido a grande quantidade de combinações dos blocos.

Esse problema será melhor abordado no Capítulo 5, onde se apresentam alguns exemplos ilustrativos além de algumas outras formas de análise que se mostram interessantes para sinais de voz. Na próxima subseção, apresenta-se outra medida de previsibilidade, a potência de previsão.

\subsubsection{Potência de Previsão}

No começo da seção 3.2, apresentou-se o MSE, mostrando várias desvantagens em seu uso como medida de previsibilidade. Assim, como uma forma de resolver esses 
problemas, Schneider e Griffies (1999) introduziram uma quantidade que usa entropia como medida da incerteza associada com as variáveis aleatórias do processo, chamada potência de previsão (PP).

A PP, diferentemente do MSE, é invariante a transformações de coordenadas lineares arbitrárias e também não depende de considerações das distribuições das variáveis aleatórias do sistema. Para definir essa medida, considera-se que o estado de um sistema, dependente do tempo em um dado instante $v$, é $\mathbf{X}_{v}$, com dimensão $M$.

Observando a evolução das distribuições dos estados, ao invés da distribuição de um único estado, cada estado é visto como um processo aleatório, portanto associado a uma PDF. Essa abordagem é uma perspectiva estocástica da dinâmica do sistema em estudo (Schneider e Griffies, 1999). A PDF de $\mathbf{X}_{v}$ reflete a incerteza desse estado quando a única informação disponível é os valores dos estados anteriores.

Uma realização desse processo é $\mathbf{x}_{v}$ e uma previsão do estado, $\hat{\mathbf{x}}_{v}$, pode ser obtida a partir de um modelo empírico ajustado aos dados observados. No caso de um modelo $\mathrm{AR}$, a previsão é uma função dos estados em instantes anteriores conforme a ordem do modelo. Considerando-se o sistema como estocástico, as previsões possuem um erro de estimativa, conforme a Equação (3.9), sendo o previsor não-tendencioso.

$$
\mathbf{e}_{v}=\mathbf{x}_{v}-\hat{\mathbf{x}}_{v}
$$

Conforme Schneider e Griffies (1999), a distribuição de probabilidade do processo aleatório $\mathbf{E}_{v}$, da qual $\mathbf{e}_{v}$ é uma realização, reflete a incerteza restante no estado $\mathbf{X}_{v}$ após ser feita uma previsão.

A forma de se estimar a PP, apresentada em Schneider e Griffies (1999), baseiase na grandeza chamada informação previsível, a qual é calculada pela diferença das incertezas do estado e do erro de previsão. A incerteza pode ser medida pela entropia, a qual analisa a PDF (Cover e Thomas, 1991). Dessa forma, utilizando a entropia, encontra-se a informação previsível $\left(R_{v}\right)$ conforme a Equação (3.10).

$$
R_{v}=S_{\mathbf{X}_{v}}-S_{\mathbf{E}_{v}}
$$


Nessa equação, $S_{\mathbf{X}_{v}}$ e $S_{\mathbf{E}_{v}}$ são as entropias do estado e do erro de previsão respectivamente. A informação previsível mede a quantidade média de informação contida em uma previsão.

De posse dessa medida, obtém-se a PP associada ao estado $v$ do sistema pela Equação (3.11). Considerando que o previsor do sistema não aumenta a incerteza do estado quando realiza uma previsão, o valor de $R_{v}$ nunca é negativo, assim a PP está limitada entre 0 e 1 .

$$
P P=1-e^{-R_{v}}
$$

Além das propriedades já citadas da PP, essa medida foi definida sem a necessidade de se fazer considerações sobre o modelo usado para obter as previsões ou sobre as dimensões ou PDFs das variáveis aleatórias que fazem parte do sistema.

Entretanto, essa forma de se calcular a PP tem alguns problemas. Para estimar a informação previsível, as entropias são calculadas a partir das PDFs que, na prática, não são conhecidas. Assim, faz-se necessário estimá-las a partir dos dados, sendo o valor da entropia muito sensível a erros dessas estimativas.

Em DelSole (2004), a forma de se calcular a informação previsível é diferente, usa-se a entropia da previsão, ao invés do erro de previsão. Mesmo assim, as duas medidas tem comportamentos iguais do ponto de vista da previsibilidade. De qualquer forma, a previsibilidade do estado tende a zero quando as duas distribuições analisadas se igualam, pois isso significa que a adição da previsão não acrescentou informação ao estado.

Outra medida de previsibilidade semelhante à informação previsível é a entropia relativa das duas distribuições mencionadas anteriormente. A entropia relativa tende a zero quando as duas distribuições se igualam, assim como a informação previsível. Isso ocorre porque a entropia KL pode ser entendida como a medida da dificuldade de discriminar duas distribuições (Cover e Thomas, 1991).

Uma das vantagens de se usar a entropia relativa como medida de previsibilidade é que ela é invariante a transformações inversíveis não-lineares (Majda et al., 2002), diferentemente da informação previsível, a qual é invariante somente a transformações 
lineares. Da mesma forma que a informação previsível, a entropia relativa pode ser decomposta em componentes previsíveis (DelSole, 2004).

Outra vantagem da entropia relativa é que ela somente é zero quando as distribuições são iguais, já a informação previsível pode ser zero em outros casos. Também, a entropia relativa é sempre positiva, caracterizando, assim, a "distância" das distribuições, resultando em uma PP entre 0 e 1 . A informação previsível pode ser negativa quando a previsão acrescenta entropia ao sistema (baixa previsibilidade) ou devido a erros de estimativa das PDFs, assim, podem-se ter PP negativas, o que não é interessante.

Uma última vantagem está no fato de que a entropia relativa de um processo Markoviano estacionário decresce monotonicamente com o aumento do tempo de previsão, enquanto que a entropia absoluta não (Kleeman, 2002). Assim, a entropia relativa se adequa à intuição que a previsibilidade decresce monotonicamente nesse tipo de sistemas com o aumento do tempo de previsão (DelSole, 2004).

Em DelSole (2004), mostra-se que, para distribuições Gaussianas, essas duas medidas se tornam dependentes do determinante de matrizes de covariância, assim, pequenos erros nos menores autovalores produzem grandes erros nas medidas.

Com base nesses argumentos, utiliza-se a entropia relativa na estimativa da PP. Assim, fazendo essa substituição na Equação (3.11), obtém-se a Equação (3.12).

$$
P P=1-e^{-D\left(\mathbf{X}_{v} \| \mathbf{E}_{v}\right)}
$$

Uma outra medida interessante é a informação mútua, a qual está relacionada com as duas medidas apresentadas e tem várias características interessantes (DelSole, 2005). Entretanto, devido a maior facilidade de implementação, preferiu-se usar a entropia relativa para a estimativa da PP.

Na próxima seção, apresenta-se o método de análise de componentes previsíveis, o qual realiza a decomposição do sinal em componentes ordenados por suas características de previsibilidade. 


\subsection{Análise de Componentes Previsíveis}

A análise de componentes previsíveis, ou PrCA como mencionado anteriormente, é uma técnica de transformação de dados que os leva para um novo sistema de coordenadas de tal forma que qualquer projeção dos dados apresentará maior previsibilidade na primeira coordenada, a segunda maior previsibilidade se dará na segunda coordenada e assim por diante. Essas coordenadas são chamadas de componentes previsíveis, sendo que os componentes são descorrelacionados entre si. A PrCA foi apresentada com esse nome em Schneider e Griffies (1999), apesar de que, conforme DelSole e Chang (2003), técnicas semelhantes já foram utilizadas anteriormente por Déqué (1998) e Renwick e Wallace (1995).

Uma das grandes vantagens das métricas apresentadas na seção anterior é a capacidade de decompor o sistema em estudo em componentes previsíveis, ou seja, indicar quais as direções do sistema que possuem maior previsibilidade. Ou, pela óptica do modelo de previsão do sistema, essa técnica identifica os componentes que o modelo prevê (em média) com maior precisão (DelSole e Chang, 2003).

A PrCA faz a projeção da série temporal do erro de previsão nos componentes principais (PCs - Principal Components) ${ }^{9}$ da série das observações do sistema. Em seguida, normalizam-se os PC por seus desvios padrões de forma que suas variâncias sejam unitárias (DelSole e Chang, 2003). Esse procedimento é chamado de branqueamento da série temporal (do termo em inglês: whitening). Chama-se assim, pois, a matriz de covariância do sinal passa a ser a matriz identidade, a qual é a matriz de covariância de um ruído branco (Schneider e Griffies, 1999). As funções ortogonais empíricas (EOF - Empirical Orthogonal Functions) da série temporal branqueada do erro são os componentes com variância de erro normalizadas ótimas.

Portanto, para realizar essa decomposição, utiliza-se a variância do erro normalizada para identificar os componentes mais previsíveis, a qual possui relação com a PP. Conforme Schneider e Griffies (1999), para variáveis Gaussianas, a PP de cada componente $\left(P P_{k}\right)$ se relaciona com a variância de erro normalizada de cada componente

\footnotetext{
${ }^{9}$ Componentes principais são o resultado da análise de componentes principais (PCA - Principal Component Analysis), a qual é definida como uma transformação linear ortogonal que rotaciona os dados para um novo sistema de coordenadas. Dessa forma, a maior variância de qualquer projeção possível dos dados está na direção do primeiro componente principal e assim sucessivamente (Jolliffe, 2002).
} 
$\left(\gamma_{k}\right)$, sendo $k$ o número do componente, conforme a Equação (3.13).

$$
P P_{k}=1-\sqrt{\gamma_{k}}
$$

Em Schneider e Griffies (1999), demonstra-se que os $\gamma_{k}$ devem ter valores entre $0 \mathrm{e}$ 1 também, da mesma forma que a PP. Dessa forma, a maximização da PP é equivalente à minimização de $\gamma$. Para o caso não-Gaussiano, essa relação não se mantém, variando de acordo com a distribuição dos dados, porém ainda se deve buscar minimizar a variância de erro normalizada.

Por isso, na PrCA, utiliza-se esse procedimento, não buscando obter os valores de PP. Como a $\gamma$ baseia-se na variância do erro de previsão dos estados do sistema normalizada pela variância das observações do estado, pode-se comparar os padrões do sistema mesmo que eles possuam variações grandes de seus valores (Schneider e Griffies, 1999; DelSole e Chang, 2003).

Para a derivação da $\operatorname{PrCA}$, consideram-se, novamente, o estado do sistema $\mathbf{X}_{v}$ no instante $v$ e o erro de previsão $\mathbf{E}_{v}$, os quais possuem média nula. $\mathrm{O}$ princípio da técnica é determinar o vetor de projeção $\mathbf{q}_{v}$ de tal forma que o erro projetado otimize a variância de erro normalizada (DelSole e Chang, 2003). O erro projetado é a projeção do erro de estimativa na direção do vetor, ou seja $\mathbf{q}_{v}^{T} \mathbf{e}_{v}$, sendo $\mathbf{e}_{v}$ uma realização de $\mathbf{E}_{v}$. De forma equivalente, a observação do estado projetada é $\mathbf{q}_{v}^{T} \mathbf{x}_{v}$, sendo $\mathbf{x}_{v}$ uma realização de $\mathbf{X}_{v}$ também. Ambas as projeções são quantidades escalares, ou seja, sinais no tempo. Portanto, obtém-se a variância de erro normalizada pela razão das variâncias desses dois sinais, Equação (3.14).

$$
\gamma=\frac{\mathbf{q}_{v}^{T} \mathbf{C}_{e} \mathbf{q}_{v}}{\mathbf{q}_{v}^{T} \mathbf{C}_{o} \mathbf{q}_{v}}
$$

Nessa equação, utilizaram-se as matrizes de covariância das projeções: $\mathbf{C}_{e}=$ $\left\langle\mathbf{E}_{v} \mathbf{E}_{v}^{T}\right\rangle$ e $\mathbf{C}_{o}=\left\langle\mathbf{X}_{v} \mathbf{X}_{v}^{T}\right\rangle$, respectivamente matriz de covariância do erro de previsão e do estado do sistema. As operações $\{.\}^{T}$ e $\langle$.$\rangle simbolizam a transposição e o$ valor esperado de $\{$.$\} respectivamente.$

Objetiva-se minimizar essa variância, a qual se caracteriza como um coeficiente de 
Rayleigh do vetor $\mathbf{q}_{v}$ (Schneider e Griffies, 1999). De acordo com DelSole e Chang (2003), a minimização do coeficiente de Rayleigh recai em um problema de autovalores generalizado, como apresentado na Equação (3.15).

$$
\mathbf{C}_{e} \mathbf{q}_{v}=\gamma \mathbf{C}_{o} \mathbf{q}_{v}
$$

Quando os autovetores $\mathbf{q}_{v}^{k}$ são ordenados conforme seus autovalores correspondentes de forma crescente, relacionam-se de forma que o primeiro autovetor minimiza a variância de erro normalizada em todos os possíveis padrões do sistema. O segundo autovetor minimiza a variância em todos os padrões descorrelacionados com o primeiro e, assim, sucessivamente. As variâncias de erro normalizada $\gamma^{k}$ são os autovalores associadas com os autovetores.

Pode-se montar uma matriz cujas colunas são os autovetores $\mathbf{Q}_{v}=\left[\mathbf{q}_{v}^{1}, \mathbf{q}_{v}^{2}, \ldots, \mathbf{q}_{v}^{M}\right]$. Assim, obtém-se a matriz $\mathbf{P}_{v}=\left[\mathbf{p}_{v}^{1}, \mathbf{p}_{v}^{2}, \ldots, \mathbf{p}_{v}^{M}\right]$ biortogonal a $\mathbf{Q}_{v}$ cujos componentes são os chamados padrões previsíveis (Schneider e Griffies, 1999). A propriedade de biortogonalidade pode ser escrita como a Equação (3.16), sendo I a matriz identidade.

$$
\mathbf{P}_{v} \mathbf{Q}_{v}^{T}=\mathbf{I}
$$

Duas relações interessantes envolvendo a matriz de autovetores $\mathbf{Q}_{v}$ são: $\mathbf{Q}_{v}^{T} \mathbf{C}_{o} \mathbf{Q}_{v}=$ I e $\mathbf{Q}_{v}^{T} \mathbf{C}_{e} \mathbf{Q}_{v}=\boldsymbol{\Gamma}_{v}$, sendo $\boldsymbol{\Gamma}_{v}$ a matriz diagonal dos autovalores da Equação (3.15). Dessas relações, pode-se ver que a matriz $\mathbf{Q}_{v}$ promove o branqueamento da matriz de covariância das observações do estado e a diagonalização da matriz de covariância do erro de previsão. Com isso, pode-se chegar a uma forma simples para estimar os padrões previsíveis, a qual será apresentada após o exemplo seguinte.

A Figura 3.4 apresenta um exemplo dos componentes previsíveis de um sinal de seno com adição de ruído branco (SNR de 20,5 dB). Nessa figura, tem-se uma representação tridimensional do sinal, a qual é obtida pela usando versões atrasadas do sinal como coordenadas, neste exemplo, usa-se um atraso de três amostras para cada coordenada. Calcula-se a PrCA usando o modelo que será apresentado no Capítulo 4, obtendo três componentes previsíveis, os quais são apresentados pelos três vetores (normalizados), CP1 a CP3, no centro da figura. 


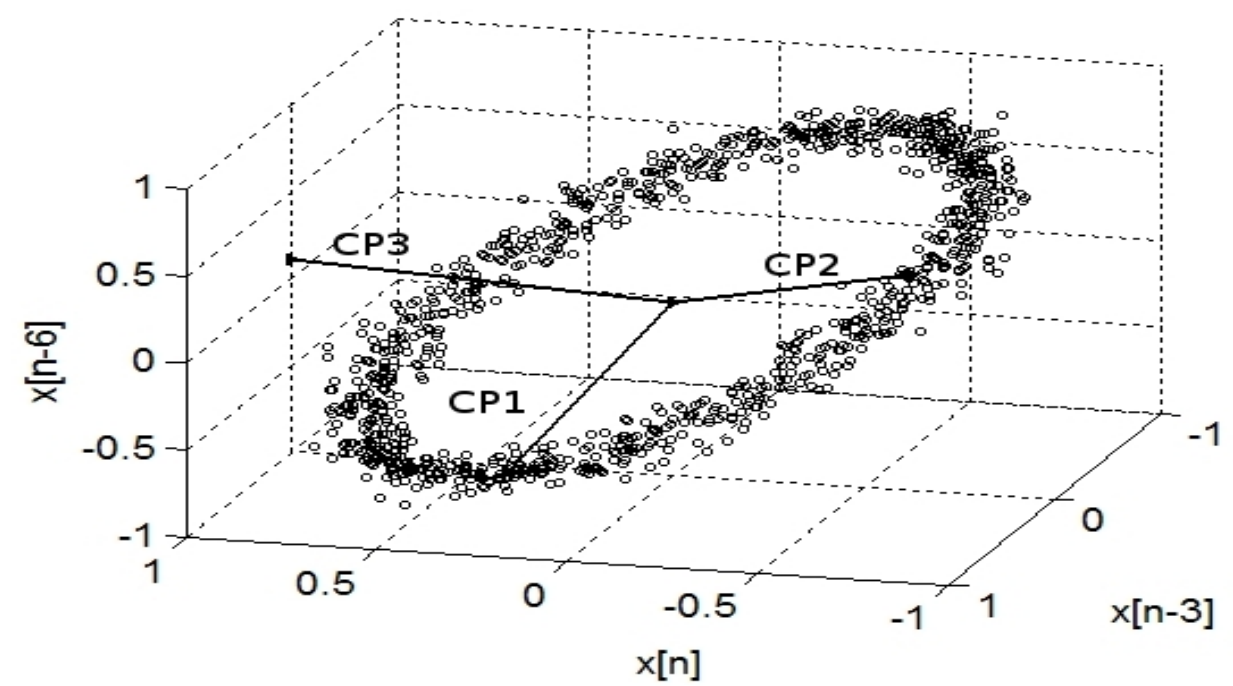

Figura 3.4: Representação tridimensional ${ }^{10}$ de um sinal composto por um seno mais ruído branco. Os três vetores CP1, CP2 e CP3 são versões normalizadas dos três componentes previsíveis da PrCA. Os valores de variância de erro normalizada relacionados a esses componentes são $0,0012,0,0044$ e 0,5865 respectivamente.

Os valores das variâncias de erro normalizadas são 0,0012, 0,0044 e 0,5865 respectivamente para os componentes $\mathrm{CP} 1, \mathrm{CP} 2$ e $\mathrm{CP} 3$. Isso mostra que os dois primeiros componentes possuem quase toda a previsibilidade do sinal, o que é confirmado pela figura, pois essa se encontra quase inteiramente no plano formado por esses dois componentes.

Para se realizar a PrCA, pode-se resolver a Equação (3.15) para cada um dos componentes previsíveis ou utilizar uma forma alternativa baseada em PCA conforme demonstrado em Schneider e Griffies (1999). Para isso, primeiramente, realiza-se a PCA da matriz de covariância das observações do estado, $\mathbf{C}_{o}$, Equação (3.17).

$$
\mathbf{C}_{o}=\mathbf{W}_{v} \Lambda_{v} \mathbf{W}_{v}^{T}
$$

Obtém-se duas matrizes: $\mathbf{W}_{v}$, cujas colunas são os autovetores, e a matriz diagonal de autovalores, $\boldsymbol{\Lambda}_{v}$, sendo $\lambda_{k}$ os elementos da diagonal. Com essas matrizes, pode-se realizar um branqueamento de $\mathbf{X}_{v}$, ou seja, uma diagonalização de $\mathbf{C}_{o}$, transformandoa na matriz identidade, I, conforme a Equação (3.18).

\footnotetext{
${ }^{10}$ Essa representação tridimensional de sinais será devidamente apresentada no Capítulo 4.
} 


$$
\boldsymbol{\Lambda}_{v}^{-1 / 2} \mathbf{W}_{v}^{T} \mathbf{C}_{o} \mathbf{W}_{v} \boldsymbol{\Lambda}_{v}^{-1 / 2}=\mathbf{I}
$$

Também, pode-se transformar $\mathbf{C}_{e}$ na matriz $\mathbf{K}_{v}$, como mostra a Equação (3.19).

$$
\boldsymbol{\Lambda}_{v}^{-1 / 2} \mathbf{W}_{v}^{T} \mathbf{C}_{e} \mathbf{W}_{v} \boldsymbol{\Lambda}_{v}^{-1 / 2}=\mathbf{K}_{v}
$$

O próximo passo do procedimento é a diagonalização da matriz transformada $\mathbf{K}_{v}$ usando uma nova PCA, Equação (3.20). Essa transformação resulta em duas matrizes: $\mathbf{T}_{v}$, formada pelos autovetores de $\mathbf{K}_{v}$, e $\boldsymbol{\Delta}_{v}$, matriz diagonal formada pelos autovalores de $\mathbf{K}_{v}$, os quais são as variâncias de erro normalizadas nas direções dos componentes previsíveis, $\gamma_{k}$.

$$
\mathbf{K}_{v}=\mathbf{T}_{v} \Delta_{v} \mathbf{T}_{v}^{T}
$$

Portanto, usando as Equações (3.19) e (3.20), pode-se escrever a transformação final de $\mathbf{C}_{e}$ para obtenção das $\gamma_{k}$, Equação (3.21). Se essa mesma transformação for aplicada na Equação (3.18), o resultado continua sendo a matriz identidade.

$$
\mathbf{T}_{v}^{T} \boldsymbol{\Lambda}_{v}^{-1 / 2} \mathbf{W}_{v}^{T} \mathbf{C}_{e} \mathbf{W}_{v} \boldsymbol{\Lambda}_{v}^{-1 / 2} \mathbf{T}_{v}=\boldsymbol{\Delta}_{v}
$$

Utilizando as matrizes de autovetores das duas PCAs das Equações (3.17) e (3.20), $\mathbf{W}_{v}$ e $\mathbf{T}_{v}$, encontra-se a solução do problema de autovalores generalizado da Equação (3.15), conforme a Equação (3.22).

$$
\mathbf{Q}_{v}=\mathbf{W}_{v} \boldsymbol{\Lambda}_{v}^{-1 / 2} \mathbf{T}_{v}
$$

Aplicando-se esse resultado na Equação (3.16), encontra-se a matriz com os componentes previsíveis, Equação (3.23).

$$
\mathbf{P}_{v}=\mathbf{W}_{v} \Lambda_{v}^{1 / 2} \mathbf{T}_{v}
$$


Se $\mathbf{C}_{o}$ for singular, ou seja, um ou mais dos autovalores de $\Lambda_{v}$ forem nulos, então, a matriz $\Lambda_{v}^{-1 / 2}$ passa a não existir. Nesse caso, faz-se necessário usar a técnica da pseudoinversa de Moore-Penrose para a solução do problema (Golub e Loan, 1996).

Para finalizar a introdução aos métodos de previsibilidade, percebe-se que a PrCA é uma técnica que decompõe o sistema em componentes que indicam as direções onde a variância de erro normalizada é minimizada, crescendo do menor valor $\gamma_{1}$ referente ao primeiro componente previsível ao maior $\gamma_{v}^{M}$ referente ao último componente previsível, ou seja, aquele cuja direção possui menor previsibilidade. Uma grande vantagem dessa decomposição é que é possível retirar os componentes com baixa previsibilidade e recompor o sinal somente com os componentes mais previsíveis, conforme será apresentado no Capítulo 5.

Com essa reconstrução, pode-se obter um sinal mais previsível, o qual pode ser considerado como uma versão filtrada da original, contendo menos informações aleatórias. Além disso, para sinais de voz, cujo sistema é formado por uma parte determinística e uma estocástica, essa reconstrução se torna promissora para melhorar as análises dos sinais, pois estes sinais se tornariam menos complicados do que os originais. Essa abordagem será utilizada em alguns ensaios nos Capítulos 5 e 6. 


\section{Capítulo 4}

\section{Sinais e Modelos de Previsão de}

\section{Voz}

Neste capítulo, apresentam-se os sinais de voz usados no estudo, descrevendo suas características e o pré-processamento necessário para permitir a análise de previsibilidade. Além disso, mostram-se os modelos de previsão de sinais de voz, pois, conforme Schneider e Griffies (1999); DelSole e Chang (2003), para utilização do método da previsibilidade, faz-se necessário um modelo para gerar as previsões do sistema.

A forma mais comum para se modelar o sistema vocal é utilizando o modelo AR (Rabiner e Schafer, 1978), o qual é uma representação paramétrica do sistema. Esse modelo utiliza informações das amostras anteriores de um sinal para tentar prever os próximos pontos. Também é conhecido como previsor linear (Markel e Gray, 1976).

Após a apresentação do modelo AR, descreve-se um modelo baseado em decomposição wavelet, junto com uma breve revisão de banco de filtros e transformada $w a$ velet. Para finalizar, mostra-se a análise, baseada em uma modificação do modelo AR, de uma representação multidimensional dos sinais de voz.

\subsection{Sinais de Voz}

Neste estudo, usaram-se dois tipos de sinais de voz: simulados e reais. Para criar os sinais simulados, utilizou-se um gerador desenvolvido a partir de uma amostra de 
voz feminina saudável de vogal sustentada "a", conforme apresentado no Apêndice A. As vozes reais foram retiradas do banco de dados do Laboratório de Processamento de Sinais (LPS) ${ }^{11}$ do Departamento de Engenharia Elétrica da Escola de Engenharia de São Carlos (EESC) da Universidade de São Paulo (USP). Esses sinais foram coletados nos últimos 10 anos, sendo usados e validados em diversos trabalhos (Rosa et al., 2000; Dajer et al., 2005; Fonseca et al., 2007).

Os sinais retirados do banco de dados são de pessoas com idades entre 18 e 60 anos, os quais foram diagnosticados por médicos dos setores de Otorrinolaringologia e Cirurgia de Cabeça e Pescoço do Hospital de Clínicas da Faculdade de Medicina de Ribeirão Preto ${ }^{12}$. Utilizaram-se videolaringoscópio e estroboscópio para esses diagnósticos. Alguns dos pacientes com laringes saudáveis também foram analisados pelos mesmos métodos. Entretanto, outros pacientes saudáveis foram avaliados somente por análise clinica de fonoaudiólogos. Porém, todos os sinais utilizados neste estudo foram re-analisados por uma fonoaudióloga.

Para a etapa de aquisição dessas amostras, antes de serem adicionados ao banco de dados, utilizou-se um método semelhante ao apresentado em Uloza et al. (2005); Rosa et al. (2000). O microfone, profissional e de boa qualidade, era posicionado a $5 \mathrm{~cm}$ da boca da pessoa, para a qual pedia-se para pronunciar um "a" em seu tom e intensidade normais por 5 segundos. Realizaram-se três testes consecutivos sendo selecionado o melhor. Os sinais de voz eram quantizados em amplitude usando 16 bits com formato WAVE monocanal e frequiência de amostragem de $22.050 \mathrm{~Hz}$.

Optou-se por usar sinais de vogal "a" sustentada por causa da disponibilidade desse tipo de sinal no banco de dados. Entretanto, estudos com outras vogais, como "e" e “i”, apresentam resultados semelhantes (Rosa et al., 2000). Além disso, características diferentes do sistema de produção vocal podem ser obtidas com essas outras vogais.

De forma a evitar a influência de fenômenos transitórios, um trecho de $1 s$ do começo e do final dos sinais eram descartados. Assim, podia-se garantir que as variações da pronúncia não afetassem as análises. Após essa etapa, as amplitudes dos sinais eram normalizados pelo seu máximo valor absoluto, eliminando a influência de diferentes

\footnotetext{
${ }^{11}$ Site da internet do Laboratório de Processamento de Sinais: http: //www.sel. eesc.usp.br/lps.

${ }^{12}$ Site da internet do HC da Faculdade de Medicina de Ribeirão Preto http: / / www . hcrp. fmrp. usp.br.
} 
intensidades de gravação. A Figura 4.1 apresenta um exemplo de sinal de voz saudável masculina de "a" sustentado antes do pré-processamento.

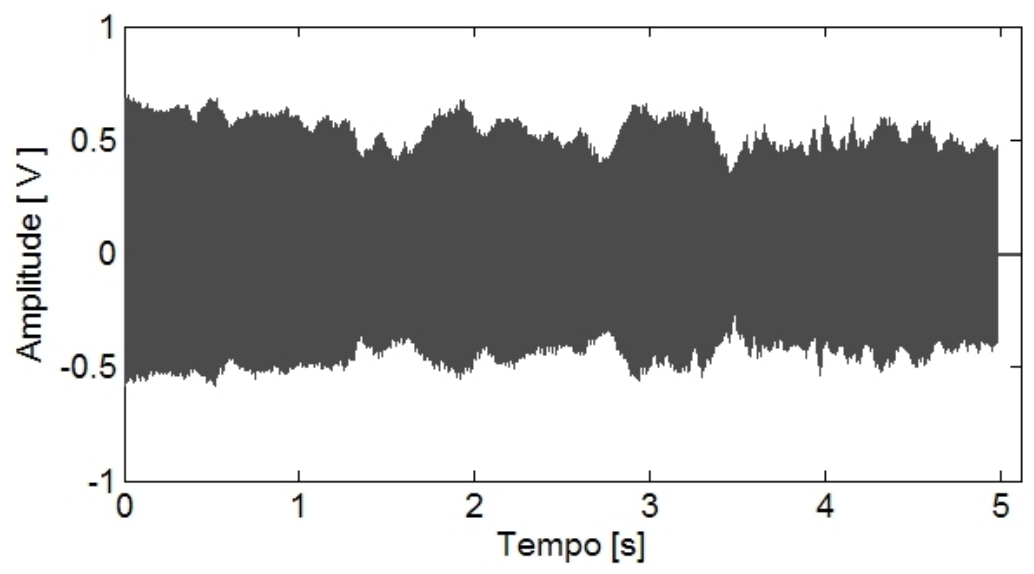

Figura 4.1: Exemplo de sinal de voz ainda não pré-processado retirado do banco de dados do LPS. O sinal é de vogal "a” sustentada de uma pessoa saudável do sexo masculino.

Além disso, considera-se que os sinais análisados são ergódicos, ou seja, as médias temporais e as médias dos conjuntos são equivalentes. Assim, pode-se fazer afirmações sobre as distribuições de probabilidade e momentos probabilísticos do sistema a partir de uma única realização do processo, ou seja, de um único sinal (Haykin, 2001).

O pré-processamento dos sinais de voz, além da retirada das extremidades do sinal e da normalização, consistia na seleção de trechos de sinal conforme um critério visual de estacionariedade em sentido amplo (WSS - wide sense stationarity). Buscava-se a região, com duração mínima de $1 s$, que apresentasse características mais próximas à estacionariedade. Segundo Haykin (2001), um sinal é estacionário em sentido amplo se seus primeiro e segundo momentos forem temporalmente invariantes. O valor médio (primeiro momento) dos sinais de voz estudados eram retirados, mas seu segundo momento é variável.

Conforme Therrien (1992), a densidade de potência espectral é a transformada de Fourier da função de autocorrelação, a qual é o segundo momento. Assim, uma análise da variação da PSD, reflete a variação da autocorrelação. Portanto, para escolher o trecho mais estacionário do sinal, analisa-se o espectrograma do sinal, ou seja, a variação da PSD com o tempo. Escolhe-se o trecho que possui a menor variação da PSD, obtendo uma região com características próximas à estacionaridade WSS. 
A Figura 4.2 apresenta uma ilustração desse método visual de escolha usando o sinal de voz da Figura 4.1. O sinal de voz apresentado na parte (a) já foi pré-processado, aproximadamente $200 \mathrm{~ms}$ foram retirados do início e final do sinal original e sua amplitude foi normalizada. Como se pode ver em (b), apesar do espectrograma apresentar pequenas variações, esse é o trecho com menos mudanças. Em (c), tem-se o trecho de sinal selecionado para análises.

(a)

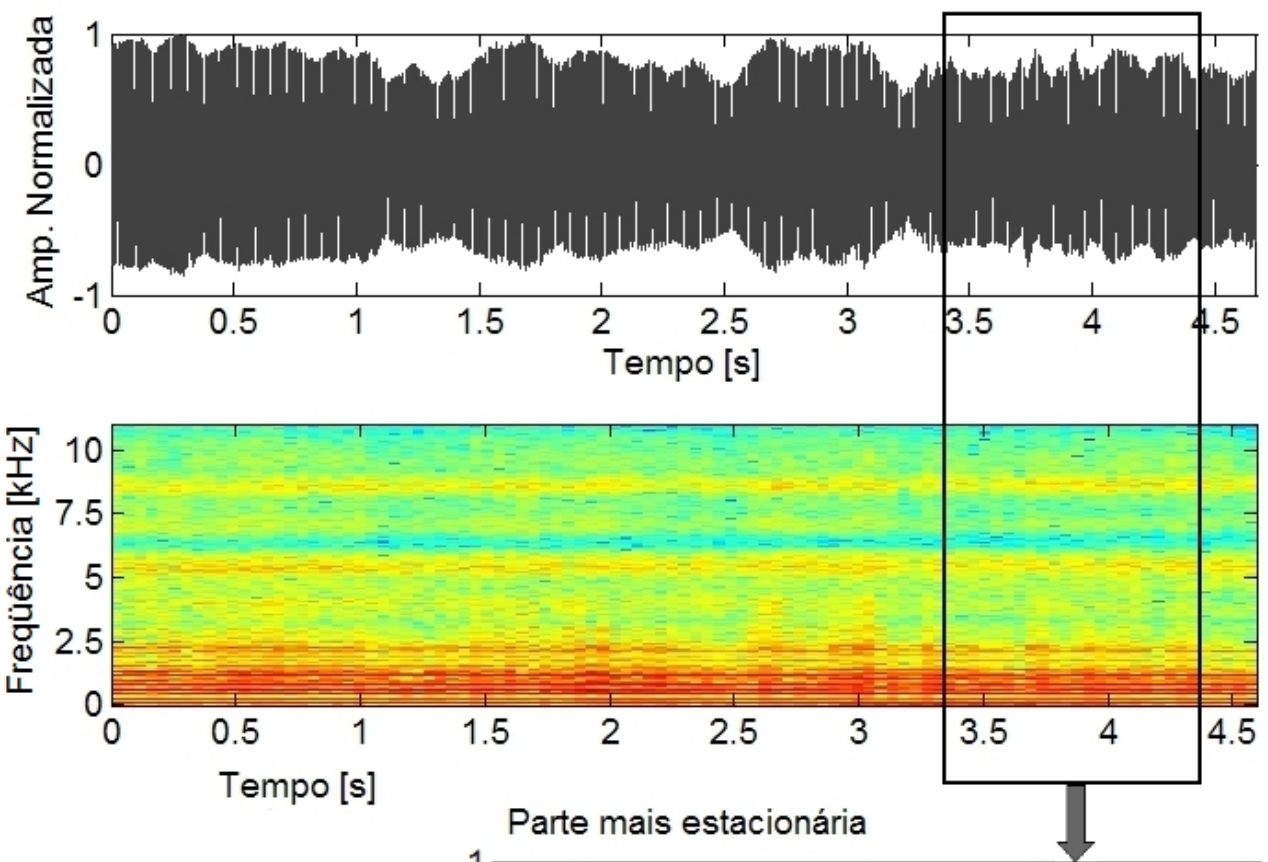

(c)

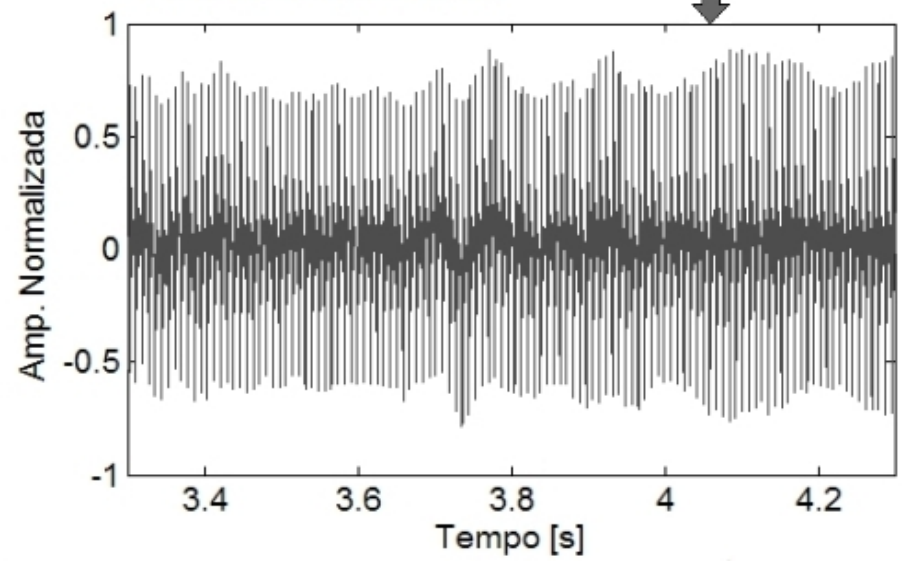

Figura 4.2: Ilustração do método visual de escolha do trecho de sinal a ser analisado. (a) Sinal de voz pré-processado, retirou-se $200 \mathrm{~ms}$ do início e final do sinal e a amplitude foi normalizada. (b) Espectrograma do sinal mostrando trecho mais estacionário. (c) Trecho selecionado.

Além das vozes saudáveis, o banco de dados possui sinais de pessoas com diversas patologias da laringe. Porém, para este estudo, utilizaram-se somente os sinais de pessoas saudáveis, com nódulo nas pregas vocais e com edema de Reinke. A Figura 
4.3 apresenta um exemplo de sinal de vogal "a" sustentada de cada grupo junto com suas representações em espaço tridimensional (melhor explicado na Subseção 4.2.3).

Os sinais patológicos apresentados nas partes (c) e (e) são de casos mais avançados de nódulo e edema de Reinke. Por isso, as diferenças entre os sinais são bem visíveis. É interessante notar as irregularidades das representações tridimensionais desses sinais, principalmente em (f).

Essa representação, conforme será melhor explicado na Subseção 4.2.3, é obtida utilizando o método dos atrasos (Fraser e Swinney, 1986). Obtém-se versões atrasadas do sinal por um valor $\tau$ e utiliza-se cada uma delas como uma coordenada do sinal reconstruído no novo espaço. No caso da Figura 4.3, tem-se duas versões atrasadas mais o sinal original, criando, assim, uma representação de três dimensões. Para os sinais anteriores usou-se atrasos iguais a 9, 5 e 10 amostras respectivamente para as partes (b), (d) e (f).

Realizou-se uma inspeção visual qualitativa das representações tridimensionais dos sinais estudados. Para os sinais de voz saudáveis, essa representação apresenta um padrão visual típico, caracteriza-se por muitos laços concêntricos de diferentes dimensões. As órbitas dos laços são correlacionadas com as interações entre a freqüência fundamental e as frequiências harmônicas do sinal, sendo planas e regulares. Além disso, as trajetórias estão bem próximas entre si, indicando uma tendência a convergência.

Para os sinais de nódulo, a representação tridimensional apresenta padrões diferentes, sendo caracterizada, em geral, por um único e irregular laço. Mesmo que os componentes harmônicos estejam presentes no pulso glotal do paciente, a maior tensão e pressão subglotal desbalanceia a razão entre a freqüência fundamental e as harmônicas. Os movimentos de compensação do trato vocal contribuem para atenuar as freqüências harmônicas, o que resulta em um único laço. A trajetória é irregular e curvada por causa do fechamento incompleto das pregas vocais, turbulência do fluxo de ar e vibração assimétrica. A trajetória também apresenta tendência de dispersão devido a mudanças no volume do fluxo de ar e variações da onda mucosa. Essa irregularidade pode ocorrer em regiões específicas ou mesmo em várias regiões das órbitas. 


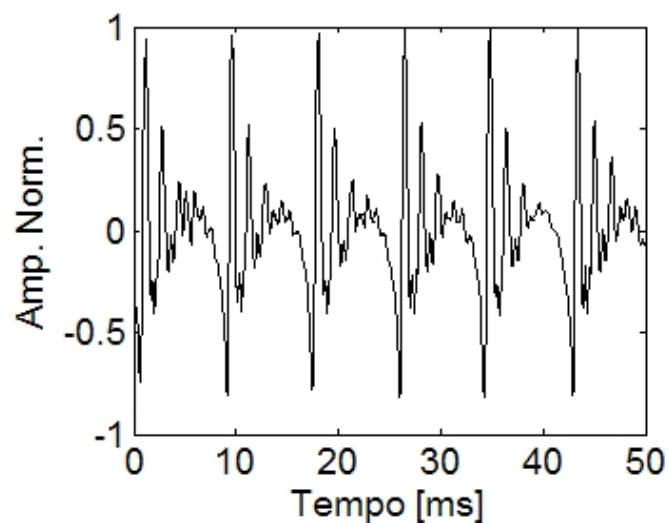

(a)

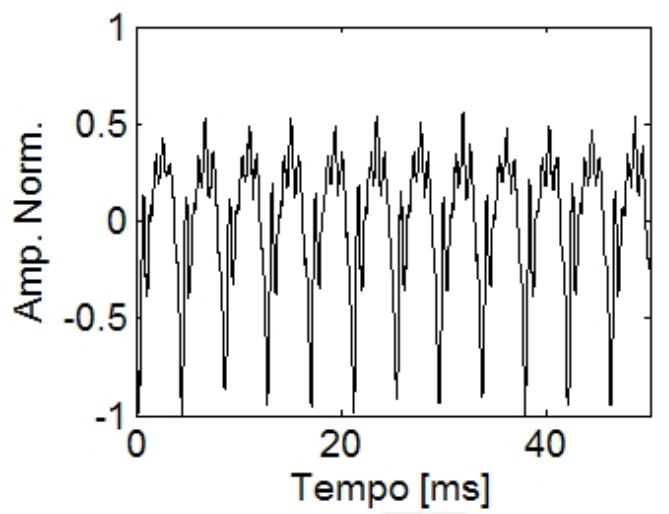

(c)

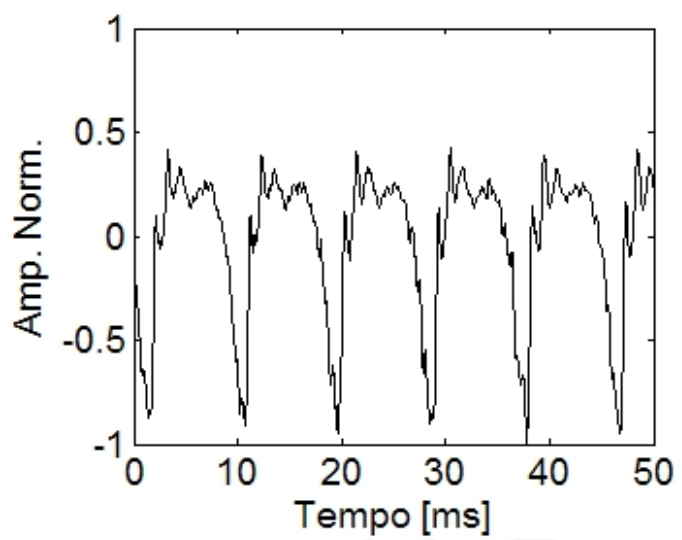

(e)

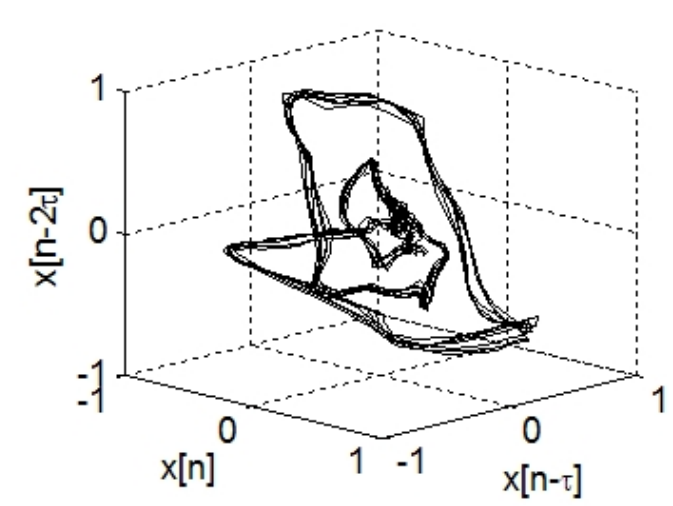

(b)

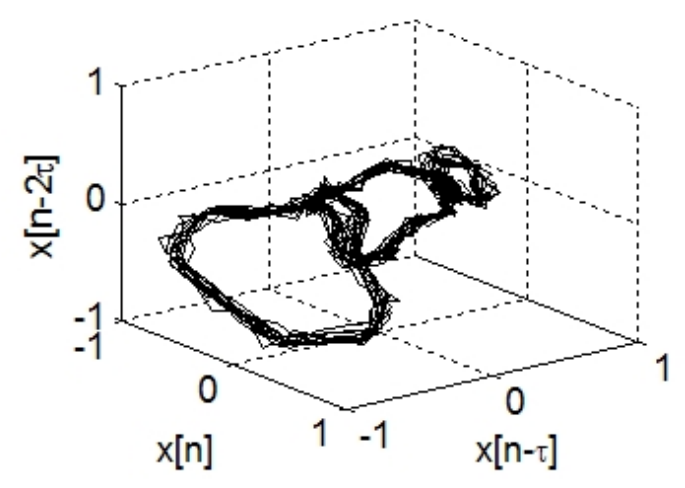

(d)

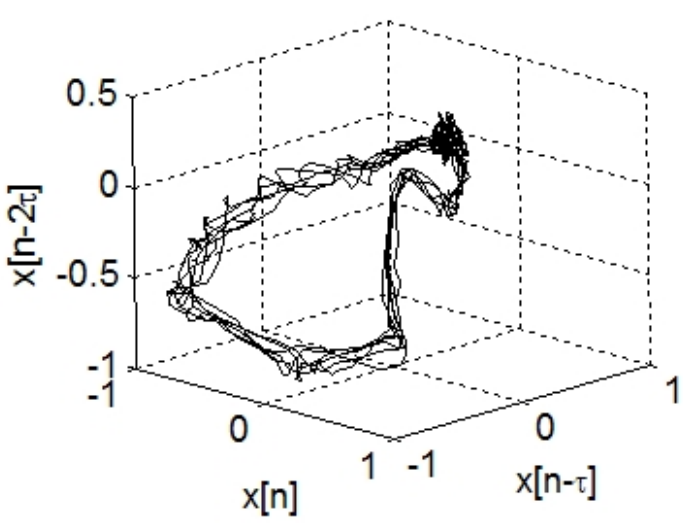

(f)

Figura 4.3: Exemplos de sinais de vogal "a" sustentada dos três grupos analisados. (a), (c) e (e) são as vozes saudável, nódulo e edema de Reinke respectivamente. (b), (d) e (f) são as representações tridimensionais desses três sinais respectivamente, sendo $\tau$ o atraso usado nessa transformação. 
A Figura 4.4 (a) apresenta outro exemplo de representação tridimensional de sinal de voz de nódulo, mas de um caso mais avançado da patologia. Nota-se a existência de somente um laço principal, o qual possui trajetória irregular e com curvas súbitas.

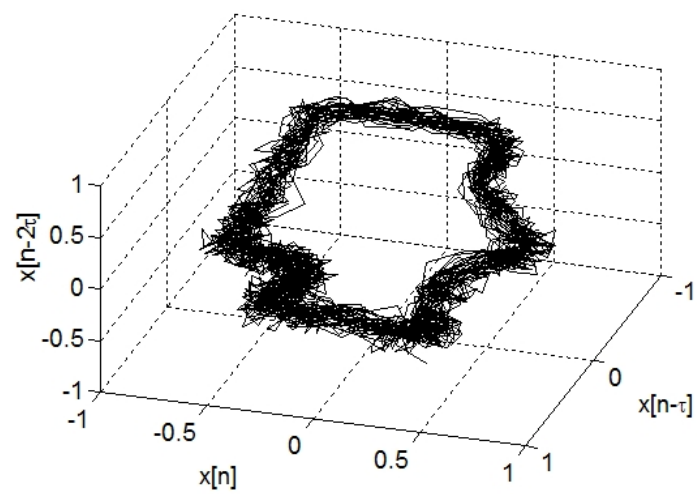

(a)

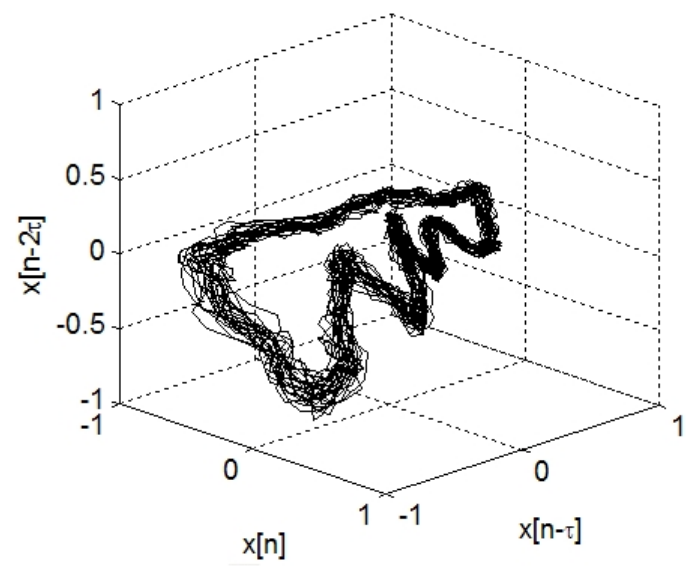

(b)

Figura 4.4: Mais dois exemplos de representações tridimensionais de sinais de voz de: (a) sinal de nódulo e (b) sinal de edema de Reinke. Em ambos, o atraso $\tau$ usado é igual a 10 amostras.

As representações tridimensionais dos sinais de edema de Reinke apresentam padrões típicos caracterizados por diversos laços, semelhante aos sinais saudáveis. Entretanto, junto com partes suaves e regulares, os trajetos possuem partes irregulares e curvadas causadas pela turbulência do fluxo de ar das pregas vocais com excesso de massa. As trajetórias mostram uma leve tendência à dispersão. 
Conforme o edema involve toda a extensão das pregas vocais, a variação da onda mucosa é menor do que na voz de nódulo. Mesmo assim, a tendência de dispersão pode mudar em diferentes regiões das órbitas. A Figura 4.4 (b) apresenta outro exemplo de representação tridimensional de sinal de voz de edema de Reinke. Esse espaço de fase é composto por vários laços, porém com trechos bem irregulares.

Tabela 4.1: Valores médios e desvios padrões dos parâmetros acústicos obtidos pelo software Análise de Voz 6.0 para os sinais utilizados neste estudo.

\begin{tabular}{|c||c|c|c|}
\hline \multicolumn{1}{|c||}{} & \multicolumn{3}{|c|}{ Grupo de Amostras } \\
\hline Parâmetro & Saudável & Nódulo & Edema de Reinke \\
\hline \hline Jitter (\%) & $0,52 \pm 0,40$ & $3,05 \pm 3,13$ & $1,64 \pm 2,24$ \\
\hline Shimmer (\%) & $3,16 \pm 0,99$ & $10,05 \pm 4,42$ & $6,81 \pm 4,22$ \\
\hline SFR (dB) & $-9,35 \pm 1,69$ & $-8,68 \pm 2,02$ & $-8,33 \pm 2,17$ \\
\hline SFF (dB) & $-14,33 \pm 2,92$ & $-15,53 \pm 3,04$ & $-15,97 \pm 4,16$ \\
\hline PA (\%) & $53,12 \pm 11,64$ & $37,44 \pm 15,78$ & $39,75 \pm 12,36$ \\
\hline EX (\%) & $13,55 \pm 5,82$ & $25,21 \pm 34,50$ & $24,30 \pm 39,67$ \\
\hline
\end{tabular}

Junto com a análise das representações tridimensionais, realizou-se a análise clássica de sinais de voz, a qual é feita por estudos de medidas acústicas dos sinais conforme apresentado anteriormente. Assim, utilizando o software comercial Análise de Voz 6.0 (Montagnoli, 1998), obtiveram-se seis estimativas desses parâmetros: jitter, shimmer, SFR, SFF, PA e EX. Os valores médios e seus desvios padrões são apresentados na Tabela 4.1 e ilustrados na Figura 4.5.

Como observado nessa figura, nenhum desses parâmetros pode ser usado para diferenciar os grupos de sinais de voz, pois seus valores não são separáveis por testes de hipótese. Entretanto, percebe-se que a variação de jitter, shimmer, e EX para os grupos patológicos é bem maior do que para o grupo saudável, pois, essas patologias se caracterizam por aumentar a variabilidade dos sinais de voz. Percebe-se que os parâmetros SFR e SFF praticamente não apresentaram diferenças entre os grupos, entretanto para os sinais patológicos o jitter e shimmer foram maiores na média, de acordo com o esperado. Além disso, o PA foi maior na média para os sinais saudáveis, pois, conforme apresentado anteriormente, esse parâmetro é elevado para sinais com períodos bem definidos, o que é um reflexo do menor valor de jitter desse grupo. 


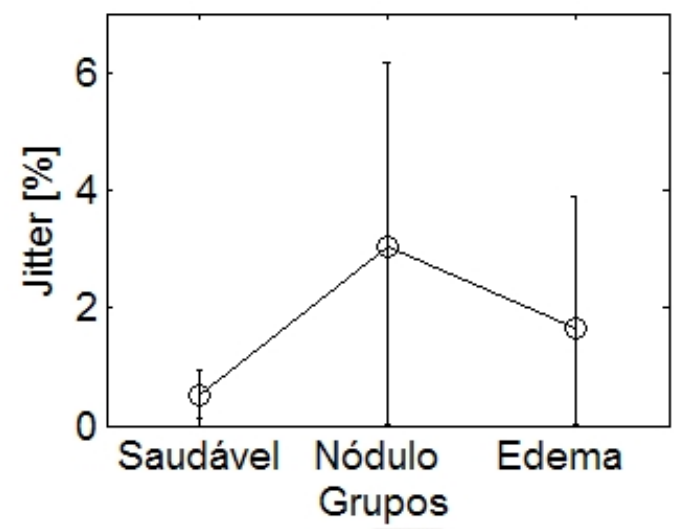

(a)

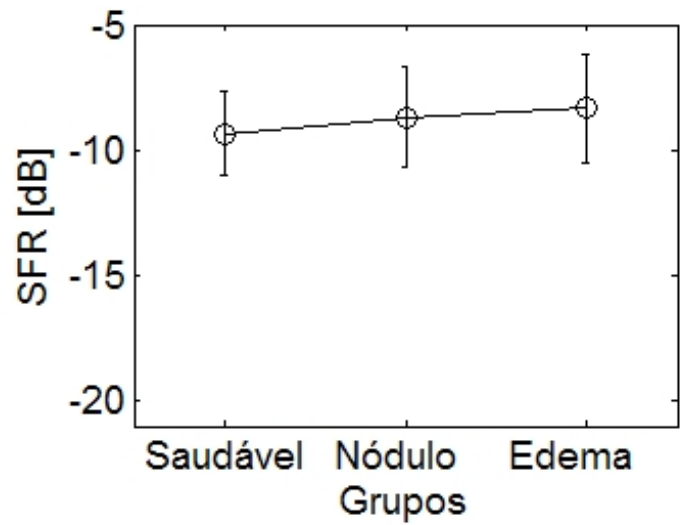

(c)

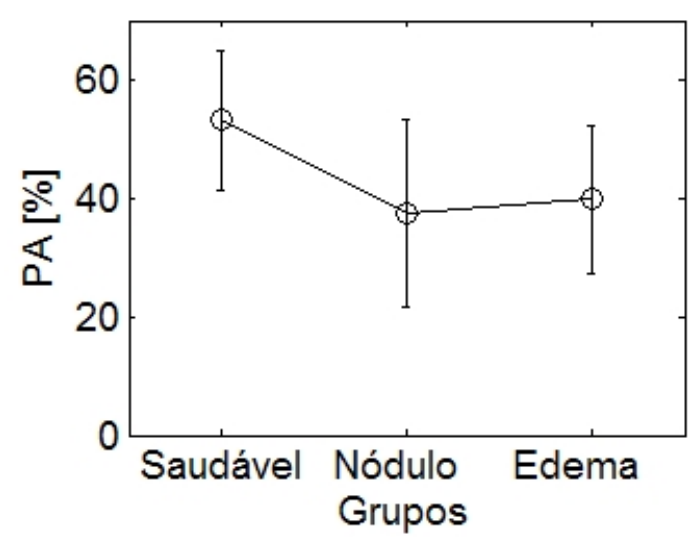

(e)

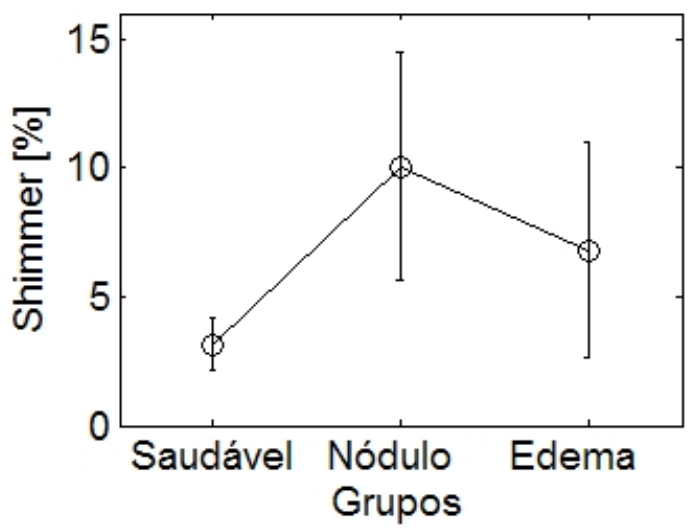

(b)

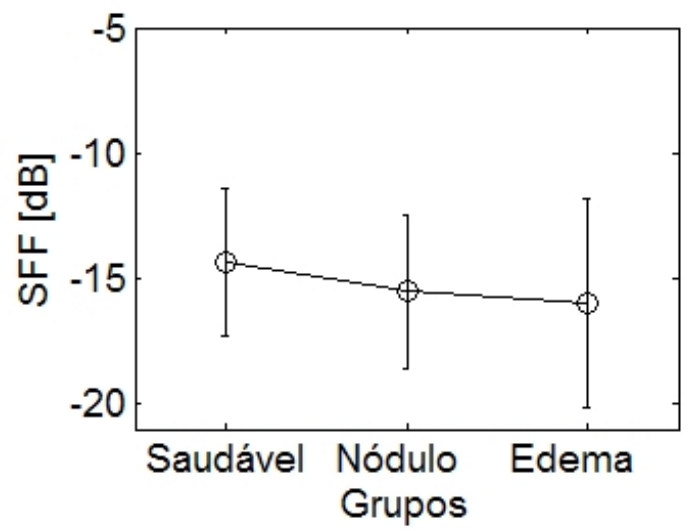

(d)

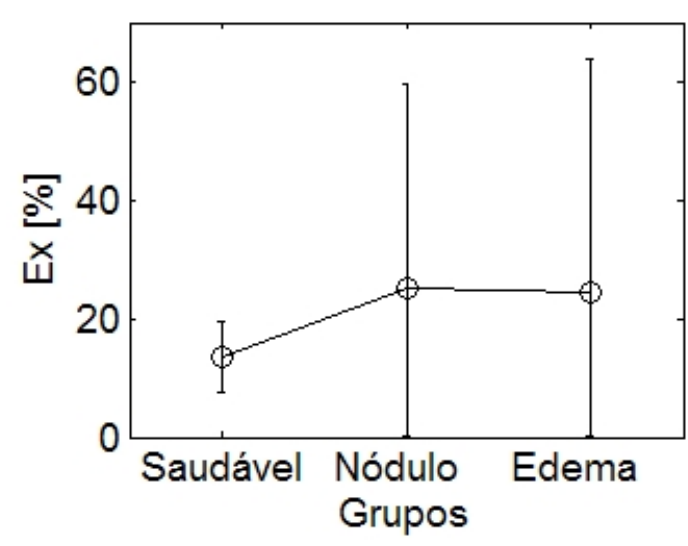

(f)

Figura 4.5: Valores médios e desvios padrões dos parâmetros acústicos dos sinais de voz usados neste estudo. Os valores estão divididos nos três grupos: saudáveis, nódulo e edema de Reinke, e foram obtidos pelo software Análise de Voz 6.0. (a) Jitter. (b) Shimmer. (c) Nivelamento espectral do resíduo (SFR). (d) Nivelamento espectral do filtro (SFF). (e) Amplitude de pitch (PA). (f) Coeficiente de excesso (EX). 


\subsection{Modelos de Previsão dos Sinais}

Para realizar a previsão dos sinais de voz, utilizaram-se dois modelos: autorregressivo e um modelo baseado em decomposição por wavelets. Inicialmente, apresenta-se uma introdução de modelos AR e um exemplo de aplicação em sinais de voz com rastreamento de pólos. Em seguida, mostra-se como a decomposição por banco de filtros wavelets Daubechies pode ser aplicada como modelo de previsão para o método da previsibilidade.

Após a apresentação desses dois modelos de previsão de sinais temporais, mostrase o modelo usado para as representações multidimensionais dos sinais de voz. Além disso, comentam-se mais sobre algumas particularidades desse tipo de representação.

\subsubsection{Modelo Autorregressivo}

Os modelos AR são parte de um tipo mais geral de modelos conhecidos como autorregressivos e média móvel, ARMA (Autoregressive Moving Average) (Hayes, 1996), os quais são caracterizados por ter função de transferência racional. Como uma definição simples, considera-se o modelo AR como uma relação linear de diferenças entre a entrada e a saída de um sistema, de forma que essa saída seja composta por versões atrasadas de si mesma. Por esse motivo que o modelo é chamado de autorregressivo. Geralmente, a saída $y[n]$ é uma seqüência altamente correlacionada, a qual modela as amostras de dados, e a entrada $x[n]$ é, normalmente, ruído branco. Para o caso em estudo, a seqüência a ser modelada é um sinal de voz. A relação citada é uma equação linear, como mostra a Equação (4.1).

$$
y[n]=-\sum_{k=1}^{p} a[k] y[n-k]+b[0] x[n]
$$

O limite superior do somatório, $p$, é a ordem do modelo e também é o número de pólos da função do sistema $H(z)$, apresentada na Equação (4.2). Os termos $a[k]$ são os coeficientes do modelo e $a[0]$ e $b[0]$ são, normalmente, considerado igual a unidade. 


$$
H(z)=\frac{b[0]}{1+\sum_{k=1}^{p} a[k] z^{-k}}=\frac{1}{\sum_{k=0}^{p} a[k] z^{-k}}
$$

Portanto, com o modelo AR pode-se gerar uma estimativa da saída do sistema $\hat{y}[n]$, sendo o erro de estimativa, $e[n]$, dado pela Equação (4.3). A estimativa da saída, usando os coeficientes $a[k]$, é dada pela Equação (4.4).

$$
\begin{gathered}
e[n]=y[n]-\hat{y}[n] \\
\hat{y}[n]=-\sum_{k=1}^{p} a[k] y[n-k]
\end{gathered}
$$

Assim, usando as duas equações anteriores, o erro de estimativa pode ser reescrito conforme a Equação 4.5.

$$
e[n]=\sum_{k=0}^{p} a[k] y[n-k]
$$

\section{Método da Autocorrelação}

Para se realizar previsões de um sistema usando esse modelo, deve-se, primeiramente, obter os coeficientes $a[k]$. Busca-se modelar um sinal desse sistema usando AR, porém esse sinal possui um conjunto de amostras finito de tamanho $N$. Em Hayes (1996), apresentam-se diversos métodos para isso, sendo um dos mais simples o método da autocorrelação. O princípio de funcionamento dessa técnica, de forma resumida, é a aplicação do método de Prony considerando que o sinal é nulo fora de seu conjunto $[0, N]$, ou seja utiliza-se uma janela retangular.

Esse método é baseado na busca da solução de um conjunto de equações lineares obtidas com o uso da função de autocorrelação do sinal. A função de autocorrelação, $r[k]$, de um sinal digital real $y[n]$, sendo $y[n]=0$ para $n<0$, é apresentada no lado esquerdo da Equação (4.6). Como o sinal possui somente $N$ pontos, pode-se estimar a 
função de autocorrelação conforme o lado direito da Equação (4.6).

$$
r[k]=\sum_{n=0}^{\infty} y[n] y[n-k] \Rightarrow r[k]=\sum_{n=k}^{N} y[n] y[n-k]
$$

Então, usando-se $r[k]$, pode-se encontrar os coeficientes $a[k]$ utilizando a Equação (4.7) obtida da derivação do método de Prony (Hayes, 1996).

$$
\sum_{k=1}^{p} \sum_{l=1}^{p} a[l] r[k-l]=-r[k]
$$

A solução é encontrada pela aplicação do algoritmo de Levinson-Durbin (Hayes, 1996; Haykin, 2001). Assim, garante-se a estabilidade da aproximação do modelo, pois todos os pólos de $H(z)$ ficam dentro do circulo unitário no plano $z$, conforme as condições de estabilidade de sistemas lineares invariantes no tempo (Oppenheim et al., 1999). Outra forma de se encontrar a solução é encontrando a solução de mínimos quadrados de um conjunto de equações lineares sobre-determinado obtido a partir do erro de estimativa, Equação (4.5). Deseja-se que o erro seja nulo, ou seja, faz-se $e[n]=$ 0, chegando-se na Equação (4.8). Nesse caso, $n>0$, pois $y[n-k]=0$ para $n<1$ e $k=1$.

$$
\sum_{k=0}^{p} a[k] y[n-k]=0 \Rightarrow \sum_{k=1}^{p} a[k] y[n-k]=-y[n]
$$

Essa equação pode ser re-escrita conforme apresentado pela Equação (4.9), sendo $\mathbf{Y}_{p}$ uma matriz $(N+p) \times p$ de versões atrasadas do sinal; $\mathbf{a}_{p}$, o vetor, de tamanho $p$, dos coeficientes do modelo AR; e $\mathbf{y}_{1}$, um vetor, de tamanho $(N+p)$, do sinal a partir do segundo ponto. A versão na forma matricial é dada pela Equação (4.10).

$$
\mathbf{Y}_{p} \mathbf{a}_{\mathbf{p}}=-\mathbf{y}_{\mathbf{1}}
$$




$$
\left[\begin{array}{ccccc}
y[0] & 0 & 0 & \cdots & 0 \\
y[1] & y[0] & 0 & \cdots & 0 \\
y[2] & y[1] & y[0] & \cdots & 0 \\
\vdots & \vdots & \vdots & \ddots & 0 \\
y[N] & y[N-1] & y[N-2] & \cdots & y[N-p+1] \\
0 & y[N] & y[N-1] & \cdots & y[N-p+2] \\
\vdots & \vdots & \vdots & \ddots & \vdots \\
0 & 0 & 0 & \cdots & y[N]
\end{array}\right]\left[\begin{array}{c}
a[1] \\
a[2] \\
a[3] \\
\vdots \\
a[p]
\end{array}\right]=-\left[\begin{array}{c}
y[1] \\
y[2] \\
\vdots \\
y[N] \\
0 \\
0 \\
\vdots \\
0
\end{array}\right]
$$

Assim, conforme Hayes (1996), os coeficientes do modelo AR por mínimos quadráticos é obtida pela solução da Equação (4.11), sendo $\{.\}^{H}$ o operador hermitiano, o qual se reduz à transposição da matriz para o caso real.

$$
\left(\mathbf{Y}_{p}^{H} \mathbf{Y}_{p}\right) \mathbf{a}_{\mathbf{p}}=\mathbf{Y}_{p} \mathbf{Y}_{\mathbf{1}}
$$

Essa forma de estimativa dos coeficientes AR foi utilizada neste estudo conforme será melhor apresentado no próximo capítulo.

\section{Aplicação em Sinais de Voz}

De acordo com vários trabalhos (Rabiner e Schafer, 1978, 2007), sabe-se que o modelo AR é adequado para modelar o sistema de produção de voz. Isso pode ser observado pela semelhança das Equações (2.2) e (4.2), respectivamente o modelo teórico da produção de voz e a função do sistema do modelo AR. Uma possível aplicação desse modelo em sinais de voz é a decomposição autorregressiva seguida de rastreamento de pólos.

Essa análise se baseia no fato de que os pólos da decomposição do sinal estão relacionados com sua densidade espectral de potência. A PSD é dividida em curvas com formato de sino, sendo a potência e a frequiência características obtidas das posições e resíduos dos pólos (Mainardi, 1995; Cazares, 2001; El-Jaroudi e Makhoul, 1989). 
Com base na variação das freqüências dos pólos dos sinais de voz, pode-se ter uma relação qualitativa do aumento do jitter dos sinais.

A Equação (4.2) pode ser representada em termos dos pólos do modelo AR, $z_{k}$, conforme a Equação (4.12). Cada par de pólos complexos conjugados de $H(z)$ corresponde à freqüência de um pico do espectro de potência do sinal.

$$
H(z)=\frac{1}{\prod_{k=1}^{p}\left(1-z_{k} z^{-1}\right)}
$$

As freqüências centrais $\left(f_{k}\right)$ desse picos do espectro de potência são obtidas pelos ângulos $\left(\theta_{k}\right)$ dos pólos da metade superior do plano complexo, conforme a Equação (4.13), sendo $f_{s}$ a frequiência de amostragem do sinal.

$$
f_{k}=\frac{\theta_{k}}{2 \pi} f_{s}
$$

A magnitude dos picos do espectro são obtidas pelo resíduo dos pólos conforme (Cazares, 2001; Oppenheim et al., 1999). Assim, quanto mais perto o pólo estiver do círculo unitário no plano $z$, maior será seu pico correspondente no espectro de potência.

A Figura 4.6 apresenta um exemplo de PSD de um sinal de voz mostrando as sete primeiras harmônicas (freqüências até $1,6 \mathrm{kHz}$ ), sendo que a frequiência de amostragem é 22,05 kHz. Utilizou-se uma modelagem AR de ordem 84, a qual foi escolhida por apresentar os menores erros de estimativa das freqüências dos pólos. Esses valores de freqüência, para os sete primeiros pares de pólos, são indicados na figura por um "x", o módulo dos pólos não é representado.

Considerando a presença de alguma patologia na laringe que resulte em aumento dos valores de jitter, espera-se um aumento proporcional dos erros de estimativa das freqüências dos picos da PSD obtidas dos pólos do modelo AR. Isso se deve a uma maior variabilidade das freqüências centrais e, como conseqüência, as potências dos picos da PSD decrescem, espalhando suas energias pelas freqüências vizinhas.

Para se ilustrar o uso do modelo AR em sinais de voz, apresenta-se a Figura 4.7, em (a), tem-se um sinal de voz saudável e, em (b), a PSD. Nas partes (c) e (d), mostram-se 


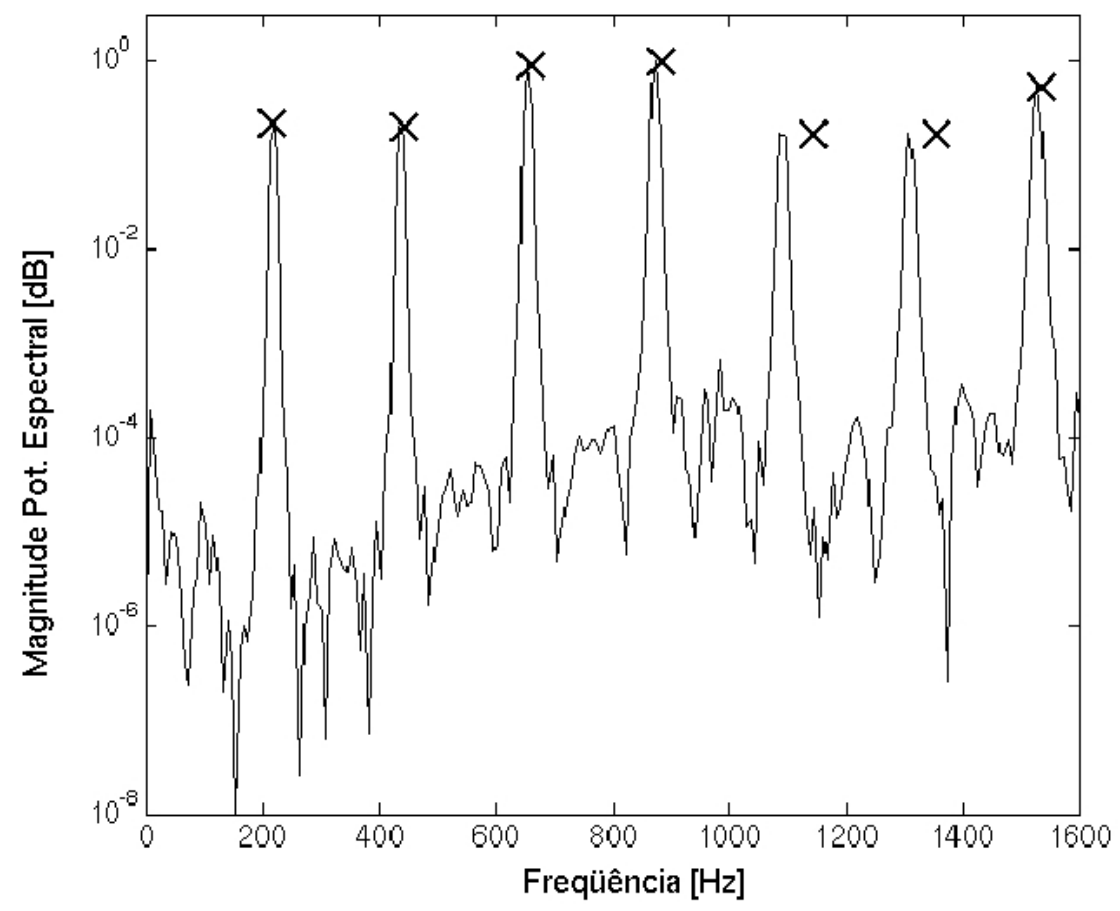

Figura 4.6: Densidade espectral de potência de um sinal de voz saudável mostrando freqüências até $1600 \mathrm{~Hz}$. As freqüências estimadas a partir dos sete primeiros pares de pólos da decomposição AR são indicadas com um "x", porém as magnitudes de potência dos pólos não estão representados.

o sinal estimado usando modelo AR(26) e a PSD da estimativa. Visualmente, os dois sinais são quase indiferenciáveis, porém, na freqüência, as diferenças são mais claras, principalmente nas freqüências mais altas. Isso, pois o modelo tem deficiências em modelar variações abruptas do sinal. Nas partes (e) e (f), apresentam-se o sinal de erro de estimativa (também conhecido como sinal residual) e sua PSD, a qual tem magnitude menor que -60 $d B$, caracterizando uma alta capacidade de previsão do modelo.

Como visto nesse exemplo, utiliza-se ordem igual a 26 para modelar os sinais de voz. Essa escolha deve-se a uma recomendação de que a ordem do modelo deve ser em torno de 4 a 5 unidades acima da freqüência de amostragem em $k H z$ (Rabiner e Schafer, 1978). Assim, como o valor é de 22,05 kHz para os sinais usados, tem-se a ordem igual a 26. 


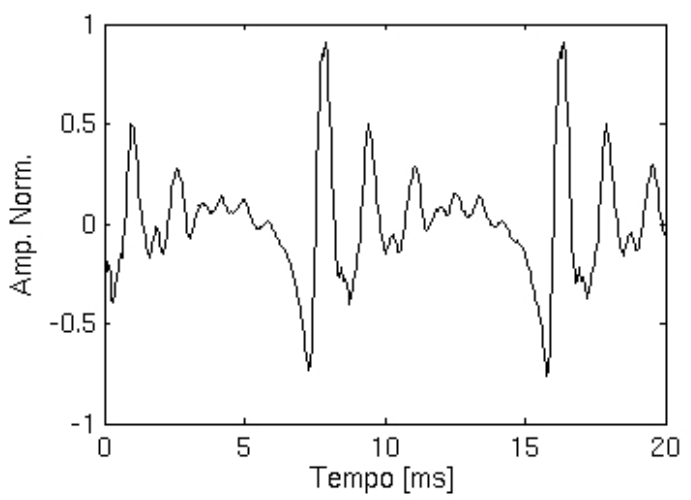

(a)

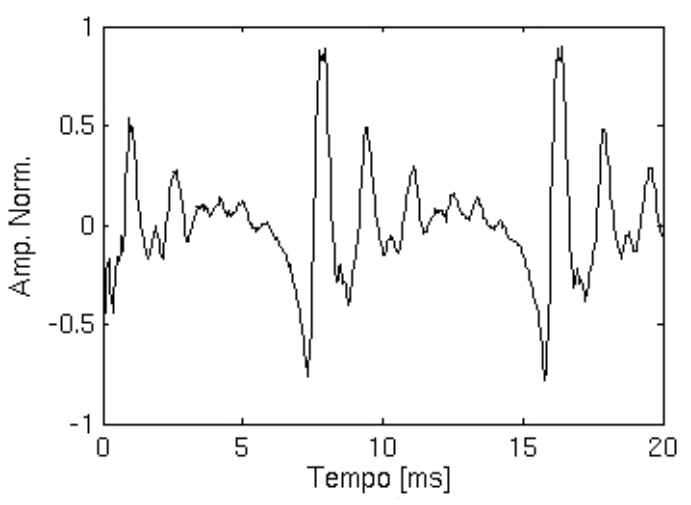

(c)

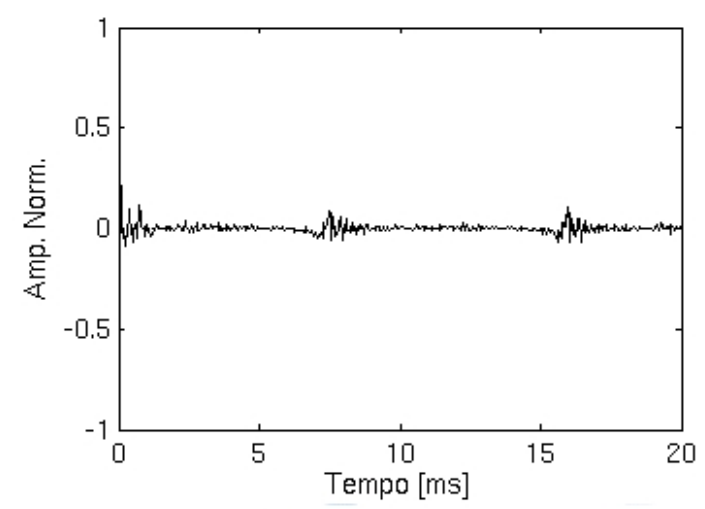

(e)

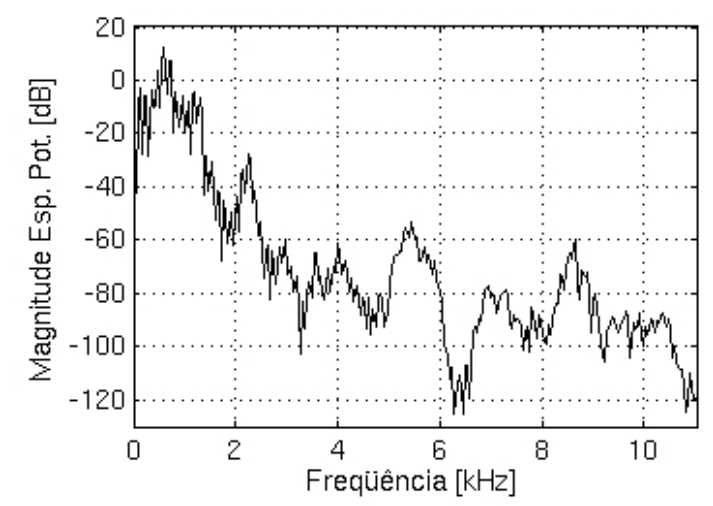

(b)

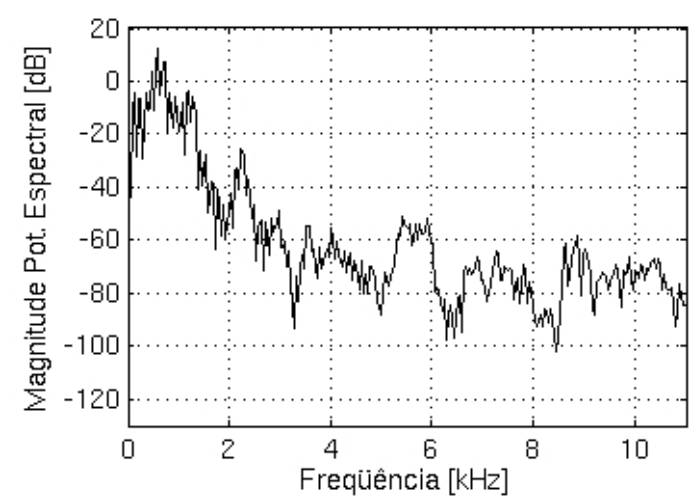

(d)

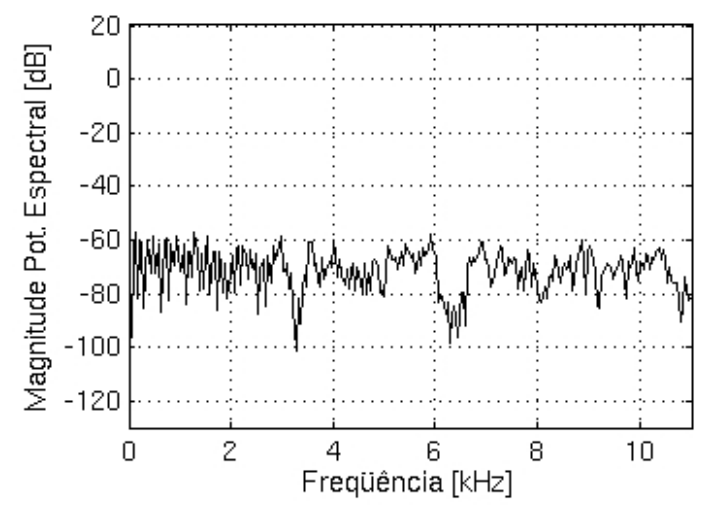

(f)

Figura 4.7: Ilustração da estimativa de um sinal de voz usando modelo autorregressivo usando ordem 26. (a) Sinal de voz saudável. (b) PSD do sinal saudável. (c) Estimativa do sinal de voz. (d) PSD do sinal estimado. (e) Erro de estimativa do modelo. (f) PSD do erro de estimativa. 
O modelo AR apresenta excelentes resultados em aplicações de processamento de sinais de voz (Markel e Gray, 1976; Rabiner e Schafer, 1978) e, além disso, é sugerido por Schneider e Griffies (1999) como um modelo interessante para ser usado junto com o método de previsibilidade. Entretanto, em testes com sinais simulados de voz e medidas de previsibilidade, observou-se que o modelo apresentou baixa sensibilidade ao jitter e shimmer, os quais são características marcantes de sinais de muitas patologias.

Provavelmente, essa característica é resultado de uma alta capacidade do modelo AR em realizar previsões de sinais de voz, mesmo em casos patológicos. Dessa forma, os erros de previsão de sinais saudáveis e patológicos são muito parecidos, possuíndo distribuições muito próximas da Gaussiana. Por essa razão, como o método da previsibilidade se baseia na quantidade de informação presente nesse erro, a qual é medida pela entropia que se baseia no histograma, as diferenças obtidas são muito pequenas.

Assim, na próxima subseção, apresenta-se uma alternativa ao modelo AR, um modelo baseado em decomposição por wavelets. Esse novo modelo apresentou bons resultados com sinais simulados, mostrando maior sensibilidade ao jitter e shimmer.

\subsubsection{Modelo de Decomposição por Wavelets}

Nesta seção, apresenta-se uma alternativa ao modelo AR, trata-se de um modelo baseado em decomposição de sinais por transformada wavelet. Basicamente, essa decomposição utiliza um banco de filtros do tipo wavelet, assim, antes de se apresentar o modelo, realiza-se uma breve descrição dos princípios da DWT e de banco de filtros.

\section{Banco de Filtros e Wavelets}

$\mathrm{O}$ uso de processamento multitaxa de sinais (multi-rate) se tornou comum nos últimos anos, especialmente a partir do final da década de 1980, com a introdução da DWT (Akansu e Haddad, 2001). Nessas técnicas, usam-se operações de decimação e interpolação para mudar as taxas de amostragem dos sinais. Isso é muito útil quando é necessário trabalhar com diversas bandas de freqüência do sinal e manter o número de amostras total após uma decomposição. 
Os sistemas que decompõem sinais em bandas de freqüência e são capazes de reconstruí-los perfeitamente são chamados de banco de filtros. A partir da teoria dos bancos de filtro, desenvolveram-se as transformadas wavelet, as quais são um tipo de análise funcional que é capaz de representar e analisar sinais que possuem tempo e freqüência com resoluções variáveis (Diniz et al., 2002).

A transformada wavelet pode ser entendida, de forma simplificada, como uma modificação da transformada de Fourier (DFT - Discrete Fourier Transform) para melhor analisar sinais não-estacionários (Bolzan, 2006). Para esse tipo de sinais, a DFT não consegue apresentar uma análise completa das freqüências, pois não mostra a variação de seus componentes. Uma solução para isso foi a introdução da DFT tempofreqüência, a qual usa uma janela móvel no tempo para analisar o sinal, entretanto o tamanho dessa janela é constante na análise (Therrien, 1992).

Com base nessa idéia de janelas e considerando o problema que a função base da DFT, as senóides, são ilimitadas no tempo, desenvolveu-se a transformada wavelet. As primeiras pesquisas foram feitas por Alfred Haar em 1909. Entretanto, as bases da DWT foram desenvolvidas por Jean Morlet e Alex Grossman na década de 1980. Para resolver o problema da função base infinita, introduziram o conceito de wavelet. A palavra wavelet surgiu da palavra francesa ondelette que significa "pequena onda". Utilizando dilatações e translações dessa função finita, que possui características especiais, poderia-se cobrir todo o eixo dos números reais (Bolzan, 2006).

Os bancos de filtros tem como função a decomposição de um sinal em bandas de freqüências usando filtros seletivos. Um sinal que seja decomposto em $M$ bandas sem aliasing, ou seja, sem efeito destrutivo de sobreposição das faixas de freqüência; pode ser reconstruído simplesmente somando-se as bandas. Entretanto, se os sinais de cada banda forem decimados por $M$ pode ser impossível reconstruir o sinal.

A Figura 4.8, modificada de Diniz et al. (2002), apresenta um banco de filtros genérico para ilustrar a análise e síntese de um sinal. Nessa figura, os filtros seletivos $H_{k}(z)$, sendo $k=1, \ldots, M$, são os chamados filtros de análise de decomposição do sinal de entrada $x(n)$, os blocos com setas para baixo são os decimadores que diminuem o número de amostras dos sinais filtrados. Os sinais das bandas de freqüência são nomeados $u_{k}$. Para a reconstrução do sinal original, usam-se os interpoladores, 
blocos com setas para cima, e os filtros de síntese, $G_{k}(z)$. O sinal $y(n)$ pode ser igual ao sinal original se algumas condições forem satisfeitas.

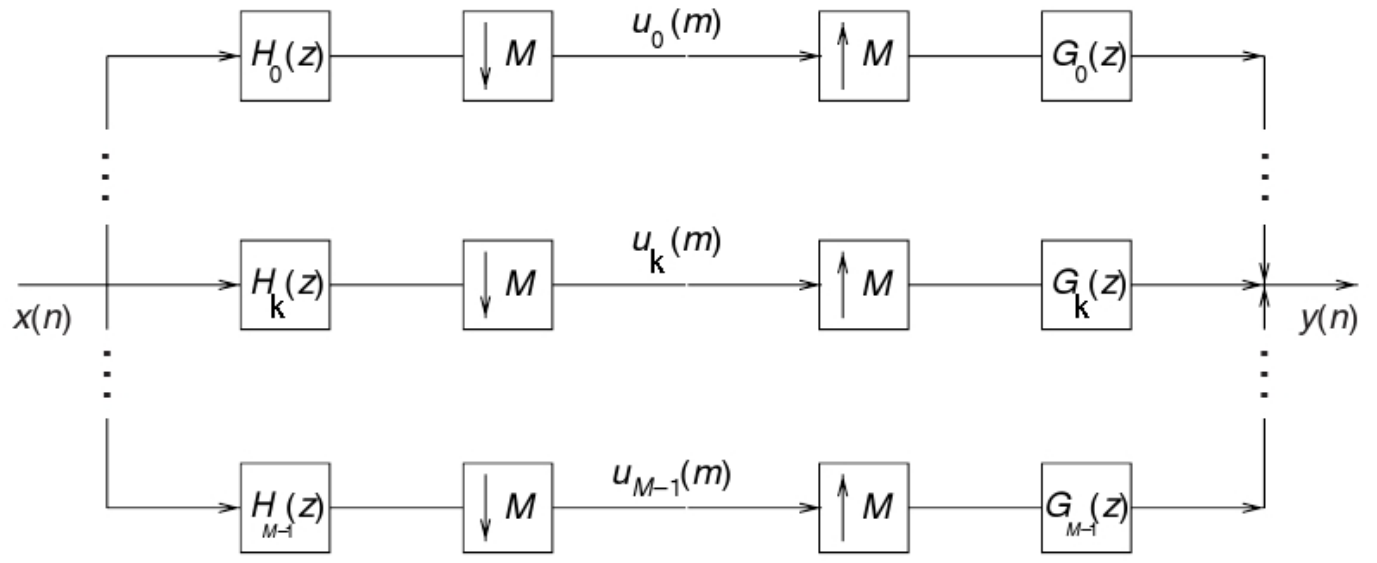

Figura 4.8: Banco de filtros genérico para demonstrar a análise e síntese de um sinal. Sendo $k=1, \ldots, M, H_{k}(z)$ são os filtros de análise e $G_{k}(z)$, os filtros de síntese. Os blocos com seta para baixo são os decimadores e os blocos com seta para cima, os interpoladores.

A decimação consiste em reduzir a taxa de amostragem de um sinal pela retirada de amostras. A interpolação é o processo inverso, adicionam-se amostras pela interpolação dos pontos (Oppenheim et al., 1999). Quando o sinal original pode ser reconstruído a partir das bandas, esse sistema é chamado de banco de filtros de $M$ bandas de reconstrução perfeita. Um fator importante é o projeto dos filtros, os quais não são ideais, portanto o sistema está sujeito a aliasing.

Porém, como os sinais reconstruídos de cada banda são somados para se obter o sinal final, esses efeitos podem ser cancelados. Para ilustrar esse procedimento, apresenta-se um exemplo na Figura 4.9, modificada de Diniz et al. (2002), para um caso específico de banco de filtros de duas bandas. Apresentam-se formas de onda típicas das respostas em frequiência dos filtros $H_{0}(z), H_{1}(z), G_{0}(z)$ e $G_{1}(z)$.

Na Figura 4.10, modificada de Diniz et al. (2002), mostra-se o resultado da aplicação de um sinal de entrada em rampa no banco de filtros da figura anterior. Também, apresentam-se os sinais intermediários de análise e síntese (reconstrução). Assim, pode-se ver que os efeitos de aliasing se cancelam quando os sinais filtrados por $G_{0}(z)$ e $G_{1}(z)$ são somados para obtenção do sinal reconstruído.

Esse cancelamento é perfeito quando os filtros são projetados corretamente e pode ser generalizado para um banco de filtros com $M$ bandas. Com isso, nota-se que, 


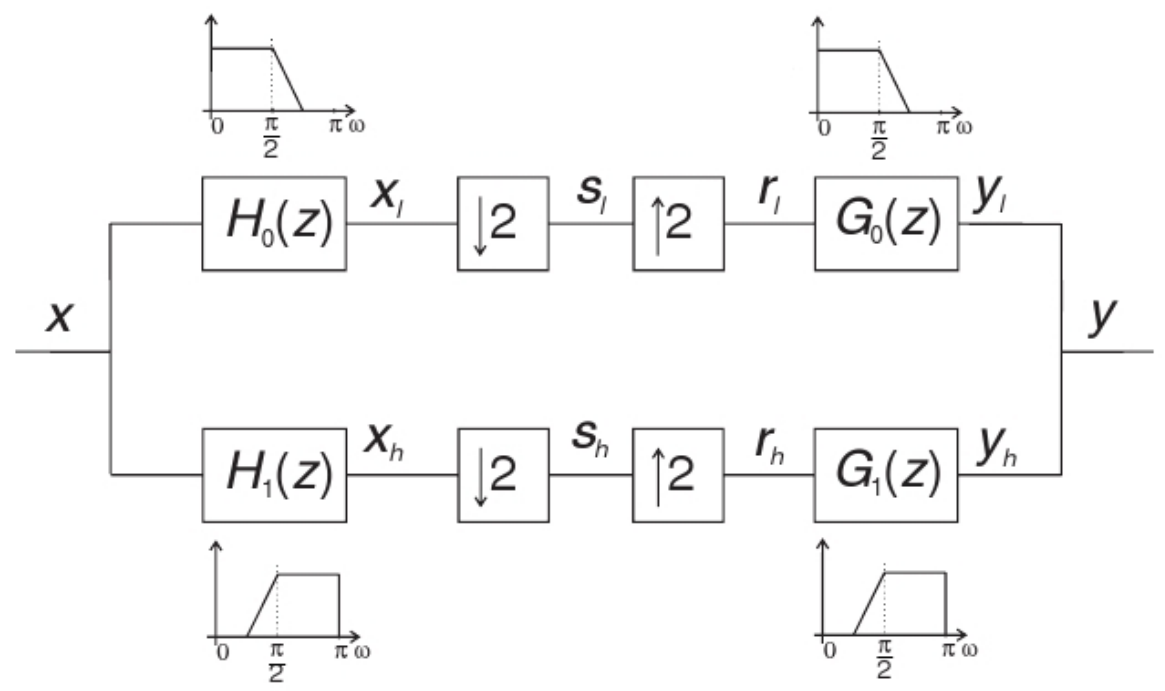

Figura 4.9: Bancos de filtros de duas bandas mostrando formas de onda típicas das respostas em freqüência dos filtros $H_{0}(z), H_{1}(z), G_{0}(z)$ e $G_{1}(z) . H_{0}$ e $G_{0}$ são filtros passa-baixas, já $H_{1}$ e $G_{1}$, passa-altas.

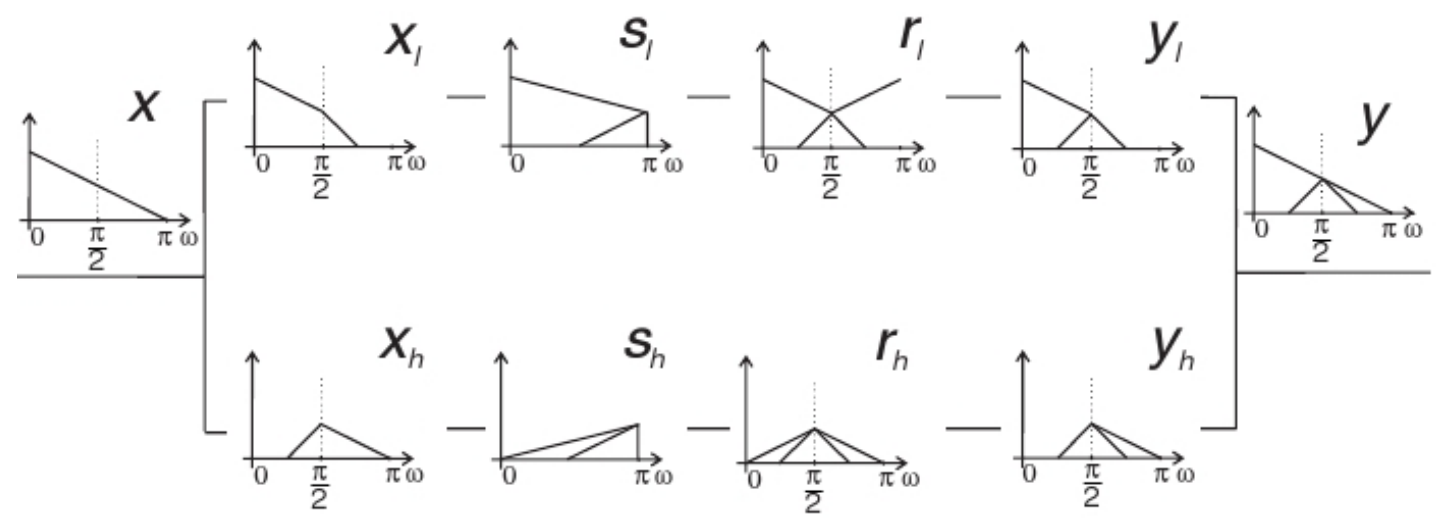

Figura 4.10: Exemplo das formas de onda do banco de filtros de duas bandas da Figura 4.9 para uma entrada em rampa. Pode-se ver o efeito do cancelamento do aliasing na reconstrução do sinal decomposto quando os filtros são projetados de forma correta.

mesmo para filtros não-ideais com bandas que possuam bastante aliasing, ainda se pode conseguir reconstrução perfeita pelo cancelamento entre as bandas.

Uma das formas mais comuns para projetar os filtros de um banco de duas bandas é usando o banco QMF (quadrature mirror filter - filtro espelhado em quadratura). Nesse banco, o filtro passa-alta de análise é projetado de forma a alternar os sinais das amostras da resposta impulsiva do filtro passa-baixa, Equação (4.14).

$$
H_{1}(z)=H_{0}(-z)
$$


Assim, considerando que os filtros possuam coeficientes reais, essa escolha resulta no módulo de $H_{1}(z)$ sendo um reflexo (imagem invertida) do módulo de $H_{0}(z)$ em relação à freqüência $\pi / 2$, chamada de freqüência de quadratura (Diniz et al., 2002).

Para os filtros de síntese, $G_{0}(z)$ e $G_{1}(z)$, de forma a evitar aliasing, usam-se as relações apresentadas nas Equações (4.15) e (4.16). Dessa forma, os efeitos são cancelados após as etapas de análise e síntese. Portanto, todo o projeto se resume em especificar $H_{0}(z)$. Esse método de projeto pode ser generalizado para bancos de filtros com $M$ bandas.

$$
\begin{aligned}
& G_{0}(z)=H_{1}(-z) \\
& G_{1}(z)=-H_{0}(-z)
\end{aligned}
$$

De forma semelhante, mas objetivando aumentar a seletividade dos filtros permitidos para se obter reconstrução perfeita, foi proposto o banco CQF (conjugate quadrature filter - filtro conjugado em quadratura). Nesse tipo de banco, projeta-se o filtro passa-alta como a resposta impulsiva do passa-baixa com tempo invertido e sinais alternados, Equação (4.17), sendo $N$ a ordem do filtro, normalmente do tipo FIR (finite impulse response).

$$
H_{1}(z)=-z^{-N} H_{0}\left(-z^{-1}\right)
$$

Para garantir a reconstrução perfeita, usam-se os filtros de síntese, $G_{0}(z)$ e $G_{1}(z)$, conforme as Equações (4.18) e (4.19).

$$
\begin{aligned}
& G_{0}(z)=z^{-N} H_{0}\left(z^{-1}\right) \\
& G_{1}(z)=-H_{0}(-z)
\end{aligned}
$$


Estabelecidos esses conceitos básicos, considera-se a transformada wavelet. Conforme Diniz et al. (2002), seja uma função que pertença ao espaço de funções quadráticas integráveis, ou seja, com energia finita (Bolzan, 2006), sua DWT é uma decomposição em uma base formada por expansões, compressões e translações de uma única função mãe, chamada wavelet. Essa decomposição é equivalente a um caso especial de banco de filtros decimados criticamente (Diniz et al., 2002; Vetterli e Herley, 1992).

Muitos tipos de decomposição podem ser feitas usando arranjos de bancos de filtros de duas bandas, uma forma comum é a chamada decomposição de banda oitava (do inglês octave band). Na Figura 4.11, modificada de Diniz et al. (2002), mostra-se um exemplo em dois estágios desse tipo de decomposição, sendo omitida a parte de síntese por ser análoga a análise.

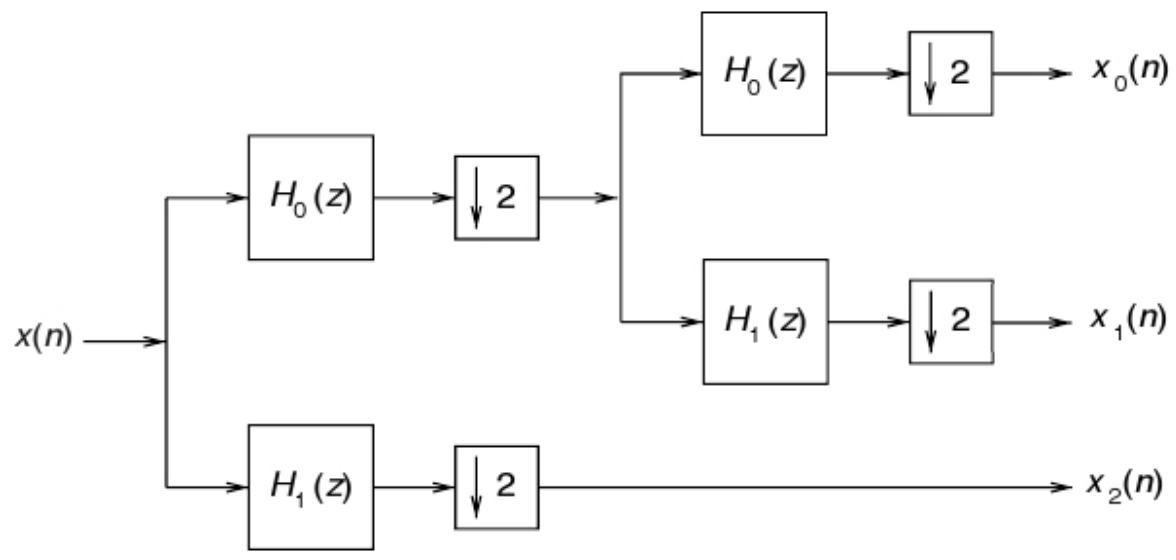

Figura 4.11: Exemplo da decomposição de um sinal por banda oitava de dois estágios. As bandas provenientes de filtragem passa-baixa continuam o processo, mas as bandas vindas de passa-alta não são mais filtradas.

Considerando esse banco de filtros da figura, se $H_{0}(z)$ possuir zeros suficientes em $z=-1$, o envelope da resposta impulsiva do filtro passa-alta de análise possui sempre o mesmo formato para todos os níveis de decomposição (Diniz et al., 2002; Mallat, 1999). Assim, esse envelope pode ser representado por expansões e contrações de uma única função wavelet $\psi(t)$ como apresentado na Figura 4.12, modificada de Diniz et al. (2002). Então, para cada novo estágio da decomposição, a resposta impulsiva fica com o dobro da largura e a taxa de amostragem fica com a metade do valor anterior.

É interessante observar que, quando a wavelet é expandida, sua largura de banda diminui como apresentado na Figura 4.13, modificada de Diniz et al. (2002). Assim, 


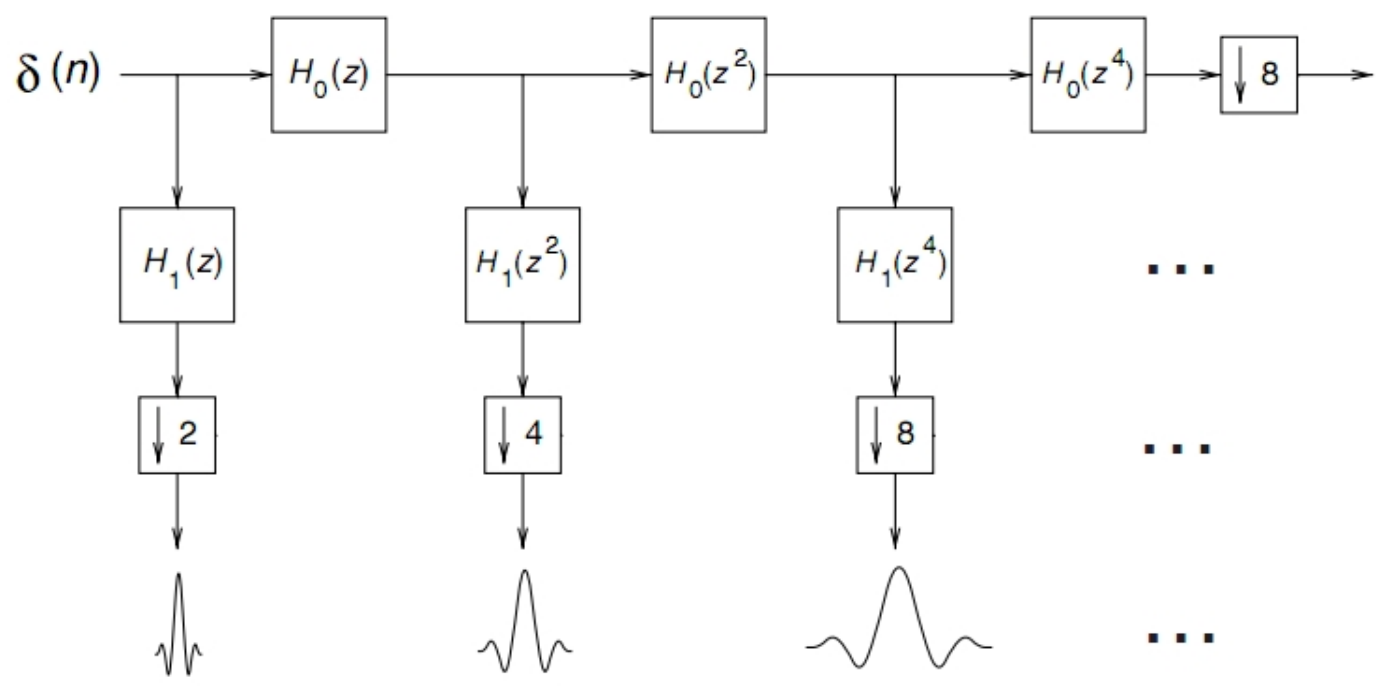

Figura 4.12: Exemplo das contrações e expansões da função wavelet em três estágios de uma decomposição em duas bandas de um sinal impulsivo.

quando se realiza uma decomposição como a da Figura 4.12, tem-se que, no espectro de potência, as larguras de banda das wavelets (comprimidas e expandidas) se comportam como ilustrado na Figura 4.14, modificada de Diniz et al. (2002). Percebe-se que as bandas se cruzam, cobrindo todas as freqüências desejadas.
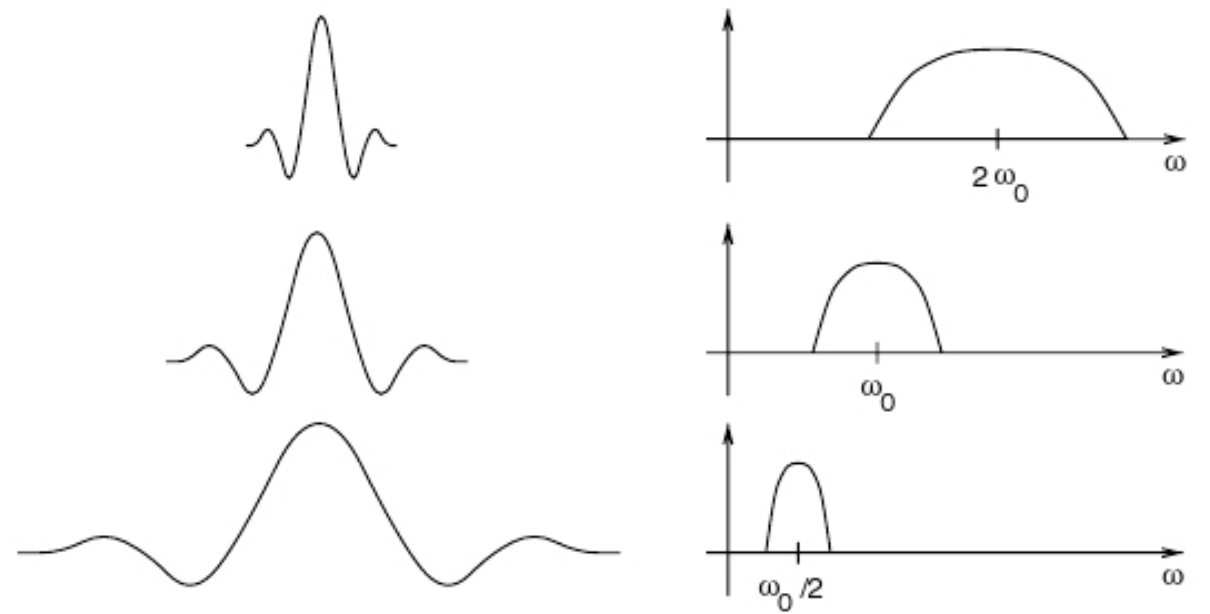

Figura 4.13: Ilustração da relação entre a compressão-expansão das wavelets e a largura de banda correspondente no espectro de potência.

Na prática, o número de estágios da decomposição é finito, após $S$ estágios, têm-se $S$ canais de passa-banda e um canal de passa-baixa. Se $H_{0}(z)$ possuir zeros suficientes em $z=-1$, os envelopes dos filtros passa-baixa de análise serão expansões e contrações de uma única função $\phi(t)$, chamada função de escala, de forma semelhante à função wavelet. 


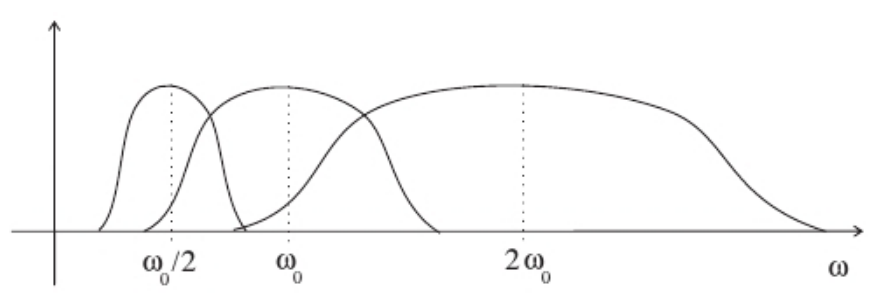

Figura 4.14: Ilustração do cruzamento das bandas de frequiência das diversas wavelets relacionadas com uma decomposição semelhante a da Figura 4.12.

Apesar dos sinais serem decompostos como combinações de funções de escala e wavelet, utilizam-se os filtros passa-baixa e passa-alta para realizar esse processo. Consideram-se as respostas impulsivas dos filtros passa-baixa e passa-alta de análise como $h_{0}(n)$ e $h_{1}(n)$ respectivamente, e $g_{0}(n)$ e $g_{1}(n)$ como os filtros de síntese. Também, consideram-se as funções de escala de análise e síntese como $\phi(t)$ e $\bar{\phi}(t)$ respectivamente, e $\psi(t)$ e $\bar{\psi}(t)$, as funções wavelet de análise e síntese. Assim, as relações entre os filtros e as funções de escala e wavelet são dadas pelas Equações (4.20) a (4.23) (Diniz et al., 2002; Vetterli e Herley, 1992).

$$
\begin{aligned}
& h_{0}(n)=\int_{-\infty}^{\infty} \phi(t) \sqrt{2} \bar{\phi}(2 t+n) d t \\
& h_{1}(n)=\int_{-\infty}^{\infty} \bar{\phi}(t) \sqrt{2} \phi(2 t-n) d t \\
& g_{0}(n)=\int_{-\infty}^{\infty} \psi(t) \sqrt{2} \bar{\phi}(2 t+n) d t \\
& g_{1}(n)=\int_{-\infty}^{\infty} \bar{\psi}(t) \sqrt{2} \phi(2 t-n) d t
\end{aligned}
$$

Quando $\phi(t)=\bar{\phi}(t)$ e $\psi(t)=\bar{\psi}(t)$, a DWT é caracterizada como ortogonal, senão, é somente biortogonal. Um bom exemplo de wavelet ortogonal e de banco de filtros CQF é a família Daubechies com comprimento 4 (Daubechies, 1992). Ao contrário das wavelets biortogonais, as ortogonais não são necessariamente simétricas (com fase linear). Essa família de wavelets é muito utilizada para análise de sinais de voz (Fonseca et al., 2007; Guido et al., 2006).

Essas wavelets foram criadas por Ingrid Daubechies em 1988, tendo a característica de serem ortonormais de suporte compacto (orthonormal compactly support wavelet) e terem magnitude maximamente plana (maximally flat). A regularidade da função 


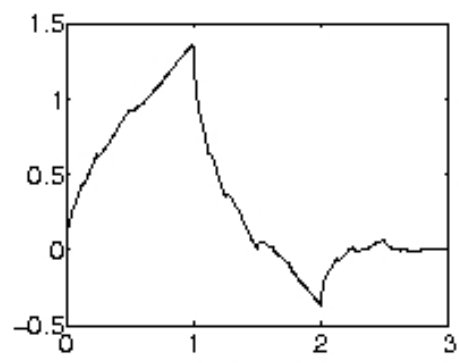

(a)

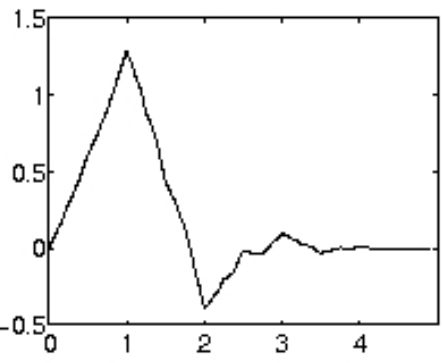

(b)

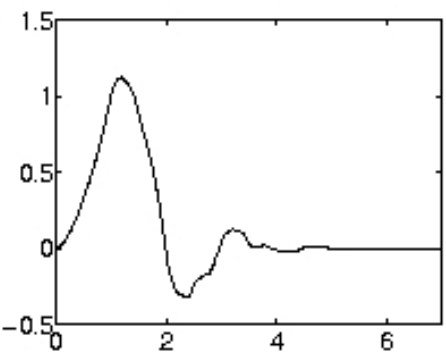

(c)

Figura 4.15: Funções de escala da família Daubechies para ordens de filtro iguais a 2, 3 e 4 nas partes (a), (b) e (c) respectivamente.

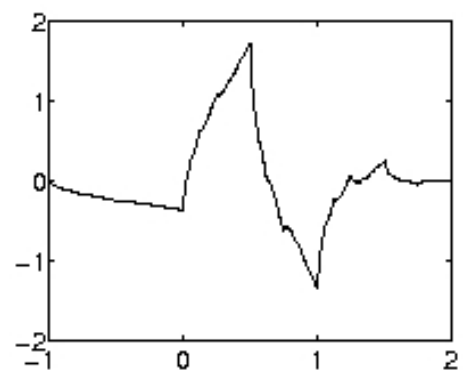

(a)

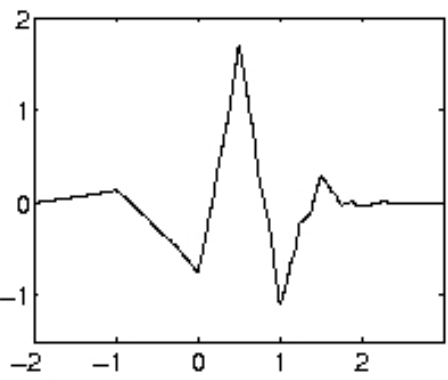

(b)

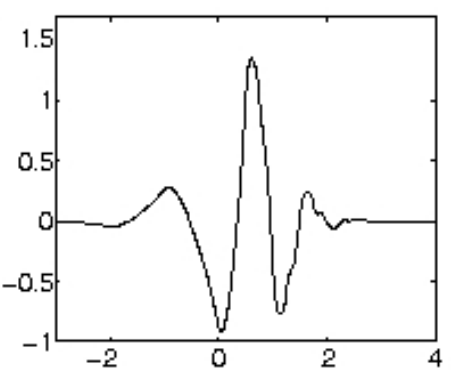

(c)

Figura 4.16: Funções wavelet da família Daubechies para ordens de filtro iguais a 2, 3 e 4 nas partes (a), (b) e (c) respectivamente.

wavelet aumenta linearmente com o aumento de sua ordem, ou seja, do tamanho do filtro FIR passa-baixa (Akansu e Haddad, 2001).

As Figuras 4.15 e 4.16, modificadas de Mallat (1999), apresentam, respectivamente, as funções de escala e wavelet da família Daubechies para ordens do filtro iguais a 2, 3 e 4 . A wavelet Daubechies de primeira ordem também é conhecida como a wavelet Haar, a qual é uma caso específico proposto por Alfréd Haar em 1909.

As funções wavelet ainda possuem mais três características: média nula; normalização, ou seja, $\|\psi(t)\|=1$; e é centrada na vizinhança de $t=0$. A Equação (4.24) apresenta a forma de compressão-expansão da wavelet, a qual é escalada pela variável $s$ e deslocada por $u$.

$$
\psi_{u, s}(t)=\frac{1}{\sqrt{s}} \psi\left(\frac{t-u}{s}\right)
$$

Para se definir a DWT, o banco de filtros correspondente deve ser de reconstrução perfeita (Diniz et al., 2002). Além disso, para garantir a existência da DWT, algu- 
mas condições de regularidade são impostas. A regularidade de uma função de escala ou wavelet está relacionada com o número de derivadas contínuas que a função possui (Diniz et al., 2002). As Equações (4.25) e (4.26) apresentam duas condições de normalização impostas aos filtros $H_{0}(z)$ e $G_{0}(z)$.

$$
\begin{aligned}
H_{0}(1) & =G_{0}(1)=\sqrt{2} \\
H_{0}(-1) & =G_{0}(-1)=0
\end{aligned}
$$

Conforme Mallat (1999), a DWT decompõe sinais sobre wavelets escaladas e deslocadas. Dessa forma, usa-se a DWT para analisar estruturas de diferentes tamanhos em um sinal, fazendo-se divisões em tempo-freqüência de tamanhos temporais diferentes. A DWT possui a propriedade de conservação de energia nos estágios da decomposição. Considerando um sinal $x(t)$, sua DWT é dada pela equação (4.27).

$$
W_{x}(u, s)=\left\langle x, \psi_{u, s}\right\rangle=\int_{-\infty}^{\infty} x(t) \frac{1}{\sqrt{s}} \psi^{*}\left(\frac{t-u}{s}\right) d t
$$

Essa equação mede a variação de $x(t)$ com tamanho proporcional a $s$ na vizinhança de $u$. Após essa decomposição, para se recuperar $x(t)$, no caso de $W_{x}(u, s)$ ser somente conhecida para $s<s_{0}$, utiliza-se a função de escala, cujo módulo também é unitário.

A função de escala pode ser interpretada como a resposta impulsiva de um filtro passa-baixa. Assim, a função $x(t)$ pode ser reescrita como uma combinação de funções de escala e wavelets. A resolução em tempo-freqüência da DWT depende do espalhamento das divisões $\psi_{u, s}$ conforme $u$ e $s$, como mostra a Figura 4.17, modificada de Mallat (1999). Mostram-se duas wavelets, $\psi_{u, s}(t)$ e $\psi_{u_{0}, s_{0}}(t)$, cujas PSDs são $\left|\hat{\psi}_{u, s}(w)\right|$ e $\left|\hat{\psi}_{u_{0}, s_{0}}(w)\right|$ respectivamente.

Como se pode ver, quanto maior a escala temporal da wavelet, menor a cobertura na freqüência, sendo o contrário também verdadeiro. O tamanho do retângulo de cobertura no espaço tempo-freqüência é igual, mas sua a resolução em cada eixo depende do valor de $s$. Dessa forma, o deslocamento da wavelet permite a cobertura do eixo do tempo e os estágios de decomposição, o eixo das freqüências. 


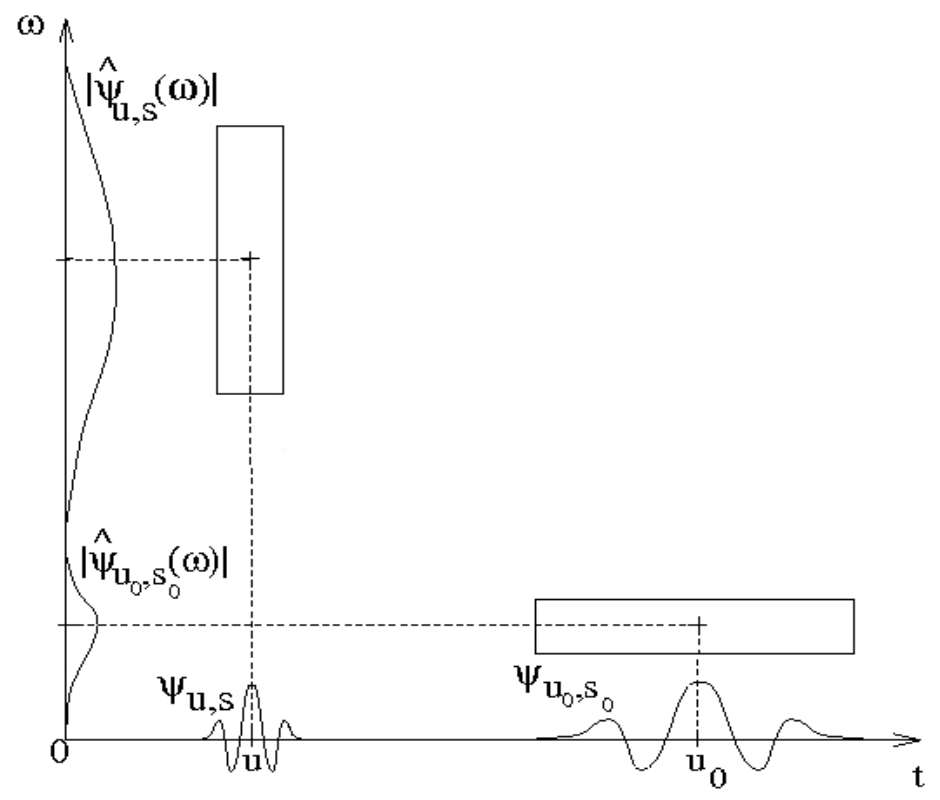

Figura 4.17: Ilustração da resolução de tempo e frequiência de acordo com a largura da wavelet. Quanto maior a largura da wavelet, mais resolução no tempo e menos na frequiência.

\section{Wavelets como Modelo de Sinais de Voz}

Após essa revisão de bancos de filtros e transformada wavelet, pode-se fazer algumas considerações a respeito da modelagem de sinais de voz usando a decomposição wavelet. Utilizaram-se os filtros da família Daubechies, devido aos seus bons resultados em processamento de voz, conforme mencionado anteriormente. A ordem escolhida dos filtros foi 30, pois, com esse valor, obtiveram-se os melhores resultados em testes preliminares. Realiza-se a decomposição em cinco níveis para se atingir uma aproximação com faixa de freqüências que inclua a freqüência fundamental e nenhuma de suas harmônicas.

Para o primeiro nível da decomposição, o sinal é filtrado por filtros passa-baixa e passa-alta, seguidos por decimação por um fator 2. Assim, o sinal é quebrado em duas partes, os coeficientes da DWT: coeficientes de aproximação $\left(c A_{1}\right)$ e detalhe $\left(c D_{1}\right)$, formados pelas partes de baixa e alta frequiência do sinal respectivamente. Os níveis seguintes são obtidos da mesma forma, entretanto, somente a aproximação é filtrada, obtendo a aproximação $\left(c A_{2}\right)$ e detalhe $\left(c D_{2}\right)$ do próximo nível. 


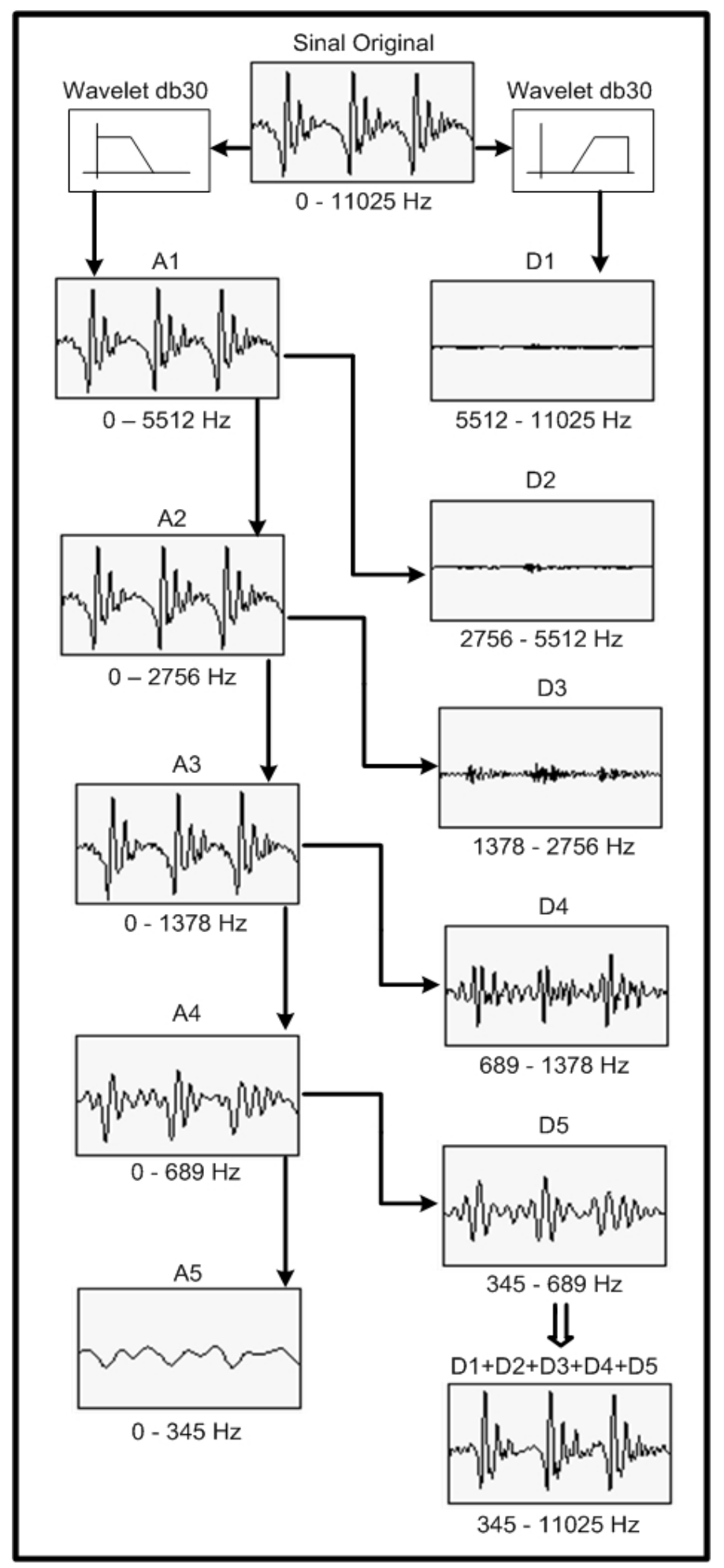

Figura 4.18: Ilustração da decomposição wavelet de cinco níveis de um sinal de voz saudável usando Daubechies de ordem 30. Os blocos "Wavelet db30" representam os filtros de primeiro nível, os filtros dos outros níveis foram omitidos por simplicidade. 
Porém, para poder usar a análise wavelet como um modelo de previsões do sinal, as decomposições devem ter o mesmo tamanho que o sinal original. Isso é obtido pela reconstrução wavelet, a qual é, basicamente, interpolação por um fator 2 e filtragem. Dessa forma, consegue-se obter o sinal original pela soma da aproximação reconstruída de nível $i, A_{i}$, e todos os detalhes reconstruídos, $D_{1}$ a $D_{i}$.

A Figura 4.18 ilustra a decomposição em 5 níveis de um sinal de voz saudável mostrando as freqüências aproximadas de cada um dos componentes de aproximação e detalhe do sinal. Os sinais de voz usados no estudo têm frequiência de amostragem de $22.050 \mathrm{~Hz}$, então, de acordo com o critério de Nyquist (Oppenheim et al., 1999), o maior componente de frequiência é $11025 \mathrm{~Hz}$. Assim, a aproximação reconstruída do quinto nível, $A_{5}$, contém componentes de freqüência até $345 \mathrm{~Hz}$ aproximadamente. Essa frequiência é um pouco acima da frequiência fundamental de vozes humanas adultas, lembrando que, neste trabalho, somente foram analisados sinais de pessoas com mais de 18 anos. A soma dos detalhes $\left(D_{1}\right.$ a $\left.D_{5}\right)$ contém o resto dos componentes de freqüência.

Devido a sua proximidade com a freqüência fundamental da voz, a aproximação $A_{5}$ pode refletir as perturbações desse parâmetro, ou seja, o jitter. Entretanto, esse sinal não pode ser selecionado como sendo a estimativa do sinal de voz porque a soma dos detalhes $\left(D_{1}\right.$ a $\left.D_{5}\right)$ contém a maioria dos componentes de freqüência do sinal. Assim, mudanças em outros parâmetros além do jitter seriam melhor refletidos nessa soma do que em $A_{5}$. Portanto, a soma dos detalhes é usada como previsão do sinal e $A_{5}$ é o erro de previsão porque ele é a diferença entre o sinal e sua previsão. Usando essa configuração o modelo de previsão wavelet está completo.

Para se ilustrar o uso desse modelo em sinais de voz, apresenta-se a Figura 4.19. Em (a), tem-se um sinal de voz saudável e, em (b), sua PSD. Nas partes (c) e (d), mostram-se o sinal estimado usando modelo de decomposição wavelet e a PSD da estimativa. Visualmente, os dois sinais são quase indiferenciáveis, da mesma forma que para o modelo AR. Nas partes (e) e (f), apresentam-se o sinal de erro de estimativa e sua PSD, a qual tem magnitude menor que $-50 \mathrm{~dB}$ para freqüências acima de $400 \mathrm{~Hz}$ conforme esperado. 


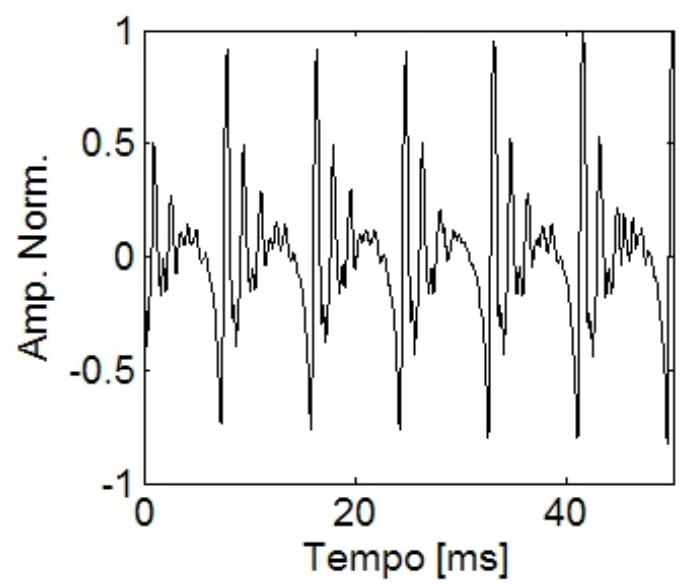

(a)

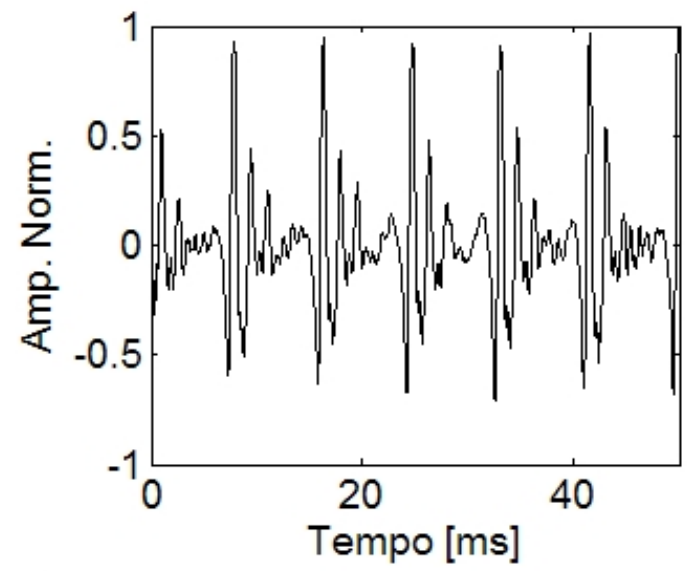

(c)

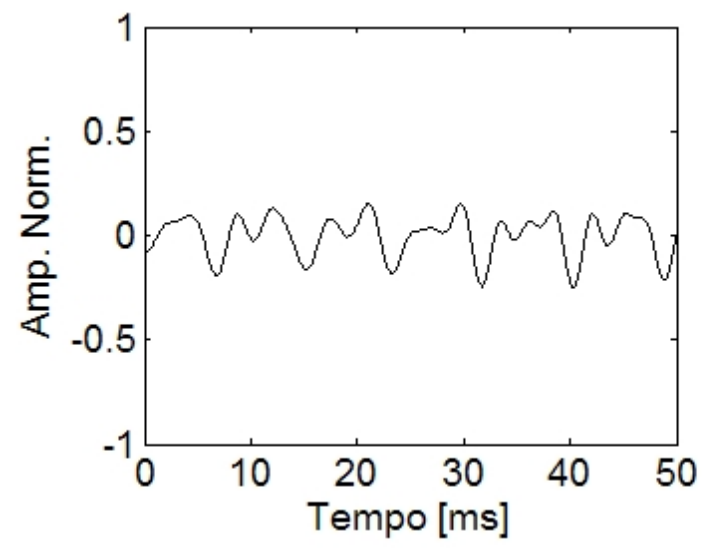

(e)

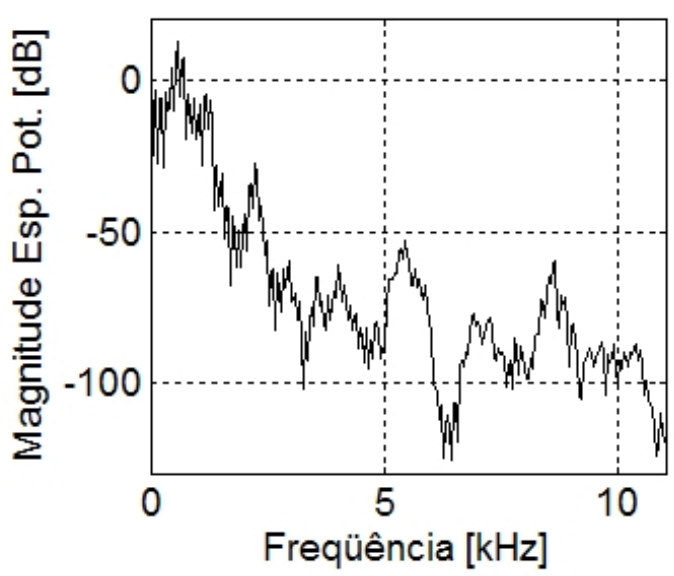

(b)

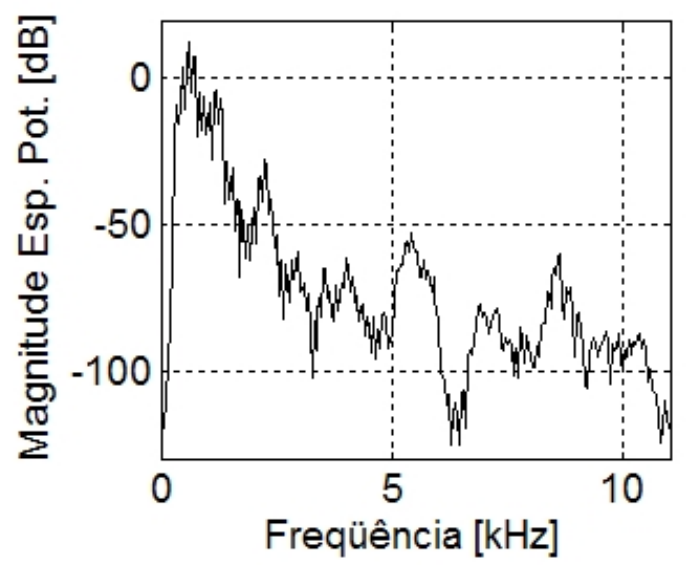

(d)

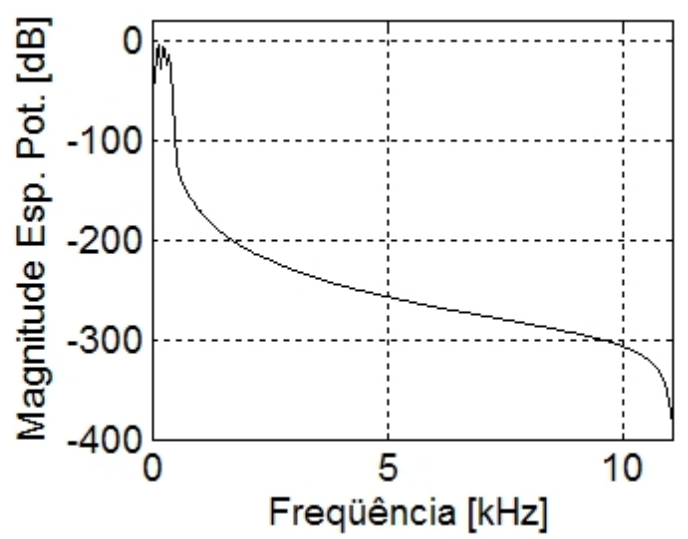

(f)

Figura 4.19: Ilustração da estimativa de um sinal de voz usando modelo por decomposição wavelet de cinco níveis por Daubechies ordem 30. (a) Sinal de voz saudável. (b) PSD do sinal saudável. (c) Estimativa do sinal de voz. (d) PSD do sinal estimado. (e) Erro de estimativa do modelo. (f) PSD do erro de estimativa. 
Para melhor comparação com o modelo AR, apresenta-se, na Figura 4.20, uma comparação entre os erros obtidos com os dois modelos, pois usa-se o mesmo sinal de voz para gerar as Figuras 4.7 e 4.19. Nas partes (a) e (b), mostram-se, respectivamente, o erro de estimativa usando o modelo $\operatorname{AR}(26)$ da seção anterior e o PSD desse sinal para freqüências até $1 \mathrm{kHz}$. Já nas partes (c) e (d), mostram-se o sinal de erro e seu PSD obtidos com o uso do modelo por wavelets.

Como se pode ver nessa figura, o erro obtido como o modelo AR apresenta clara demarcação da frequiência fundamental da voz e valores do espectro de potência sempre menores do que $-60 d B$. Já, para o erro do modelo wavelet, os valores de erro próximos da freqüência fundamental são bem maiores próximos de $0 d B$, além desta não ser visível no sinal temporal, ao contrário do modelo AR.

Com isso, percebe-se que o modelo wavelet não é um bom previsor dos sinais de voz, mas reflete bem suas variações como será observado nos resultados das análises de previsibilidade posteriormente. Dessa forma, usando esse modelo, pode-se conseguir valores das medidas de previsibilidade (especialmente PP) com maior sensibilidade às variações dos sinais de voz.

Na próxima subseção, apresenta-se a ferramenta de transformação dos sinais de voz para um espaço multidimensional junto com um modelo AR específico para obtenção de previsões.

\subsubsection{Análise da Representação Multidimensional da Voz}

Nesta subseção, apresentam-se discussões a respeito da análise de um tipo de representação multidimensional dos sinais de voz utilizando um modelo AR multidimensional. A transformação de um sinal para essa representação consiste em mostrar, em uma certa dimensão, versões atrasadas do próprio sinal para cada eixo do espaço. Conforme Broomhead e King (1986), esse tipo de representação é considerada como uma imersão dos dados em outro espaço.

Em Dajer (2006); Kumar e Mullick (1996), apresenta-se representação semelhante, porém com a consideração de não-linearidade na produção de voz. Nesse tipo de 


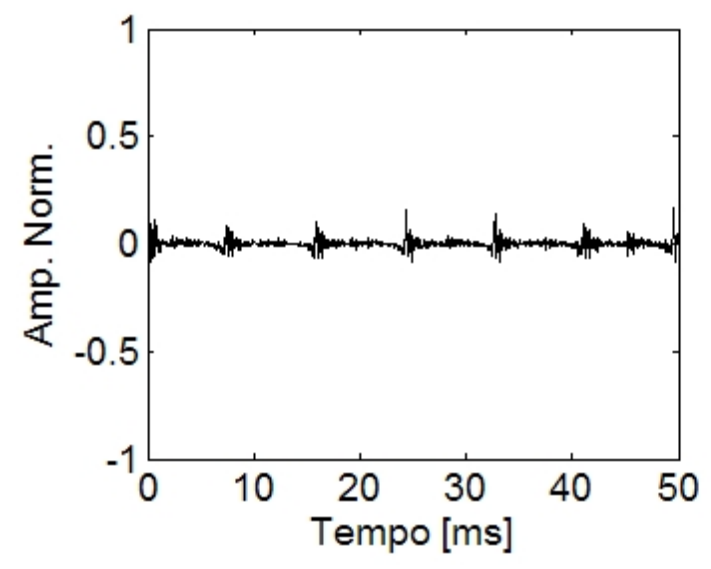

(a)

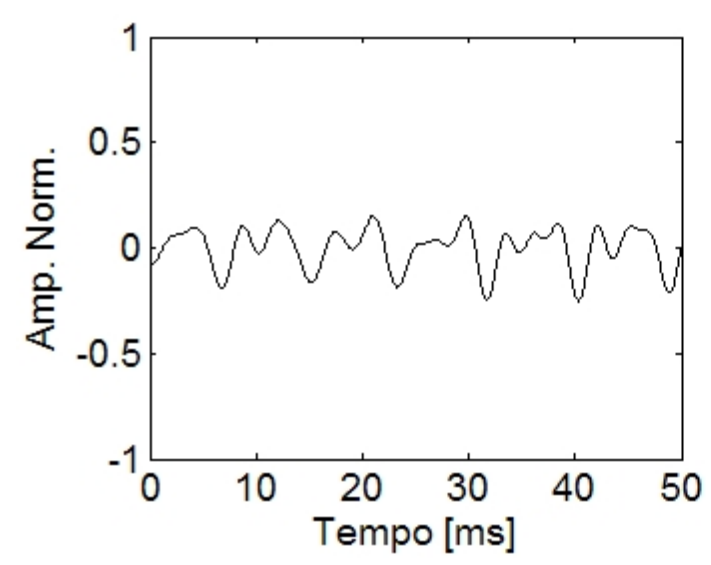

(c)

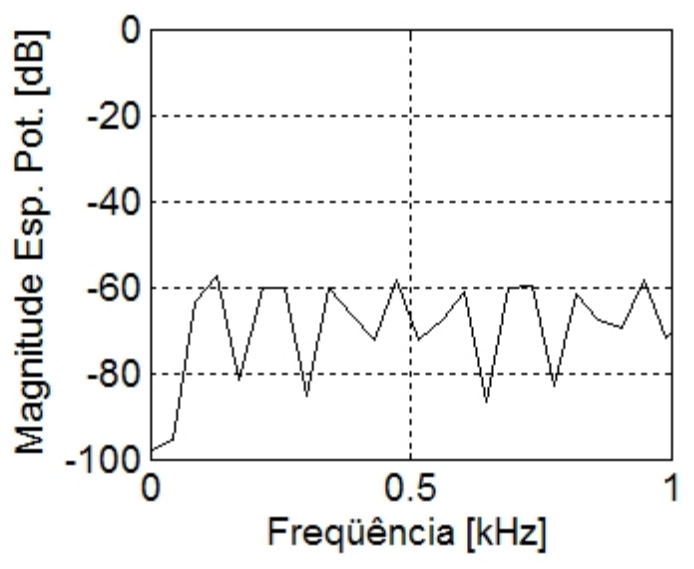

(b)

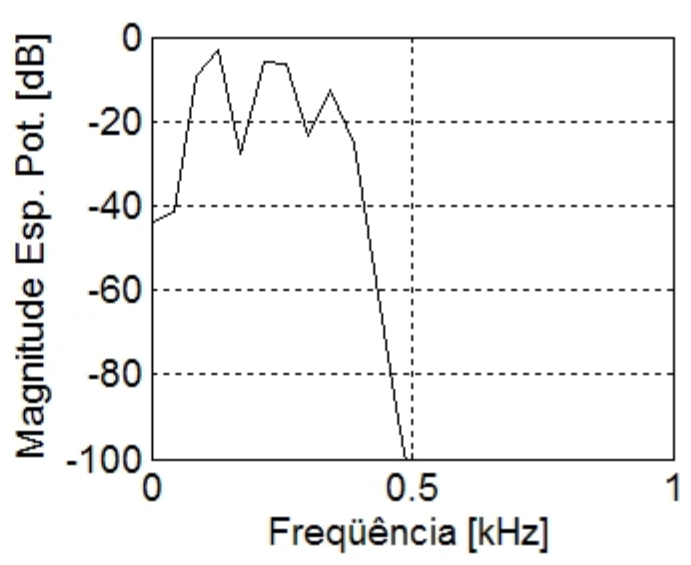

(d)

Figura 4.20: Comparação entre os erros de estimativa do sinal de voz usando os dois modelos propostos. (a) Erro de estimativa do modelo AR(26). (b) PSD do erro de estimativa com AR(26). (c) Erro de estimativa do modelo de decomposição wavelet (d) PSD do erro de estimativa com modelo wavelet.

análise, essa representação é chamada de reconstrução no espaço de fase ${ }^{13}$.

Um sinal de voz pode ser representado pela série temporal $x\left(t_{i}\right), t_{i}=t_{0}+i T_{s}$, com $i=1,2, \ldots, N$, sendo $N$ o tamanho do sinal e $T_{s}$ o período de amostragem. Assim, obtém-se a representação multidimensional desse sinal usando-se o método dos atrasos (Broomhead e King, 1986; Hegger et al., 1999), ou seja, fazendo-se o gráfico de $x\left(t_{i}\right)$ versus ela mesma atrasada de algumas amostras (Ott et al., 1994; Packard et al., 1980).

\footnotetext{
${ }^{13}$ Apesar de ser obtido de forma semelhante ao espaço de fase de Jiang et al. (2006) ou Kumar e Mullick (1996), a representação multidimensional usada se refere somente à transformação de coordenadas. As informações contidas nesse espaço serão analisadas com métodos probabilísticos sem o uso de ferramentas não-lineares.
} 
Um conjunto de $M$ vetores, o mencionado espaço de imersão, é formado por versões atrasadas de $x\left(t_{i}\right)$, Equação (4.28), sendo que $M$ é a dimensão de imersão e $\tau$ é o atraso de tempo entre os dados dos vetores. Esse atraso $\tau$ é obtido pelo primeiro mínimo local da função de informação mútua do sinal versus suas versões atrasadas (Fraser e Swinney, 1986).

$$
X\left(t_{i}\right)=\left\{x\left(t_{i}\right), x\left(t_{i}-\tau\right), \ldots, x\left(t_{i}-(M-1) \tau\right)\right\}
$$

Quando se utiliza essa representação para análisar sistemas caóticos, então chamada de espaço de fase reconstruído, considera-se que se $M>2 D_{h}+1$, sendo $D_{h}$ a dimensão de Hausdorff, o espaço de fase reconstruído é topologicamente equivalente ao espaço de fase original (Fraser e Swinney, 1986). Entretanto, neste trabalho, não se faz a consideração de caos, ou mesmo não-linearidade, na geração dos sinais de voz, utiliza-se a representação multidimensional somente como uma ferramenta que transforma o sinal temporal para outro conjunto de coordenadas buscando-se uma nova visão da dinâmica do sistema vocálico.

Para ilustrar esse procedimento de transformação do sinal de voz, apresentam-se as figuras a seguir, as quais usam o sinal da Figura 4.19 (a). Inicialmente, obtém-se a curva de informação mútua entre o sinal e suas versões atrasadas, buscando-se o primeiro mínimo local, conforme ilustrado na Figura 4.21.

Como observado, um atraso de 9 unidades resulta no primeiro mínimo local. Usase o mínimo pois é o atraso que possibilita a maior diferença entre os sinais atrasados. Com esse valor, geram-se versões atrasadas do sinal de voz conforme o número de dimensões desejadas para a representação multidimensional. As Figuras 4.22 e 4.23 apresentam essas representações para duas e três dimensões respectivamente.

A estimativa da informação mútua e das versões atrasadas do sinal são obtidas usando o pacote Tisean ${ }^{14}$ versão 3.0.1 (Hegger et al., 1999; Kantz e Schreiber, 2004). Esse pacote consiste em um conjunto de ferramentas para análise não-linear desenvolvido em linguagem $\mathrm{C}$.

\footnotetext{
${ }^{14} \mathrm{O}$ pacote Tisean foi desenvolvido em linguagem C para sistemas Linux e Windows está disponível no site de Internet: http://www.mpipks-dresden.mpg.de/ tisean/Tisean_3.0.1/index.html.
} 


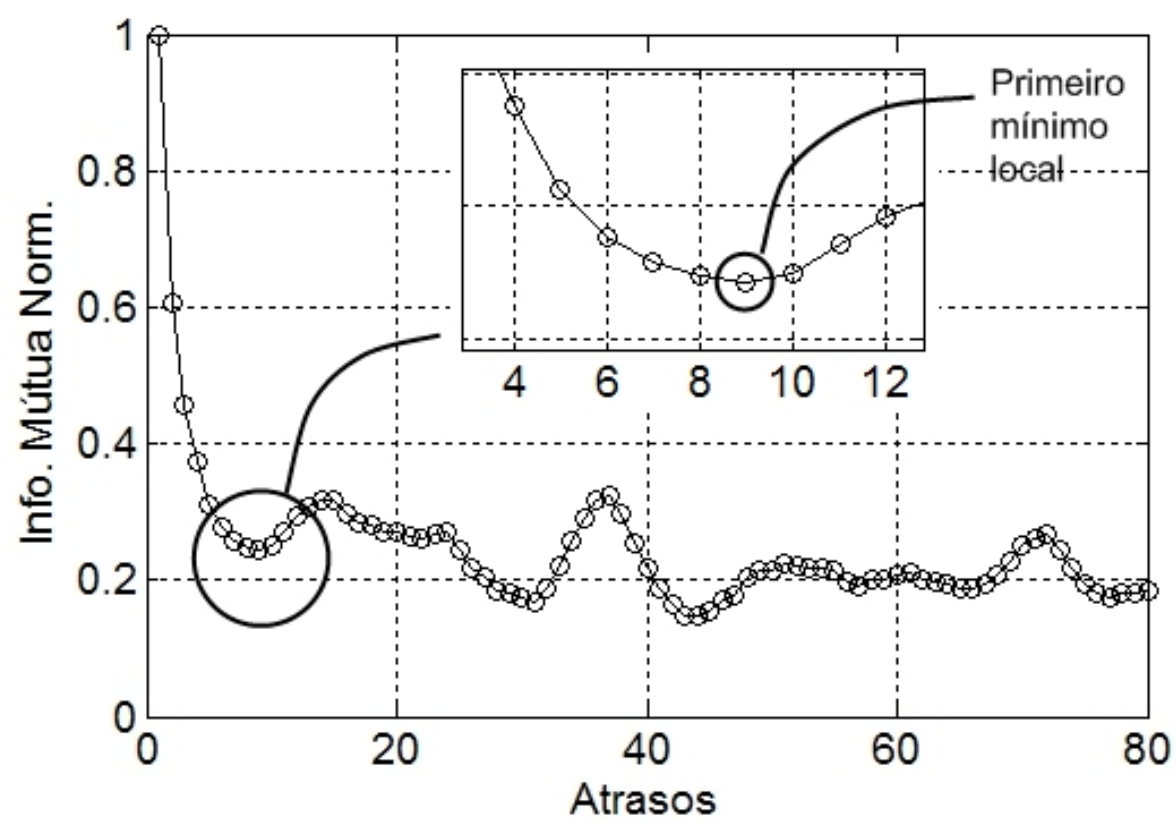

Figura 4.21: Ilustração da seleção do primeiro mínimo local da curva da informação mútua do sinal versus suas versões atrasas.

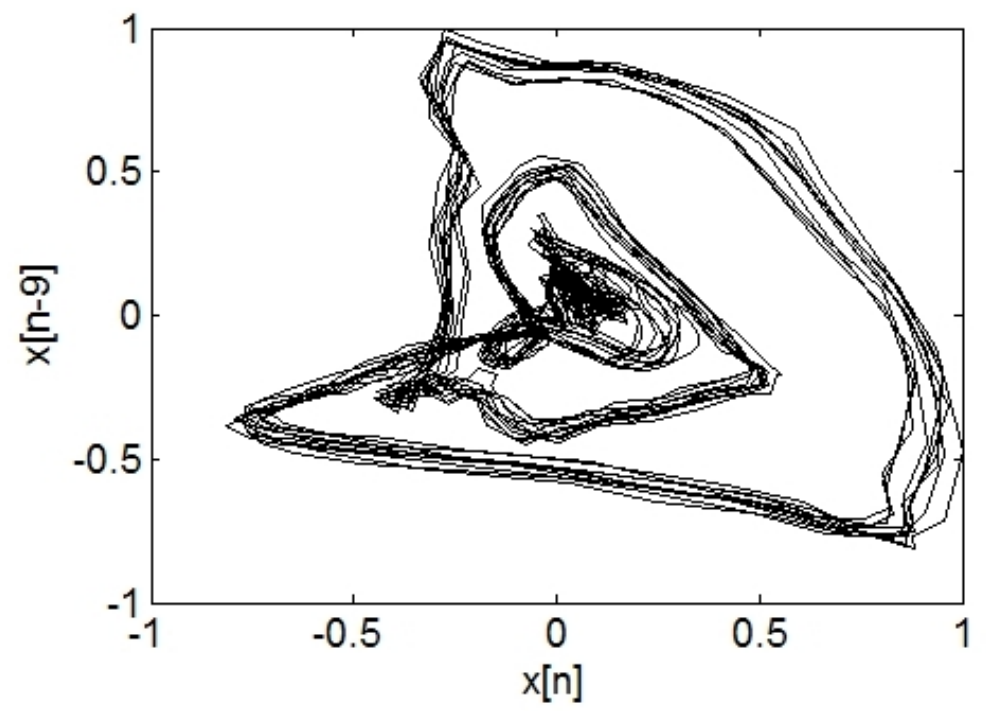

Figura 4.22: Representação bidimensional do sinal de voz da Figura 4.19 usando o método dos atrasos, sendo esse atraso igual a 9 unidades. 


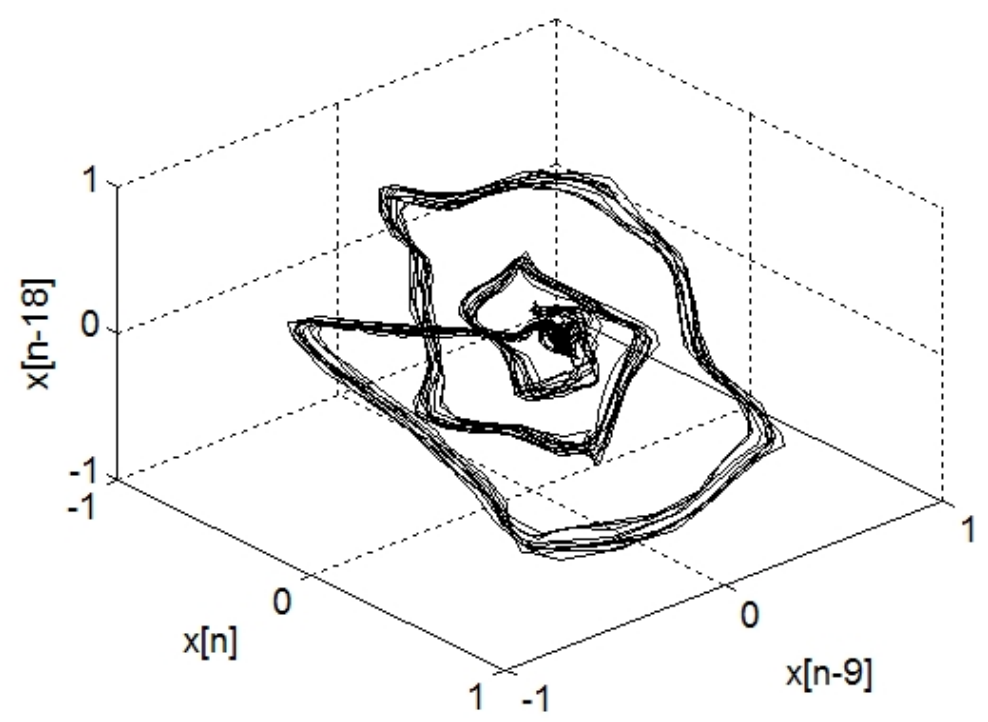

Figura 4.23: Representação tridimensional do sinal de voz da Figura 4.19 usando o método dos atrasos, sendo esse atraso igual a 9 unidades.

A representação multidimensional de sinais de voz pode ser usada para analisar mudanças dos parâmetros acústicos como jitter, shimmer e quantidade de ruído. Para uma melhor compreensão das mudanças dos sinais nesse espaço causadas pelas variações desses parâmetros, apresenta-se a Figura 4.24. Para gerar esses gráficos, utilizaram-se sinais obtidos com o simulador de vozes (Apêndice A). Essa figura consiste em quatro representações, em (a) tem-se um sinal com baixos níveis de ruído (SNR igual a 34,1 $d B)$, jitter (1\%) e shimmer (1\%), servindo de referência. Em (b), modifica-se somente o nível de ruído, aumentando-se o nível de ruído (SNR igual a 14,25 $d B$ ). Em (c), alto jitter, $10 \%$, e, em (d), alto shimmer, $15 \%$.

O aumento do ruído nos sinais adiciona irregularidades em todo o trajeto da figura tridimensional gerada, não se concentrando em um ponto em específico. Já com o aumento do jitter, tem-se, em algumas porções do espaço, uma abertura maior da linha da trajetória, parecendo uma fuga do padrão, causada pela variação da freqüência do sinal. Com o aumento do shimmer, a trajetória se torna mais longa ou mais curta conforme a variação, apresentado um padrão característico. Assim, espera-se que as medidas de previsibilidade possam diferenciar essas variações.

Para utilizar o método da previsibilidade nos sinais de voz representados nesse novo espaço, é necessário um modelo que faça as previsões do sistema. O modelo AR não pode mais ser usado do jeito que está, faz-se necessária uma modificação para 


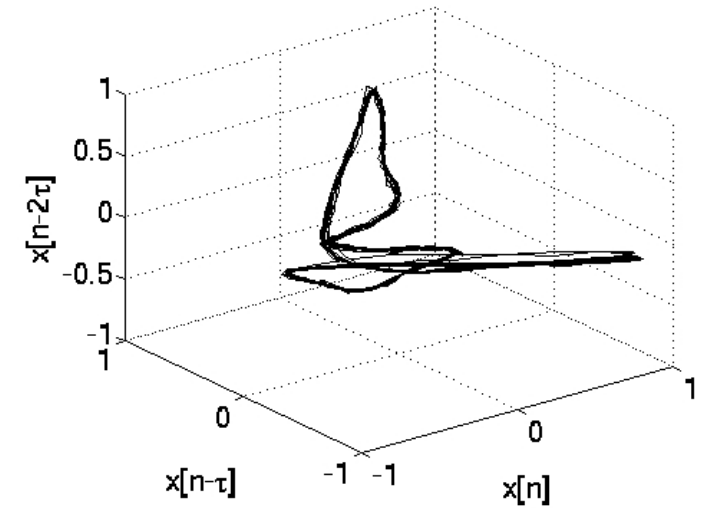

(a)

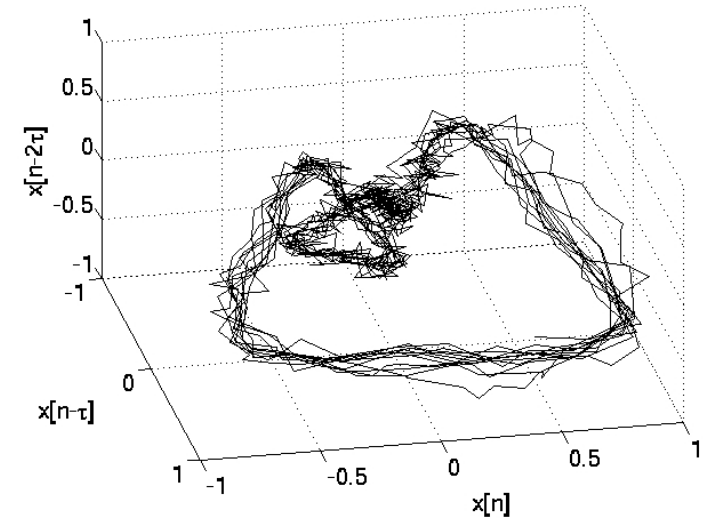

(c)

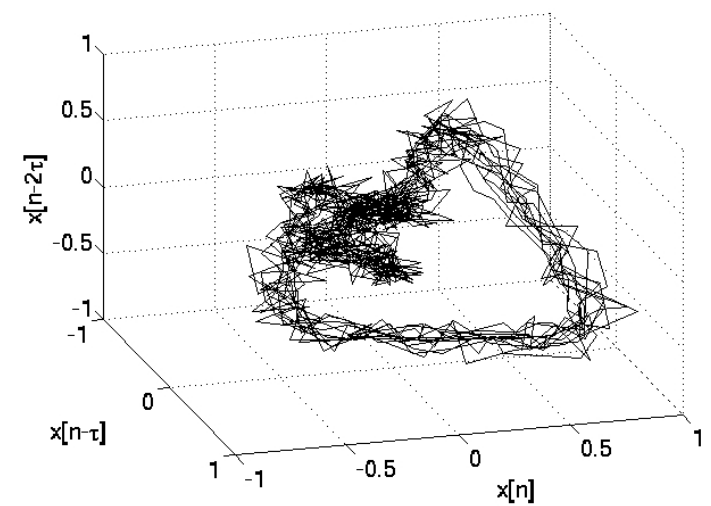

(b)

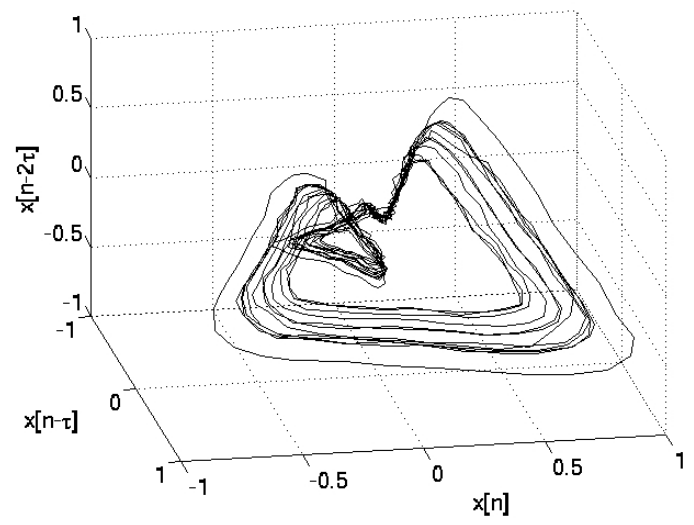

(d)

Figura 4.24: Comparação entre representações tridimensionais de sinais simulados. (a) Sinal com baixos níveis de ruído (SNR igual a 34,1 dB), jitter (1\%) e shimmer (1\%). (b) Sinal com alto nível de ruído, SNR igual a 14,25 $d B$. (c) Sinal com alto jitter, $10 \%$. (d) Sinal com alto shimmer, $15 \%$.

espaços multidimensionais. Os coeficientes desse modelo são estimados usando-se o pacote ARfit desenvolvido para o Matlab (Neumaier e Schneider, 2001; Schneider e Neumaier, 2001 $)^{15}$.

A decomposição de uma série temporal estacionária de vetores de estado $\mathbf{X}_{v} \in$ $\Re^{M}$, observados em instantes igualmente espaçados $v$, em um $\operatorname{AR}(\mathrm{p})$ de $M$ variáveis é realizada pela Equação (4.29).

$$
\mathbf{X}_{v}=\mathbf{w}+\sum_{k=1}^{p} \mathbf{A}_{k} \mathbf{X}_{v-k}+\epsilon_{v}
$$

Nessa equação, os vetores $\epsilon_{v}$, de dimensão $M$, são vetores aleatórios descorrelacionados com média zero e matriz de covariância $\mathbf{C} \in \Re^{M \times M}$. As matrizes $\mathbf{A}_{1}, \ldots, \mathbf{A}_{p}$,

\footnotetext{
${ }^{15}$ O pacote ARfit está disponível no site de Internet: http: / / www . gps . caltech. edu/ tapio/arfit/.
} 
que pertencem a $\Re^{M \times M}$, são as matrizes de coeficientes do modelo $\mathrm{AR}$ e w $\in \Re^{M}$ é um vetor de termos de intersecção (Neumaier e Schneider, 2001). Esse vetor de intersecção é adicionado, segundo Schneider e Neumaier (2001), para permitir que a média da série temporal seja não-nula, conforme apresentado na Equação (4.30).

$$
\left\langle\mathbf{X}_{v}\right\rangle=\left(\mathbf{I}-\mathbf{A}_{1}-\ldots-\mathbf{A}_{p}\right)^{-1} \mathbf{W}
$$

O algoritmo apresentado em Neumaier e Schneider (2001), usa o método dos mínimos quadráticos para estimar os parâmetros do modelo AR, realiza-se uma fatoração QR de uma matriz de dados, estimando um fator de seleção para diversas ordens do modelo (até o máximo de $p$ ), buscando os resultados ótimos.

Para se obter uma estimativa do sinal multidimensional, $\hat{\mathbf{X}}_{v}$, modifica-se a Equação (4.29), retirando-se os vetores descorrelacionados da mesma forma que para o modelo AR unidimensional, Equações (4.1) e (4.4). Assim, chega-se na Equação (4.31).

$$
\hat{\mathbf{X}}_{v}=\mathbf{w}+\sum_{k=1}^{p} \mathbf{A}_{k} \mathbf{X}_{v-k}
$$

Essa equação pode ser melhor compreendida se for reescrita em formato matricial, conforme apresentado na Equação (4.32), sendo que se ocultaram os instantes $v$ dos vetores de estado $\mathbf{X}_{v}$.

$$
\begin{gathered}
{\left[\begin{array}{c}
\hat{X}_{k\{1\}} \\
\hat{X}_{k\{2\}} \\
\vdots \\
\hat{X}_{k\{M\}}
\end{array}\right]=\left[\begin{array}{c}
w_{1} \\
w_{1} \\
\vdots \\
w_{M}
\end{array}\right]+\left[\begin{array}{ccc}
A_{1\{11\}} & \ldots & A_{1\{1 M\}} \\
A_{1\{21\}} & \ldots & A_{1\{2 M\}} \\
\vdots & \ddots & \vdots \\
A_{1\{M 1\}} & \ldots & A_{1\{M M\}}
\end{array}\right]\left[\begin{array}{c}
X_{k-1\{1\}} \\
X_{k-1\{2\}} \\
\vdots \\
X_{k-1\{M\}}
\end{array}\right]+\ldots} \\
\ldots+\left[\begin{array}{ccc}
A_{p\{11\}} & \ldots & A_{p\{1 M\}} \\
A_{p_{\{21\}}} & \ldots & A_{p_{\{2 M\}}} \\
\vdots & \ddots & \vdots \\
A_{p_{\{M 1\}}} & \cdots & A_{p_{\{M M\}}}
\end{array}\right]\left[\begin{array}{c}
X_{k-p\{1\}} \\
X_{k-p\{2\}} \\
\vdots \\
X_{k-p}
\end{array}\right]
\end{gathered}
$$


Para ilustrar o uso desse modelo, apresenta-se um exemplo usando a representação tridimensional da Figura 4.23. Usa-se o modelo AR multidimensional de ordem 10, calculado com o pacote ARfit, sendo a estimativa da figura apresentada na Figura 4.25.

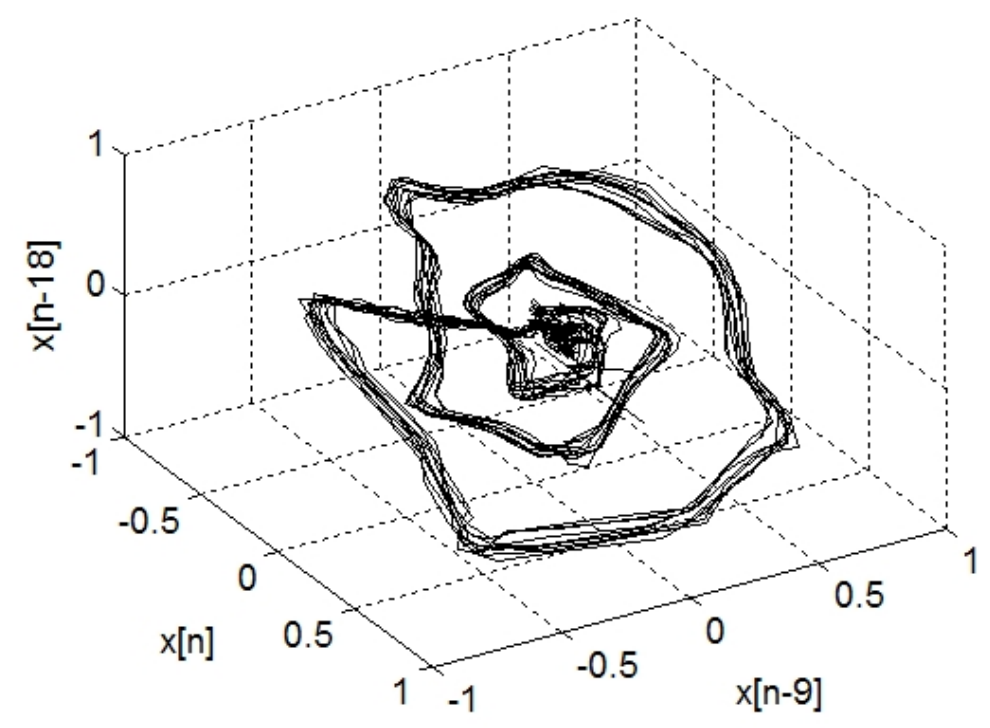

Figura 4.25: Estimativa da representação tridimensional da Figura 4.23 usando modelo AR multidimensional de ordem 10 calculado com pacote ARfit.

O erro de estimativa obtido pela diferença entre as duas figuras (4.23 e 4.25), é apresentado na Figura 4.26. Como observado, o modelo é bem eficiente em estimar o sinal nesse tipo de representação, sendo quase imperceptível a diferença entre as figuras, o que é comprovado pelo pequeno erro obtido. Nesse exemplo, o conjunto de matrizes de coeficientes $\mathbf{A}_{1}, \ldots, \mathbf{A}_{10}$ possuem dimensão $3 \times 3$, pois $M=3$. O vetor de termos de intersecção $\mathbf{w}$ possui dimensão $3 \times 1$.

Mais detalhes sobre a modelagem AR multidimensional usada pelo pacote ARfit pode ser obtido em Neumaier e Schneider (2001). No próximo capítulo, serão apresentados mais informações dos algoritmos usados para as análises apresentadas neste estudo. 


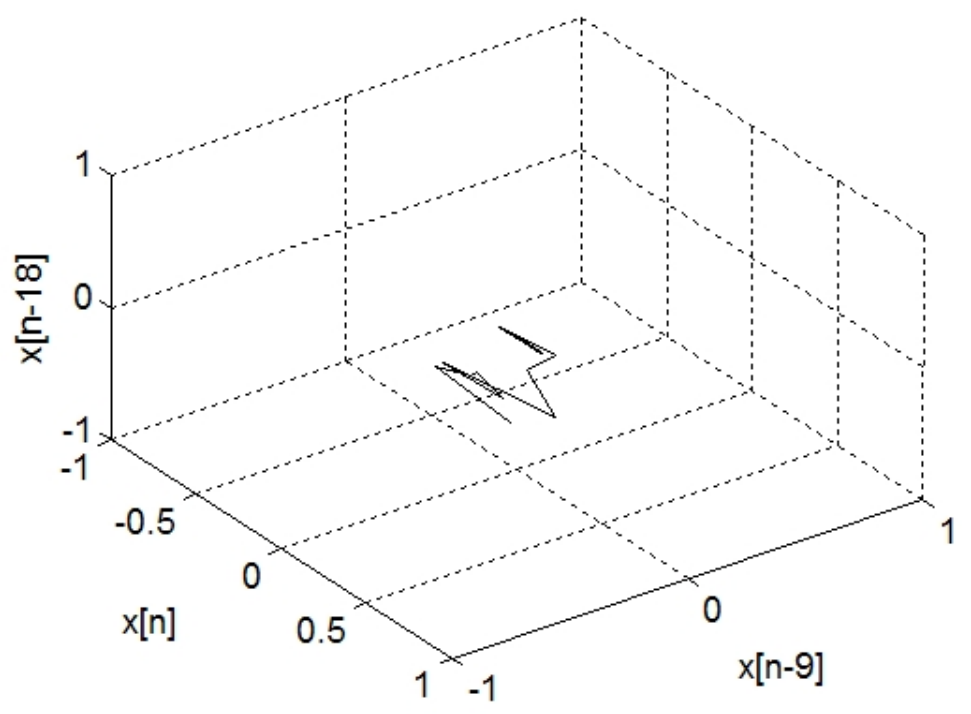

Figura 4.26: Erro de estimativa da representação tridimensional da Figura 4.26 usando modelo AR multidimensional de ordem 10 calculado com pacote ARfit. 


\section{Capítulo 5}

\section{Algoritmos}

Neste capítulo, descrevem-se os algoritmos utilizados nos ensaios de sinais de voz apresentados no próximo capítulo. Mostram-se três técnicas usadas para estimativa da entropia: primeiramente, o método da discretização da entropia diferencial, seguido pelo método do passo de quantização constante, os quais possuem células do histograma de tamanho constante. Por fim, mostra-se o método de equalização do histograma, o qual possui células de tamanho variável. Além disso, comenta-se sobre a estimativa da entropia de blocos e a curva de crescimento dessa entropia, mostrando os problemas para essa estimativa e uma possível solução para análise.

Após apresentar os algoritmos de entropia, explicam-se os algoritmos de estimativa da potência de previsão usando modelos AR e de decomposição por wavelets. Finalizase o capítulo descrevendo o método de cálculo da análise de componentes previsíveis tanto para sinais temporais como para sua representação tridimensional. Para isso, usa-se o modelo AR multidimensional.

Para todos esses algoritmos, apresentam-se diversos exemplos ilustrativos e, também, ensaios usando sinais simulados com variação de nível de ruído, jitter e shimmer.

\subsection{Estimativa da Entropia}

Nesta seção, apresentam-se alguns métodos de estimativa da entropia de um sinal. Como apresentado nos capítulos anteriores, para o cálculo da PP ou para realizar a 
PrCA, é necessário utilizar medidas de entropia. O cálculo da entropia é uma tarefa complicada, pois conforme visto na Equação (3.1), esse cálculo depende da PDF do sinal, a qual só é obtida quando se conhece todos os eventos do sistema em estudo. Assim, para um sinal finito, deve-se fazer uma estimativa de sua PDF a partir dos dados disponíveis, mas se essa estimativa for ruim, podem-se ter efeitos negativos no valor de entropia (Wit, 1999). Conforme apresentado em Bercher e Vignat (2000), um sinal geralmente possui PDF contínua por causa do ruído inerente ao sistemas reais.

Esse problema da estimativa da PDF é especialmente complicado para a entropia de blocos como mostram Schürmann e Grassberger (1996). Geralmente, esse tipo de entropia é obtido por meio de estimativa de verossimilhança padrão (standard likelihood estimate), ou seja, a estimativa de todas as probabilidade de palavras até um certo comprimento. A entropia de blocos, conforme apresentado no Capítulo 3, é utilizada para se obter a curva de crescimento de entropia e suas características.

A estimativa da entropia é um tema muito estudado, diversos trabalhos já foram feitos sobre formas de estimativa a até sobre outras abordagens. Um exemplo é apresentado em Pincus (1991), chamado entropia aproximada, conforme mencionado no Capítulo 2, a qual objetiva quantificar regularidade e complexidade dos sinais. Outra modificação é apresentada em Lake et al. (2002), a entropia amostral, que também tenta quantificar as mesmas grandezas.

Como descrito em Erdogmus e Principe (2006), normalmente, a entropia é estimada usando uma de duas formas: paramétrica ou não-paramétrica; entretanto, alguns autores chegam a caracterizar uma terceira forma, semiparamétrica, a qual é uma forma intermediária.

A abordagem paramétrica consiste em fazer uma consideração a respeito da distribuição dos dados e, então, fazer uma estimativa dos parâmetros dessa distribuição (Viola et al., 1996). Um problema é que essa consideração não é muito flexível, isso pois, somente se a estimativa da PDF se adequar aos dados, o resultado será satisfatório. Geralmente, faz-se a consideração de distribuição Gaussiana porque, primeiro, é simples encontrar uma Gaussiana que se adeque aos dados e, segundo, a entropia dessa distribuição é direta. Nessa abordagem, na maioria das vezes, os parâmetros são estimados usando método da máxima verossimilhança. 
Considerando a abordagem não-paramétrica, em Bercher e Vignat (2000), mostramse alguns exemplos como baseados em histogramas (Moddemeijer, 1989), espaços amostrais (Wachowiak et al., 2005) e métodos de kernel (Erdogmus et al., 2004). Considerando a técnica de histogramas, podem-se ter células de tamanho fixo; variável, conforme a distribuição local dos dados; ou obtidas por janelas móveis retangulares. Se, ao invés da janela retangular, usar-se uma função diferente, o método passa a ser chamado de estimativa de densidade por kernel (kernel density estimation)(Erdogmus e Principe, 2006).

Um desses métodos é a estimativa por janelamento de Parzen (Duin, 1976). De acordo com Erdogmus e Principe (2000), a PDF é estimada por uma soma de kernels simétricos e regulares que são sobrepostos sobre cada amostra do sinal. Novamente, a Gaussiana é normalmente usada como kernel, basicamente por sua característica de diferenciação contínua. Assim, com a estimativa da PDF, a entropia pode ser obtida diretamente (Erdogmus et al., 2004; Beirlant et al., 1997).

Em Viola et al. (1996), apresentam-se três vantagens da estimativa de Parzen ao invés da abordagem paramétrica. Primeira, a estimativa de Parzen pode modelar qualquer distribuição contanto que tenha PDF suave; segunda, não é necessário fazer busca pelos parâmetros, pois, usa-se o sinal diretamente; terceira, é fácil calcular a derivada da entropia.

Neste estudo, utilizou-se somente a abordagem não-paramétrica baseada em histogramas, tanto com tamanho de célula fixa quanto variável. Assim, a estimativa da entropia se resume na estimativa do histograma do sinal. Dos diversos métodos existentes para esse procedimento, neste capítulo, apresentam-se somente três: método da discretização da entropia diferencial, método do passo de quantização constante e método da equalização do histograma.

Dessas técnicas, utilizou-se somente a segunda para as análises apresentadas no capítulo seguinte. Isso pois a primeira apresenta deficiências quando os sinais apresentam diferenças grandes de amplitude e, com a terceira, obtiveram-se resultados muito próximos dos gerados pela segunda técnica, a qual é mais simples. Esses métodos serão descritos nas subseções a seguir. 
Para finalizar a seção, comenta-se sobre a estimativa da entropia de bloco e da curva de crescimento de entropia. Mostram-se os problemas para a obtenção dessa curva e uma abordagem de análise alternativa.

\subsubsection{Método da Discretização da Entropia Diferencial}

A discretização da entropia diferencial foi um primeiro método utilizado para a estimativa da entropia a ser usada nas análises de previsibilidade. Esse algoritmo baseiase nos conceitos apresentados em Moddemeijer (1989), o qual utiliza um algoritmo simples de histograma com correção de tendências (bias). Algo semelhante é apresentado em Paninski (2003), sendo chamado de estimador de máxima verossimilhança (ou plug-in).

Para a estimativa da PDF do sinal em estudo, divide-se essa função contínua em um reticulado com $I$ células igualmente espaçadas. Assim, a probabilidade, $p_{i}$, de cada célula $i$, é estimada por $k_{i} / N$, sendo que $k_{i}$ é o número de ocorrências dos pontos do sinal em cada célula, $N$ é o total de amostras do sinal e $\Delta x$ é a largura da célula (Cover e Thomas, 1991; Moddemeijer, 1989). Dessa forma, obtém-se o estimador da entropia dado pela Equação (5.1), com unidade em bits.

$$
\hat{H}=-\sum_{i}\left(\frac{k_{i}}{N} \log _{2} \frac{k_{i}}{N}\right)+\log _{2} \Delta x
$$

Em Moddemeijer (1989), apresenta-se uma correção de tendência do estimador para sistemas discretos conforme a Equação (5.2).

$$
E\{\hat{H}\} \approx H-\frac{I-1}{2 N}
$$

Para ilustrar o uso desse estimador, apresenta-se um exemplo a seguir ${ }^{16}$, o qual consiste em obter a entropia de um sinal composto por ruído com distribuição Gaussiana, média nula e desvio padrão unitário. O sinal e seu histograma (usando 30 células) são apresentados na Figura 5.1 (a) e (b) respectivamente.

\footnotetext{
${ }^{16}$ Esse exemplo é apresentado por R. Moddemeijer, autor de Moddemeijer (1989), em seu site da Internet: http://www.cs.rug.nl/ rudy/matlab/doc/entropy.html.
} 


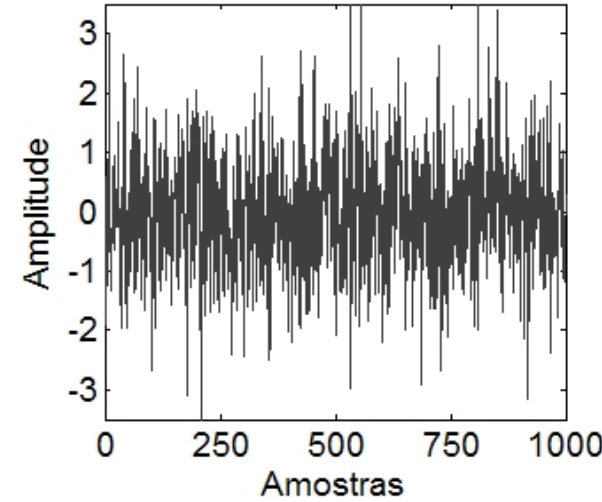

(a)

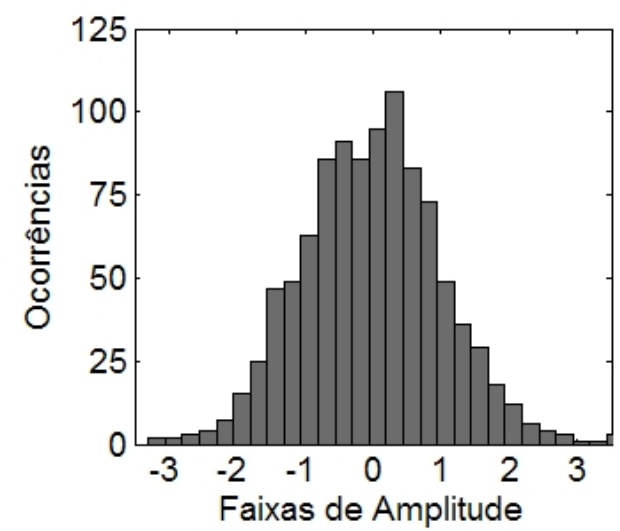

(b)

Figura 5.1: Sinal usado para ilustrar o estimador de entropia por método da discretização da entropia diferencial. (a) Sinal de ruído Gaussiano com média nula e desvio padrão unitário. (b) Histograma do sinal usando 30 células.

A entropia diferencial de uma distribuição Gaussiana é apresentada no Apêndice C e dada pela Equação (5.3), sendo $\mu$ e $\sigma$ a média e desvio padrão da distribuição.

$$
H_{D}(x)=\ln (\sigma \sqrt{2 \pi e})
$$

Assim, a entropia teórica para o sinal do exemplo anterior é de 1,4189 nats e, usando o estimador, o resultado foi 1,3984 nats, ou seja, um erro de 1,44\%.

A Tabela 5.1 apresenta um resumo do algoritmo de estimativa da entropia usando o método de discretização da entropia diferencial. Na etapa de pré-processamento do sinal, retira-se o valor médio dos sinais e faz-se a normalização da amplitude para evitar efeitos de diferença de volume na coleta dos sinais de voz.

Tabela 5.1: Algoritmo da entropia usando método de discretização da entropia diferencial.

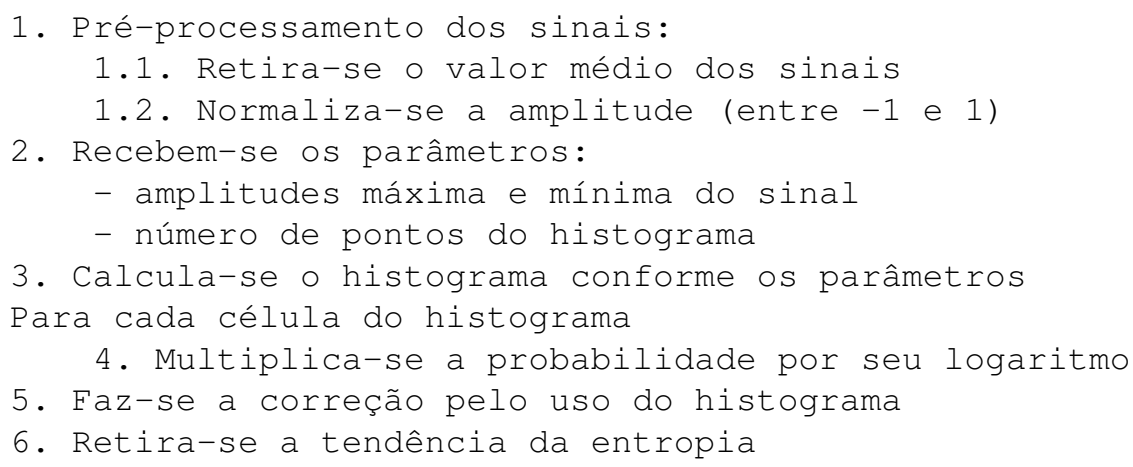


O passo número 6 do algoritmo mostra a correção de tendência conforme a Equação (5.2). O passo número 5 mostra uma outra correção devido ao uso do histograma, isso pois o algoritmo de estimativa de histograma resulta no número de ocorrências das células e não na PDF de um sinal. A PDF possui soma de todas as probabilidades igual a unidade, o que não ocorre com o histograma. Dessa forma, antes da correção de tendência, aplica-se a correção apresentada na Equação (5.4) conforme Moddemeijer (1989). Tem-se que $\hat{H}_{h}$ é a estimativa da entropia usando o histograma e não a PDF.

$$
\hat{H}(X)=\hat{H}_{h}+\log (N)+\log (\Delta x)
$$

Para ilustrar o uso desse algoritmo, realizou-se três ensaios com sinais de voz simulados obtidos com o simulador de voz apresentado no Apêndice A. Em cada um dos ensaios, variou-se um dos três parâmetros do simulador: nível de ruído (SNR), jitter ou shimmer. Conforme se aumentam os valores desses parâmetros, espera-se que a entropia aumente, devido ao aumento da desorganização do sinal simulado.

Inicialmente, realiza-se um ensaio variando o nível de ruído, faz-se o parâmetro $A d$ variar de 0,025 a 0,25 com passos de 0,025 , sendo que o SNR dos sinais simulados fica entre 5 a $25 d B$. O resultado da estimativa de entropia usando o método da discretização da entropia diferencial para os sinais simulados com esses valores de SNR é apresentado na Figura 5.2.

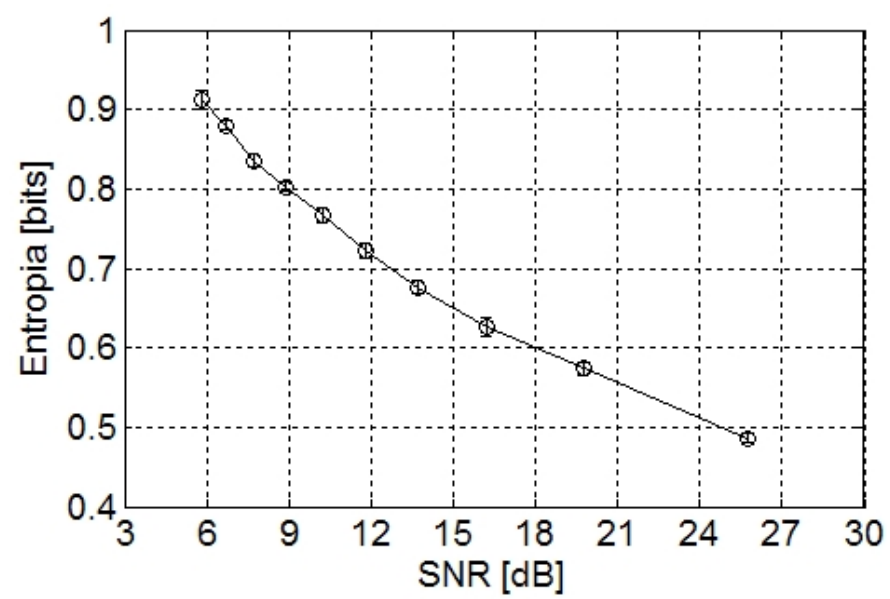

Figura 5.2: Resultados de entropia usando o método da discretização da entropia diferencial para o ensaio de variação de nível de ruído (SNR) de sinais simulados.

Como visto na figura, conforme se aumenta o ruído dos sinais (diminuição do 
SNR), a entropia aumenta. Esse é o comportamento esperado, pois maior ruído significa maior desorganização do sinal.

Em seguida, testou-se o comportamento do algoritmo com variações de jitter e, depois, de shimmer, os quais foram variados de $2 \%$ a $20 \%$, em passos de $2 \%$. Os resultados de entropia para esses dois ensaios são apresentados nas Figuras 5.3 e 5.4 respectivamente.

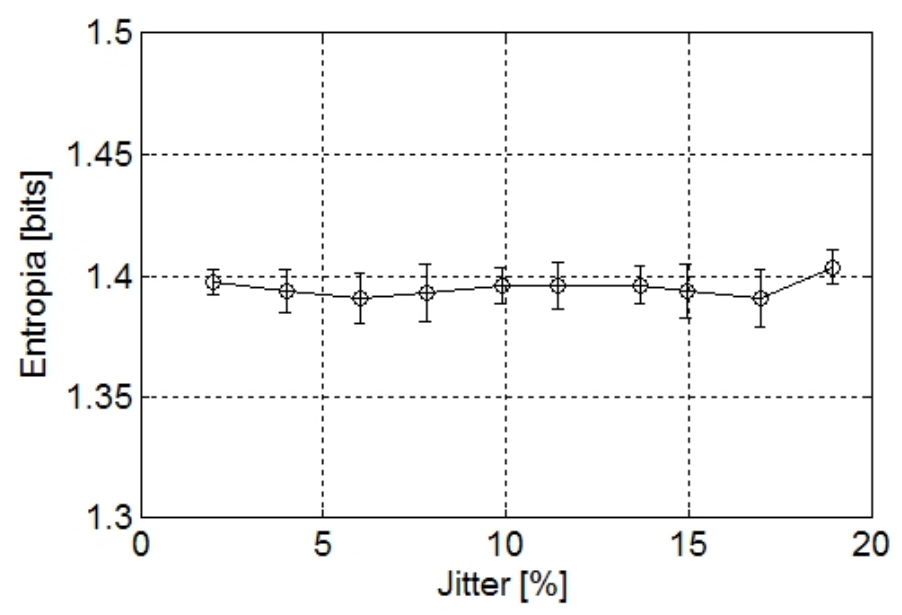

Figura 5.3: Resultados de entropia usando o método da discretização da entropia diferencial para o ensaio de variação de jitter de sinais simulados.

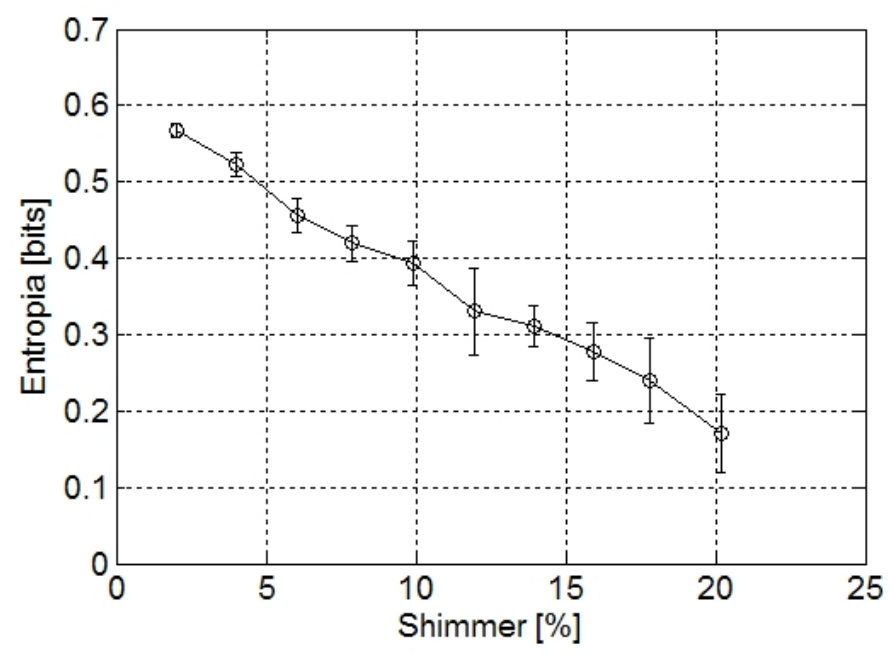

Figura 5.4: Resultados de entropia usando o método da discretização da entropia diferencial para o ensaio de variação de shimmer de sinais simulados.

Ao contrário do ensaio com variação de SNR, a entropia dos sinais com variações de jitter e shimmer não se comporta da maneira esperada. Conforme se aumenta esses parâmetros, a entropia deveria aumentar também. Entretanto, o algoritmo se mostrou 
insensível à variação de jitter e inversamente proporcional à variação de shimmer, ou seja, diminui quando esse parâmetro aumenta.

Neste estudo, utilizou-se também a entropia relativa entre sinais. Para estimar essa medida, usou-se o algoritmo anterior com leves modificações, entretanto sem a correção de tendência. Da mesma forma que para a entropia, as PDFs dos sinais, $p_{X}(x) \mathrm{e}$ $q_{X}(x)$, foram divididas em células de tamanho $\Delta x$. As ocorrências dos pontos dos sinais em cada célula $i$ é $p_{i}$ e $q_{i}$ para $p_{X}(x)$ e $q_{X}(x)$ respectivamente, assim, substituíndose esses valores na Equação (3.5), pode-se reescrevê-la como a Equação (5.5).

$$
D\left(p_{X} \| q_{X}\right) \approx \sum_{i=1}^{N} p_{i} \log _{2} \frac{p_{i}}{q_{i}}
$$

Considerando que as amostras são independentes, as probabilidades $p_{i}$ e $q_{i}$ podem ser substituídas pelas estimativas $k_{p i} / N$ e $k_{q i} / N$ respectivamente, sendo $k_{p i}$ e $k_{q i}$, as ocorrências nas células $i$ de $p_{X}(x)$ e $q_{X}(x)$ respectivamente e $N$ é o total de amostras dos sinais. Então, modificando-se a equação anterior, obtém-se o estimador da entropia relativa, Equação (5.6), com unidade em bits.

$$
\hat{D}\left(p_{X} \| q_{X}\right)=\frac{1}{N} \sum_{i=1}^{N} k_{p i} \log _{2} \frac{k_{p i}}{k_{q i}}
$$

De posse desse estimador, modifica-se ligeiramente a Tabela 5.1 para uma versão da entropia relativa, Tabela 5.2.

Tabela 5.2: Algoritmo da entropia relativa usando método de discretização da entropia diferencial.

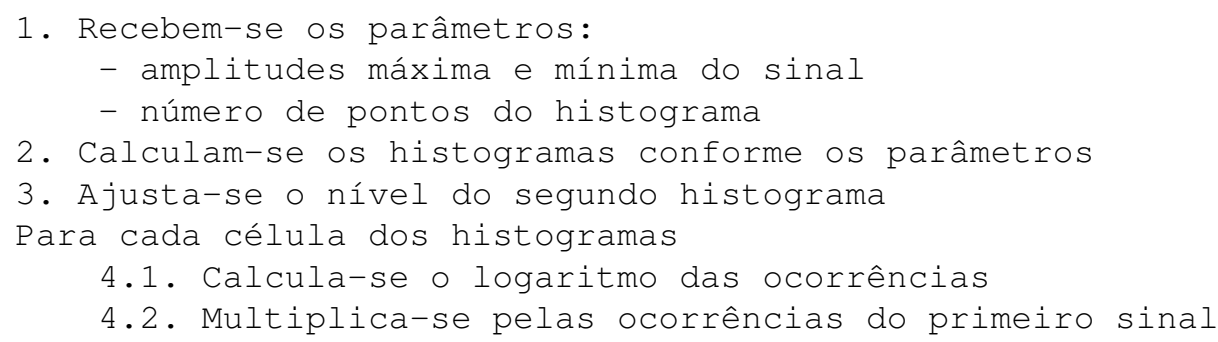

Comparando-se as Tabelas 5.1 e 5.2, percebe-se que para a estimativa da entropia relativa não se realizam as etapas de pré-processamento, pois como ela compara as 
distribuições dos sinais, não se modifica as suas amplitudes. Também, não se realiza correção de tendência.

Além disso, adiciona-se uma etapa de ajuste do nível do segundo histograma (passo número 3 da tabela). Essa etapa é necessária pois, na entropia relativa, tem-se um logaritmo de uma razão de duas PDFs, portanto o denominador não pode ser nulo. Para evitar isso, soma-se um pequeno valor ao histograma do segundo sinal. No Apêndice $\mathrm{B}$, mostra-se que, se esse valor for suficientemente pequeno, o erro adicionado à entropia relativa é nulo.

Conforme mencionado anteriormente, o algoritmo do método de discretização da entropia diferencial apresenta problemas quando os sinais analisados possuem diferenças grandes de amplitude. Como o número de células é fixo, dois sinais com faixa de amplitude diferentes vão apresentar resoluções diferentes. Essa variação de resolução pode surtir efeito negativo na estimativa de entropia relativa, principalmente no cálculo da PP, pois essa depende da entropia relativa entre o sinal e seu erro de previsão, o qual geralmente possui baixa amplitude.

Para ilustração desse problema, apresenta-se na Figura 5.5 (a) o histograma de um ruído Gaussiano e, em (b), o histograma do mesmo sinal mas com a amplitude dividida por três.

Para a estimativa da entropia relativa, utiliza-se a mesma configuração para os dois histogramas, baseando-se no com faixa de amplitudes maior, assim, usa-se a faixa do primeiro sinal, com valores máximo e mínimo iguais a 3 e -3 respectivamente. Portanto, o tamanho da célula do histograma é 0,20. Para o segundo sinal, esse tamanho equivale a usar somente 10 células, o que claramente diminui a resolução da estimativa, como se observa na parte (b) da figura, a qual deveria ter o mesmo formato da parte (a).

Com base nesse problema, na próxima subseção, apresenta-se um outro método de estimativa da entropia, o qual se baseia no passo de quantização constante. 


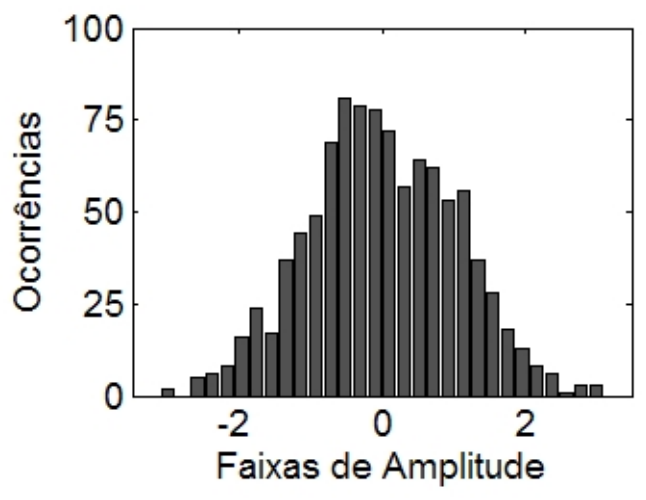

(a)

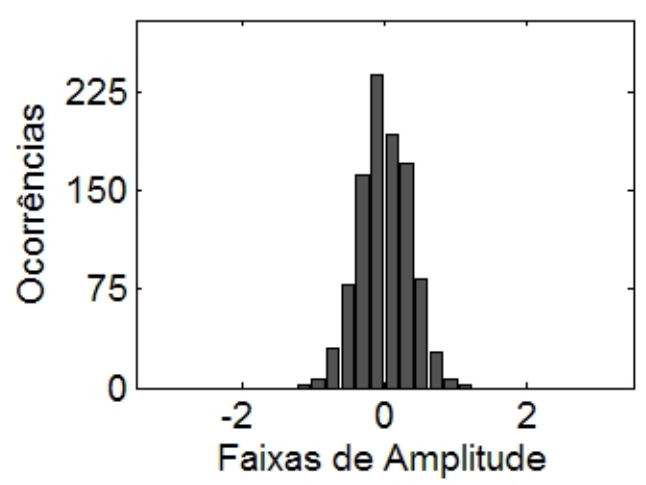

(b)

Figura 5.5: Comparação de dois histogramas (usando 30 células) de sinais de ruído Gaussiano; em (a), sinal possui variância aproximadamente unitária; em (b), mesmo sinal mas com variância em torno de 0,12 .

\subsubsection{Método do Passo de Quantização Constante}

O método da subseção anterior apresenta bons resultados mas, como apresentado, pode não ser a melhor opção para alguns tipos de análise. Melhor seria usar um método que não dependesse de uma discretização da PDF contínua, mas sim que considerasse diretamente o caso discreto. Tal método é apresentado nesta subseção, este usa o passo de quantização constante na estimativa do histograma ao invés de usar um número fixo de células para todos os sinais.

Para se estimar a PDF de um sinal digital, deve-se considerar a quantização da amplitude usada e a faixa de amplitudes do sinal. Os sinais de voz utilizados neste estudo apresentam 16 bits de quantização e, após a normalização da etapa de préprocessamento apresentada no Capítulo 4, amplitudes que variam de -1 a 1 . Dessa forma, o passo de quantização ideal, o qual é definido como a faixa de amplitude dividido pelas combinações permitadas pela quantização, seria igual a $q=2 / 2^{16}=$ $3.052 \times 10^{-5}$.

Porém, com esse passo de quantização, o histograma resultante seria quase vazio, a não ser que o sinal possuísse muitos pontos. Entretanto, os sinais de voz usados possuem aproximadamente $1 s$ de duração com frequiência de amostragem igual a 22.050 $H z$, o que resulta em pouco mais de 20.000 pontos. Com essa consideração, deve-se buscar o passo de quantização menor possível conforme o número de pontos do sinal, para se manter uma boa resolução do histograma. 
O método do passo de quantização constante é interessante quando se precisa comparar a entropia de diversos sinais com faixas de amplitude diferentes, pois, assim, o número de células de cada histograma é diferente, melhorando a estimativa. Outras técnicas para selecionar o tamanho apropriado das células são apresentadas em Shimazaki e Shinomoto (2007).

Como, nesta abordagem, não se considera a discretização da entropia diferencial, mas sim, utiliza-se diretamente o caso discreto, não se realiza correção de tendência. O algoritmo para a estimativa da entropia usando o método do passo de quantização constante é apresentado na Tabela 5.3.

Tabela 5.3: Algoritmo da entropia usando método do passo de quantização constante.

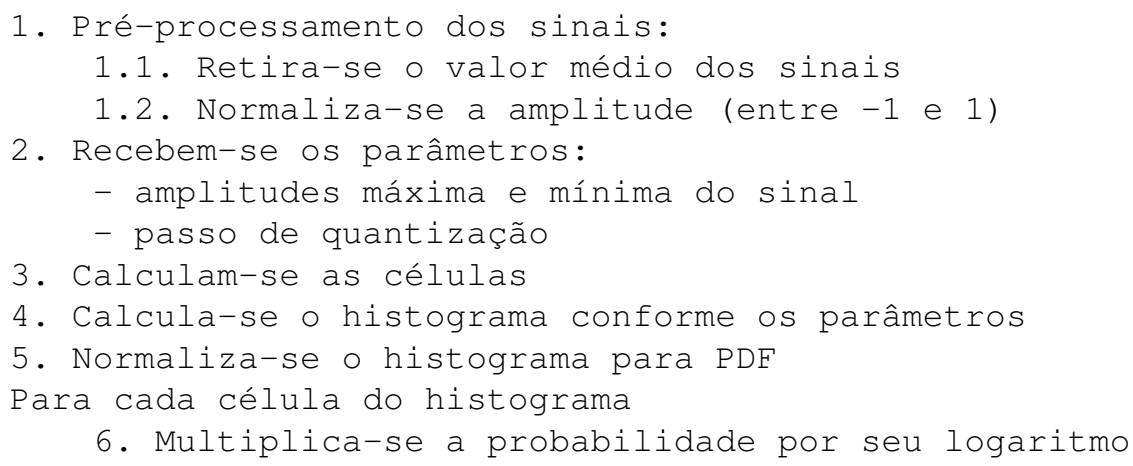

O passo número 5 apresenta a normalização do histograma, o qual é feito dividindose o histograma obtido por sua soma. Assim, o resultado possui probabilidade total igual a unidade, o que é uma condição das PDFs.

Para ilustrar a escolha do passo de quantização, apresenta-se a Figura 5.6. Obtémse dois histogramas com passos de quantização diferentes para o sinal de voz de 2.000 pontos da Figura 4.3. Em (a), tem-se $q=0,08$, o que resulta em histograma de 25 células; em (b), tem-se $q=0,02$, resultando em 100 células.

Como se pode ver na parte (a) da figura, a resolução do histograma é baixa, perdemse diversos detalhes. Isso é resolvido na parte (b), usando passo de quantização quatro vezes menor, obtendo-se uma resolução satisfatória. 


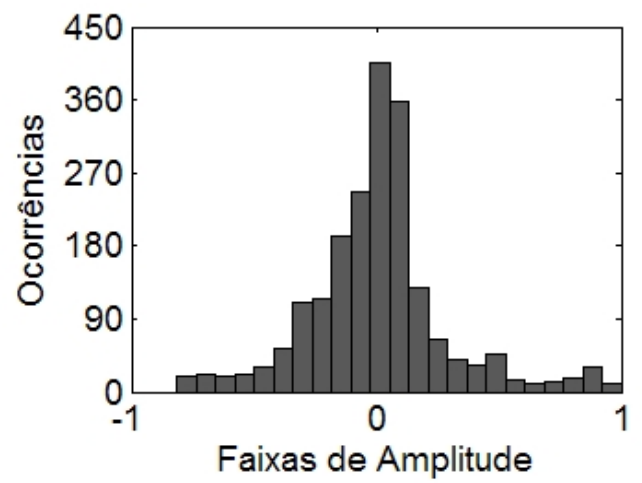

(a)

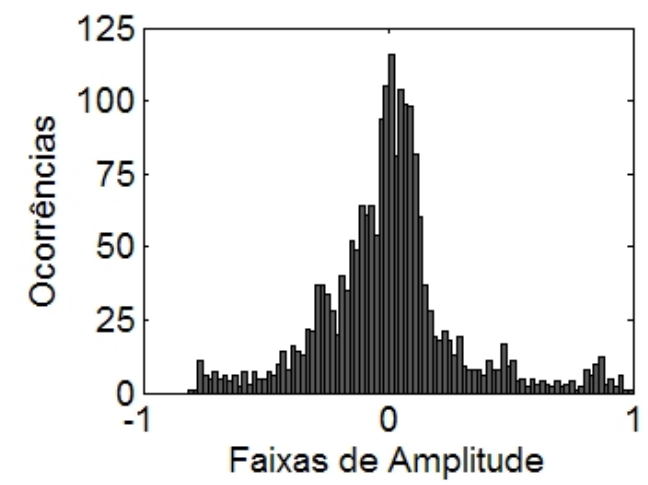

(b)

Figura 5.6: Ilustração da escolha do passo de quantização. Usando um sinal de voz de 2.000 pontos, tem-se dois histogramas usando: (a) $q=0,08$ (25 células) e (b) $q=0,02$ (100 células).

Para avaliar a eficiência do algoritmo proposto, faz-se uma comparação entre a entropia de uma distribuição Gaussiana estimada pelo algoritmo e a esperada, dada pela Equação (5.3). Cria-se um sinal composto por ruído Gaussiano de comprimento igual a 10.000 pontos, média nula e desvio padrão variando entre 0,25 e 3 .

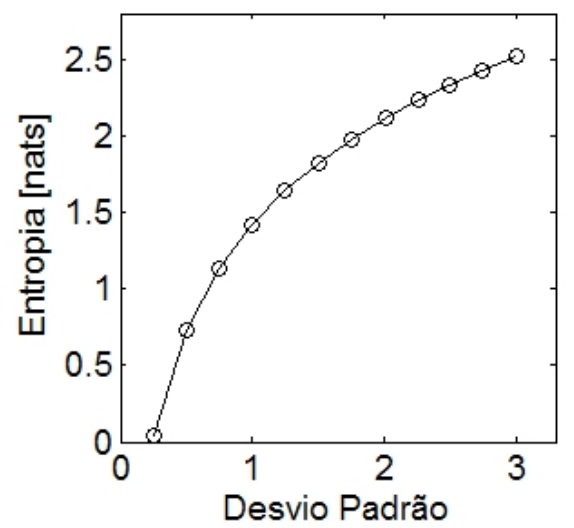

(a)

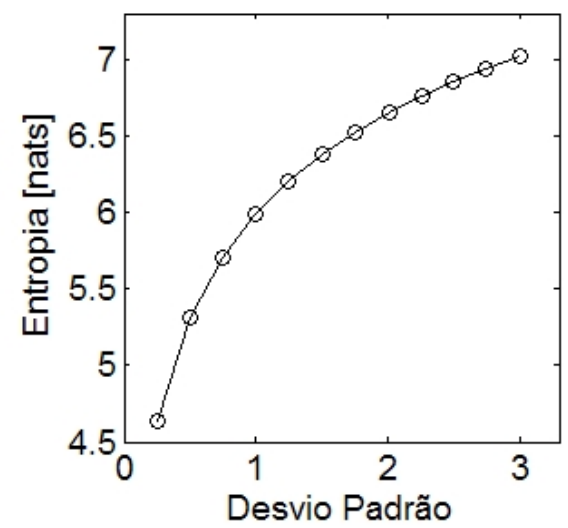

(b)

Figura 5.7: Resultado da comparação entre a entropia teórica de uma distribuição Gaussiana e a entropia estimada com o algoritmo do passo de quantização constante. Em (a), tem-se a entropia teórica obtida pela Equação (5.3). Em (b), tem-se a entropia estimada.

O resultado desse ensaio é apresentado na Figura 5.7. Na parte (a), mostra-se a entropia obtida pela formulação teórica e, na parte (b), mostra-se a entropia estimada pelo algoritmo do passo de quantização constante. Percebe-se que os valores diferem, mas a faixa de variação e o comportamento da curva são muito semelhantes. Como, neste estudo, os valores absolutos da entropia não são tão importantes, mas sim sua variação de sinal para sinal, o algoritmo obteve um resultado adequado. 
Da mesma forma que na subseção anterior, realizou-se ensaios com sinais de voz simulados variando-se os três parâmetros: nível de ruído (SNR), jitter ou shimmer. Como anteriormente, no primeiro ensaio, varia-se o nível de ruído (SNR) entre 5 e 25 $d B$ ( $A d$ entre 0,025 e 0,25$)$. O resultado da estimativa de entropia para esse ensaio usando o método do passo de quantização constante é apresentado na Figura 5.8.

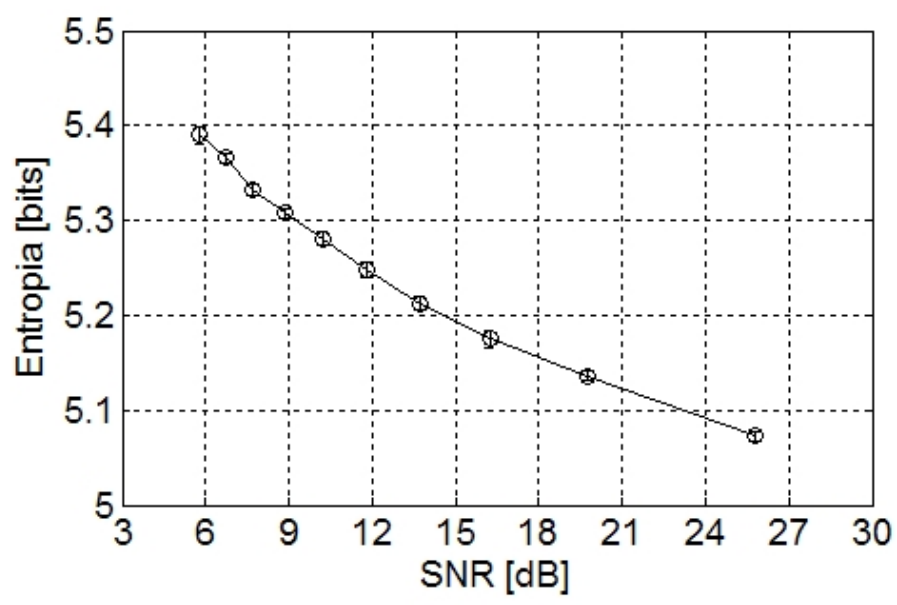

Figura 5.8: Resultados de entropia usando o método do passo de quantização constante para o ensaio de variação de nível de ruído (SNR) de sinais simulados.

Como na Figura 5.2, conforme se aumenta o ruído dos sinais (diminuição do SNR), a entropia aumenta, o qual é o comportamento esperado. Porém, percebe-se a diferença dos valores de entropia com relação aos obtidos pelo método anterior. Isso ocorre devido a diferença de métodos de histograma, qualquer diferença reflete nos valores de entropia. Assim, o importante, como se buscam comparações entre os sinais, é avaliar a diferença entre os valores de cada sinal e não o valor absoluto.

Em seguida, realizaram-se os ensaios de variação de jitter e shimmer, usando a mesma variação de anteriormente: $2 \%$ a $20 \%$. Os resultados de entropia para esses dois ensaios são apresentados nas Figuras 5.9 e 5.10 respectivamente.

Novamente, como no método da discretização da entropia diferencial, os valores de entropia para a variação de jitter não foram influenciados por esse parâmetro. No ensaios de shimmer, a entropia foi inversamente proporcional à variação do parâmetro. 


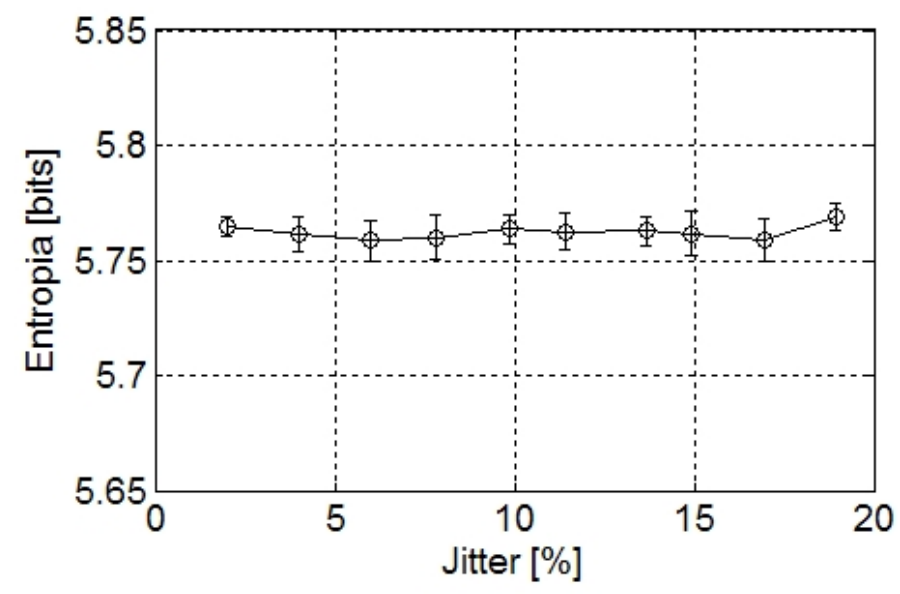

Figura 5.9: Resultados de entropia usando o método do passo de quantização constante para o ensaio de variação de jitter de sinais simulados.

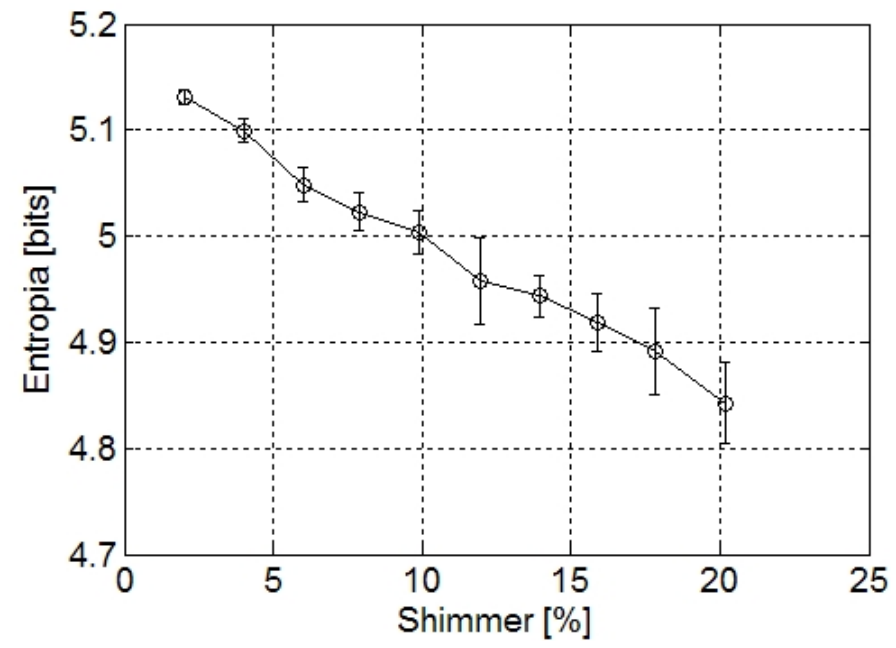

Figura 5.10: Resultados de entropia usando o método do passo de quantização constante para o ensaio de variação de shimmer de sinais simulados.

Para a estimativa da entropia relativa utilizando esse método, são necessárias algumas modificações em relação ao algoritmo apresentado na Tabela 5.2. Esse algoritmo modificado é apresentado na Tabela 5.4.

Tem-se as modificações relevantes ao método, como apresentado para o algoritmo do cálculo da entropia de Shannon, mas tem-se ainda o passo número 6, alinhamento dos histogramas. Ao contrário do que acontece com o método de discretização de entropia diferencial, o qual resulta em dois histogramas com células de mesmo número e alinhadas; para este segundo método, isso não ocorre, portanto, deve-se realizar o alinhamento. 
Tabela 5.4: Algoritmo da entropia relativa usando método do passo de quantização constante.

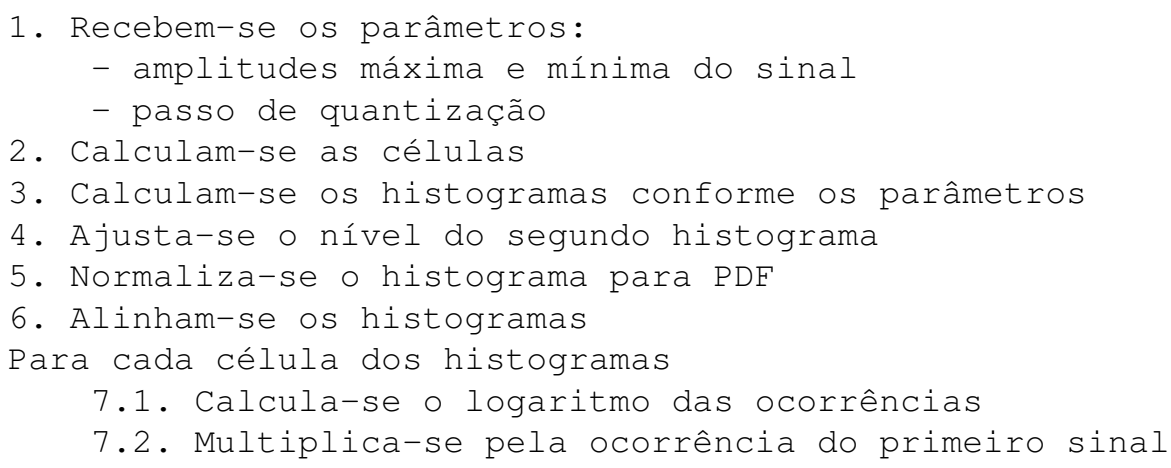

Para ilustrar esse procedimento, apresentam-se as Figuras 5.11 e 5.12. Na primeira, mostra-se o erro de previsão usando um modelo AR(10) do sinal da Figura 4.3. Assim, para o cálculo da PP do sinal de voz, seria necessário estimar a entropia relativa entre o sinal de voz e seu erro de previsão. Usando-se o método do passo de quantização constante com o algoritmo da Tabela 5.4, precisa-se alinhar os histogramas.

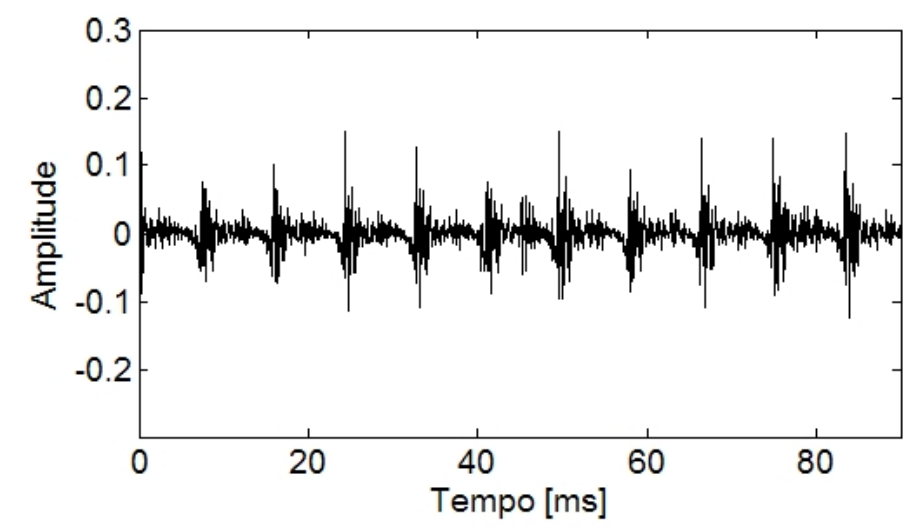

Figura 5.11: Erro de previsão do sinal de voz da Figura 4.3 usando modelo AR(10).

As Figuras 5.12 (a) e (b) apresentam, respectivamente, os histogramas normalizados (PDFs) do sinal de voz e do erro de previsão em função do número de células (100 e 25). Pode-se ver que esses histogramas estão desalinhados e a estimativa da entropia relativa dessa forma resultaria em erro. Já nas partes (c) e (d) da figura, apresentam-se os histogramas alinhados, permitindo-se o cálculo da entropia relativa.

Para avaliar o desempenho do algoritmo, realiza-se um ensaio com duas distribuições Gaussianas de médias nulas e desvios padrões variáveis, comparando-se os resultados obtidos pelo algoritmo com os valores esperados teoricamente para entro- 


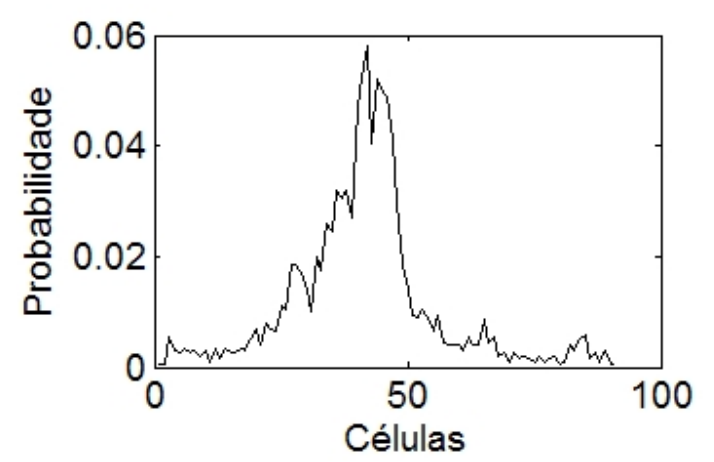

(a)

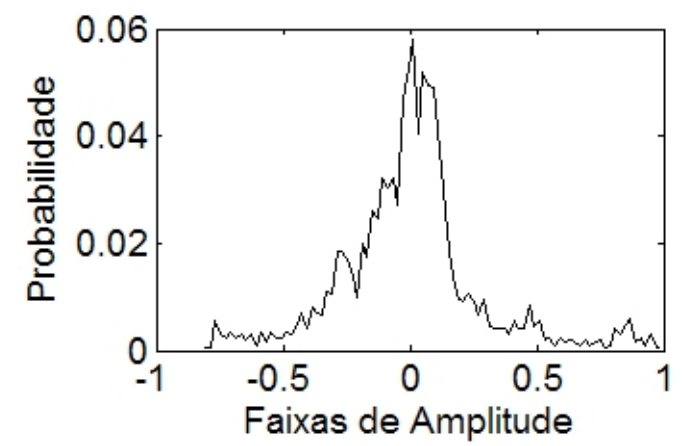

(c)

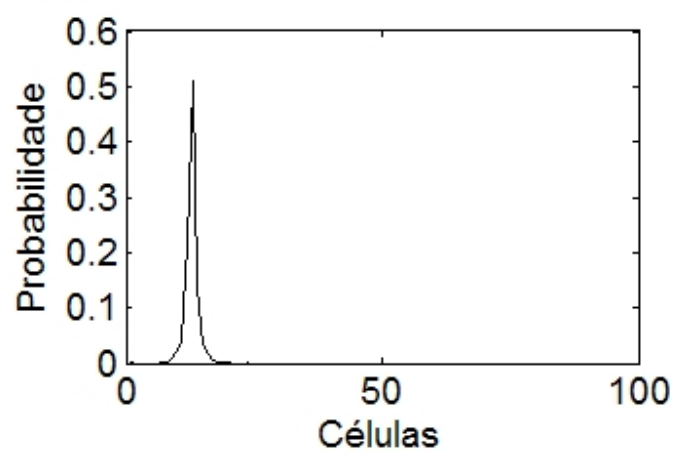

(b)

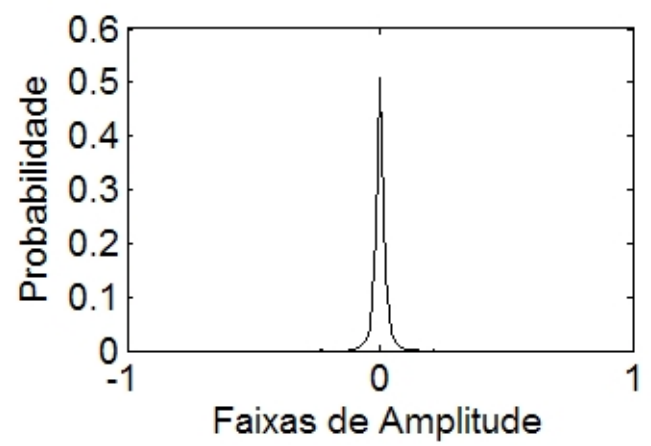

(d)

Figura 5.12: Ilustração do alinhamento dos histogramas para a estimativa da entropia relativa usando o método do passo de quantização constante. Histogramas (normalizados) desalinhados do sinal de voz da Figura 4.3 em (a) e, em (b), do erro de previsão da Figura 5.11. Em (c) e (d), os mesmos histogramas anteriores mas alinhados conforme suas faixas de amplitude.

pia diferencial. A dedução da entropia relativa diferencial para duas PDFs Gaussianas, $p_{X}(x)$ e $q_{X}(x)$, é apresentada no Apêndice C, sendo repetida na Equação (5.7), com $\sigma_{p}$ e $\sigma_{q}$ os desvios padrões das PDFs.

$$
D\left(p_{X} \| q_{X}\right)=\frac{\sigma_{p}^{2}-\sigma_{q}^{2}}{2 \sigma_{q}^{2}}+\ln \frac{\sigma_{q}}{\sigma_{p}}
$$

Inicialmente, criou-se dois sinais com distribuições Gaussianas e desvios padrões variando entre 0,25 e 3 . O resultado da entropia relativa pela fórmula teórica é apresentada na Figura 5.13 (a) e o resultado pelo algoritmo na parte (b).

Para a entropia relativa de duas Gaussianas, quanto maior o desvio padrão da primeira PDF $\left(\sigma_{p}\right)$ e menor a da segunda $\left(\sigma_{q}\right)$, maior é a entropia relativa. Isso pois na definição da entropia relativa, Equação (3.5), $q_{X}(x)$ aparece no denominador do logaritmo. Essa combinação geralmente ocorre no cálculo da PP, pois o erro de previsão, que é a segunda PDF, sempre tem PDF com menor largura. 


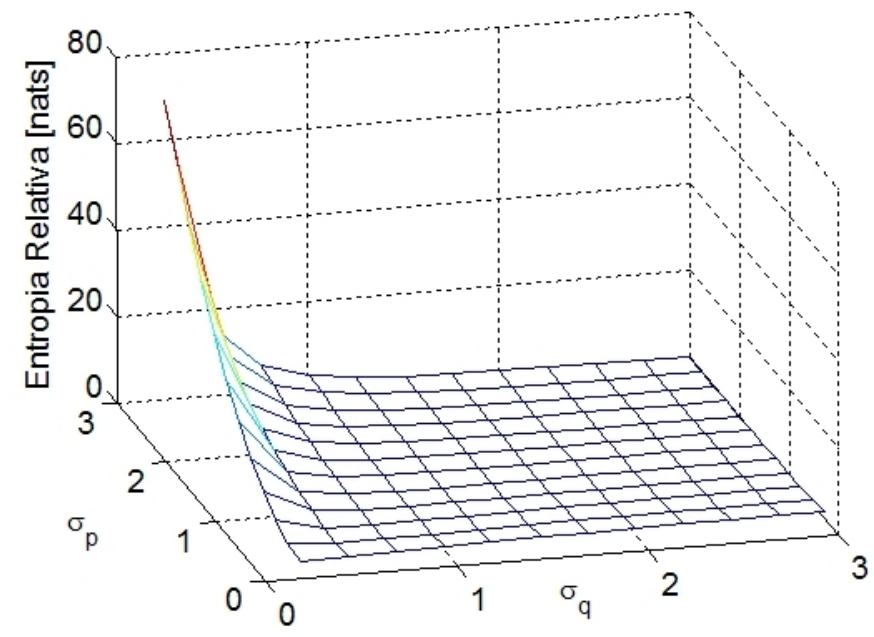

(a)

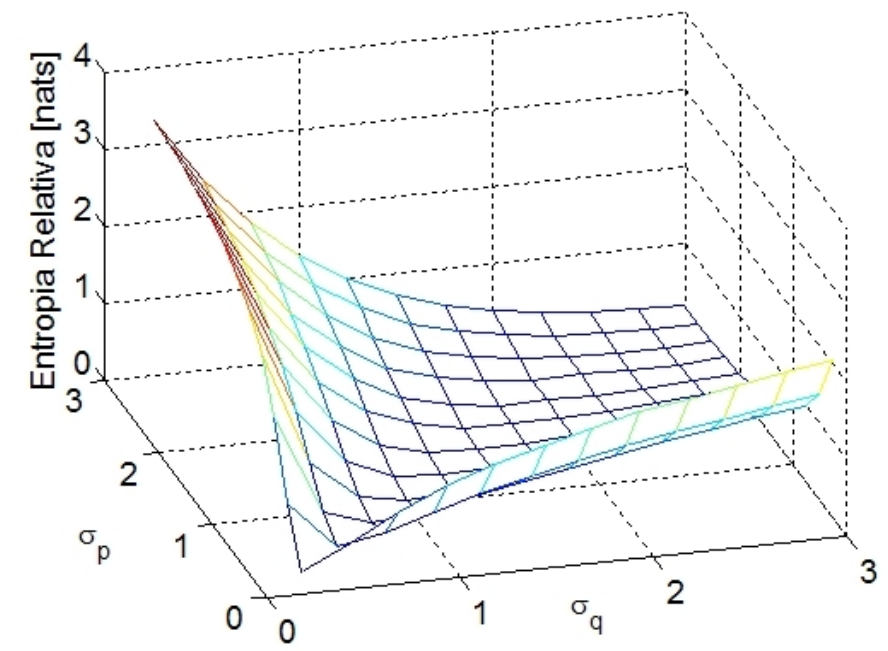

(b)

Figura 5.13: Resultado da comparação entre a entropia relativa diferencial de duas distribuições Gaussianas e a entropia estimada com o algoritmo do passo de quantização constante. Em (a), tem-se os valores teóricos obtidos pela Equação (5.7). Em (b), tem-se o valor estimado.

Observando-se a parte (a) da figura, percebe-se que, nessa região, realmente, a entropia relativa apresenta valores bem maiores do que no resto. Já na parte (b), esse valor é mais limitado por causa da correção da segunda PDF realizada pelo algoritmo, evitando essa tendência de obter valores muito altos.

Par melhor comparar os dois resultados, refez-se esse ensaio evitando valores muito pequenos de desvios padrões, usou-se variação de 1 a 3 somente. A Figura 5.14 apresenta os novos resultados. Novamente, em (a), tem-se o teórico e, em (b), o estimado pelo algoritmo. 


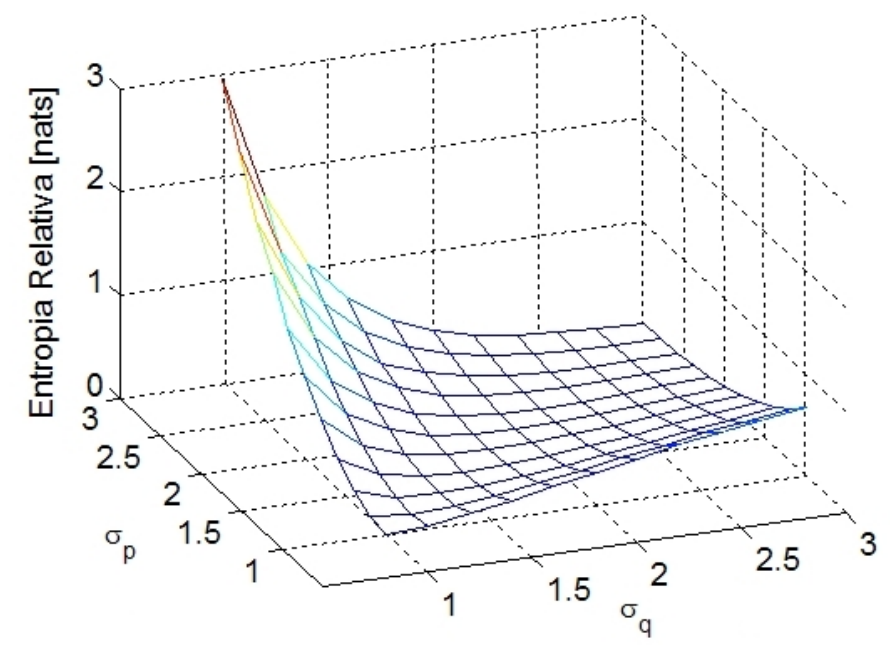

(a)

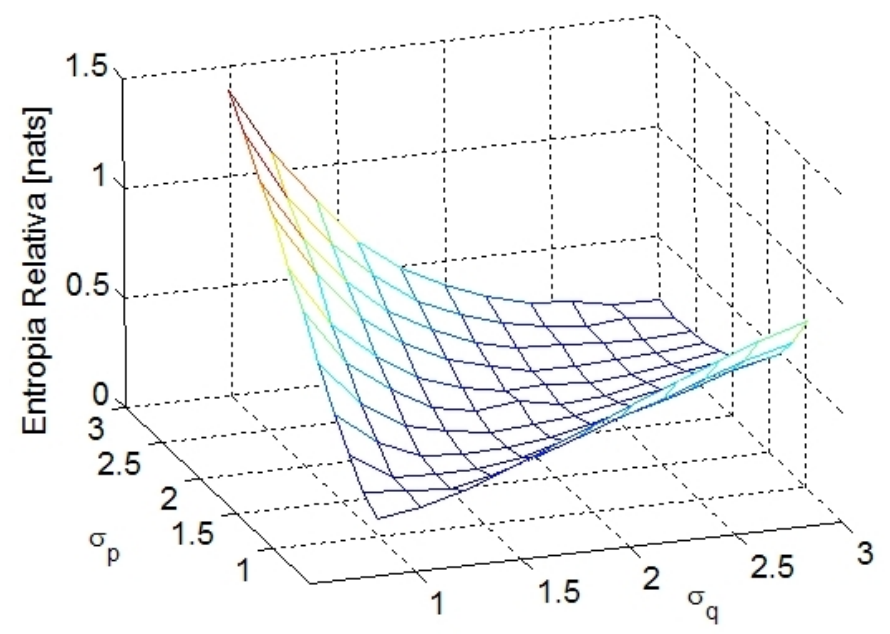

(b)

Figura 5.14: Resultado da comparação entre a entropia relativa diferencial de duas distribuições Gaussianas e a entropia estimada com o algoritmo do passo de quantização constante. Em (a), tem-se os valores teóricos obtidos pela Equação (5.7). Em (b), tem-se o valor estimado.

Observa-se que o comportamento das duas curvas é bem semelhante, a não ser pelos valores, os quais são diferentes. Entretanto, como já mencionado para o caso da entropia de Shannon, interessa mais, neste estudo, a diferença entre os valores de entropia. Portanto, pode-se considerar que o algoritmo tem um desempenho satisfatório.

Apesar desse método ter um tamanho de célula variável, esse é constante para cada sinal analisado. Assim, apresenta-se o método da equalização do histograma na subseção seguinte, o qual tem células de tamanho variável para um mesmo sinal, de acordo com a sua distribuição. 


\subsubsection{Método da Equalização do Histograma}

Este método usa uma equalização do histograma para melhorar a estimativa da entropia relativa entre dois sinais. Baseia-se nas técnicas de processamento de imagens, as quais são usadas para correção de cor e contraste de imagens digitais (Lim, 1990).

O objetivo do algoritmo é tentar obter um histograma mais plano pelo aumento do tamanho de suas células conforme o número de ocorrências começam a cair. Usaramse comparações simples para realizar esse procedimento, entretanto técnicas mais sofisticadas podem ser usadas como a apresentada em Engel (1997), o qual usa transformada wavelet para criar um histograma adaptativo com células variáveis.

A Tabela 5.5 apresenta um resumo do algoritmo da entropia usando método da equalização do histograma. Como observado no passo número 2, os parâmetros fornecidos para o algoritmo são o número de amostras da primeira célula e o passo de busca.

Tabela 5.5: Algoritmo da entropia usando método da equalização do histograma.

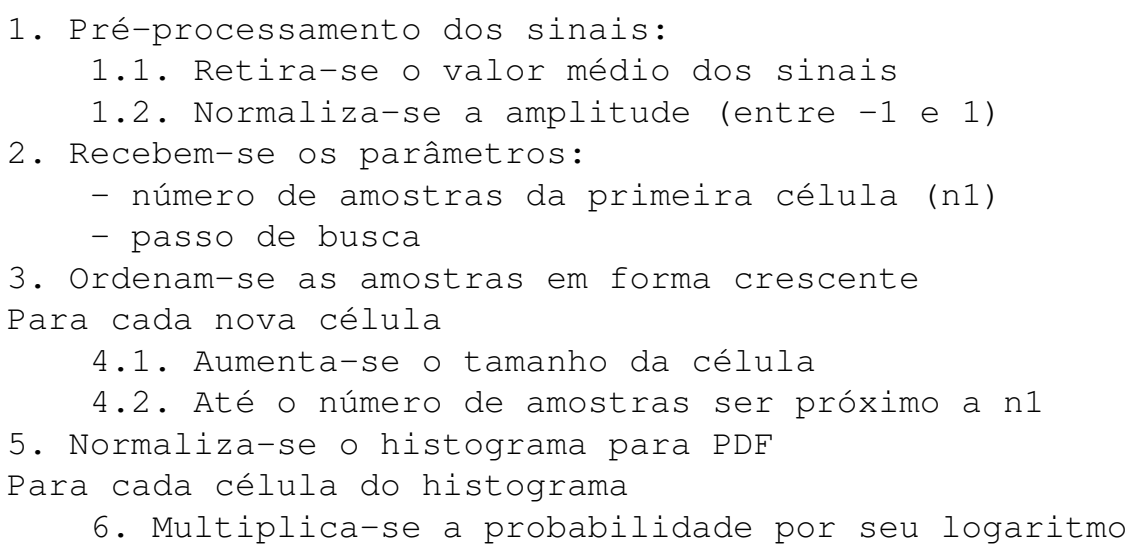

O critério de parada do passo 4.2 é dado pelo passo de busca. Conforme se realiza a busca para amostras de cada célula (adicionando o passo de busca), se o número das amostras passar do valor da primeira célula, pára-se a busca. Se o número de amostras que passaram do valor for maior do que as que faltaram no passo anterior, escolhe-se o valor anterior.

Para ilustrar esse algoritmo, apresenta-se o exemplo a seguir. Utiliza-se o sinal de ruído cujo histograma é apresentado na Figura 5.5 (b), o qual tem faixa de amplitude 
entre -1 e 1. A Figura 5.15 (a) mostra a PDF desse sinal calculado pelo algoritmo do passo de quantização constante, e também a PDF esperada para uma distribuição Gaussiana (linha tracejada). Não se apresenta a PDF obtida com o método da discretização da entropia diferencial pois, para esse exemplo, essa é muito parecida com a parte (a).

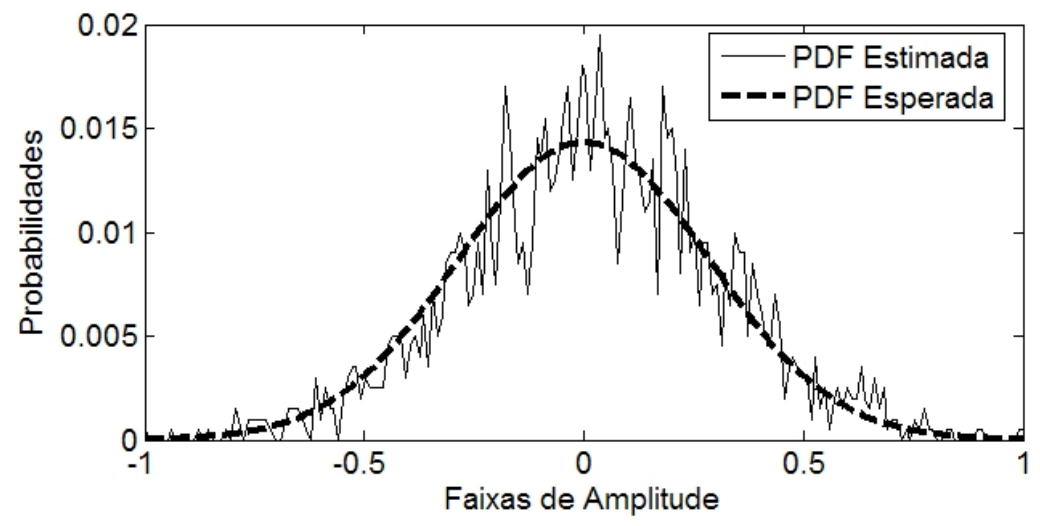

(a)

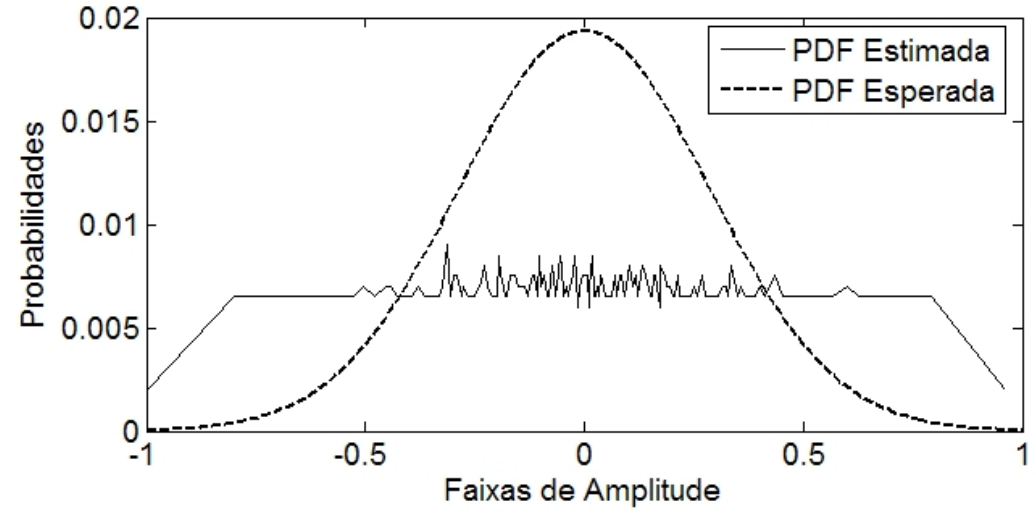

(b)

Figura 5.15: Ilustração do algoritmo da equalização do histograma. (a) PDF obtida com o método do passo de quantização constante e PDF esperada para distribuição Gaussiana (linha tracejada). (b) PDF obtida pelo método de equalização, sendo o número de amostras da primeira célula igual a 15 e passo de busca de 0,001 .

Na parte (b) da figura, mostra-se a PDF obtida pelo algoritmo da equalização do histograma, usando-se número de amostras da primeira célula igual a 15 e passo de busca de 0,001. Mostra-se, também, a PDF esperada para uma distribuição Gaussiana (linha tracejada). Como observado, a PDF normalizada é mais plana do que nos outros métodos. Além disso, apresenta leve oscilações nas faixas próximas do zero.

Visualmente, a PDF obtida por este método parece ser uma péssima aproximação da PDF esperada, entretanto, seu objetivo não é esse. No cálculo da PP usando a en- 
tropia relativa entre o sinal de voz e seu erro de previsão, como visto na Figura 5.12 (c) e (d), a PDF do erro possui pequena faixa de amplitudes. Isso pode resultar em problemas no cálculo da entropia, pois a segunda PDF é usada no denominador da estimativa, passo 7.1 da Tabela 5.4, assim, valores muito baixos mascaram os resultados dessa entropia.

Visando amenizar esse problema, utiliza-se o método de equalização do histograma, para evitar que valores muito baixos de probabilidade sejam usados para o cálculo da entropia relativa. A Tabela 5.6 apresenta um resumo do algoritmo usando para estimar a entropia relativa usando o método de equalização do histograma.

Tabela 5.6: Algoritmo da entropia relativa usando método de equalização do histograma.

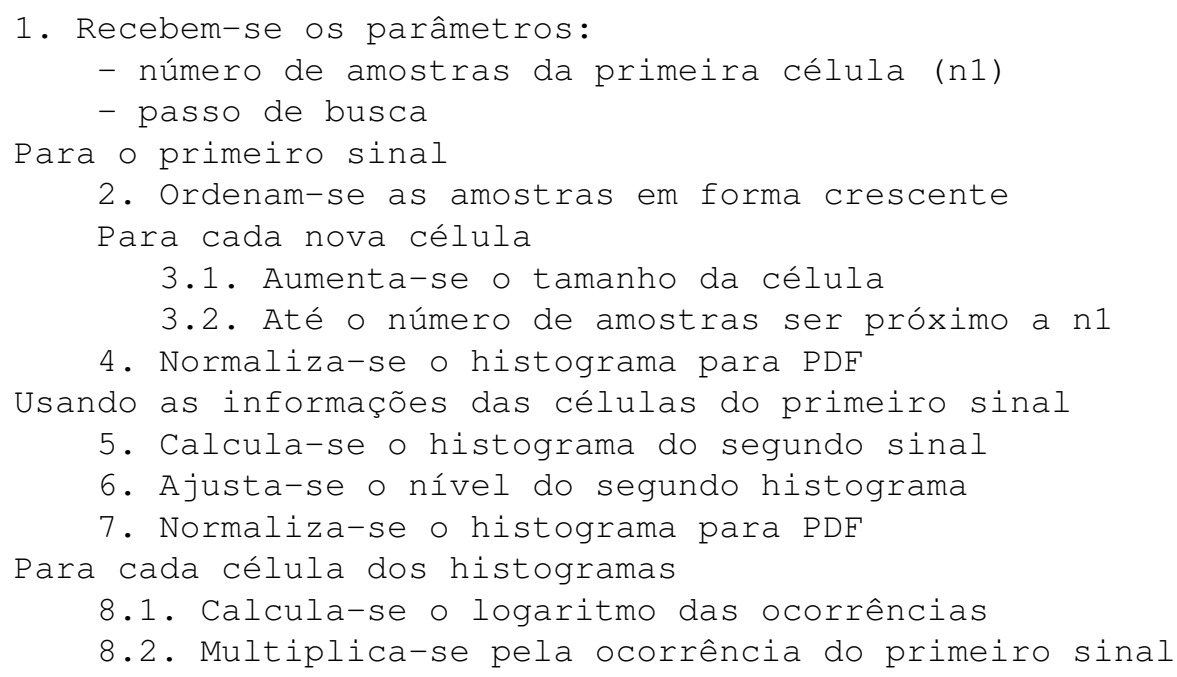

Para evitar o problema do alinhamento dos histogramas, realiza-se a equalização do histograma do primeiro sinal e usam-se as informações encontradas das células para estimar o histograma do segundo sinal. Para ilustrar esse procedimento, apresenta-se um exemplo usando o sinal de voz da Figura 4.3 e o erro de previsão usando AR(10) da Figura 5.11. As PDFs desses dois sinais são apresentados na Figura 5.16 (a) e (b) respectivamente, sendo o erro o segundo sinal na estimativa da entropia relativa.

Como se pode ver nessa figura, a PDF do primeiro sinal foi equalizada corretamente, entretanto, a PDF do erro de previsão, a qual é obtida com os valores de células da primeira PDF, ficou muito parecida com a da Figura 5.12 (d), obtida com o método do passo de quantização constante. Por esse motivo, os resultados de PP usando esse 

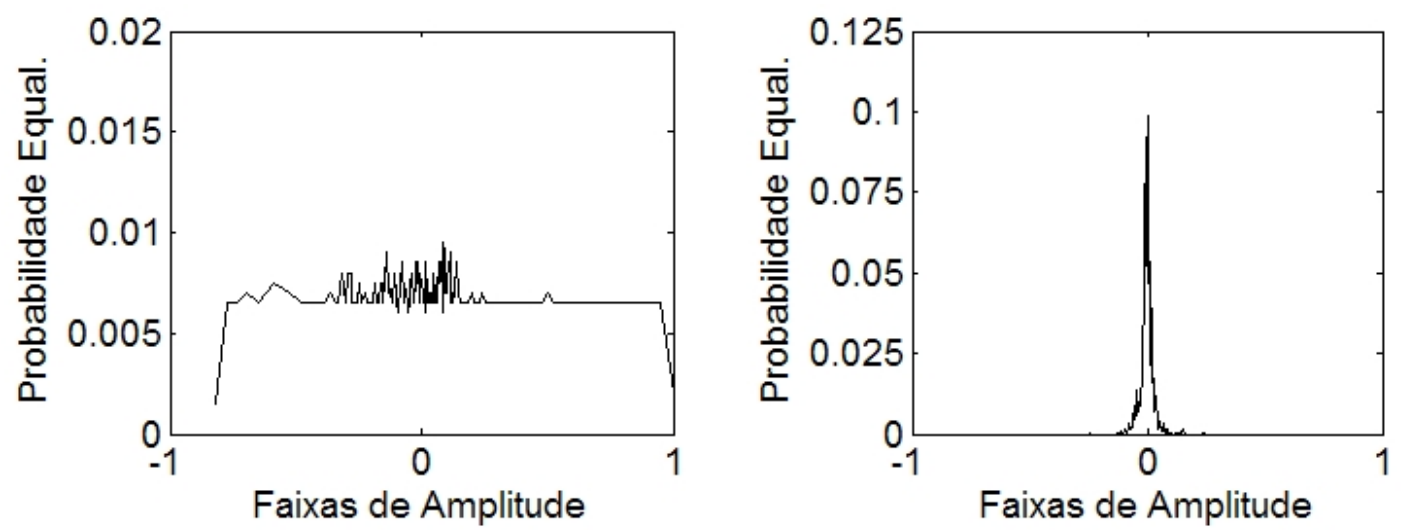

Figura 5.16: Ilustração do uso do algoritmo da Tabela 5.6. (a) PDF do sinal de voz da Figura 4.3. (b) PDF do erro de previsão usando AR(10) da Figura 5.11.

algoritmo foram muito semelhantes aos obtidos com o método do passo de quantização constante. Dessa forma, optou-se por utilizar esse método ao invés do método de equalização do histograma, devido à simplicidade do primeiro.

Apesar desse resultado, realizaram-se os mesmos ensaios com sinais simulados das subseções anteriores com o método de equalização do histograma. Primeiramente, variou-se o nível de ruído (SNR) entre 5 e $25 d B$, o resultado da estimativa de entropia é apresentado na Figura 5.17.

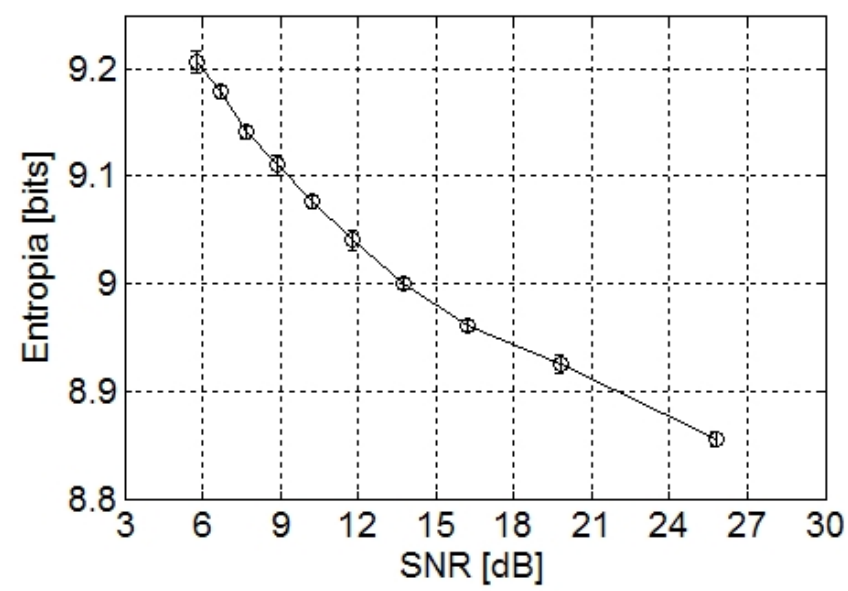

Figura 5.17: Resultados de entropia usando o método de equalização do histograma para o ensaio de variação de nível de ruído (SNR) de sinais simulados.

Para os ensaios de variação de jitter e shimmer, com a variação desses parâmetros de $2 \%$ a 20\%, os resultados de entropia são apresentados nas Figuras 5.18 e 5.19 respectivamente. Os resultados dos três ensaios foi muito semelhante aos obtidos pelos dois métodos anteriores. 


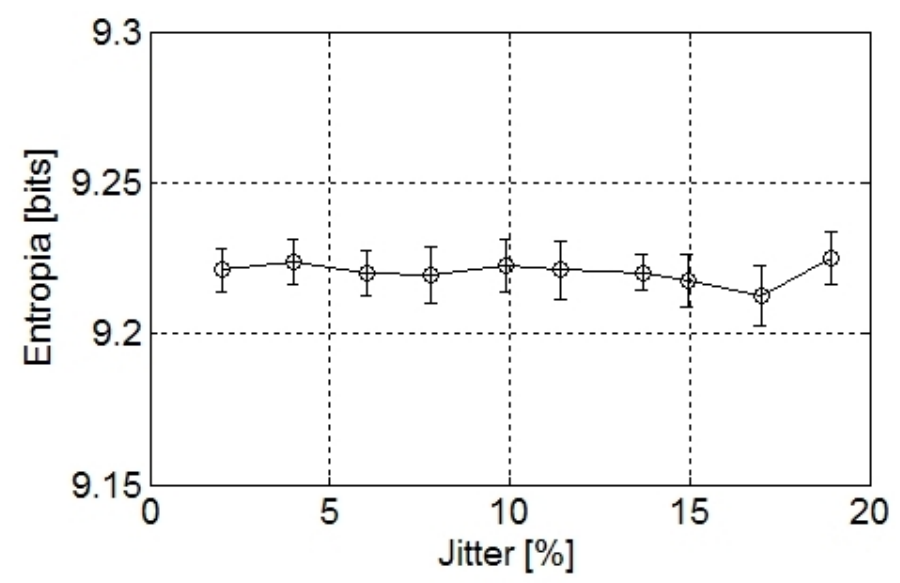

Figura 5.18: Resultados de entropia usando o método de equalização do histograma para o ensaio de variação de jitter de sinais simulados.

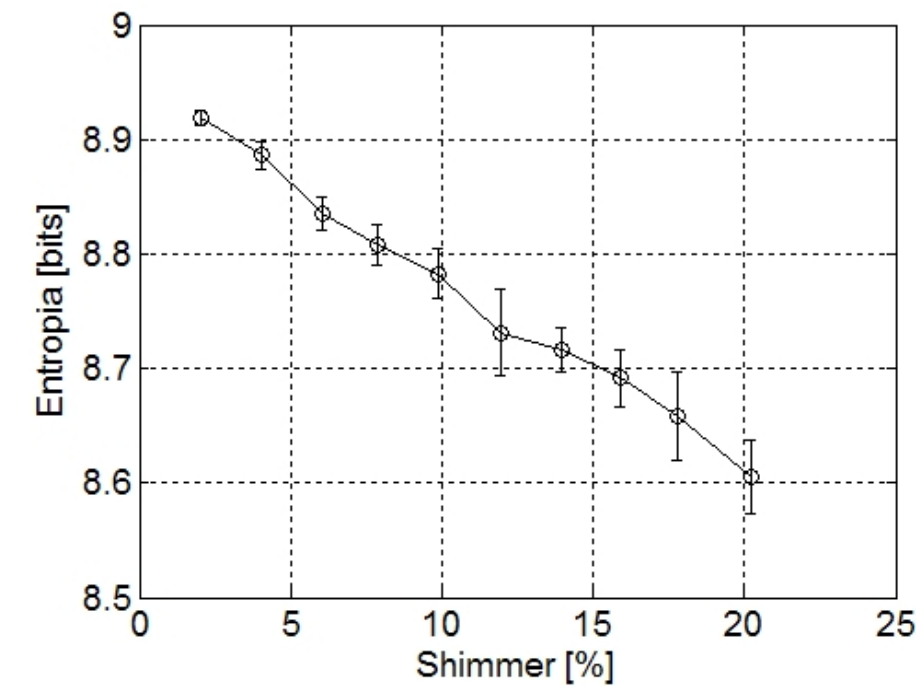

Figura 5.19: Resultados de entropia usando o método de equalização do histograma para o ensaio de variação de shimmer de sinais simulados. 
Na próxima subseção, aborda-se a estimativa da entropia de bloco, a qual é usada para se obter a curva de crescimento de entropia e suas características.

\subsubsection{Entropia de Blocos}

Nesta seção, comenta-se sobre a estimativa da entropia de blocos, a qual foi apresentada no Capítulo 3. Mostram-se alguns testes com sinais artificiais para demonstrar o comportamento dessa medida e de sua curva de crescimento.

De acordo com Schürmann e Grassberger (1996), para uma seqüência finita de tamanho $N$, uma forma comum de estimar a probabilidade de uma palavra $x^{L}$ de comprimento $L$ é usando o método da verossimilhança padrão, Equação (5.8), sendo que $n_{x^{L}}$ é o número de ocorrências da palavra $x^{L}$.

$$
\hat{p}\left(x^{L}\right)=\frac{n_{x^{L}}}{N}
$$

Assim, com a estimativa da PDF da seqüência, a entropia de bloco por ser obtida substituíndo-se a Equação (5.8) em (3.6). Dessa forma, obtém-se a Equação (5.9), sendo $\hat{\mathcal{X}}^{L}$, o alfabeto de possibilidades das palavras $x^{L}$ obtidas dos $N$ pontos da seqüência.

$$
\hat{H}_{B}(L)=-\sum_{x^{L} \in \hat{\mathcal{X}}^{L}} \hat{p}\left(x^{L}\right) \log _{2} \hat{p}\left(x^{L}\right)
$$

Usando essa formulação, desenvolveu-se um algoritmo para estimativa da entropia de bloco conforme apresentado na Tabela 5.7. Como visto no passo número 3, o valor da entropia de bloco para $L=1$ é igual a entropia de Shannon do sinal. O passo número 4 mostra a transformação do sinal para um vetor cujos pontos são o número da célula na qual se encaixam cada um dos pontos do sinal.

Para ilustrar o algoritmo, apresenta-se um exemplo similar a um em Crutchfield e Feldman (2003), no qual se deseja obter a curva de crescimento da entropia de um sinal binário com período de 5 amostras. Esse sinal é composto pela repetição da sequiência $\{1,0,1,0,1\}$ com tamanho de 5.000 símbolos. A Figura 5.20 mostra a curva de crescimento da entropia (de bloco) para comprimento máximo de 6 símbolos. 
Tabela 5.7: Algoritmo da estimativa da entropia de bloco.
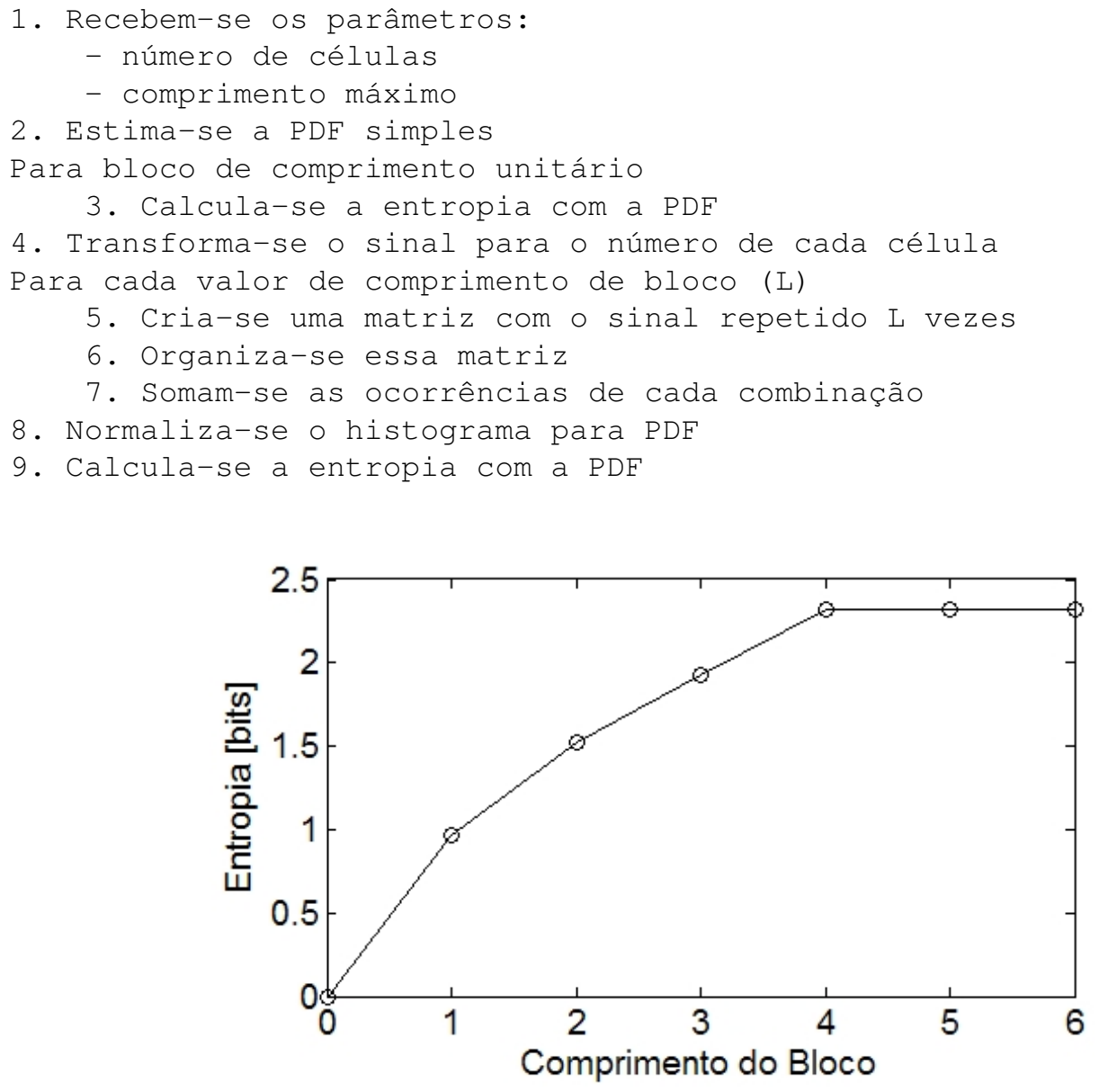

Figura 5.20: Curva de crescimento da entropia de bloco de um sinal binário com período de 5 símbolos, $\{1,0,1,0,1\}$, para comprimento máximo de 6 símbolos.

Conforme apresentado no Capítulo 3, a assíntota da curva de crescimento da entropia possui caracteríticas que definem o sistema gerador do sinal. A inclinação da assíntota é a taxa de entropia da fonte, a qual, como já mencionado, está relacionada com a quantidade de aleatoriedade que continua sendo observada nas medidas após todas as correlações e estruturas serem consideradas. Portanto, como o sinal é periódico, a taxa de entropia da fonte é zero, pois, após considerar a periodicidade do sinal, não resta mais aleatoriedade no sistema.

A curva converge para $L=4$ antes do período do sinal, mostrando que a quantidade de informação necessária já havia sido obtida. O excesso de entropia, valor da assíntota para $L=0$, o qual está relacionado com a redundância do sistema, é aproximadamente 2,32 bits. 
O problema da estimativa da entropia em blocos ocorre com sinais reais, porque as combinações possuem tamanhos muito grandes, assim, não se consegue usar a Equação (5.8). Uma possível solução é limitar a codificação do sinal e, então, estimar as probabilidades com essa equação.

Assim, modificou-se o exemplo anterior para um sinal com período de cinco símbolos reais, formado por $\{0.2380,0.8119,-0.25,0.3817,0.1411\}$. A curva de crescimento de entropia resultante, para comprimento máximo de bloco igual a 6 símbolos, é apresentada na Figura 5.21, quando se usa codificação de amplitude de somente 5 valores. Comparando-se com o exemplo anterior, tem-se que a convergência é mais rápida, provavelmente pela maior codificação usada, 5 valores.

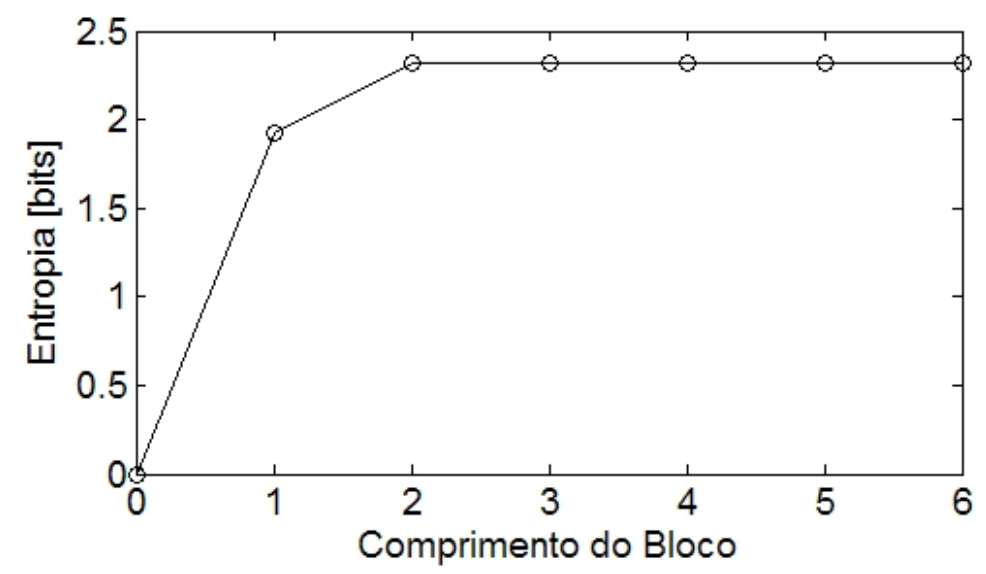

Figura 5.21: Curva de crescimento da entropia de bloco de um sinal real com período de 5 símbolos, $\{0.2380,0.8119,-0.25,0.3817,0.1411\}$, para comprimento máximo de 6 símbolos e codificação de amplitude de somente 5 valores.

Apesar do problema estar aparentemente resolvido, o exemplo utilizado foi muito simples. Em um caso mais complexo, o número de possibilidades de blocos apresenta um crescimento exponencialmente acentuado conforme $L$ aumenta. Assim, faz-se necessário possuir muitos pontos para se estimar confiavelmente as probabilidades dos blocos.

Para ilustrar esse problema, apresenta-se outro exemplo. Considera-se a estimativa da curva de crescimento de entropia para um sinal binário aleatório (distribuição uniforme) com tamanho igual a 10.000 pontos para comprimento de bloco máximo de 20 símbolos. A Figura 5.22 mostra a curva de entropia para esse exemplo.

Como o sinal é aleatório, a entropia de bloco deveria crescer indefinidamente, pois 


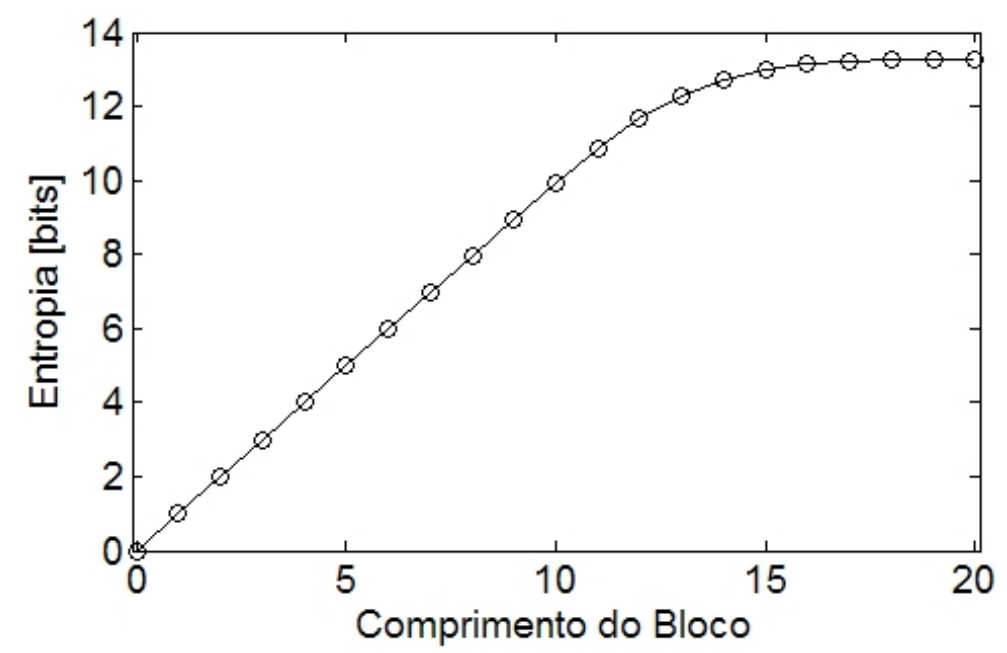

Figura 5.22: Curva de crescimento da entropia de bloco de um sinal binário aleatório (distribuição uniforme) para comprimento de bloco máximo de 20 símbolos.

a taxa de entropia da fonte é não-nula, devido a aleatoriedade do sinal. Entretanto, ao redor de $L=15$, acontece uma saturação por causa da limitada disponibilidade de amostras para a grande quantidade de possibilidade de blocos.

Essa saturação é muito mais rápida para sinais reais, como mostra a Figura 5.23, a curva de entropia (comprimento de bloco máximo de 20 símbolos) de um sinal aleatório (distribuição Gaussiana) com valores reais. Entretanto, a entropia de blocos é calculada para codificação de amplitude de somente 20 valores.

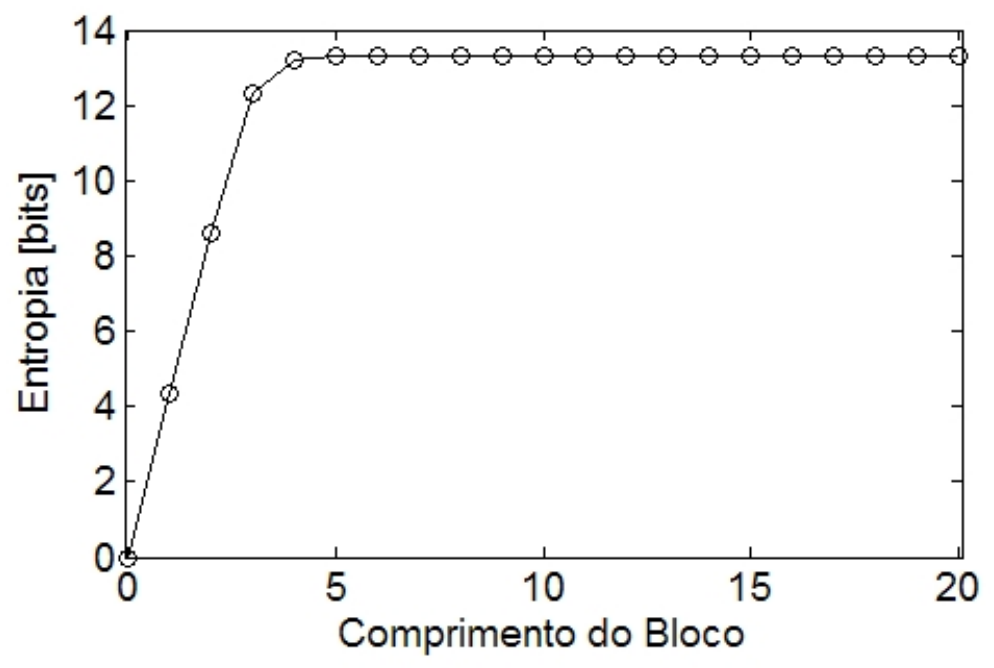

Figura 5.23: Curva de crescimento da entropia de bloco de um sinal real aleatório (distribuição Gaussiana) para comprimento de bloco máximo de 20 símbolos e codificação de amplitude de 20 valores. 
Como se pode ver, da mesma forma que para o caso binário, a curva de entropia do sinal real satura, quando não deveria. Porém, essa saturação ocorre bem antes, por volta de $L=4$. Esse ponto de saturação é também função da codificação de amplitude utilizada, nesse caso, 20 valores (faixas de amplitude), conforme o passo número 4 do algoritmo da Tabela 5.7.

Considerando a codificação de amplitude dos sinais de voz deste estudo, 16 bits, sendo a amplitude normalizada entre -1 e 1, o número máximo de possibilidades de amplitude do sinal para $L=1$ seria $2^{16}=65536$, com resolução (passo de quantização) de $3,05 \times 10^{-5}$. Entretanto, esse número de possibilidades é muito grande para ser usado, por isso, usa-se uma quantidade bem menor. No exemplo anterior, usou-se somente 20, uma resolução de 0,10 . Quanto maior o número de possibilidades, maior a resolução da entropia, porém mais rápido se chega na saturação.

A Figura 5.24 ilustra a resolução da amplitude obtida pelo uso de 20 possibilidades para o sinal do exemplo. Em (a), apresenta-se um trecho do sinal real obtido de distribuição Gaussiana; em (b), tem-se a versão transformada conforme a nova faixa de amplitudes (passo número 4 do algoritmo), contendo 20 possibilidades. Em (c) e (d), respectivamente, tem-se os histogramas do sinal e de sua versão transformada, usam-se 50 células. Pode-se ver como diminuem as possibilidades de valores.

A Figura 5.25 ilustra a razão de ocorrer a saturação da estimativa da entropia de bloco conforme $L$ aumenta. Nessa figura, apresenta-se o número de possibilidades encontrados no sinal real aleatório do exemplo anterior conforme se estimava $\hat{p}\left(x^{L}\right)$.

Quando $L=5$, o número de possibilidades é quase igual ao tamanho do sinal, 10.000 pontos. Dessa forma, a estimativa das probabilidades para comprimentos de bloco a partir desse valor possuem péssima qualidade. Com isso, percebe-se que a estimativa da assíntota da curva de crescimento de entropia para sinais reais com uma codificação razoável torna-se impossível. Além disso, as derivadas dessa curva, conforme apresentado no Capítulo 3, também se tornam inúteis. 


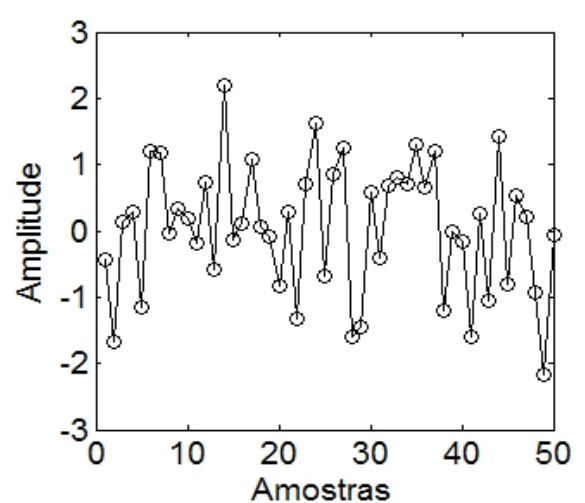

(a)

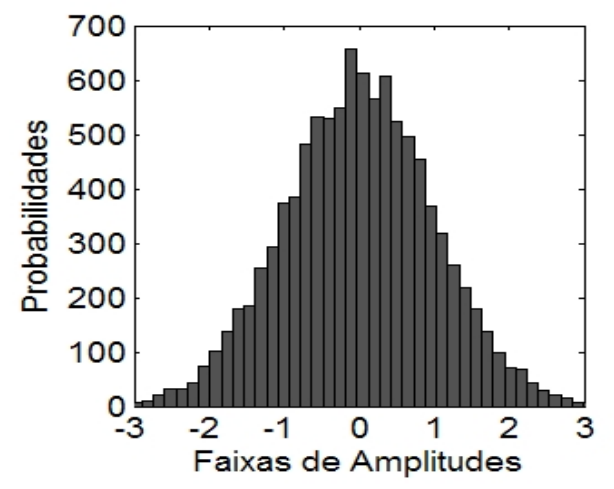

(c)

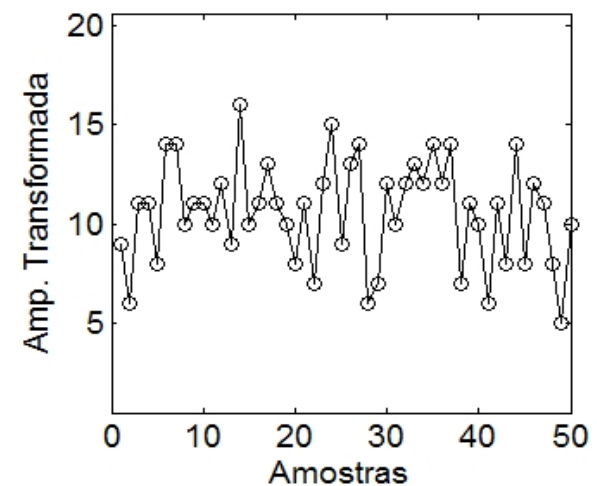

(b)

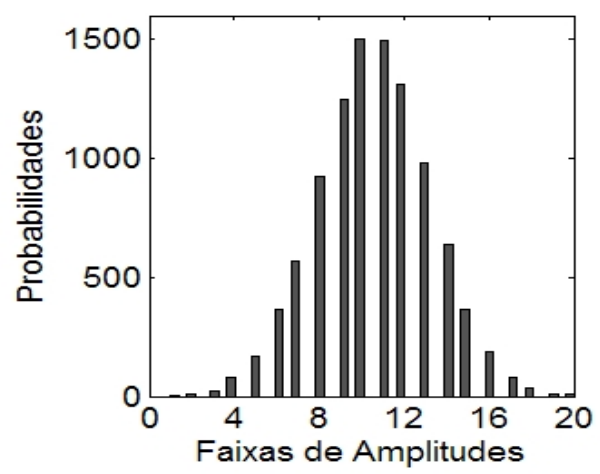

(d)

Figura 5.24: Ilustração da utilização de menor quantidade de faixas de amplitude para a estimativa da entropia de bloco para sinais reais. (a) Trecho do sinal real obtido de distribuição Gaussiana do exemplo anterior. (b) Versão transformada desse sinal com nova faixa de amplitudes contendo 20 possibilidades. (c) Histograma do sinal usando 50 células. (d) Histograma do sinal transformado usando 50 células.

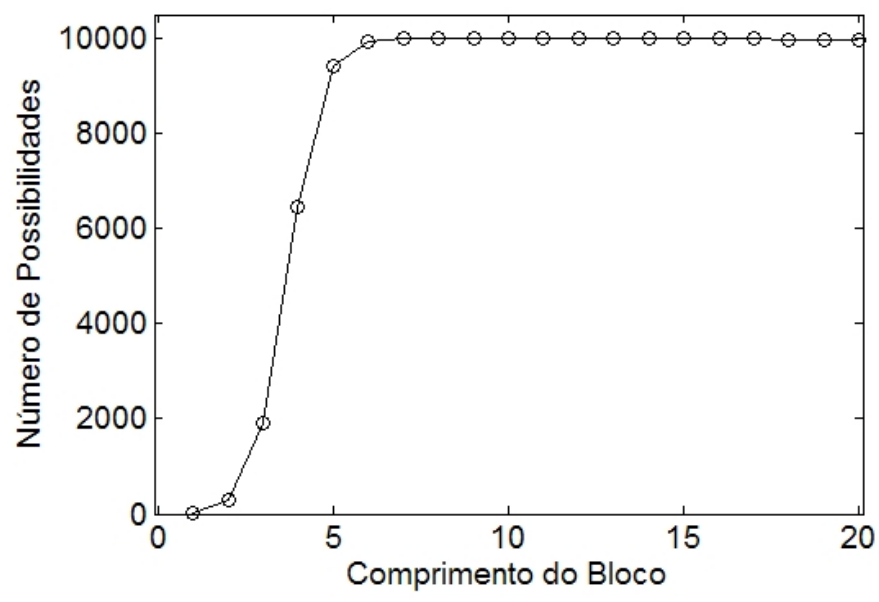

Figura 5.25: Ilustração do número de possibilidades encontrados no sinal real aleatório do exemplo anterior. Mostra-se que, para $L=5$, esse número é quase igual ao tamanho do sinal, 10.000 pontos, o que resulta em saturação da entropia de bloco. 
Como um exemplo mais próximo da realidade, apresenta-se alguns sinais senoidais corrompidos por ruído Gaussiano. Estimou-se a entropia de bloco de cinco sinais, os quais possuem diferentes níveis de ruído, usando codificação de amplitude de 16 valores. As curvas de crescimento da entropia são apresentadas na Figura 5.26.

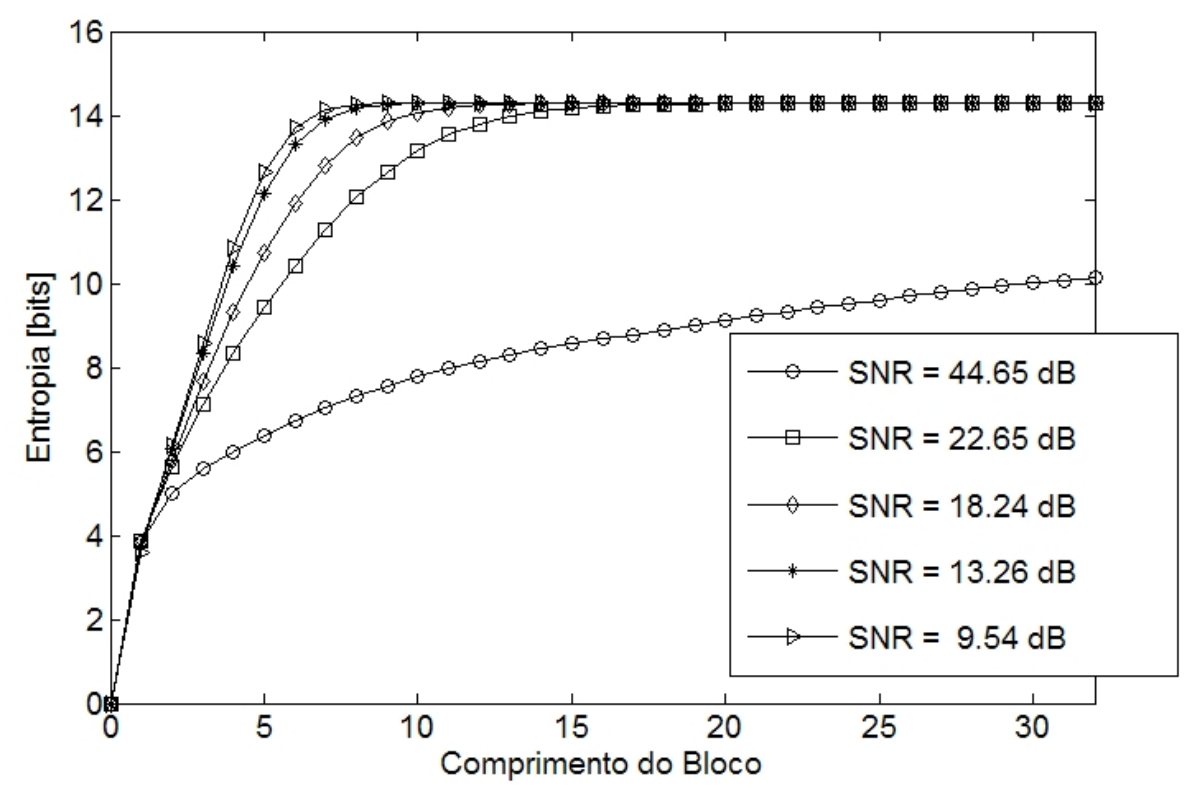

Figura 5.26: Curvas de crescimento da entropia de bloco para cinco sinais senoidais corrompidos por diferentes níveis de ruído Gaussiano, usando codificação de amplitude de 16 valores. Conforme se diminui a SNR, acelera-se a saturação da entropia.

Conforme o nível do ruído aumenta (SNR diminui), o número de possibilidades cresce mais rápido, devido a maior aleatoriedade do sinal, assim, a entropia de bloco satura mais rapidamente. Enquanto o sinal com SNR de 22,65 $d B$ satura aproximadamente em $L=14$, o sinal com 9,54 $d B$ satura em $L=7$. O sinal com 44,65 $d B$, basicamente um seno puro, aparentemente não satura até o $L$ máximo estimado, porém, raramente os sinais reais possuem essa forma.

Para finalizar os exemplos, apresenta-se a estimativa da entropia de bloco, para comprimento de bloco até $L=50$, do sinal de voz da Figura 4.3, usando-se 20.000 pontos do sinal e codificação de amplitude de 64 valores. A curva de crescimento é apresentada na Figura 5.27, percebe-se que a partir de $L=10$, a curva começa a saturar, impossibilitando a obtenção da assíntota e suas características.

Uma abordagem diferente é a análise da curva de crescimento da entropia de Shannon (entropia de bloco para $L=1$ ) conforme se aumenta o tamanho do sinal. Essa 


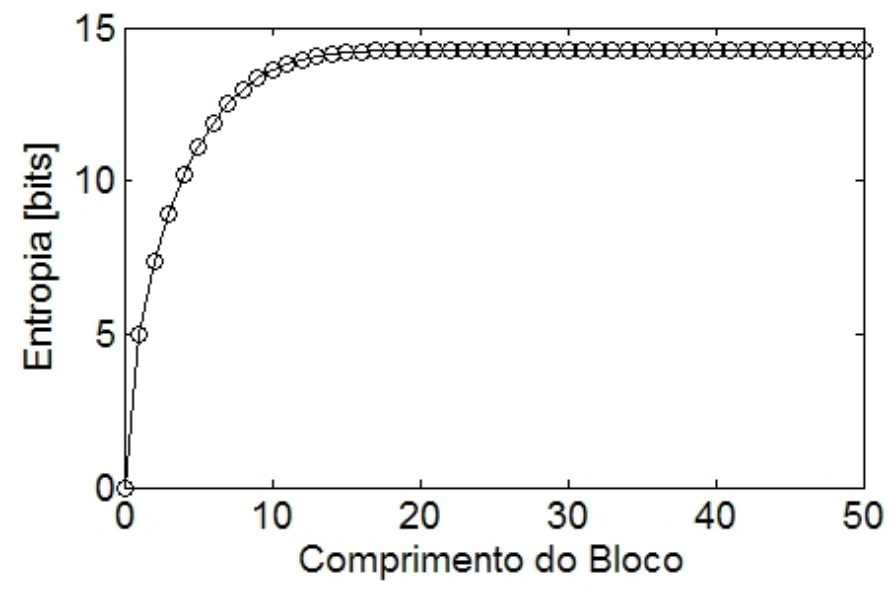

Figura 5.27: Curva de crescimento da entropia de bloco do sinal de voz da Figura 4.3 de 20.000 pontos, usando codificação de amplitude de 64 valores.

curva pode ser interpretada como a convergência da entropia do sistema quando se obtém mais informações. A Figura 5.28 apresenta a convergência da entropia de Shannon para o sinal de voz do exemplo anterior, usando passo de crescimento do sinal de 25 pontos e passo de quantização de 0,01 (usa-se estimativa da entropia pelo método do passo de quantização constante).

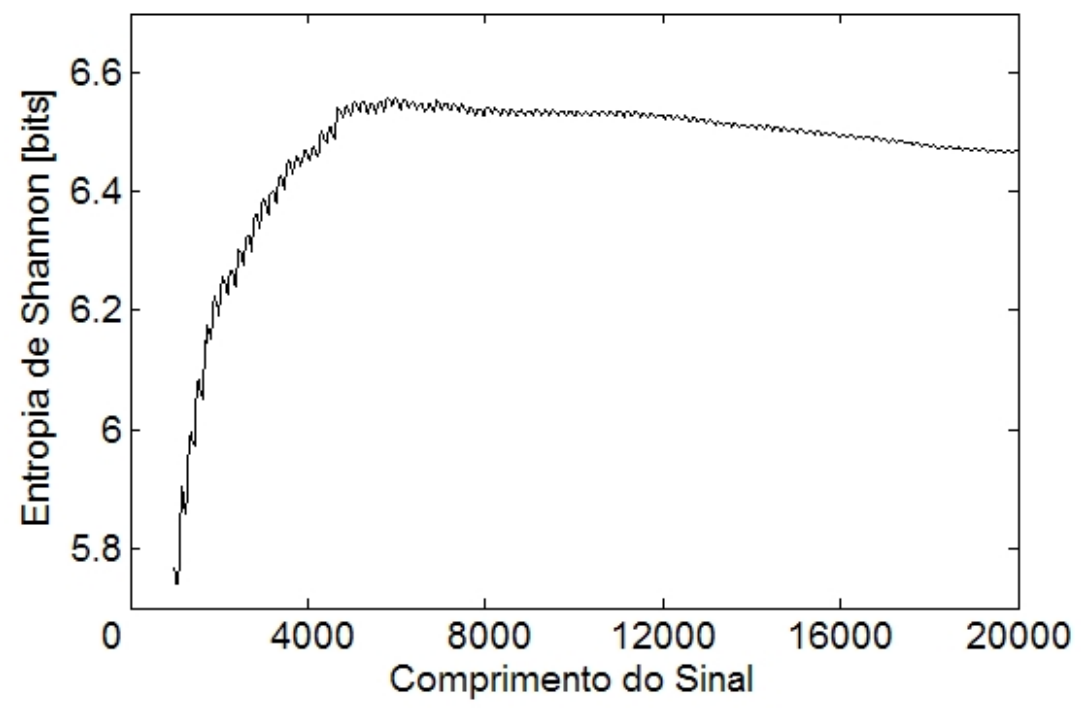

Figura 5.28: Curva de convergência da entropia de Shannon do sinal de voz da Figura 4.3 de 20.000 pontos, usando passo de 25 pontos. 
Conforme será apresentado no Capítulo 6, o comportamento dessa curva fornece informações a respeito da periodicidade e regularidade do sinal em estudo. As pequenas variações da curva durante sua convergência estão relacionadas ao pitch da voz.

\subsection{Estimativa da Potência de Previsão}

Nesta seção, apresentam-se os algoritmos de estimativa da PP usando os dois modelos de previsão dos sinais de voz propostos no Capítulo 4. Junto com os algoritmos, mostram-se alguns ensaios usando sinais simulados com variação do nível de ruído, jitter e shimmer.

Inicialmente, apresenta-se o algoritmo e ensaios usando o modelo AR. Em seguida, na Subseção 5.2.2, passa-se para o modelo baseado em decomposição por wavelets.

\subsubsection{PP com Modelo AR}

Como apresentado anteriormente, para a estimativa da PP, faz-se necessário um modelo de previsão dos sinais de voz. Inicialmente, optou-se pelo modelo AR devido a sua ampla utilização em análise de voz. Assim, o procedimento para se chegar a PP é utilizar o modelo AR para obtenção do erro de previsão do sinal de voz em estudo e, em seguida, calcular a entropia relativa entre o sinal original e seu erro de previsão. Para uma melhor apresentação do algoritmo, a Tabela 5.8 mostra um resumo passo a passo desse algoritmo o qual usa um $\operatorname{AR}(p)$, sendo $p$ a ordem do modelo.

Tabela 5.8: Resumo do algoritmo de estimativa da PP usando modelo $\operatorname{AR}(p)$.

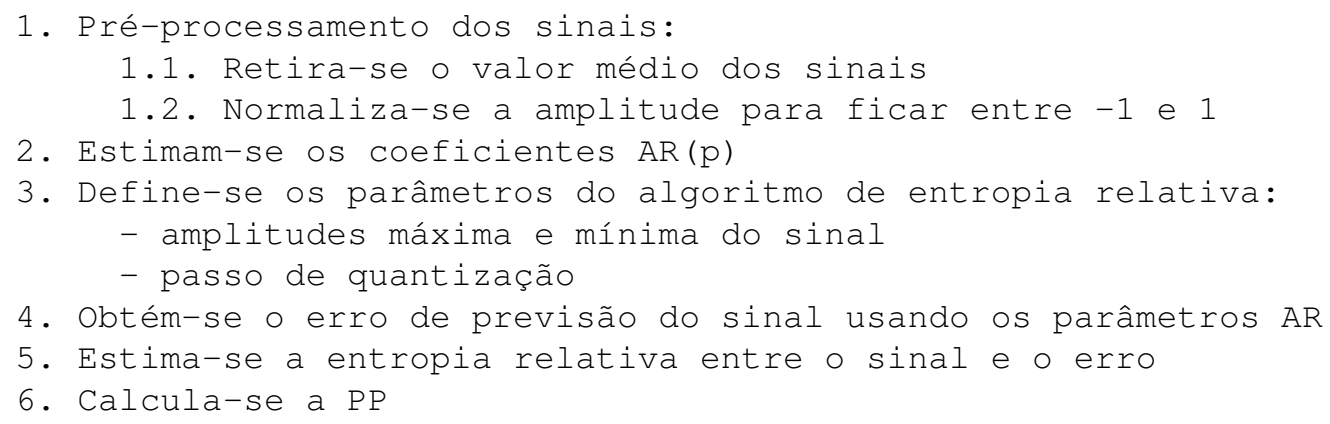

A estimativa dos coeficientes do modelo AR, passo número 2, é realizada usando-se 
o método da autocorrelação apresentado no Capítulo 4. O algoritmo desse método foi retirado do Apêndice A.4 de Hayes (1996). A entropia relativa é calculada usando-se o método de passo de quantização constante apresentada na Subseção 5.1.2.

Para visualização dos sinais e PDFs envolvidos na execução do algoritmo, na Figura 5.29, apresenta-se um exemplo de sinal simulado com SNR, jitter e shimmer iguais a 25,65 $d B, 2 \%$ e $4 \%$ respectivamente. Nas partes (a) e (b), respectivamente, mostram-se um trecho de $20 \mathrm{~ms}$ do sinal simulado e sua PDF (obtida com 200 células sobre 2.000 pontos do sinal). Nas partes (c) e (d), mostram-se o sinal de erro de previsão obtido com um modelo AR(10) e sua PDF. Omite-se a previsão do sinal simulado pois esta é visualmente muito parecida com o sinal original.

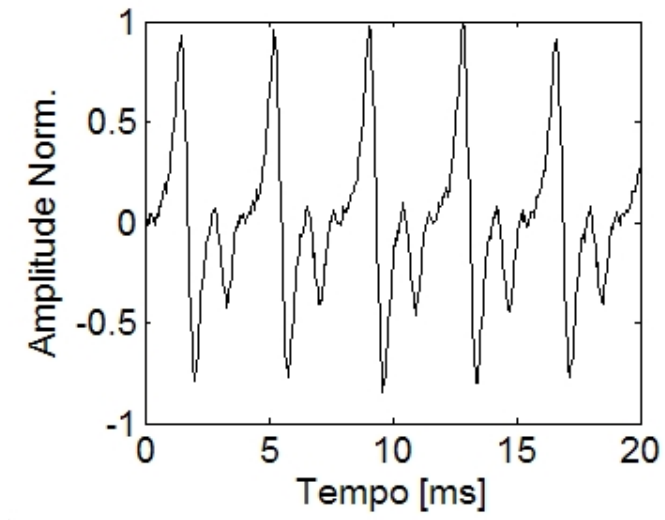

(a)

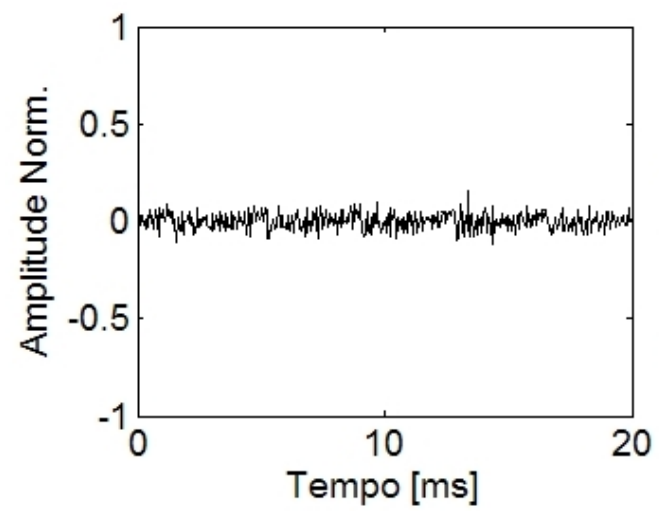

(c)

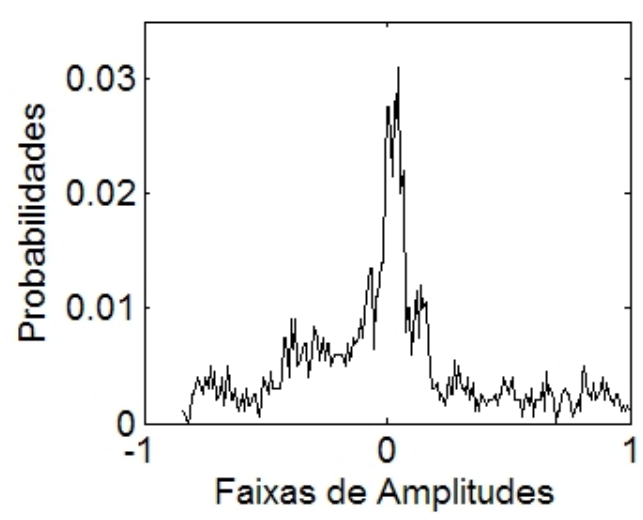

(b)

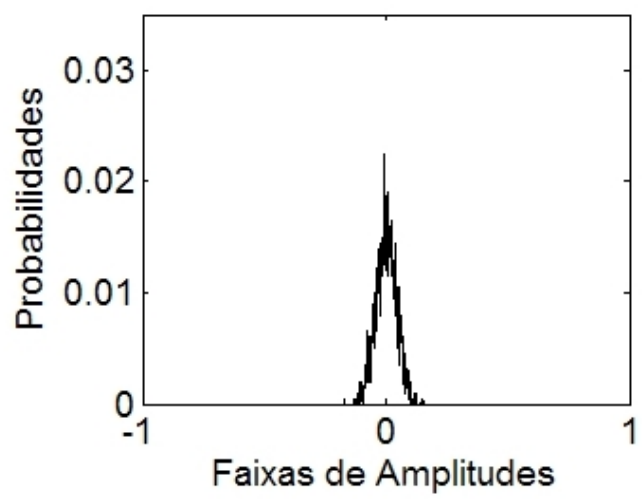

(d)

Figura 5.29: Exemplo dos sinais e PDFs envolvidos na execução do algoritmo de estimativa da PP usando modelo AR(10). (a) Sinal simulado com SNR, jitter e shimmer iguais a 25,65 dB, $2 \%$ e $4 \%$ respectivamente. (b) PDF do sinal simulado (200 células). (c) Erro de previsão. (f) PDF do erro de previsão (200 células).

Então, usando esse algoritmo, da mesma forma que para os algoritmos de entropia, realizou-se ensaios com sinais simulados variando-se os três parâmetros do simulador 
(Apêndice A). Como apresentado no Capítulo 4, utiliza-se ordem do modelo AR igual a 26. Inicialmente, variou-se o nível de ruído (SNR) dos sinais de 5,80 a 25,80 dB aproximadamente, mantendo-se o jitter e shimmer constantes a $2 \%$ cada. Para cada uma dessas combinações de parâmetros, obtiveram-se cinco valores de PP para se chegar a um valor médio. Esses valores são apresentados na Figura 5.30.

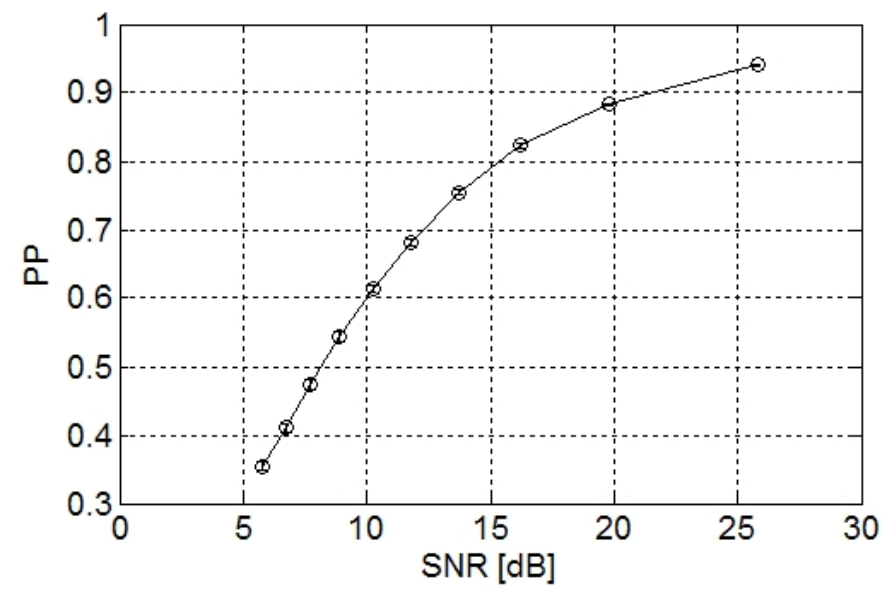

Figura 5.30: Resultado do ensaio de PP de sinais simulados variando-se os níveis de ruído usando modelo AR(26). Apresentam-se os valores médios e desvios padrões de cinco testes para cada valor de SNR.

Como observado, conforme o nível de ruído aumenta, ou seja, SNR diminui, a PP diminui. Isso está de acordo com o esperado, ao se aumentar o ruído, diminui-se a previsibilidade dos sinais.

Em seguida, realizou-se o ensaio de variação do jitter, o qual foi variado de $2 \%$ a $20 \%$, mantendo-se o SNR a 25,80 dB e o shimmer a $2 \%$. Da mesma forma que para o ensaio anterior, obtiveram-se cinco valores de PP para cada configuração, conforme apresentado na Figura 5.31.

Ao contrário do resultado de PP para variação de SNR, para a variação de jitter, o algoritmo se mostrou ineficiente em detectar as diferenças dos sinais. Entretanto, para altos valores de jitter, observa-se um aumento significativo do desvio padrão dos valores. Essa mesma insensibilidade do algoritmo ocorre para o ensaio de shimmer, o qual foi variado de $2 \%$ a $20 \%$, conforme Figura 5.32 .

Para avaliar essa insensibilidade, apresenta-se uma comparação entre PDFs de erros de previsão de sinais simulados com diferentes configurações dos parâmetros. A PDF do erro é muito parecida com uma Gaussiana, pois o algoritmo de estimativa dos 


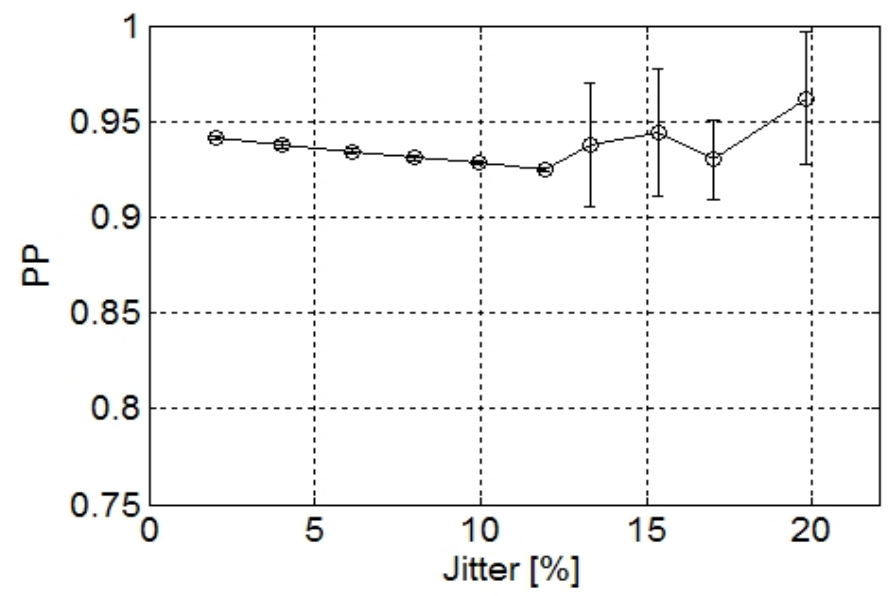

Figura 5.31: Resultados do ensaio de PP de sinais simulados variando-se o jitter usando modelo AR(26). Apresentam-se os valores médios e desvios padrões de cinco testes para cada valor de jitter.

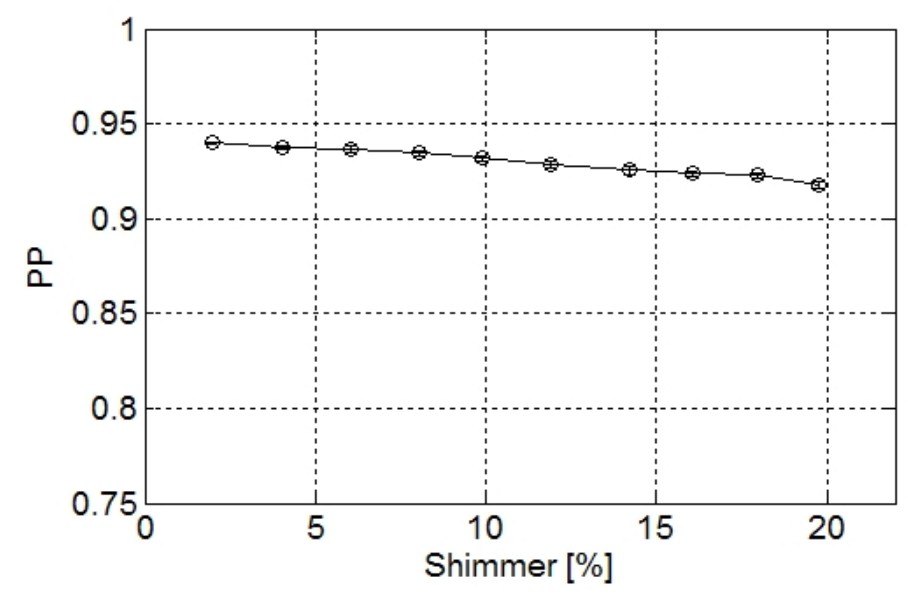

Figura 5.32: Resultados do ensaio de PP de sinais simulados variando-se o shimmer usando modelo AR(26). Apresentam-se os valores médios e desvios padrões de cinco testes para cada valor de shimmer.

parâmetros do modelo AR é otimizado por mínimos quadráticos. Essa característica torna o AR muito eficiente em modelar os sinais de voz, porém, um pouco insensível para o uso com o método da previsibilidade.

A Figura 5.33 apresenta quatro PDFs dos erros de previsão usando o modelo AR(26). Na parte (a), tem-se o erro de um sinal simulado com SNR igual a $25,80 \mathrm{~dB}$, jitter e shimmer iguais a 2\%. Em (b), tem-se um aumento do nível de ruído, SNR igual a 5,80 $d B$. Em (c) e (d), aumentam-se o jitter e shimmer para $20 \%$ respectivamente. 


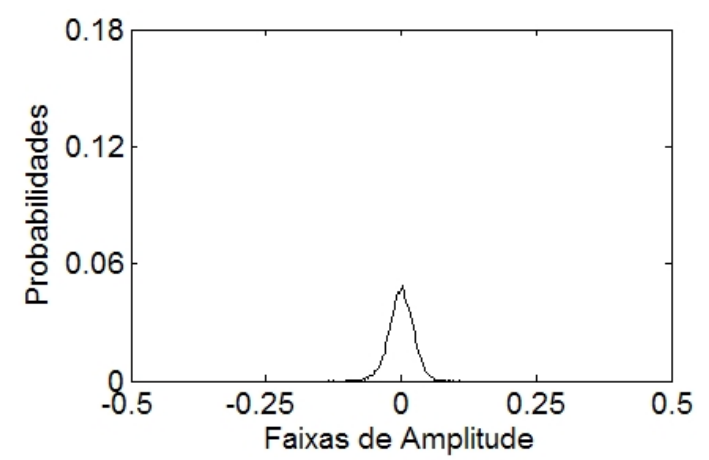

(a)

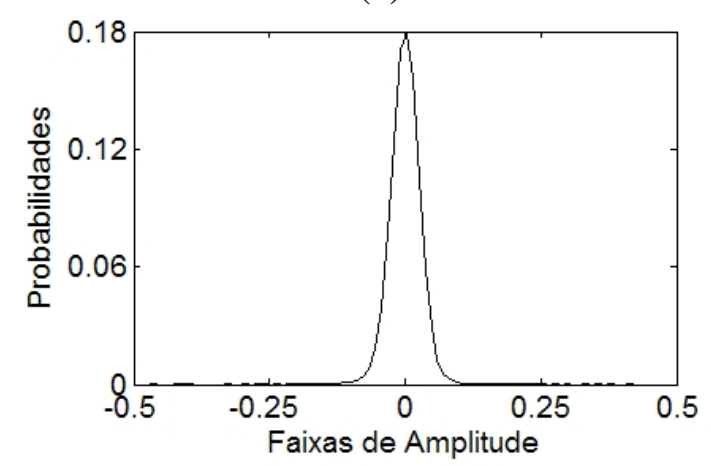

(c)

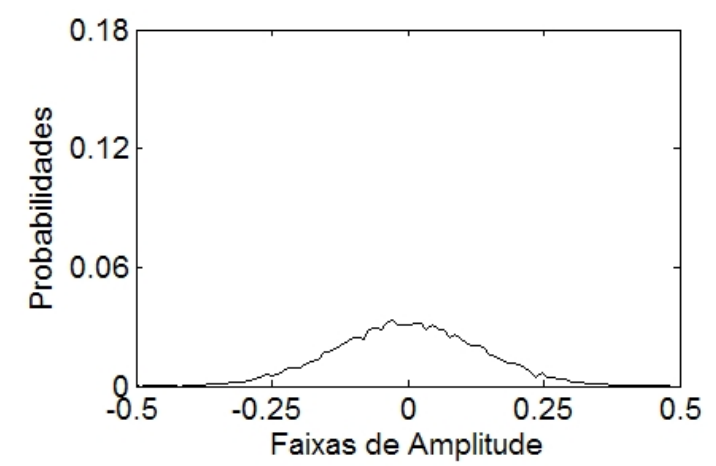

(b)

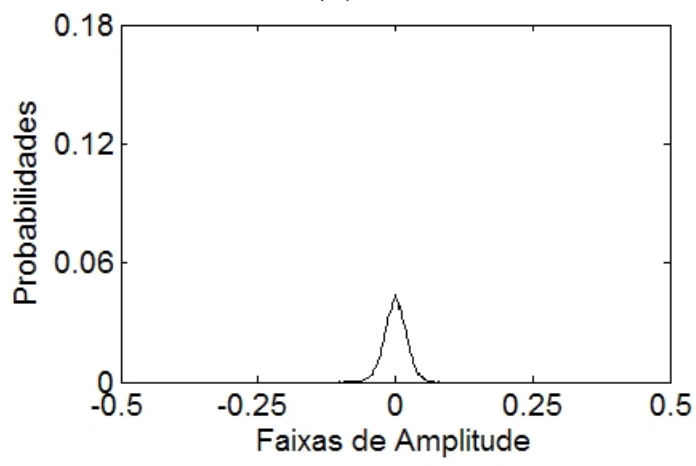

(d)

Figura 5.33: Comparação das PDFs dos erros de previsão de sinais simulados usando AR(26) com a variação dos parâmetros do simulador. (a) SNR de $25,80 \mathrm{~dB}$, jitter e shimmer iguais a 2\%. (b) Aumenta-se o nível de ruído, SNR igual 5,80 dB. (c) Jitter igual a 20\%. (d) Shimmer igual a $20 \%$.

Como se observa nessa figura, somente quando se modifica o SNR do sinal simulado, a PDF apresenta alguma diferença suficiente para resultar em variação da PP. Isso mostra que mesmo com altos índices de jitter e shimmer, o modelo AR consegue estimar suficientemente bem os sinais simulados.

Por causa dessa insensibilidade do algoritmo da PP com modelo AR em detectar mudanças desses parâmetros, apresenta-se o algoritmo com modelo baseado em decomposição por wavelets.

\subsubsection{PP com Modelo Baseado em Decomposição por Wavelets}

A modelagem dos sinais de voz usando decomposição por wavelets foi apresentada com detalhes no Capítulo 4. Agora, mostra-se um resumo do algoritmo para estimativa da PP usando esse modelo e alguns ensaios com sinais simulados semelhantes aos da subseção anterior. 
Para usar o modelo wavelet, modificou-se o algoritmo da Tabela 5.8 conforme apresentado na Tabela 5.9. Como mencionado anteriormente, escolheu-se a família Daubechies de filtros wavelet, usando ordem igual a 30, devido a bons resultados em testes preliminares. O nível máximo de decomposição é igual a 5. Utilizam-se os algoritmos wavedec e wrcoef da toolbox Wavelet do Matlab 7.0 R14 ${ }^{17}$ para a decomposição wavelet do passo número 4.

Tabela 5.9: Resumo do algoritmo de estimativa da PP usando modelo baseado em decomposição wavelet.

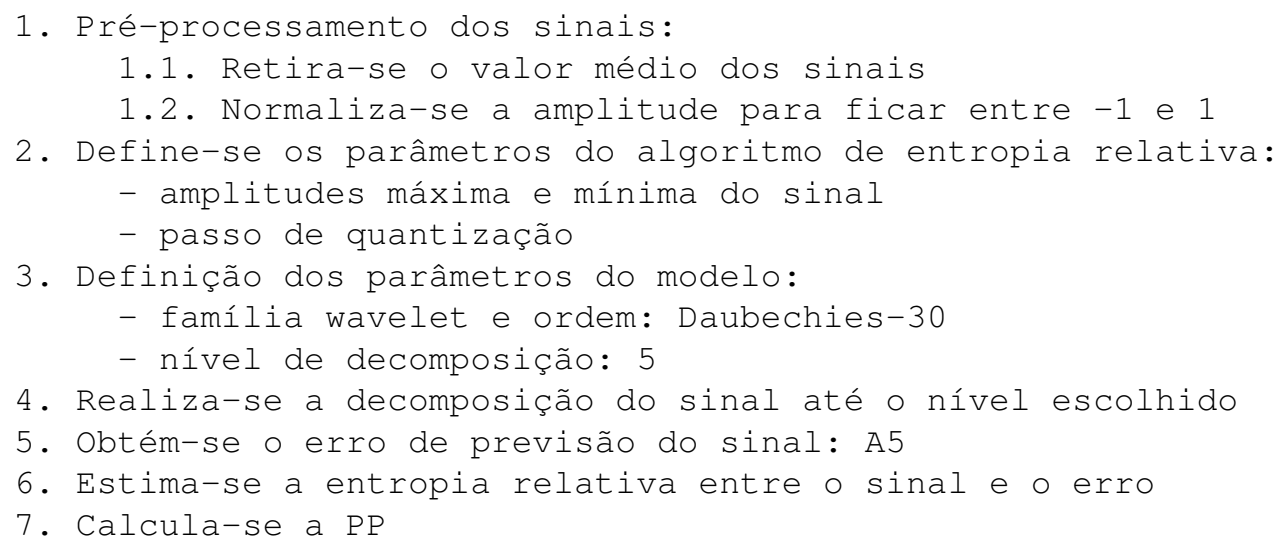

Quando se faz a decomposição do sinal, obtém-se a aproximação reconstruída $A_{5}$ e os detalhes reconstruídos de todos os níveis $D_{1}$ a $D_{5}$. Quando se somam a aproximação e os detalhes, obtém-se o sinal original. Dessa forma, fez-se a consideração que $A_{5}$ é o erro de previsão e a soma dos detalhes é a previsão do sinal de voz.

Para ilustrar a execução desse algoritmo, apresenta-se um exemplo com sinal simulado na Figura 5.34. Na parte (a), mostra-se um trecho de $20 \mathrm{~ms}$ de sinal simulado com SNR, jitter e shimmer iguais a $25,80 \mathrm{~dB}, 2 \%$ e $4 \%$ respectivamente. Na parte (b), mostra-se a PDF do sinal da parte (a), obtida com 200 células sobre 2.000 pontos do sinal. Nas partes (c) e (d), mostram-se o sinal de previsão (soma dos detalhes reconstruídos $D_{1}$ a $D_{5}$ ) obtido com o modelo wavelet e sua PDF. Nas partes (e) e (f), mostram-se o sinal de erro de previsão (aproximação reconstruída $A_{5}$ ) e sua PDF.

Para testar o algoritmo, da mesma forma que para o modelo AR, realizaram-se ensaios usando sinais simulados com variação dos parâmetros do simulador. Inicial-

\footnotetext{
${ }^{17}$ Mais informações no site da Internet: http : / /www. mathworks. com/products/wavelet/.
} 
mente, variou-se o nível de ruído (SNR) dos sinais de 5,80 a 25,80 dB aproximadamente, mantendo-se o jitter e shimmer constantes a $2 \%$ cada. Para cada uma dessas combinações de parâmetros, obtiveram-se cinco valores de PP para se chegar a um valor médio. Esses valores são apresentados na Figura 5.35.

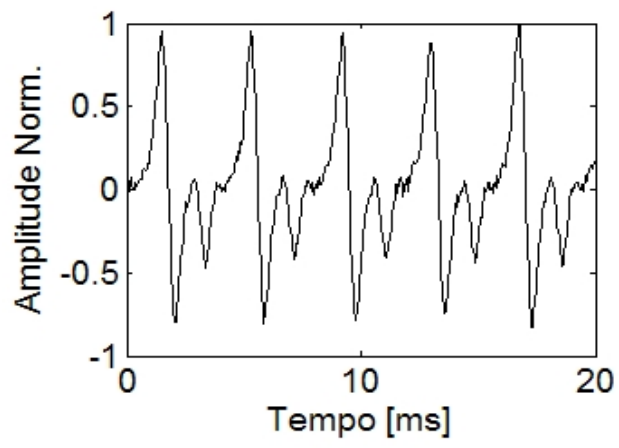

(a)

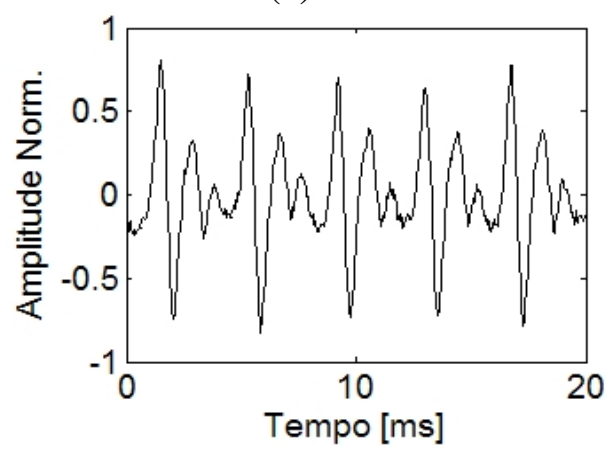

(c)

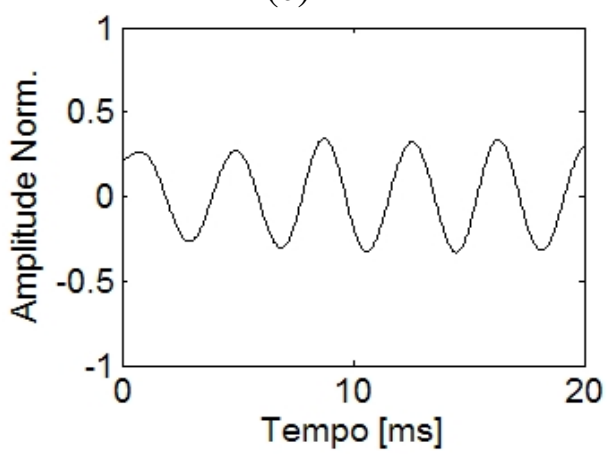

(e)

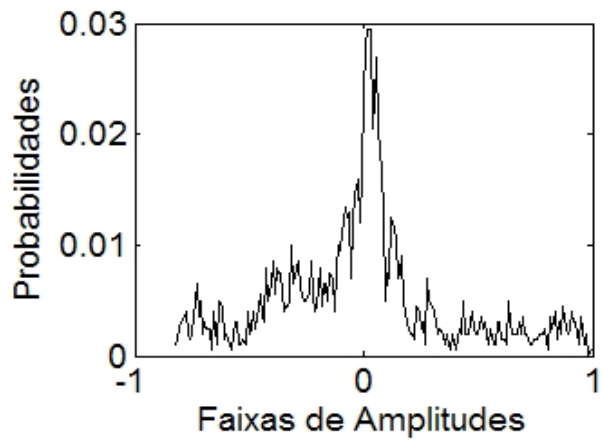

(b)

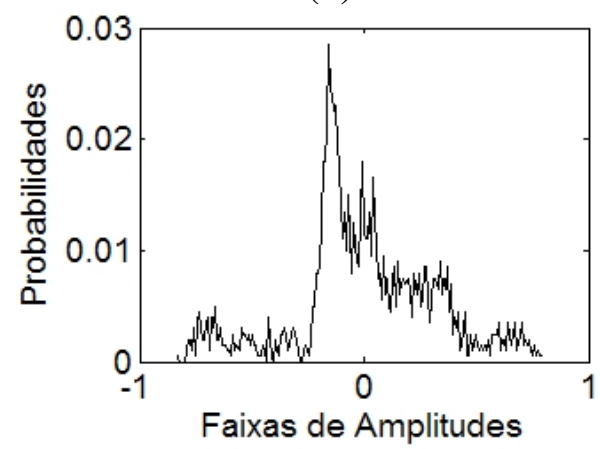

(d)

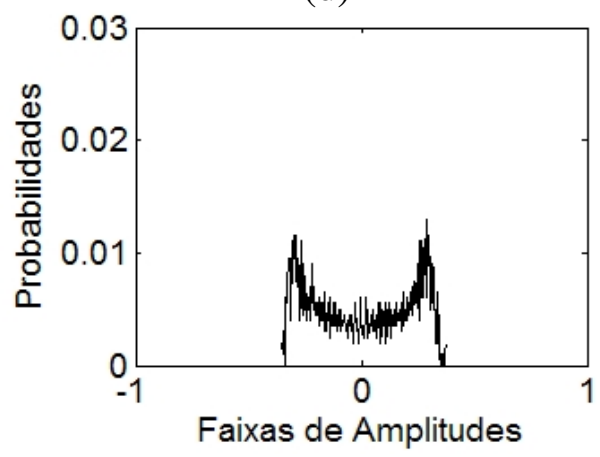

(f)

Figura 5.34: Exemplo de aplicação do algoritmo de estimativa da PP usando modelo de decomposição wavelet. (a) Sinal simulado com SNR, jitter e shimmer iguais a 25,65 dB, $2 \%$ e $4 \%$ respectivamente. (b) PDF do sinal simulado (200 células). (c) Previsão do sinal (soma de $D_{1}$ a $D_{5}$ ). (d) PDF da previsão do sinal (200 células). (e) Erro de previsão $\left(A_{5}\right)$. (f) PDF do erro de previsão (200 células). 
Observando-se a figura, percebe-se que, conforme o nível de ruído aumenta (diminui a SNR), a PP diminui, de acordo com o esperado. Porém, comparando-se com o resultado obtido para o modelo AR, Figura 5.30, vê-se que a sensibilidade do modelo wavelet é menor.

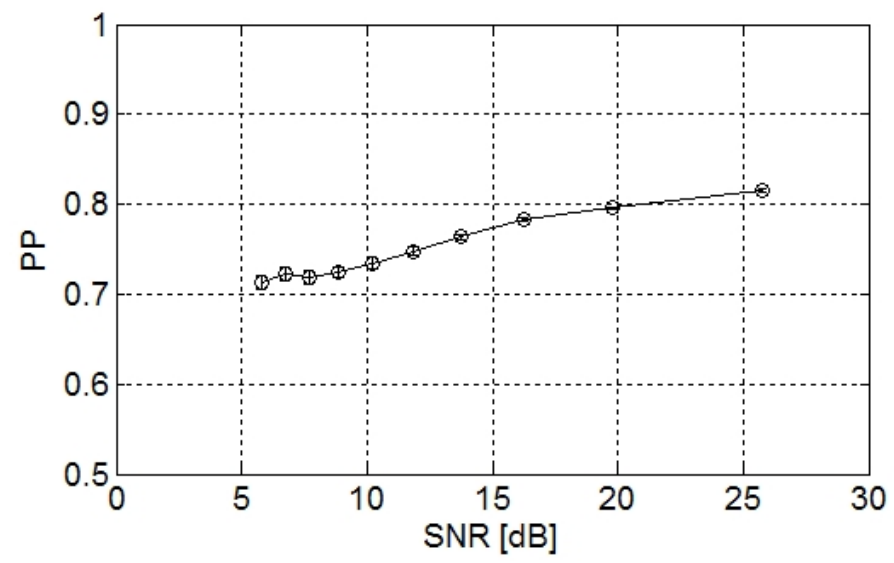

Figura 5.35: Resultado do ensaio de PP de sinais simulados variando-se os níveis de ruído usando modelo wavelet. Apresentam-se os valores médios e desvios padrões de cinco testes para cada valor de SNR.

Em seguida, realizou-se o ensaio de variação do jitter, de $2 \%$ a $20 \%$, mantendose o SNR a $25,80 d B$ e o shimmer a $2 \%$. O resultado é apresentado na Figura 5.36. Da mesma forma, fez-se o ensaios de variação do shimmer, também de $2 \%$ a $20 \%$, mantendo-se os outros parâmetros constantes, sendo o resultado apresentado na Figura 5.37 .

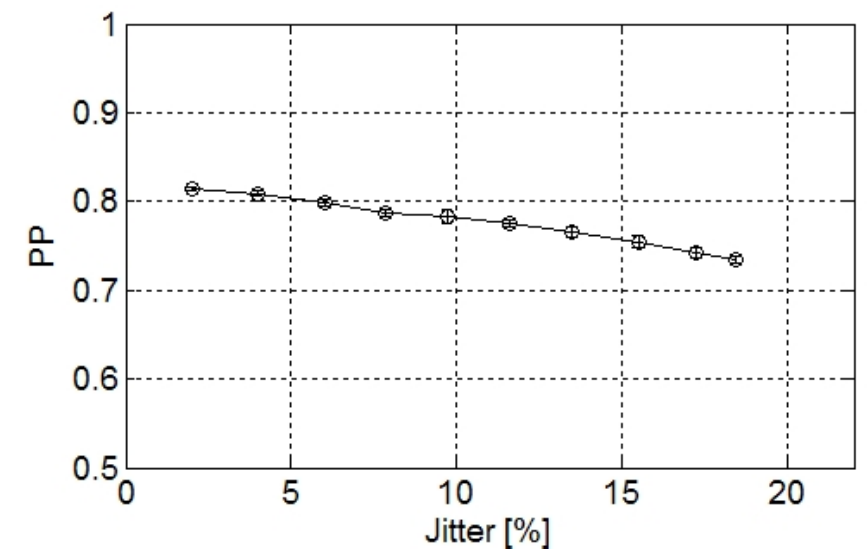

Figura 5.36: Resultado do ensaio de PP de sinais simulados variando-se o jitter usando modelo wavelet. Apresentam-se os valores médios e desvios padrões de cinco testes para cada valor de jitter. 
Ao contrário do obtido para o modelo AR, os ensaios de variação de jitter e shimmer para o modelo wavelet apresentaram resultados conforme o esperado, ou seja, conforme se aumentaram as perturbações de freqüência e amplitude, diminui-se a previsibilidade dos sinais.

Assim, pode-se dizer que o modelo wavelet não possui insensibilidade a nenhum dos três parâmetros do simulador: nível de ruído, jitter e shimmer, os quais, geralmente, apresentam valores alterados em sinais de voz patológicos.

Para comparação com a Figura 5.33, obtida com o uso do modelo AR, apresenta-se a Figura 5.38. Da mesma forma, tem-se as quatro PDFs dos erros de previsão com variação dos parâmetros do simulador. Em (a), tem-se o erro de um sinal simulado com SNR igual a 25,80 dB, jitter e shimmer iguais a 2\%. Em (b), aumenta-se o nível de ruído, SNR igual a 5,80 dB. Em (c) e (d), aumentam-se o jitter e shimmer para $20 \%$ respectivamente.

Nessa figura, ao contrário da versão obtida com o modelo AR, pode-se diferenciar visualmente as PDFs dos erros de previsão. Apesar de não serem diferenças tão significativas, são o suficiente para apresentar modificação dos valores de PP dos sinais.

Na próxima seção, apresenta-se os algoritmos de análise de componentes previsíveis usando tanto sinais temporais quanto as representações tridimensionais dos sinais.

\subsection{Algoritmo de Análise de Componentes Previsíveis}

Neste seção, mostra-se a implementação da PrCA usando a forma alternativa por PCA demonstrada em Schneider e Griffies (1999), conforme apresentado na Seção 3.3. Como visto anteriormente, esse método baseia-se na aplicação de PCA para branqueamento da matriz de covariância das observações, $C_{o}$, e depois a diagonalização da matriz $K_{v}$. Assim, desvia-se de solucionar o problema de autovalores generalizado da Equação (3.15). 


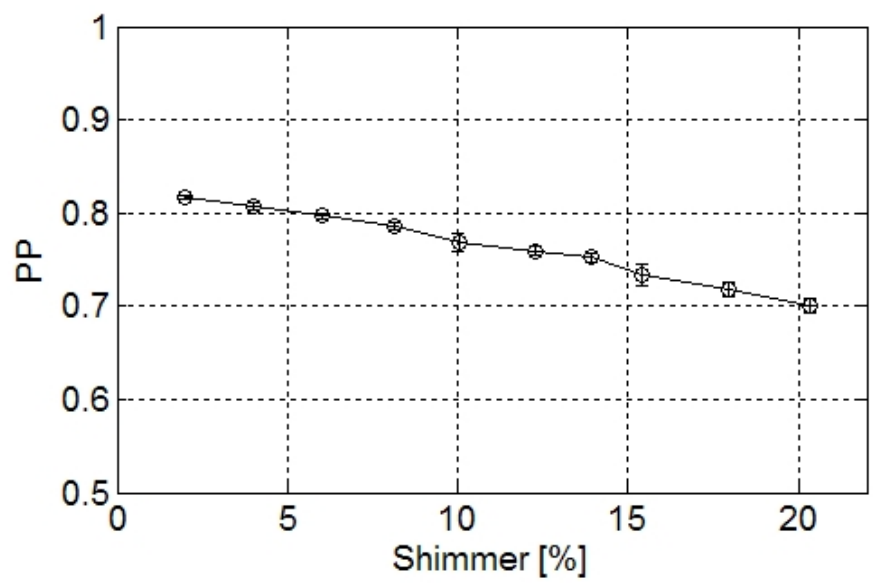

Figura 5.37: Resultado do ensaio de PP de sinais simulados variando-se o shimmer usando modelo wavelet. Apresentam-se os valores médios e desvios padrões de cinco testes para cada valor de shimmer.

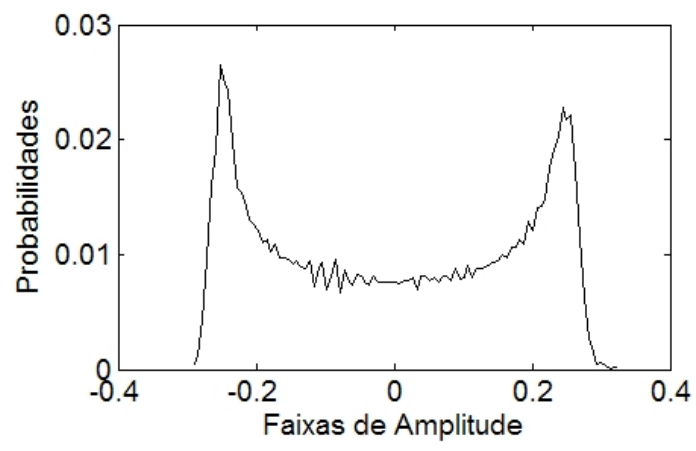

(a)

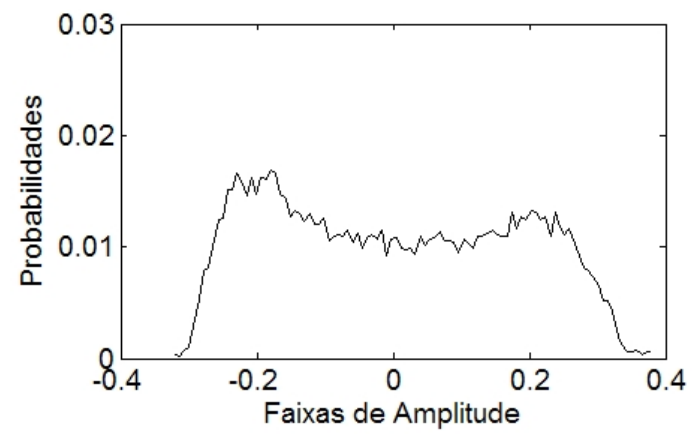

(c)

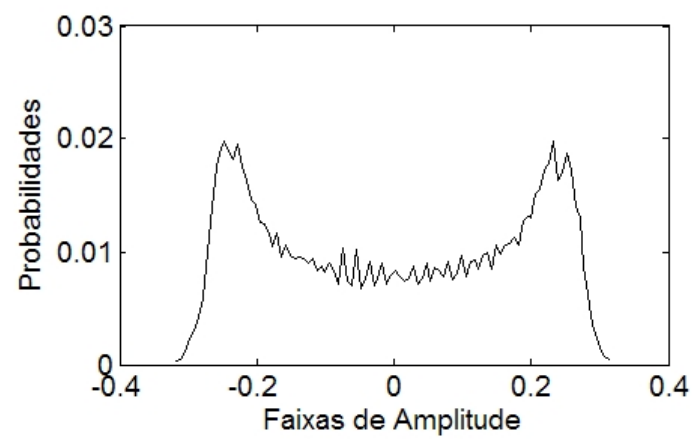

(b)

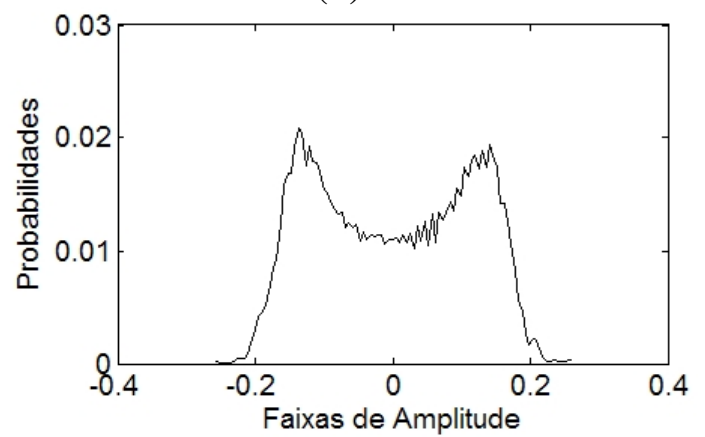

(d)

Figura 5.38: Comparação das PDFs dos erros de previsão de sinais simulados usando modelo wavelet com a variação dos parâmetros do simulador. (a) SNR de 25,80 dB, jitter e shimmer iguais a 2\%. (b) Aumenta-se o nível de ruído, SNR igual 5,80 dB. (c) Jitter igual a 20\%. (d) Shimmer igual a $20 \%$. 
Neste estudo, realizaram-se dois tipos de PrCA; primeiramente, utilizando sinais temporais com modelagem AR ou de decomposição por wavelets, construindo-se versões multidimensionais por atrasos unitários dos sinais envolvidos. O segundo tipo de PrCA utiliza a representação tridimensional da Subseção 4.2.3 e modelo AR multidimensional.

\subsubsection{PrCA e Sinais Temporais}

Um resumo do algoritmo da PrCA e reconstrução de sinais temporais é apresentado na Tabela 5.10. As matrizes de covariância são obtidas usando algoritmo apresentado no Apêndice A.2 de Hayes (1996). A decomposição de matrizes de covariância em seus autovetores e autovalores é realizada pelo algoritmo eig do Matlab 7.0 R14.

Tabela 5.10: Resumo do algoritmo de PrCA e reconstrução de sinais temporais.

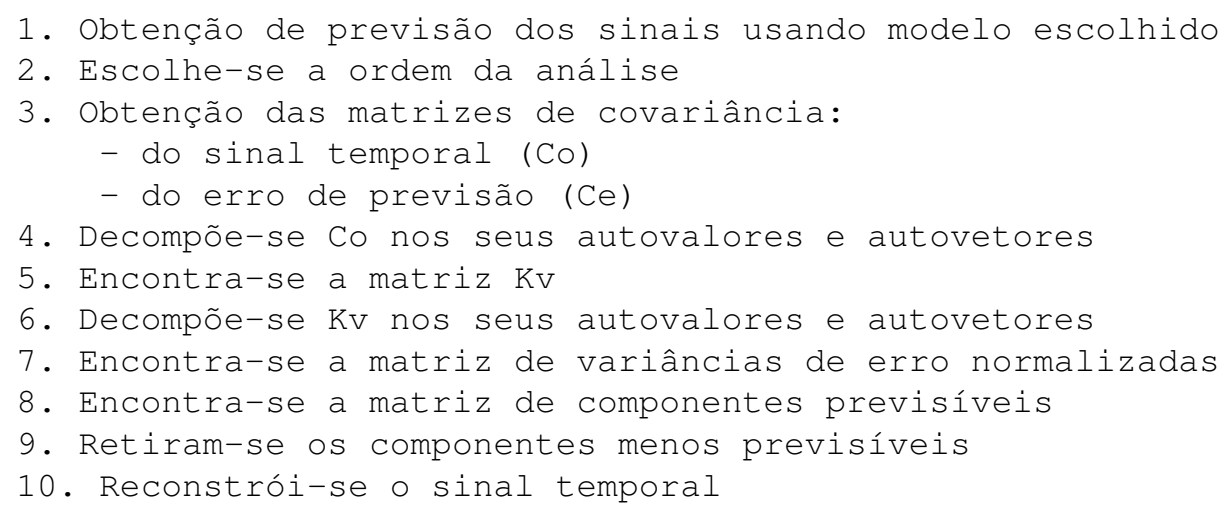

Para exemplificar a decomposição realizada por esse algoritmo, utiliza-se um sinal simulado com parâmetros: SNR igual a $25,80 \mathrm{~dB}$, jitter de $2 \%$ e shimmer de $4 \%$. Um trecho de $20 \mathrm{~ms}$ desse sinal é apresentado na Figura 5.39 (a). Para utilizar o algoritmo da Tabela 5.10, escolhe-se o modelo AR(26) e ordem da PrCA igual a 3. Assim, obtémse três componentes previsíveis cujas variâncias de erro normalizadas são 0,003; 0,141 e 3,221 respectivamente. Portanto, o primeiro componente é o que possui a maior previsibilidade e o último, a menor. As reconstruções do sinal usando cada um dos componentes isoladamente são apresentadas nas partes (b), (c) e (d) respectivamente.

Essa análise realizou uma decomposição do sinal em somente três componentes previsíveis para se poder observar os sinais reconstruídos. Entretanto, usando-se mais 


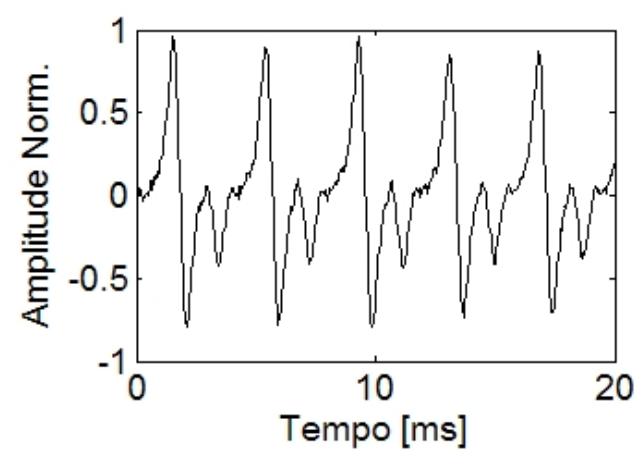

(a)

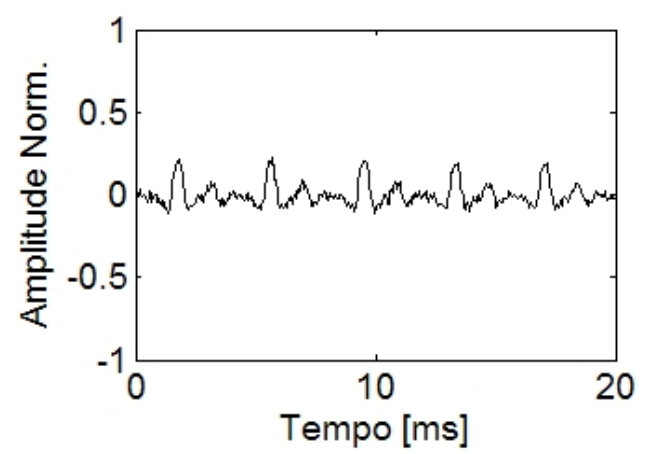

(c)

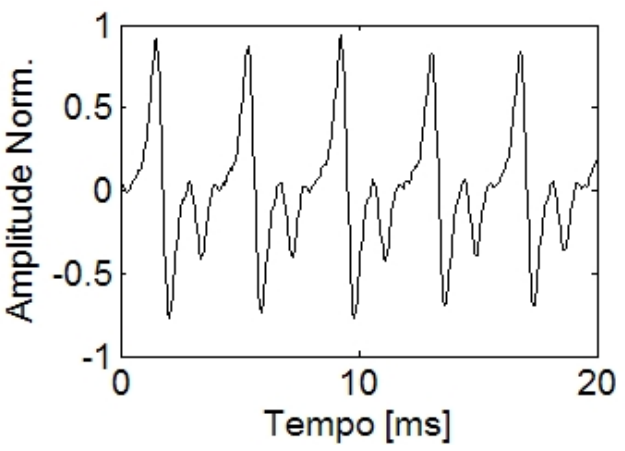

(b)

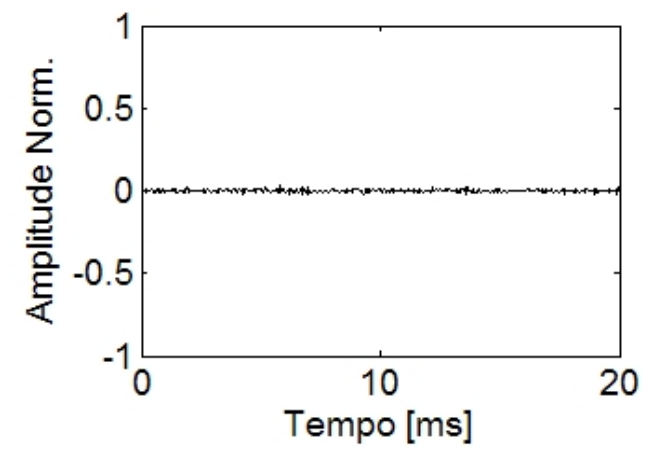

(d)

Figura 5.39: Exemplo de PrCA de um sinal simulado. (a) Sinal simulado com SNR, jitter e shimmer iguais a $25,65 \mathrm{~dB}, 2 \%$ e $4 \%$ respectivamente. (b) Reconstrução do sinal usando o primeiro componente previsível. (c) Reconstrução usando o segundo componente. (d) Reconstrução usando o terceiro componente.

componentes, pode-se analisar o formato dos componentes. Assim, refez-se essa análise usando 26 componentes, o mesmo número da ordem do modelo AR. A Figura 5.40 apresenta as variâncias de erro normalizadas associadas aos componentes previsíveis e a Figura 5.41 apresenta um gráfico dos 26 componentes em função de seus comprimentos (26 pontos).

As variâncias de erro normalizadas $\left(\gamma_{k}\right)$, as quais são inversamente proporcionais à previsibilidade dos componentes, estão organizadas em ordem crescente. Assim, retirando-se os componentes com maior valor de $\gamma$ e reconstruíndo-se o sinal, obtémse uma versão mais previsível do mesmo.

Optou-se por escolher como os componentes mais previsíveis aqueles que possuírem $\gamma$ menor do que $10 \%$ do máximo dos $\gamma_{k}$. No caso da Figura 5.40, escolhe-se os primeiros 6 componentes. Assim, fazendo-se a reconstrução do sinal decomposto usando somente esses componentes, obtém-se a Figura 5.42 (a), a qual é, visualmente, muito semelhante a Figura 5.40 (a). Já na parte (b), tem-se o sinal reconstruído com os 


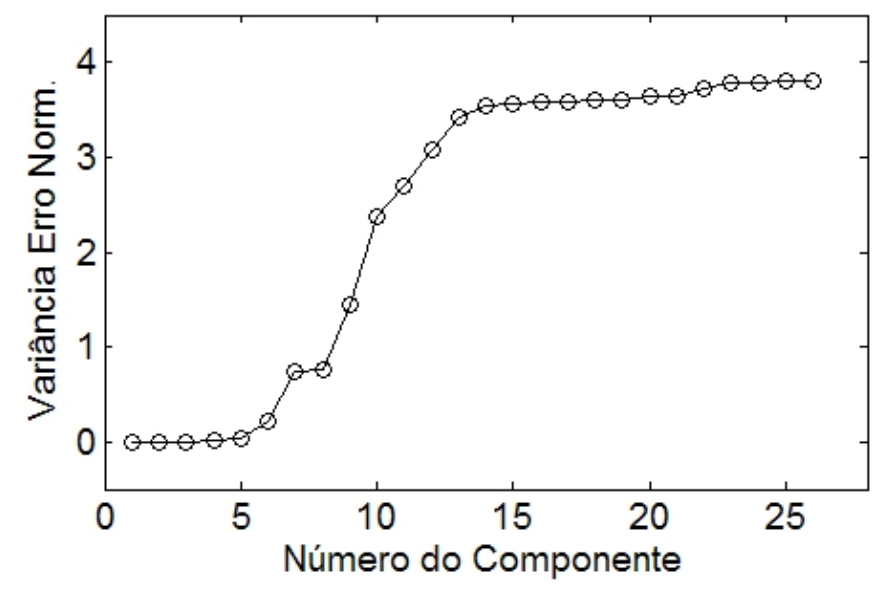

Figura 5.40: Representação das variâncias de erro normalizadas associadas aos componentes previsíveis da decomposição do sinal da Figura 5.39 (a) porém ordem da PrCA igual a 26.

outros 20 componentes menos previsíveis, pode-se ver que realmente, sua contribuição para o sinal é pequena, entretanto, trata-se de um sinal simulado, o qual possui poucas variações normais para sinais reais de voz.

Além desses exemplos anteriores, apresentam-se ensaios usando sinais simualdos variando-se os três parâmetros do simulador como feito para os algoritmos anteriores (entropia e PP). Então, utiliza-se a PrCA para reconstrução de versões mais previsíveis dos sinais, assim, usam-se essas reconstruções para se obter um sinal de erro, o qual é usado para calcular a PP.

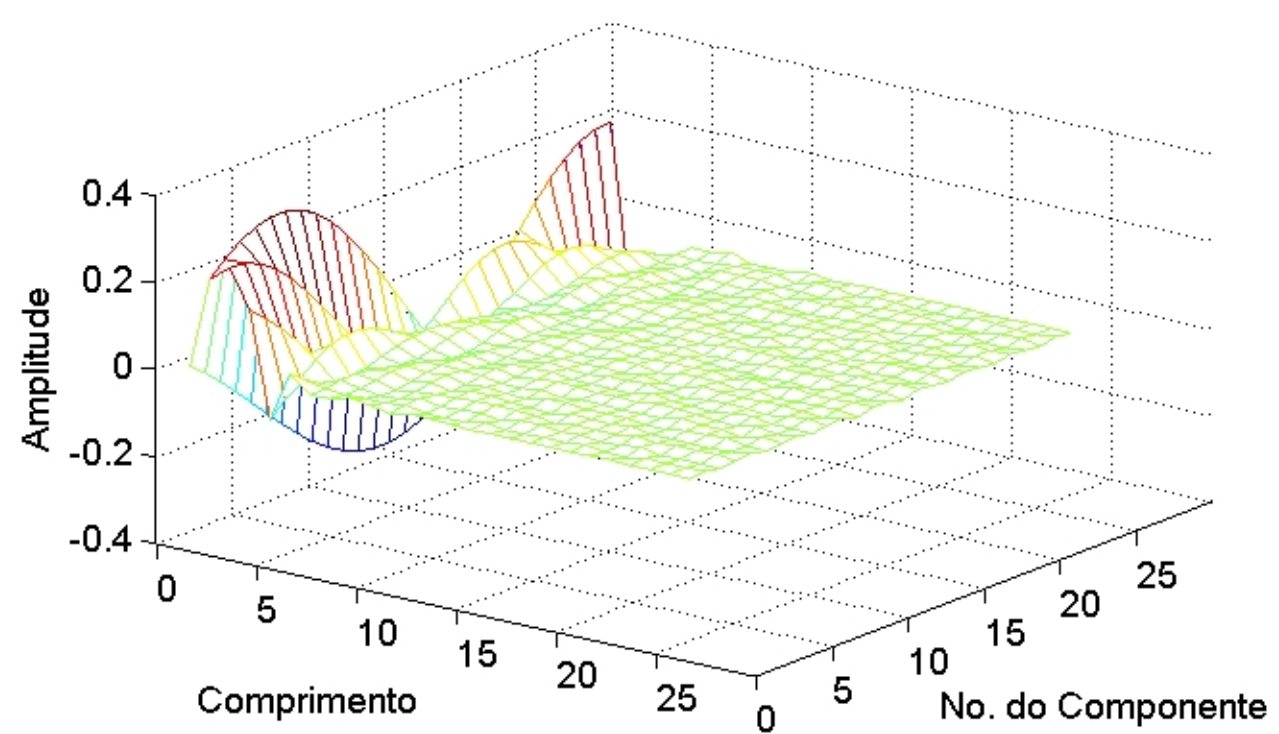

Figura 5.41: Representação dos componentes previsíveis da decomposição do sinal da Figura 5.39 (a) usando ordem da PrCA igual a 26. 


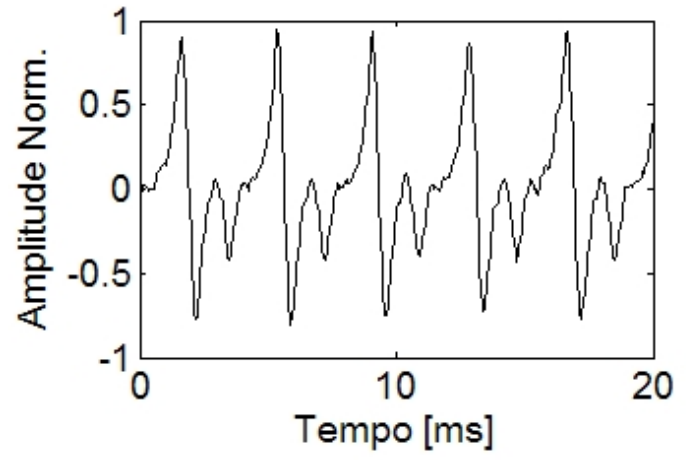

(a)

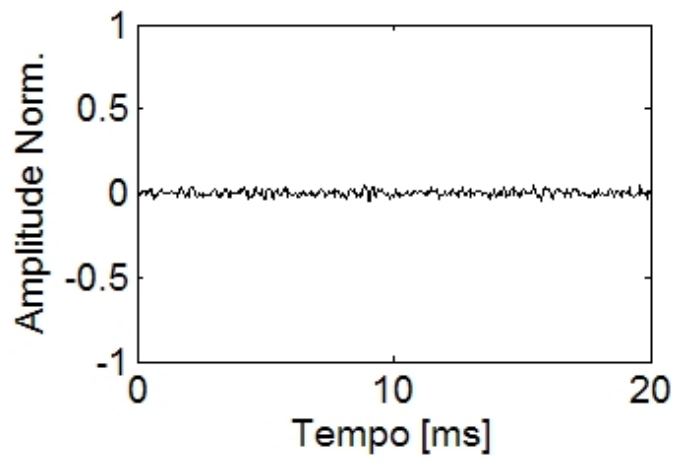

(b)

Figura 5.42: Reconstrução do sinal da Figura 5.39 (a). Em (a), tem-se a reconstrução com os primeiros 6 componentes (mais previsíveis) da PrCA de ordem 26. Em (b), a reconstrução usando os outros 20 componentes menos previsíveis.

Novamente, variam-se o nível de ruído, SNR entre 5,80 e 25,80 dB, jitter e shimmer de $2 \%$ a 20\%. Primeiramente, usa-se o modelo AR(26) para obtenção das previsões, os resultados dos três ensaios são apresentados nas Figuras 5.43 a 5.45, respectivamente para variação de SNR, jitter e shimmer.

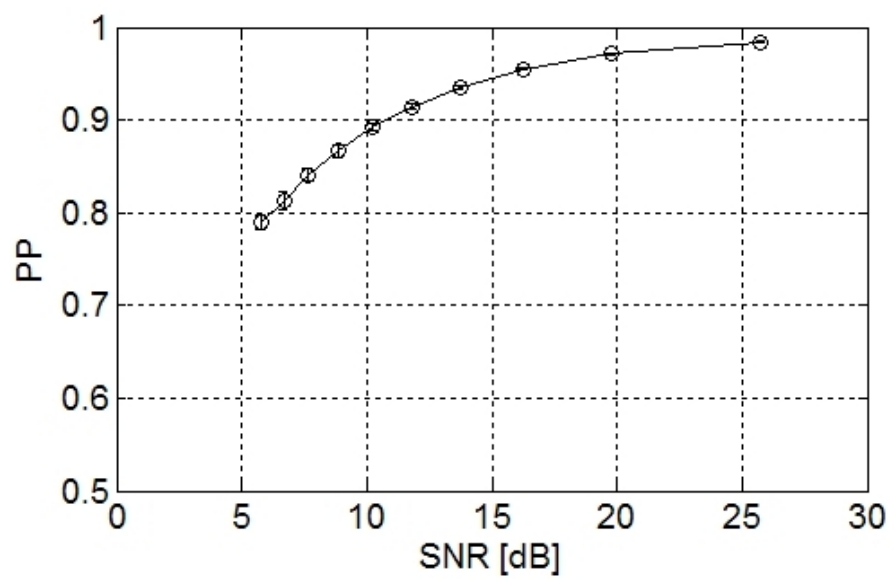

Figura 5.43: Resultado do ensaio de PP de sinais simulados variando-se o nível de ruído (SNR) usando PrCA com modelo AR(26). Valores médios e desvios padrões de cinco testes para cada combinação de parâmetros.

Observa-se que o comportamento dos ensaio de variação de SNR foi conforme o esperado, diminuindo-se a PP conforme se aumentava a desorganização do sinal. Já para os ensaios de jitter e shimmer, nota-se, novamente, a insensibilidade do algoritmo diante da variação dos parâmtros. Demonstra-se a grande dependência da PrCA ao modelo AR, pois o comportamento dos resultados foi bem semelhante ao obtido pela análise direta do sinal usando o AR. 


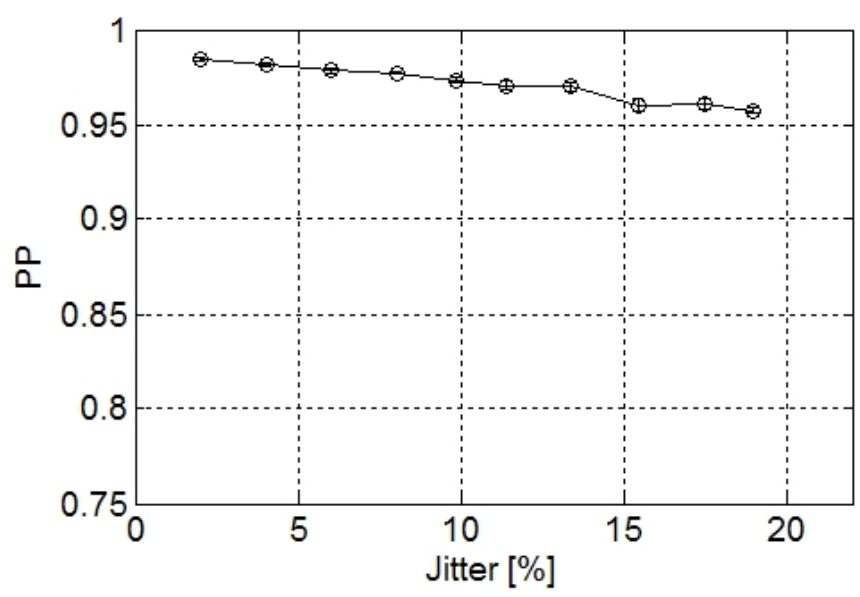

Figura 5.44: Resultado do ensaio de PP de sinais simulados variando-se o jitter usando PrCA com modelo AR(26). Valores médios e desvios padrões de cinco testes para cada combinação de parâmetros.

Assim, trocou-se o modelo AR(26) pelo baseado em decomposição por wavelets. Refazendo-se os ensaios anteriores, chega-se nas Figuras 5.46 a 5.48, respectivamente para variação de SNR, jitter e shimmer. Percebe-se que o comportamento do algoritmo continua seguindo o do modelo wavelet aplicado diretamente nos sinais originais, entretanto, nota-se uma certa irregularidade da PP durante a variação dos parâmetros. Mas, mesmo assim, diminui-se a PP quando se aumenta a desorganização dos sinais, apresentando uma diminuição um pouco mais acentuada do que na aplicação direta do modelo aos sinais originais.

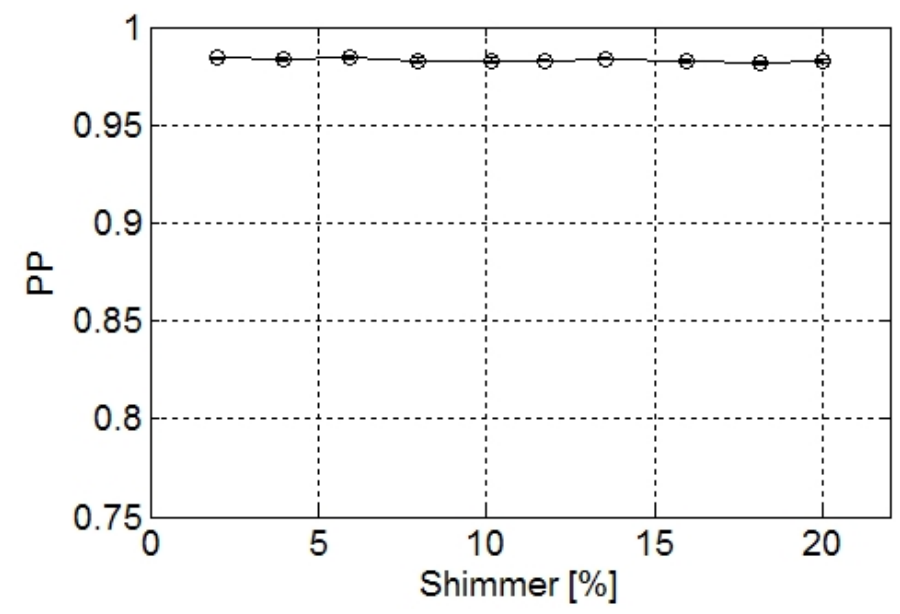

Figura 5.45: Resultado do ensaio de PP de sinais simulados variando-se o shimmer usando PrCA com modelo AR(26). Valores médios e desvios padrões de cinco testes para cada combinação de parâmetros. 


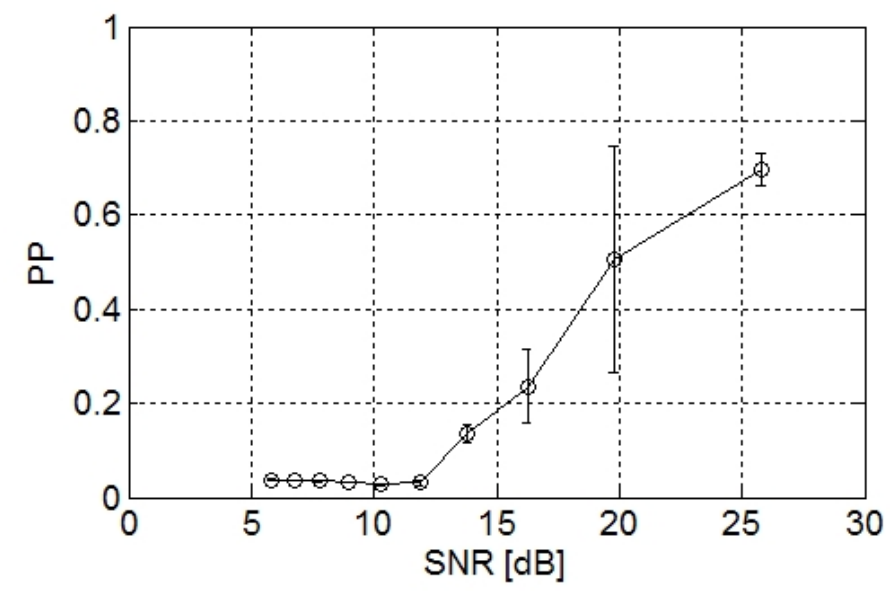

Figura 5.46: Resultado do ensaio de PP de sinais simulados variando-se o nível de ruído (SNR) usando PrCA com modelo wavelet. Valores médios e desvios padrões de cinco testes para cada combinação de parâmetros.

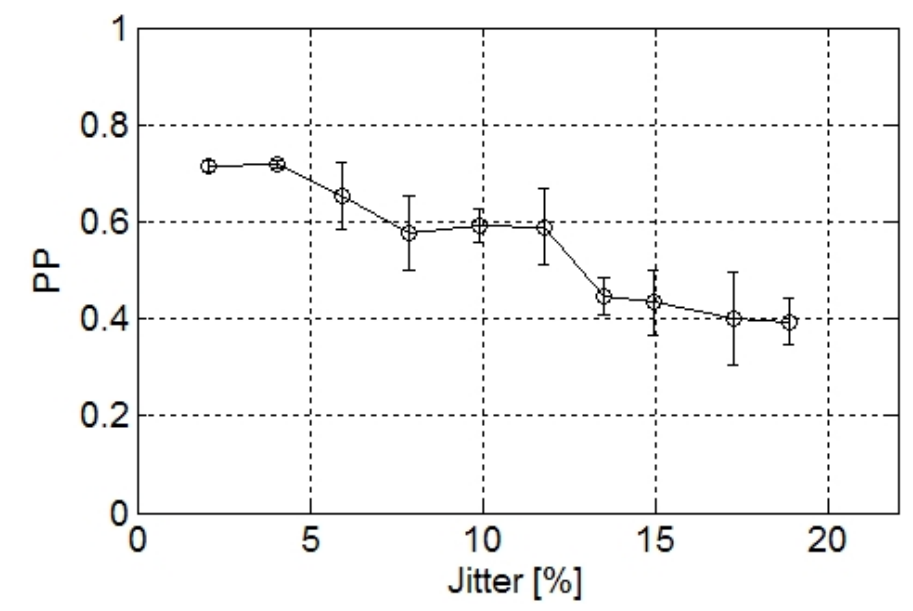

Figura 5.47: Resultado do ensaio de PP de sinais simulados variando-se o jitter usando PrCA com modelo wavelet. Valores médios e desvios padrões de cinco testes para cada combinação de parâmetros.

\subsubsection{PrCA e Representações Tridimensionais}

Nesta subseção, apresenta-se uma abordagem diferente com relação a aplicação da PrCA. Ao invés de usar os sinais temporais nessa análise, usam-se as representações tridimensionais apresentadas no Capítulo 4. Dessa forma, não se criam mais as versões multidimensionais usando atrasos unitários dos sinais. Agora, usa-se o primeiro mínimo local da curva de informação mútua dos sinais como valor de atraso e criam-se representações tridimensionais, portanto, a PrCA possui ordem igual a três. 


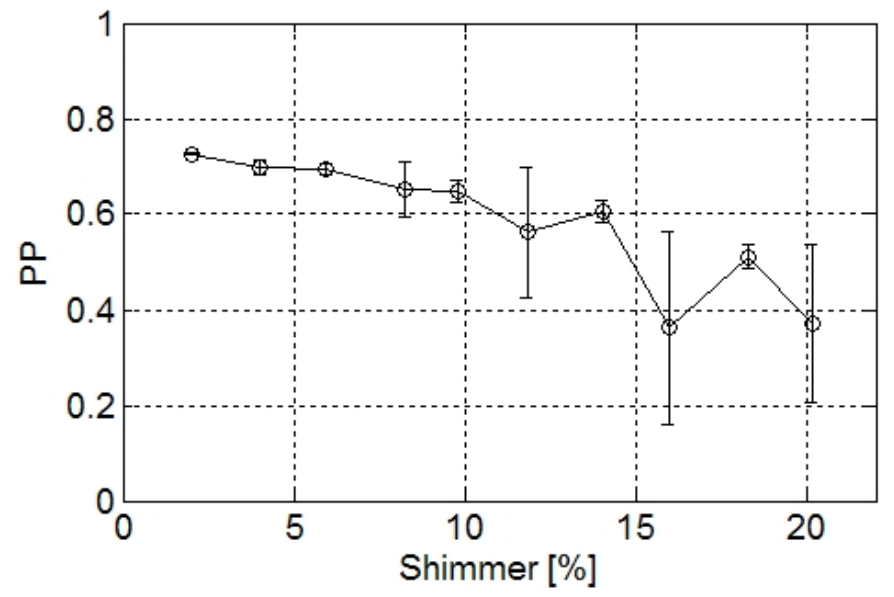

Figura 5.48: Resultado do ensaio de PP de sinais simulados variando-se o shimmer usando PrCA com modelo wavelet. Valores médios e desvios padrões de cinco testes para cada combinação de parâmetros.

Para essa abordagem de PrCA, modifica-se ligeiramente o algoritmo da Tabela 5.10 para utilização da representação tridimensional de sinais conforme apresentado na Tabela 5.11.

Tabela 5.11: Resumo do algoritmo de PrCA e reconstrução com abordagem da representação tridimensional de sinais temporais.

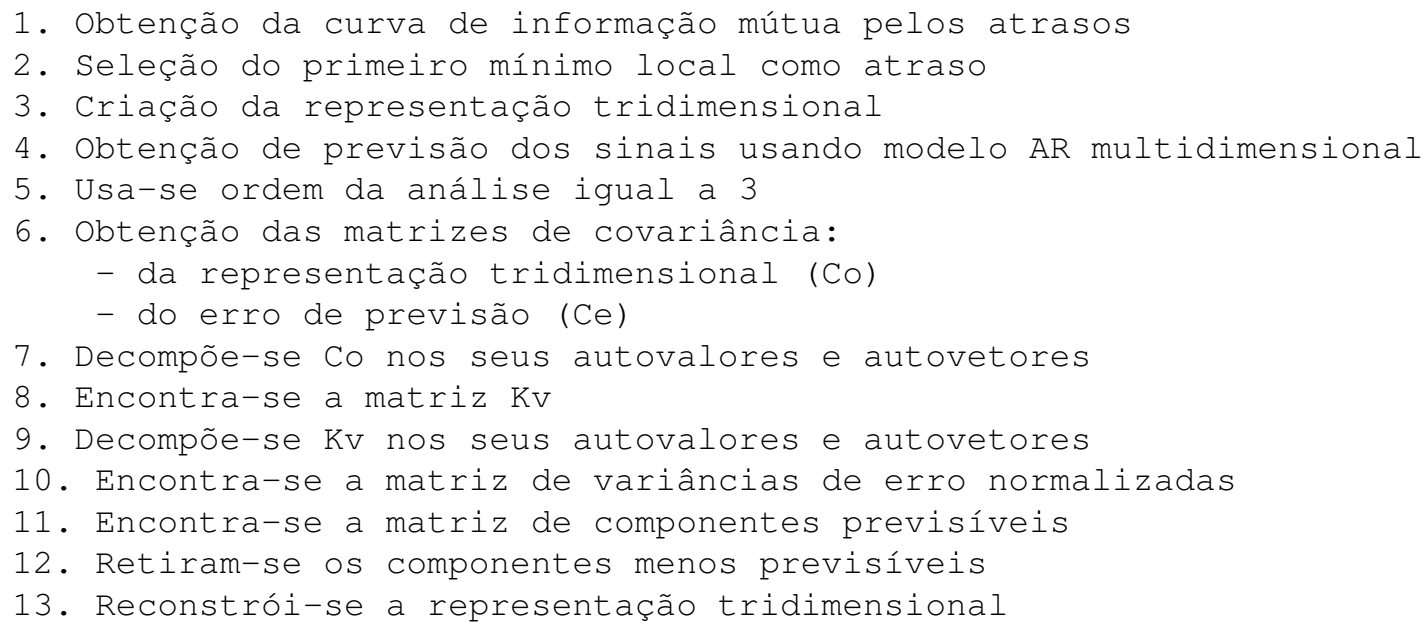

O primeiro e terceiro passos desse algoritmo são realizados com auxílio do pacote de ferramentas Tisean (desenvolvido em C), conforme apresentado na Subseção 4.2.3. Usam-se as ferramentas mutual e delay para efetuar esses dois passos respectivamente. Para obtenção das previsões da representação tridimensional, passo número 4 do algoritmo, usa-se o modelo AR multidimensional obtido com o auxílio do pacote 
de ferramentas ARfit desenvolvido para Matlab. Usa-se a função arfit.m desse pacote para a implementação.

Escrevendo-se a representação tridimensional de um sinal temporal $x_{t}$, de comprimento $N$, como $X_{3}$ e o erro de previsão fornecido pelo modelo AR multidimensional como $E_{3}$, encontram-se as matrizes de covariância do passo número 6 do algoritmo pelas Equações (5.10) e (5.11).

$$
\begin{aligned}
& C_{o}=X_{3}^{H} \times X_{3} \\
& C_{e}=E_{3}^{H} \times E_{3}
\end{aligned}
$$

Como essas matrizes são compostas de números reais, o operador hermitiano é, simplesmente, a transposição das matrizes. Considera-se que as matrizes $X_{3}$ e $E_{3}$ possuem dimensão $N \times 3$, assim, as matrizes de covariância possuem dimensão $3 \times 3$.

Como foi feito na subseção anterior, apresenta-se um exemplo de sinal simulado com parâmetros: SNR igual a 25,80 dB, jitter de $2 \%$ e shimmer de $4 \%$. A Figura 5.49 (a) mostra a representação tridimensional desse sinal usando 10 amostras de atraso (obtida do mínimo da informação mútua). Realiza-se a PrCA (ordem 3) usando o modelo AR multidimensional com ordem 3 também. Obtém-se os três componentes previsíveis com variâncias de erro normalizadas iguais a 0,008; 0,010 e 0,015 respectivamente.

Nas partes (b), (c) e (d) da Figura 5.49, mostram-se as representações tridimensionais reconstruídas a partir dos três componentes previsíveis respectivamente. Percebese que se obtém somente uma direção de maior previsibilidade. Entretanto, observandose o sinal temporal relacionado com cada uma dessas representações, Figura 5.50, pode-se avaliar melhor o comportamento do algoritmo.

Para esta abordagem da PrCA, como se obtém somente três componentes previsíveis, sendo o último o menos previsível, escolhe-se realizar reconstruções usando os dois primeiros componentes. Assim, realizam-se os mesmos ensaios da subseção anterior com variações dos parâmetros do simulador. Novamente, utiliza-se a PrCA para 


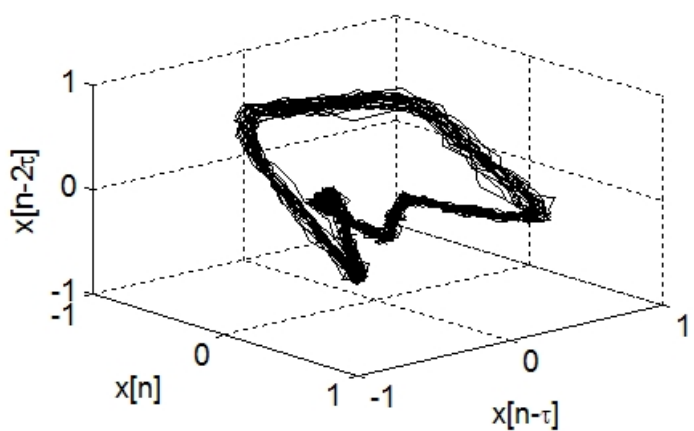

(a)

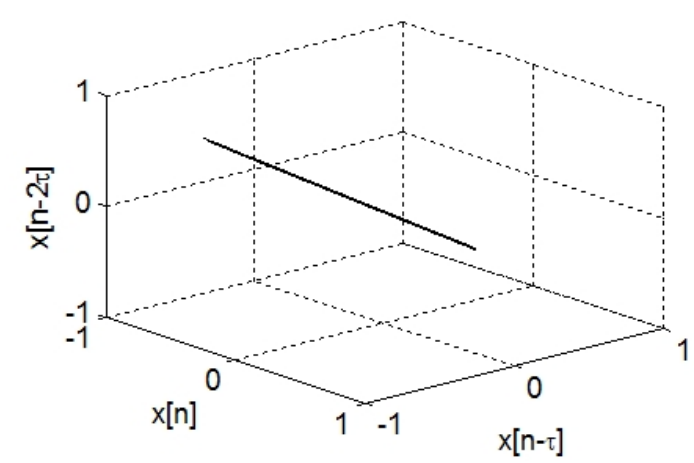

(c)

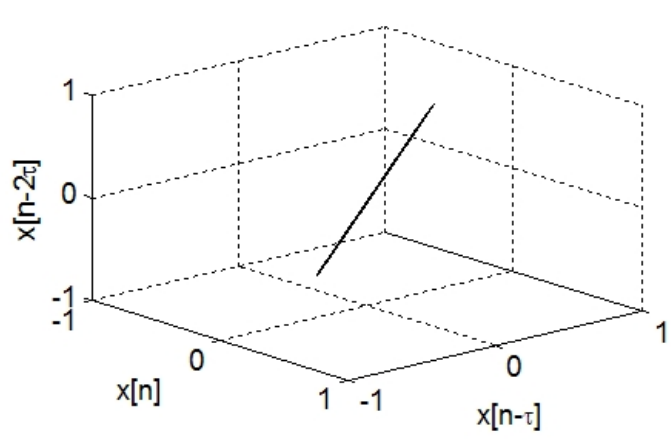

(b)

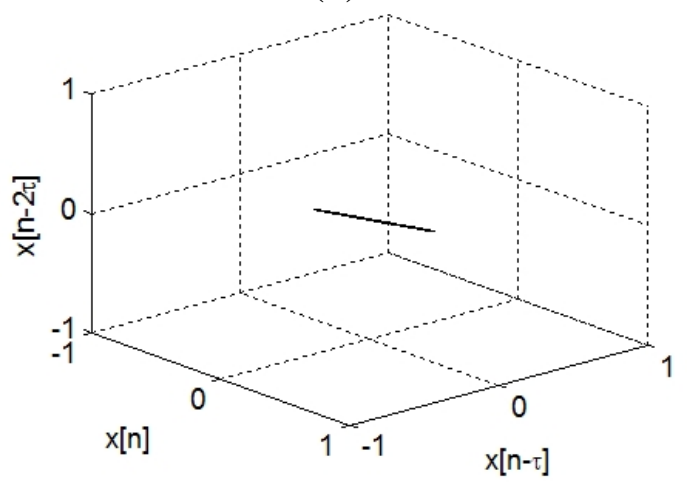

(d)

Figura 5.49: Representações tridimensionais de exemplo com sinal simulado de SNR igual a $25,80 \mathrm{~dB}$, jitter de $2 \%$ e shimmer de $4 \%$. (a) Sinal simulado original. (b) Sinal reconstruído com primeiro componente previsível (maior previsibilidade). (c) Sinal reconstruído com segundo componente. (d) Sinal reconstruído com terceiro componente (menor previsibilidade).

reconstrução de versões mais previsíveis dos sinais, obtendo um sinal de erro usado para calcular a PP. Então, variam-se o nível de ruído, SNR entre 5,80 e 25,80 dB, jitter e shimmer de $2 \%$ a $20 \%$. Para o modelamento AR multidimensional, escolhe-se ordem igual a 26, como usado para o modelo AR unidimensional. Os resultados de PP para esses ensaios são apresentados nas Figuras 5.51 a 5.53, respectivamente para variação de SNR, jitter e shimmer. 


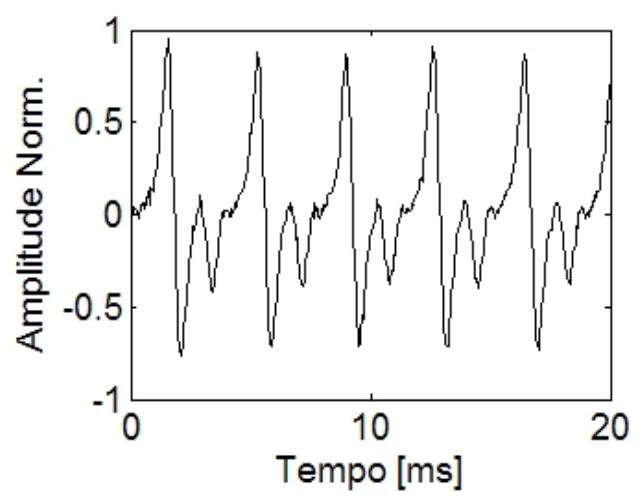

(a)

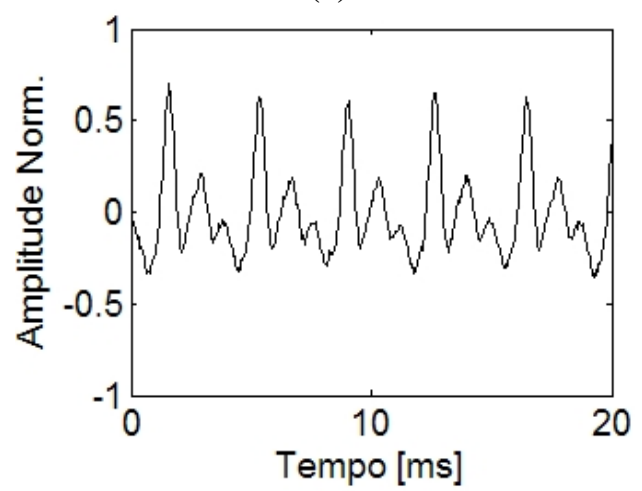

(c)

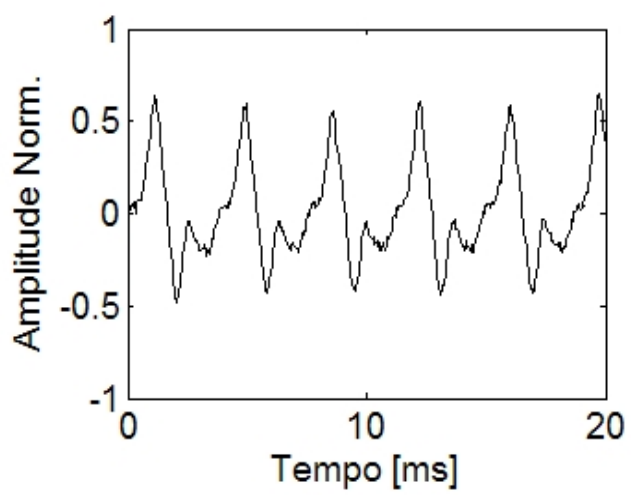

(b)

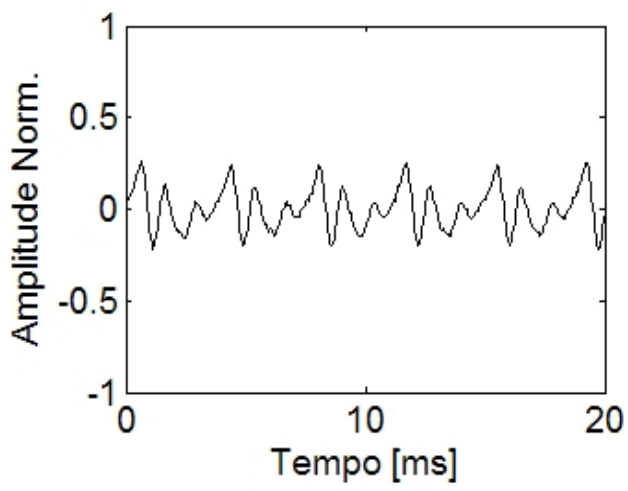

(d)

Figura 5.50: Sinais temporais relacionados com cada uma das representações da Figura 5.49. (a) Sinal original. (b) Sinal reconstruído com primeiro componente previsível. (b) Sinal reconstruído com segundo componente. (d) Sinal reconstruído com terceiro componente.

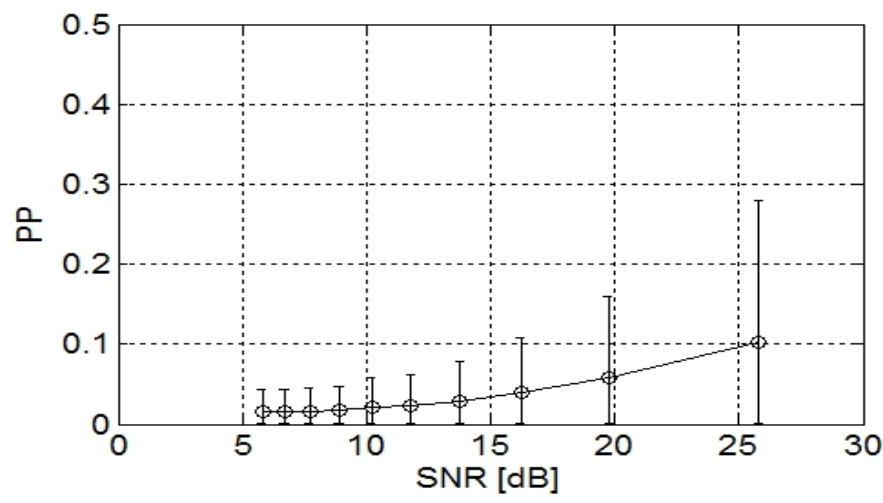

Figura 5.51: Resultado de PP do ensaio de variação do nível de ruído (SNR) usando PrCA na representação tridimensional dos sinais simulados (modelo AR multidimensional com ordem 26). Valores médios e desvios padrões de cinco testes para cada combinação de parâmetros. 


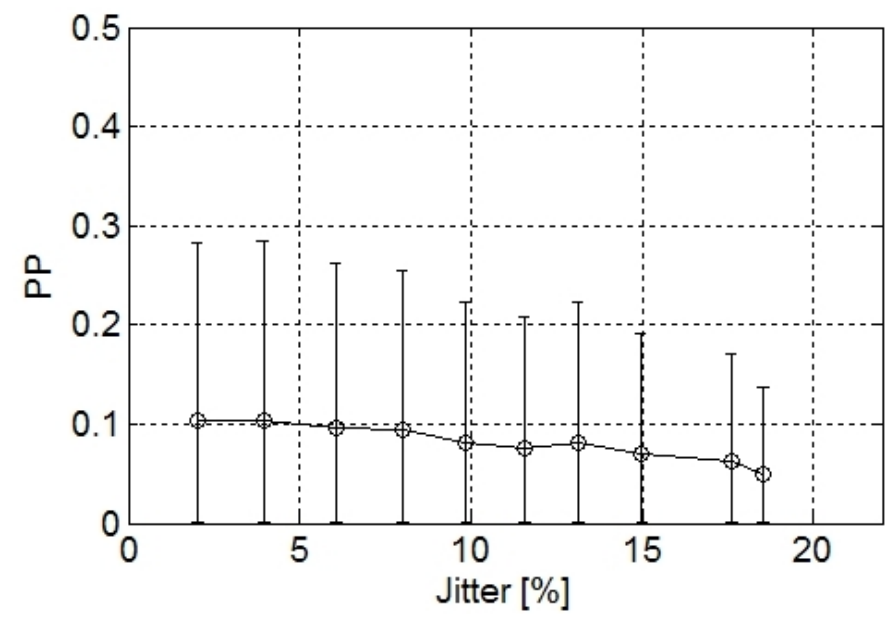

Figura 5.52: Resultado de PP do ensaio de variação do jitter usando PrCA na representação tridimensional dos sinais simulados (modelo AR multidimensional com ordem 26). Valores médios e desvios padrões de cinco testes para cada combinação de parâmetros.

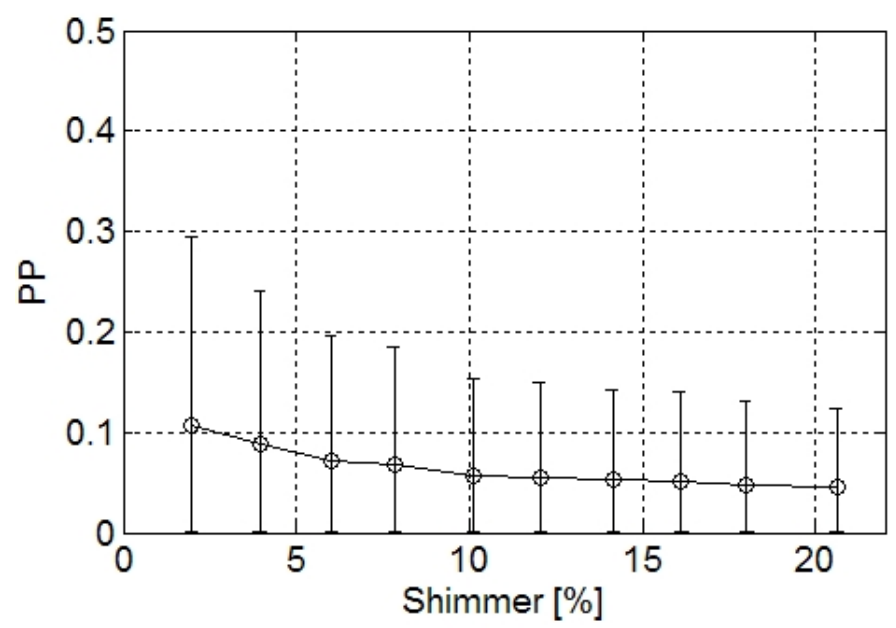

Figura 5.53: Resultado de PP do ensaio de variação do shimmer usando PrCA na representação tridimensional dos sinais simulado (modelo AR multidimensional com ordem 26). Valores médios e desvios padrões de cinco testes para cada combinação de parâmetros.

O comportamento do algoritmo para as variações dos parâmetros tende ao esperado, ou seja, diminuindo a PP conforme se aumenta a desorganização dos sinais simulados. Porém, os desvios padrões dos resultados são muito grandes e os valores médios de PP apresentam pequena faixa de variação com a modificação dos parâmetros. Assim, pelo menos nas análises com sinais simulados, esse último algoritmo não se mostrou melhor do que usar a PrCA diretamente no sinal temporal ou estimando-se a PP com modelo wavelet. No próximo capítulo, mostram-se os resultados de ensaios usando sinais reais de voz para todos os métodos apresentados até agora. 


\section{Capítulo 6}

\section{Ensaios e Resultados}

Neste capítulo, mostram-se os resultados obtidos em ensaios de sinais de voz reais. Esses sinais e o pré-processamento utilizado foram apresentados no Capítulo 4. Primeiramente, comentam-se os ensaios com medidas de entropia de Shannon e de entropia relativa entre os sinais dos grupos.

Em seguida, mostram-se os resultados dos ensaios com curva de crescimento de entropia. Como discutido na Subseção 5.1.4, para sinais de voz, não se consegue obter essa curva usando a entropia de blocos, devido a excessiva quantidade de possibilidades dos blocos. Assim, realizam-se os ensaios usando comprimento de bloco unitário, variando somente o tamanho do sinal analisado.

Após os ensaios com entropia, apresentam-se os resultados de PP usando modelo AR para previsão dos sinais e, também, modelo de decomposição por wavelets. Para finalizar o capítulo, mostram-se os ensaios de PrCA dos sinais de voz usando os dois modelos anteriores e, além disso, ensaios de PrCA das representações tridimensionais usando modelo AR multidimensional, conforme apresentado no Capítulo 5.

\subsection{Ensaios de Medidas de Entropia}

Nesta seção, apresentam-se os ensaios de medidas de entropia para os sinais de voz pertencentes a pessoas de três grupos: saudáveis, com nódulo nas pregas vocais e com edema de Reinke. O ensaio com entropia de Shannon foi realizado com o algoritmo 
do método do passo de quantização constante da Tabela 5.3, conforme discutido na Subseção 5.1.2.

Já para o ensaio com entropia relativa, usou-se o algoritmo da Tabela 5.4, também usando o mesmo método, o qual foi usado em todas as estimativas de entropia, como comentado anteriormente. Realizou-se, também, um ensaio com curvas de entropia para blocos de comprimento unitário, o qual é apresentado na Subseção 6.1.1.

Para todas as estimativas de entropia, tanto de Shannon como relativa, apresentadas neste capítulo, utilizou-se passo de quantização igual a 0,004, o qual obtém uma boa resolução das PDFs dos sinais de voz estudados.

Esses sinais de voz possuem em torno de $1 s$ de duração com freqüência de amostragem de $22.050 \mathrm{~Hz}$, ou seja, pouco mais de 20.000 amostras por sinal. Portanto, para melhor analisar cada sinal, divide-se cada um em cinco partes de 4.000 amostras. Essa divisão é realizada em todos os ensaios apresentados neste capítulo, resultando em valores médios e seus desvios padrões.

Dessa forma, os valores médios e desvios padrões de entropia de Shannon para os 16 sinais de voz dos cada grupo estudado são apresentados na Figura 6.1. Os valores foram ordenados em forma crescente para melhor visualização. Pode-se ver que, somente usando essa medida, não se consegue diferenciar os sinais dos três grupos.

Para se analisar melhor esses resultados, na Figura 6.2, apresentam-se os valores médios (e desvios padrões) da entropia de cada grupo, consolidando os resultados dos 48 sinais (16 de cada grupo) da Figura 6.1.

A entropia média dos sinais de nódulo foi maior do que a dos sinais saudáveis, porém o desvio padrão foi muito alto para permitir uma diferenciação entre os dois grupos. Além disso, a média dos sinais de Edema de Reinke foi abaixo do valor para o grupo saudável, o que poderia indicar uma menor incerteza com respeito a esses sinais, mas o grande desvio padrão também impossibilita essa análise.

A Figura 6.3 apresenta trechos de $50 \mathrm{~ms}$ de exemplos de sinais de voz de cada grupo junto com suas PDFs. As partes (a), (c) e (e) são os sinais saudável, nódulo e edema de Reinke respectivamente. As partes (b), (d) e (f) são suas respectivas PDFs, as quais são obtidas usando todas as 20.000 amostras dos sinais. 


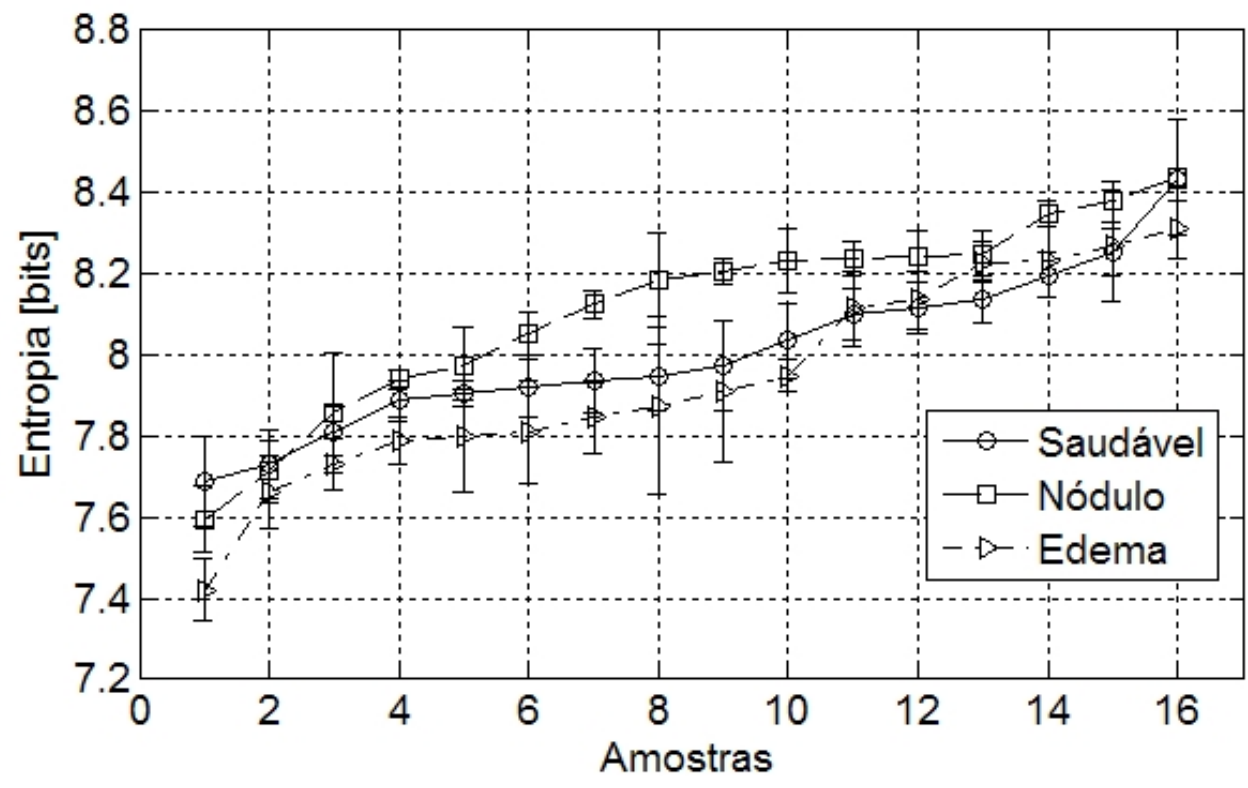

Figura 6.1: Resultados do ensaio de medidas de entropia de Shannon, usando método do passo de quantização constante, para os sinais dos três grupos estudados: saudável, nódulo e edema de Reinke.

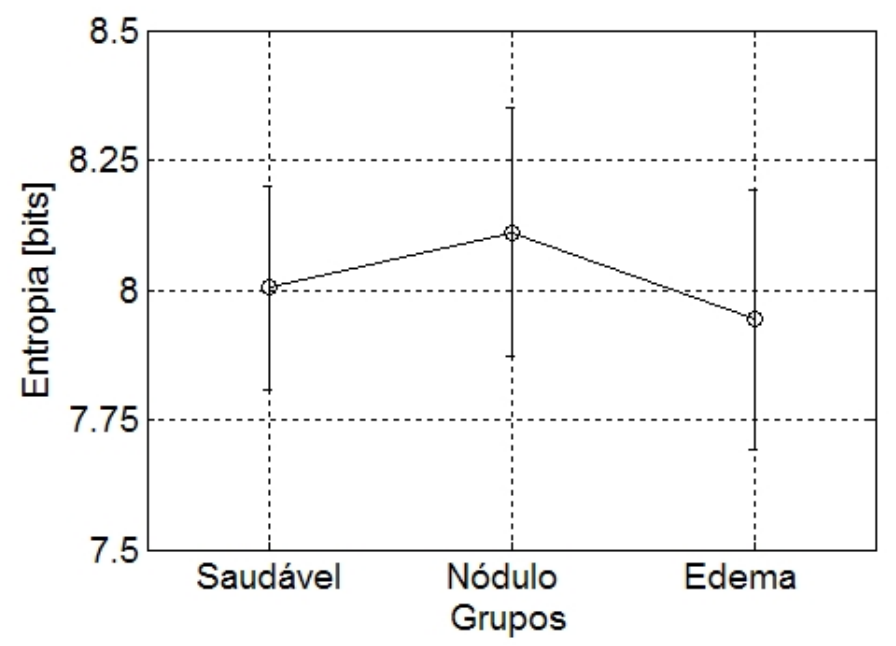

Figura 6.2: Resultados consolidados para o ensaio de entropia de Shannon dos sinais de voz dos três grupos estudados. Apresentam-se a média e desvio padrão da entropia de cada grupo. 


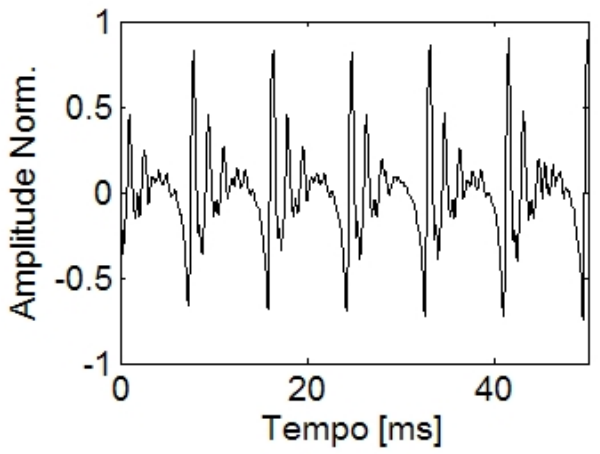

(a)

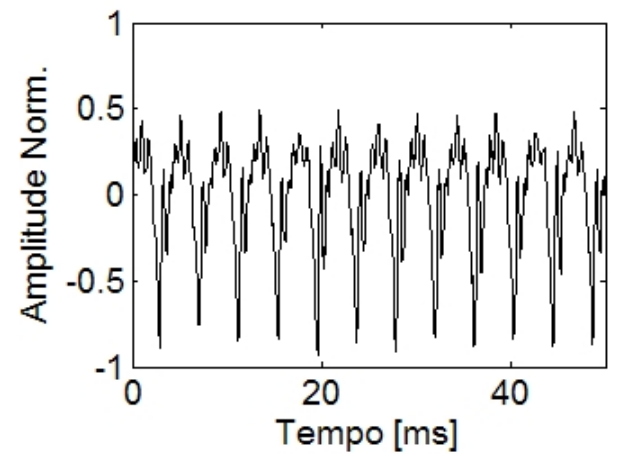

(c)

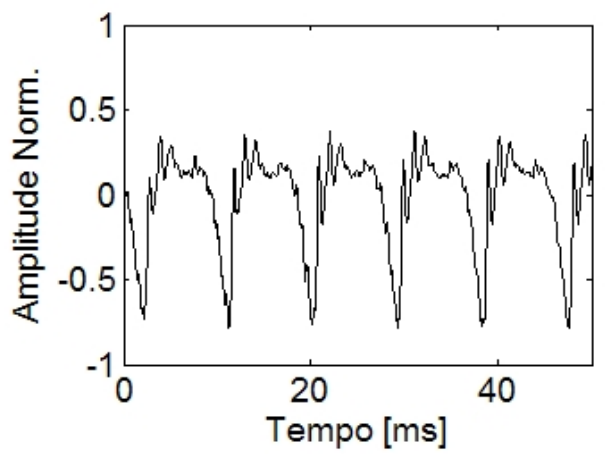

(e)

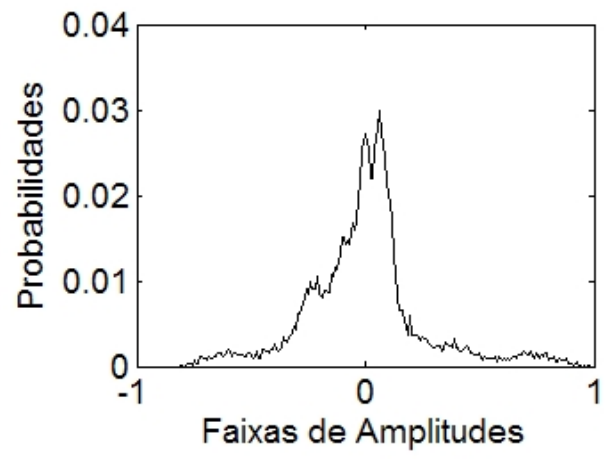

(b)

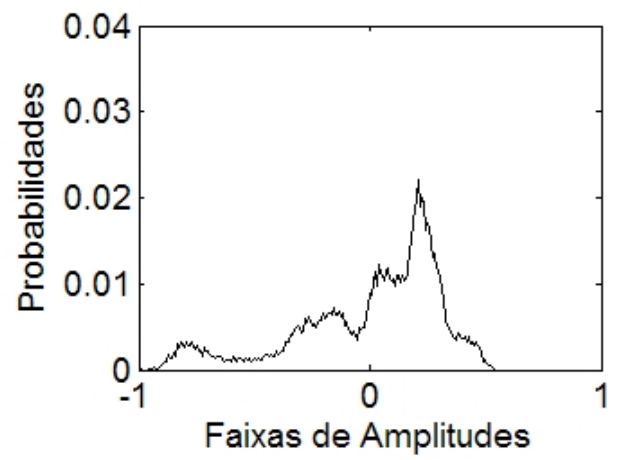

(d)

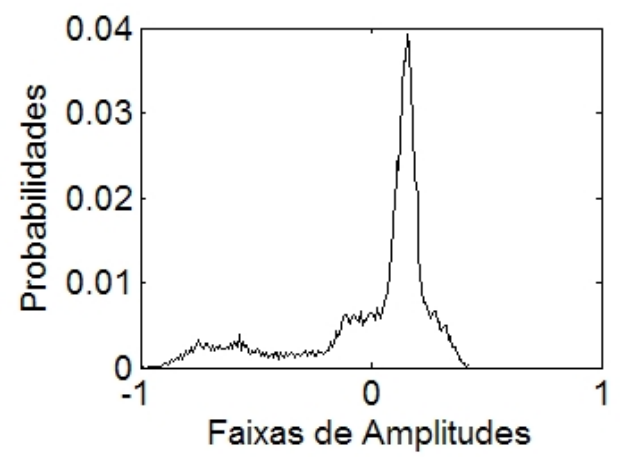

(f)

Figura 6.3: Exemplos de sinais de voz dos grupos estudados e suas PDFs. (a) Sinal de voz de pessoa saudável. (b) PDF do sinal saudável. (c) Sinal de voz de pessoa com nódulo nas pregas vocais. (d) PDF do sinal de nódulo. (e) Sinal de pessoa com edema de Reinke. (f) PDF do sinal de edema.

Pode-se ver que o sinal saudável apresenta grande regularidade, mas o sinal de edema também, pelo menos nesse pequeno trecho. A PDF do sinal saudável possui maior proximidade com uma distribuição Gaussiana, do que os outros sinais, principalmente do que o sinal de nódulo. Como a PDF de (d) é mais achatada, tem-se sua maior entropia (mais próxima de uma distribuição uniforme), como seria mais esperado pela menor regularidade, portanto, menor previsibilidade. 
Mas, para o sinal de edema, como este apresenta muitos valores próximos do zero, a PDF resultante é mais concentrada no zero, resultando em menor entropia do que para os sinais saudáveis. Isso seria uma característica de maior previsibilidade, porém esses sinais possuem maior jitter e shimmer, em média, conforme discutido no Capítulo 4. Portanto, a medida de entropia de Shannon talvez não seja a mais indicada para caracterizar a previsibilidade dos sinais de voz.

Após esse ensaio, realizou-se outro com medidas de entropia relativa entre os sinais de voz. Estimou-se a entropia relativa entre os sinais saudáveis e os sinais dos outros grupos. Além dos sinais dos grupos patológicos, calculou-se os valores entre os próprios sinais saudáveis para serem usados como referência.

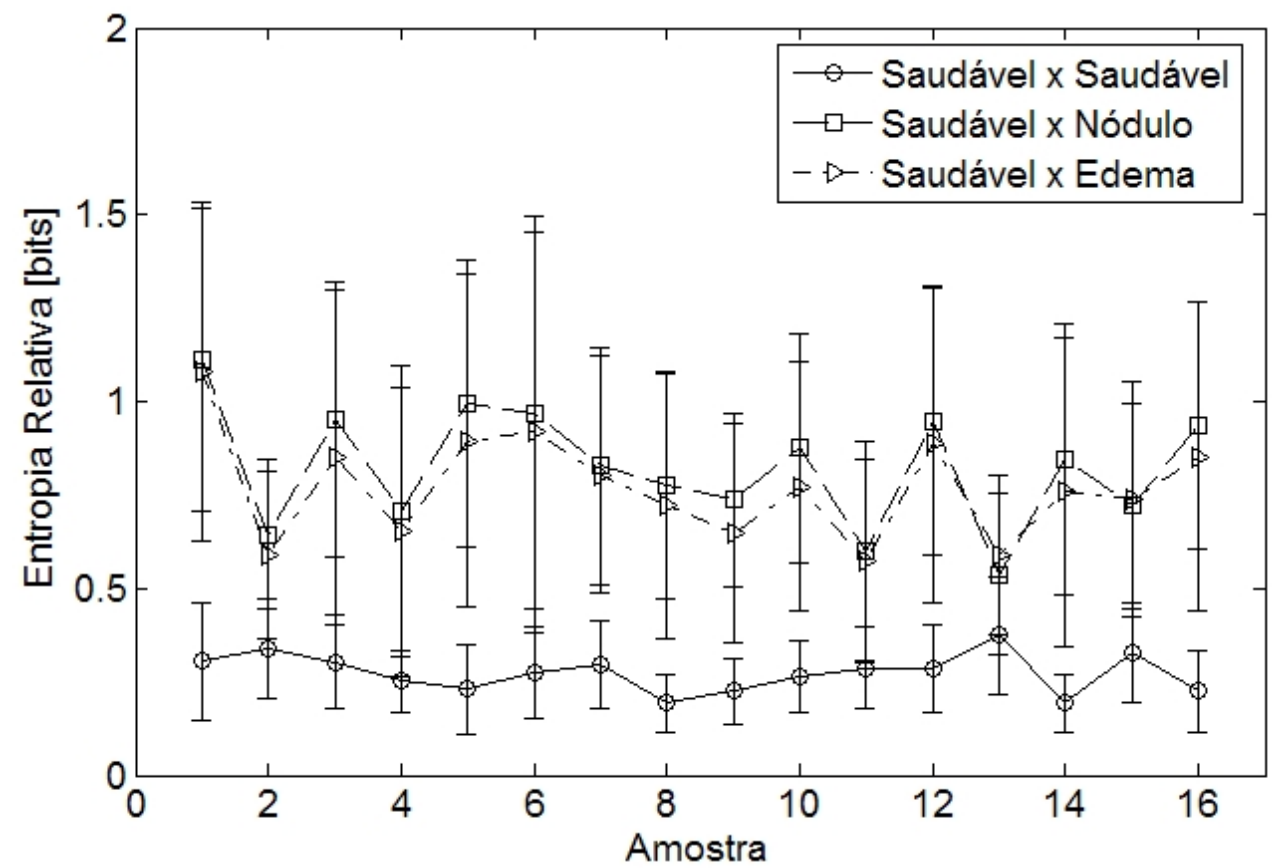

Figura 6.4: Resultados do ensaio de medidas de entropia relativa entre os sinais reais de voz, usam-se três combinações de sinais: saudáveis versus saudáveis (grupo de controle), saudáveis versus nódulo e saudáveis versus edema.

Para cada sinal saudável, estimou-se a entropia relativa entre este e todos os outros. Os valores médios e desvios padrões resultantes são apresentados na Figura 6.4. Como visto, a separação entre o grupo saudável e os patológicos foi muito eficiente, como melhor observado na Figura 6.5, a qual apresenta os resultados consolidados para os três grupos. 


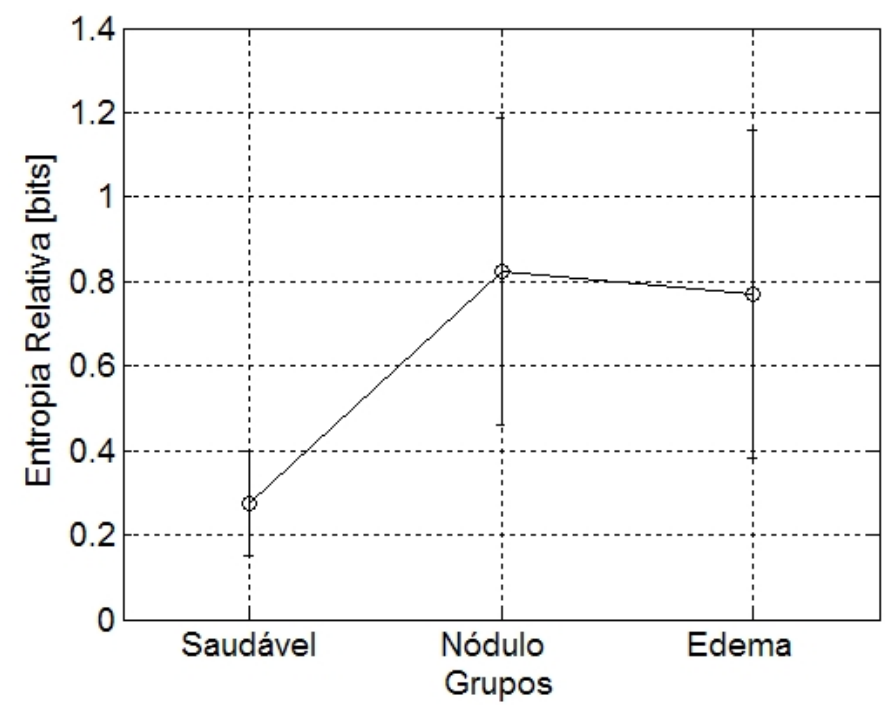

Figura 6.5: Resultados do ensaio de medidas de entropia relativa entre os sinais reais de voz, usam-se três combinações de sinais: saudáveis versus saudáveis (grupo de controle), saudáveis versus nódulo e saudáveis versus edema.

Portanto, com base no conjunto de sinais analisados, esse método pode ser considerado satisfatório para separação entre sinais saudáveis e os sinais das patologias estudadas. Entretanto, para se ter uma base de comparação, são necessários diversos sinais já classificados para obtenção dos valores entropia de cada grupo.

Em seguida, comentam-se sobre os resultados do ensaio com curvas de entropia para blocos de comprimento unitário.

\subsubsection{Curvas de Entropia}

Nesta subseção, apresenta-se o ensaio com curva de crescimento da entropia para blocos de comprimento unitário usando sinais de voz. Conforme discutido na Subseção 5.1.4, não se consegue obter a curva de entropia para blocos com grande faixa de comprimento. Com isso, não é possível se obter a assíntota da curva, a qual possui características relacionadas com a regularidade do sistema em estudo.

Assim, o único ensaio possível foi para comprimento de bloco unitário, o qual, na verdade, indica a convergência do valor de entropia de Shannon conforme se obtém mais informações sobre o sistema, ou seja, se aumenta o tamanho do sinal usado.

Dessa forma, estimou-se as curvas de entropia para todos os sinais de voz usados nesse estudo, 16 sinais de cada grupo. As Figuras 6.6 a 6.8 apresentam essas cur- 
vas respectivamente para sinais saudáveis, nódulo e edema de Reinke. Nesse ensaio, iniciaram-se as estimativas das curvas com sinais de 1.000 amostras, aumentando-se esses sinais de 20 amostras a cada passo.

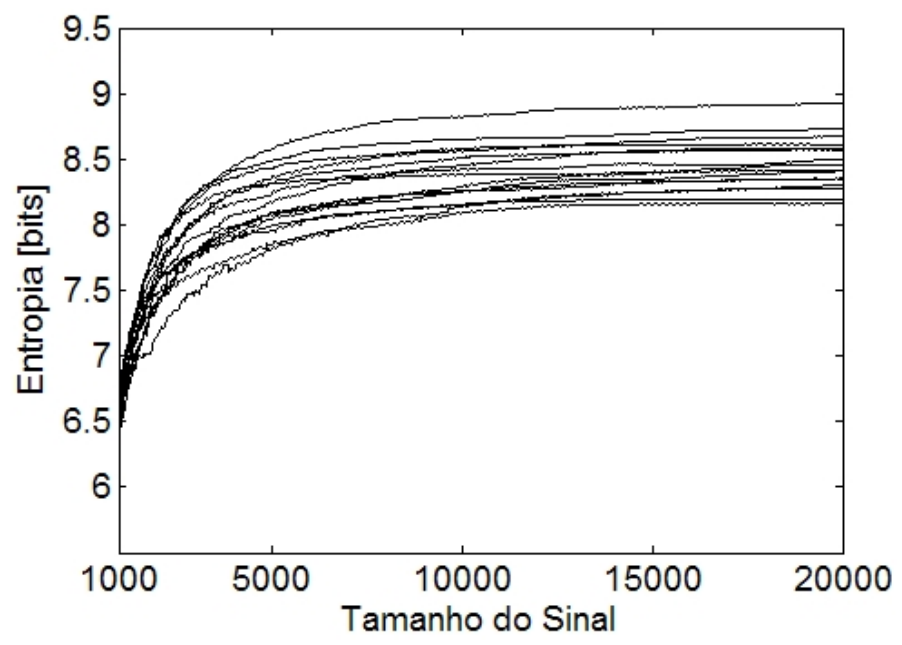

Figura 6.6: Curva de crescimento da entropia de Shannon para os sinais de voz saudáveis conforme se aumenta o tamanho do sinal usado para a estimativa.

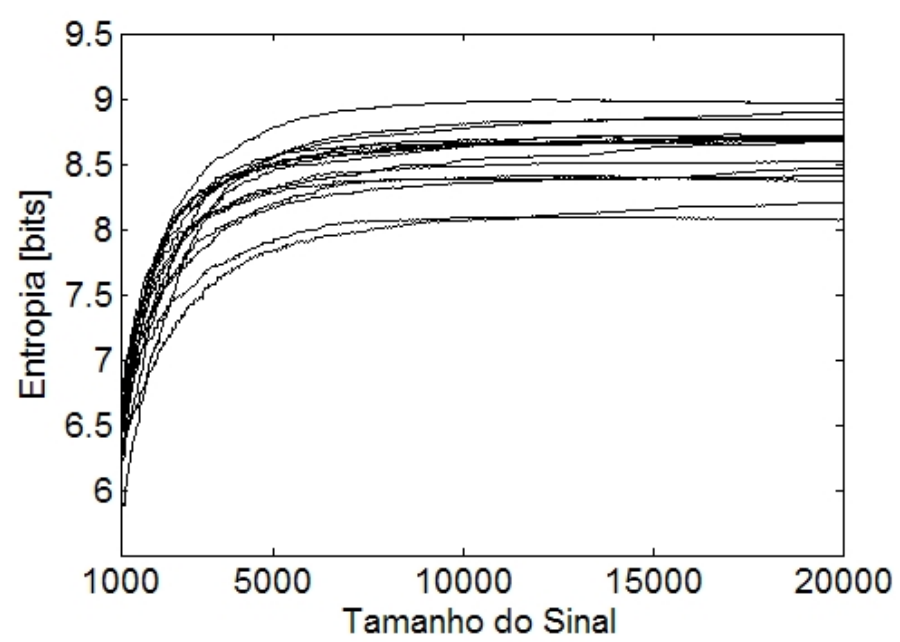

Figura 6.7: Curva de crescimento da entropia de Shannon para os sinais de nódulo conforme se aumenta o tamanho do sinal usado para a estimativa.

Como visto nessas figuras, as curvas possuem características muito similares, não sendo diferenciáveis visualmente. Dessa forma, pouca informação sobre esses sinais de voz especificamente seria obtida da análise dessas curvas na presente forma. $\mathrm{Na}$ seção 7.2 do capítulo seguinte, apresenta uma breve discussão sobre um estudo mais aprofundado dessas curvas para sinais saudáveis e de nódulo somente, a qual chega a algumas conclusões interessantes. 


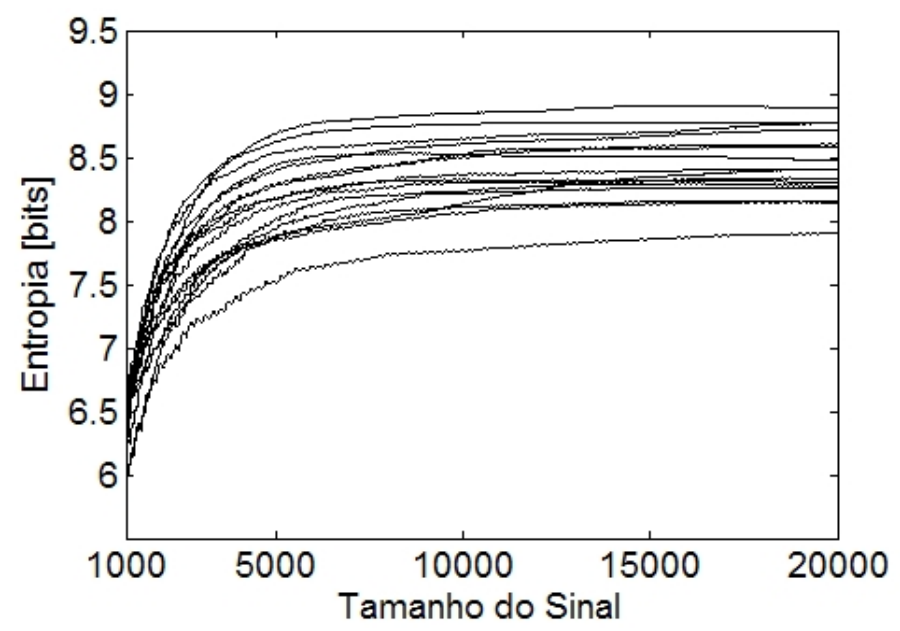

Figura 6.8: Curva de crescimento da entropia de Shannon para os sinais de edema de Reinke conforme se aumenta o tamanho do sinal usado para a estimativa.

Apesar disso, uma análise mais cuidadosa desse tipo de curva mostra uma peculiaridade interessante. Percebe-se que a curva possui pequenas variações que estão relacionadas com o período de pitch dos sinais. Essa característica é ilustrada na Figura 6.9, a qual foi obtida para um sinal de voz saudável usando passo unitário de aumento do tamanho do sinal analisado.

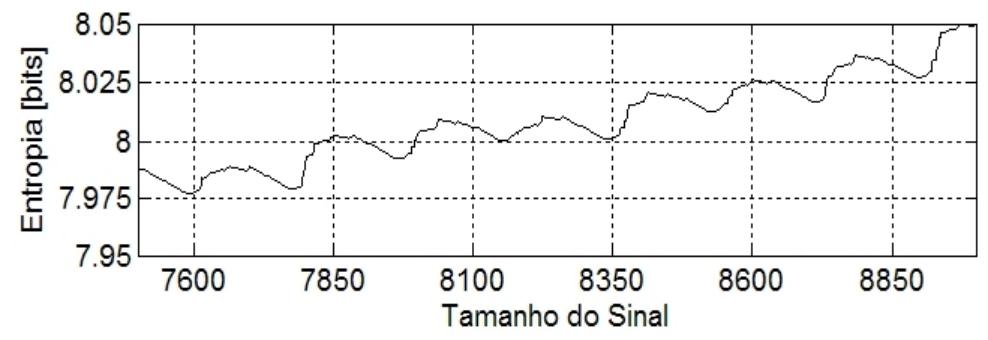

(a)

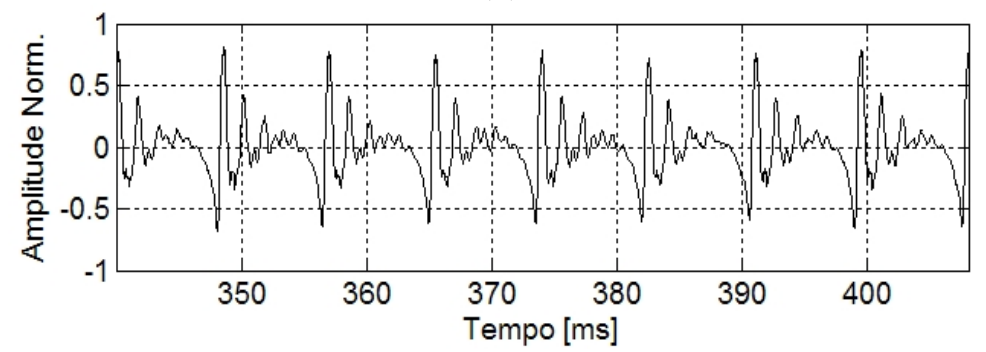

(b)

Figura 6.9: Ilustração da relação entre a variação da curva de crescimento da entropia e o período de pitch dos sinais de voz. Em (a), tem-se um trecho da curva de entropia e, em (b), o trecho equivalente do sinal de voz. 
Na parte (a), tem-se um trecho da curva de entropia entre, aproximadamente, 7.500 e 9.000 pontos do tamanho do sinal, mostrando a variação mencionada. Já na parte (b) da figura, mostra o sinal de voz correspondente a esse trecho. Percebe-se a relação da variação da curva e do período do sinal. Quando o sinal se encontra em seu máximo, a curva de entropia também está no máximo de sua variação. Assim, essa característica poderia ser explorada para obtenção de informações da regularidade dos sinais estudados. Entretanto, esse estudo ficará para trabalhos futuros.

Na próxima seção, apresentam-se os ensaios de PP para os sinais de voz usando tanto modelo AR quanto modelo baseado em decomposição por wavelets.

\subsection{Ensaios de Potência de Previsão}

Nesta seção, mostram-se os resultados dos ensaios de PP para os sinais de voz. Primeiramente, apresenta-se o ensaio usando modelo AR(26), conforme discutido na Subseção 5.2.1. Em seguida, apresenta-se o ensaio usando modelagem baseada em decomposição por wavelets, conforme a Subseção 5.2.2.

\subsubsection{Modelagem AR}

Para o ensaio com o modelo AR, utilizou-se o algoritmo da Tabela 5.8 com o método da autocorrelação, sendo a ordem igual a 26, como discutido anteriormente. Para o cálculo da entropia relativa entre os sinais e seus erros de previsão, usa-se o método do passo de quantização constante.

Para ilustrar o efeito da aplicação do algoritmo de estimativa de PP com modelo AR nos sinais de voz, apresenta-se a Figura 6.10. Tem-se uma comparação, semelhante ao apresentado na Figura 5.29 do Capítulo 5 para sinais simulados, entre os erros de estimativa com $\mathrm{AR}(26)$ para exemplos dos sinais de voz de cada grupo junto com suas respectivas PDFs. Nessa figura, nas partes (a), (c) e (e), tem-se trechos de $50 \mathrm{~ms}$ dos erros de previsão dos sinais saudável, de nódulo e de edema de Reinke respectivamente. Já nas partes (b), (d) e (f), as PDFs respectivas desses sinais, as quais foram obtidas usando todas as 20.000 amostras dos sinais e 200 células. 


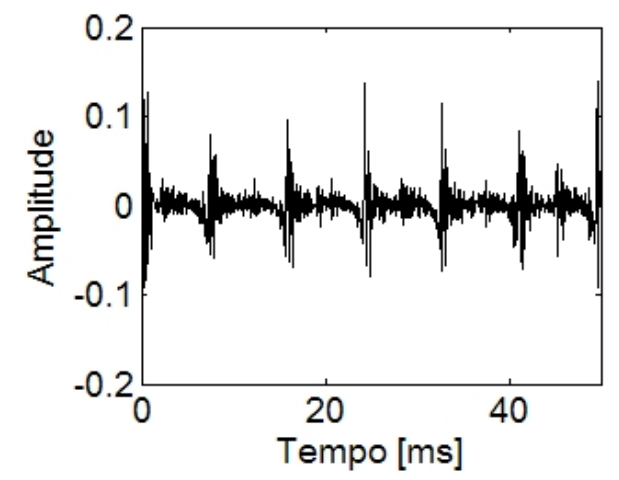

(a)

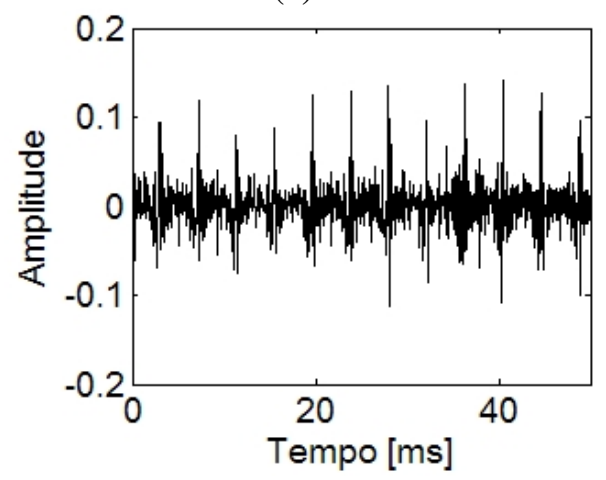

(c)

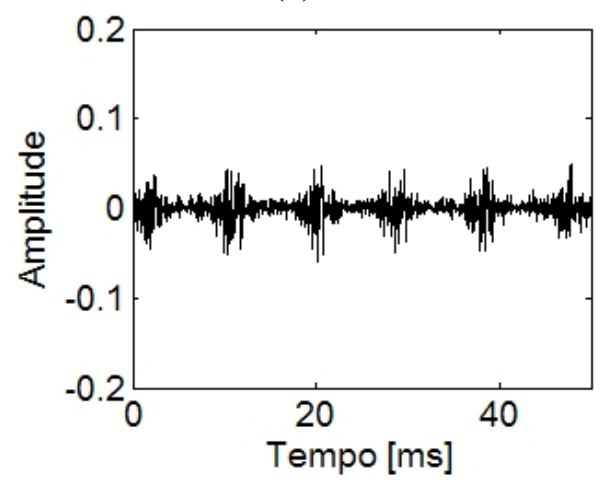

(e)

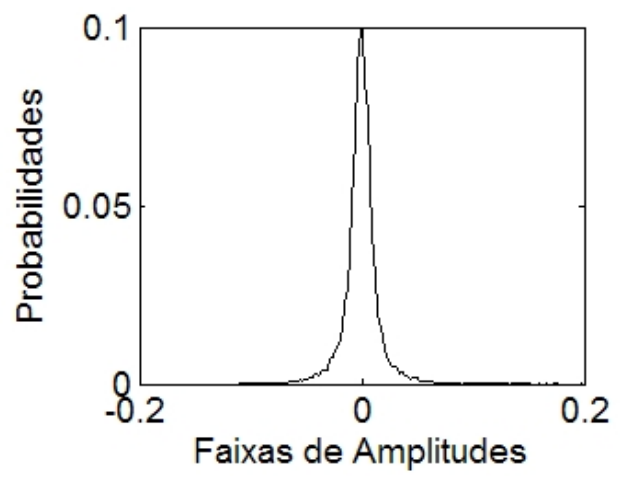

(b)

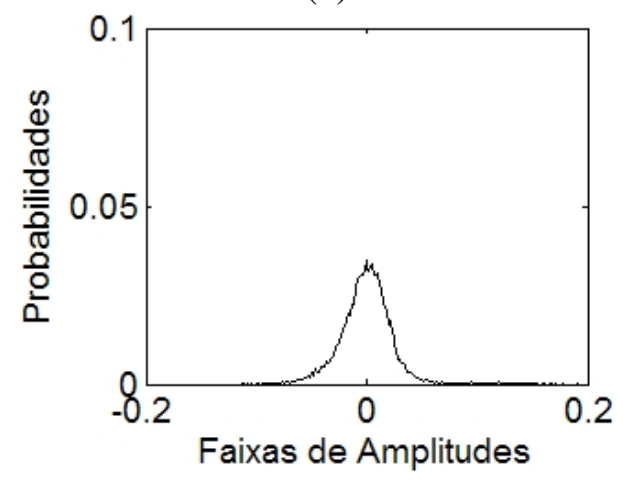

(d)

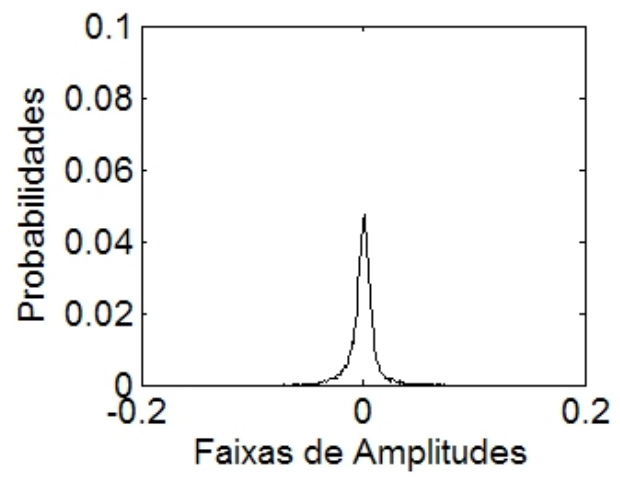

(f)

Figura 6.10: Exemplos de trechos de erros de previsão de sinais de voz usando modelo AR(26). Em (a), (c) e (e), tem-se os erros de previsão dos sinais saudável, de nódulo e de edema de Reinke respectivamente. Em (b), (d) e (f), tem-se as respectivas PDFs desses sinais.

Como visto nessa figura, as PDFs dos erros de estimativa são bem próximas da PDF Gaussiana, fato devido ao algoritmo de modelagem AR que utiliza mínimos quadrados, resultando em erros Gaussianos. Porém, percebe-se que a PDF do erro do sinal saudável possui as maiores probabilidades e a do erro do sinal de nódulo é a mais achatada. Já para o edema de Reinke, a PDF é intermediária entre as anteriores. 
Observando-se os sinais temporais, percebe-se a regularidade do erro do sinal saudável, porém sua amplitude é grande, o que pode mascarar os valores de PP obtidos, podendo ser interpretado como menor previsibilidade desse tipo de sinal.

Na estimativa da PP, como apresentado anteriormente, utiliza-se a entropia relativa entre o sinal de voz e seu erro de previsão, portanto, são essas diferenças indicadas na figura anterior que serão refletidas nos valores de PP.

Após essa ilustração, apresentam-se os resultados do ensaio de PP para os sinais de voz dos três grupos usando modelo AR(26) na Figura 6.11. Nessa figura, mostram-se os valores médios e os desvios padrões de PP para os 16 sinais de voz de cada grupo.

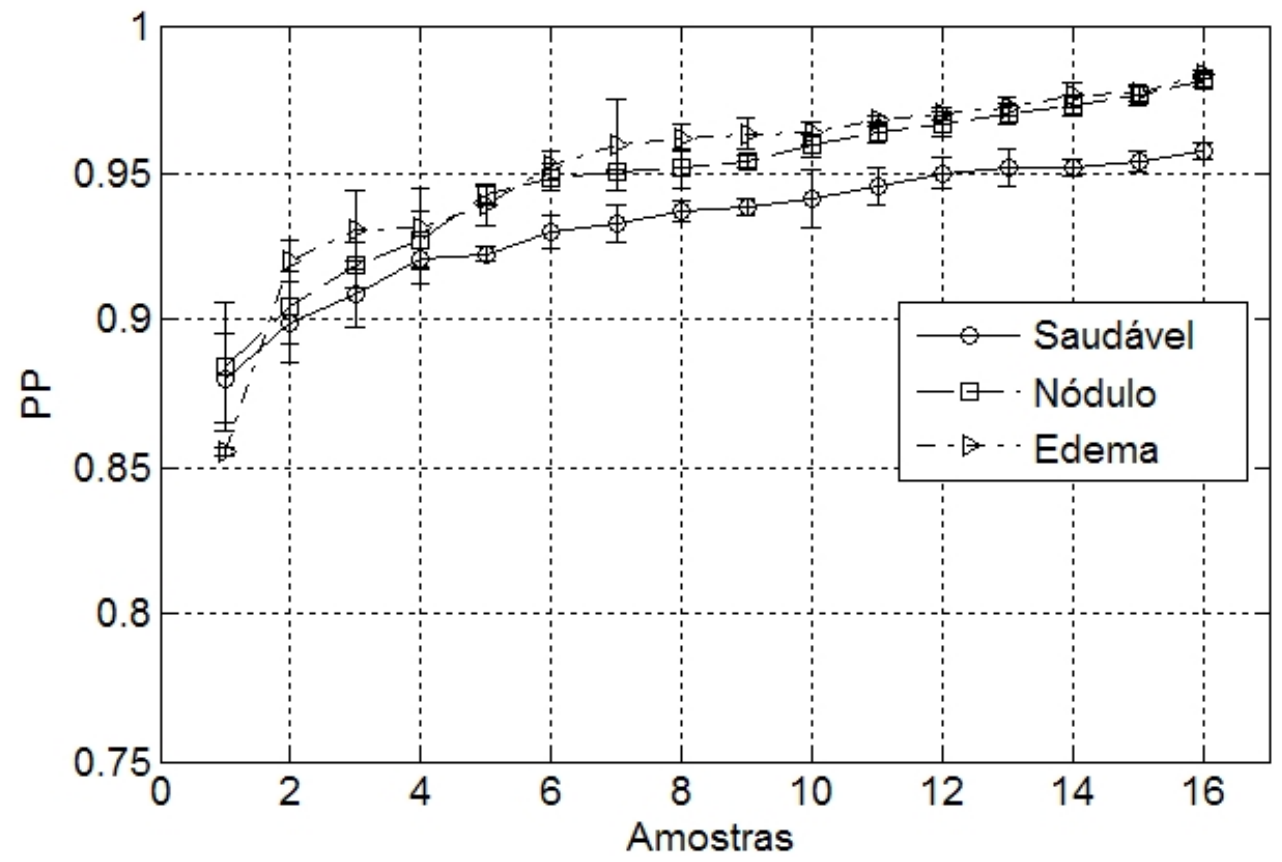

Figura 6.11: Valores médios e desvios padrões de PP, usando modelo AR(26), para os sinais dos três grupos estudados: saudável, com nódulo e com edema de Reinke.

Da mesma forma que para o ensaio de entropia de Shannon, os valores de PP dessa figura não podem ser usados para diferenciar os sinais dos grupos estudados. Para melhor visualização dos valores dos grupos, apresenta-se a Figura 6.12, na qual mostram-se os valores de PP consolidados para cada um dos grupos.

Observando-se essa figura, percebe-se que o valor médio de PP para os sinais saudáveis é um pouco menor do que dos sinais dos grupos patológicos, indicando uma tendência para a análise com modelo AR indicar que os sinais saudáveis são menos previsíveis em média. Isso, provavelmente, porque as PDFs dos erros de previsão são 


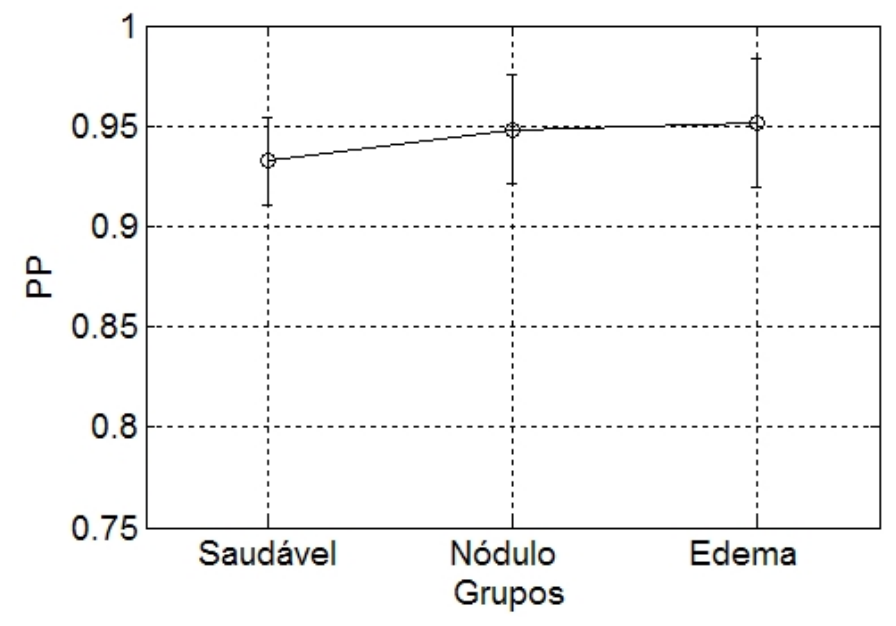

Figura 6.12: Resultados consolidados, para os três grupos analisados, do ensaio de PP usando modelo $\operatorname{AR}(26)$.

muito parecidas (o que explica a proximidade das PPs dos grupos) e os erros dos sinais saudáveis possuem maiores amplitudes.

Assim, como já indicado pela insensibilidade do modelo AR para variações de jitter e shimmer de sinais simulados (Capítulo 5), a estimativa de PP com esse modelo não foi suficiente para diferenciar os sinais de voz dos três grupos. Portanto, na próxima subseção, apresenta-se o ensaio usando o modelo de previsão baseado em decomposição por wavelets.

\subsubsection{Modelagem Baseada em Decomposição por Wavelets}

Para o ensaio com o modelo de decomposição por wavelets, utilizou-se o algoritmo da Tabela 5.9, com nível de decomposição máximo igual a 5 e família de filtros Daubechies de ordem 30. Como discutido na Subseção 5.2.2, utilizam-se a soma dos detalhes reconstruídos, $D_{1}$ a $D_{5}$, como a previsão do modelo e a aproximação reconstruída, $A_{5}$, como o erro de previsão.

Da mesma forma que feito para a modelagem AR, apresenta-se a Figura 6.13 para ilustrar o efeito da aplicação do algoritmo de estimativa de PP com modelo wavelet. Assim, tem-se, nas partes (a), (c) e (e) da figura, trechos de $50 \mathrm{~ms}$ dos erros de previsão dos sinais saudável, de nódulo e de edema de Reinke respectivamente. E, nas partes (b), (d) e (f), as PDFs respectivas desses sinais (obtidas usando todas as 20.000 amostras dos sinais e 200 células). 


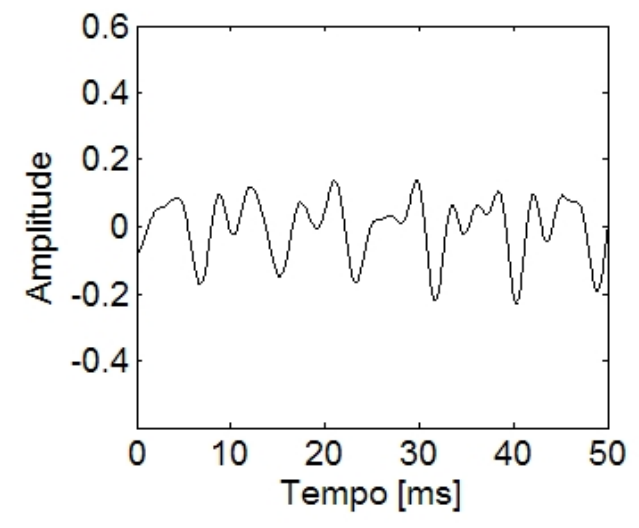

(a)

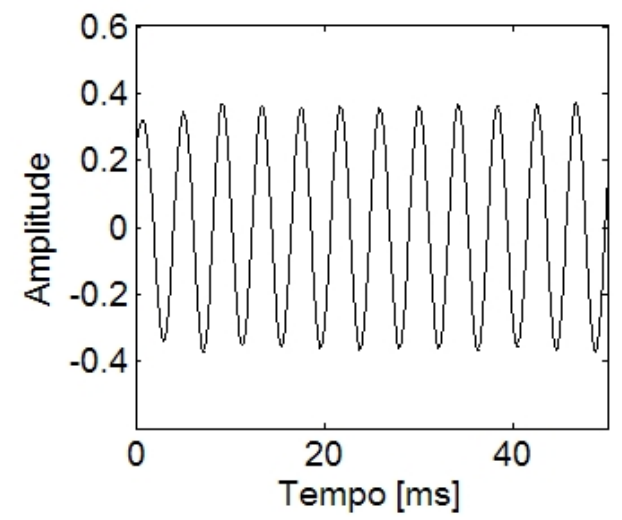

(c)

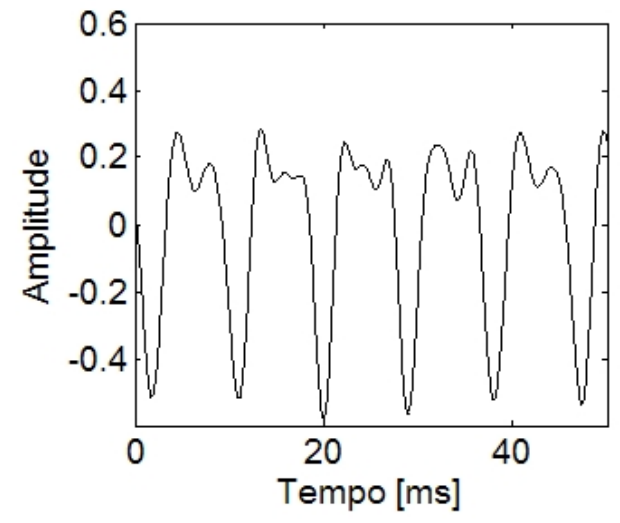

(e)

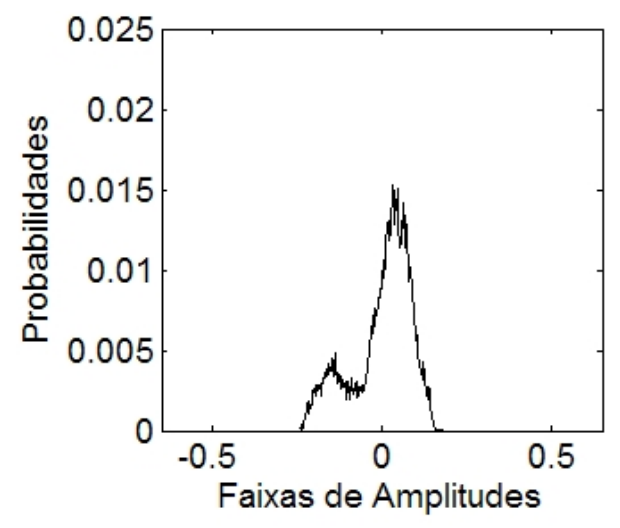

(b)

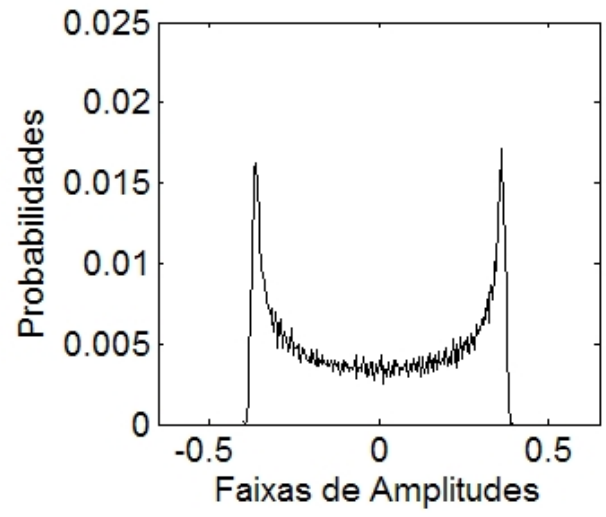

(d)

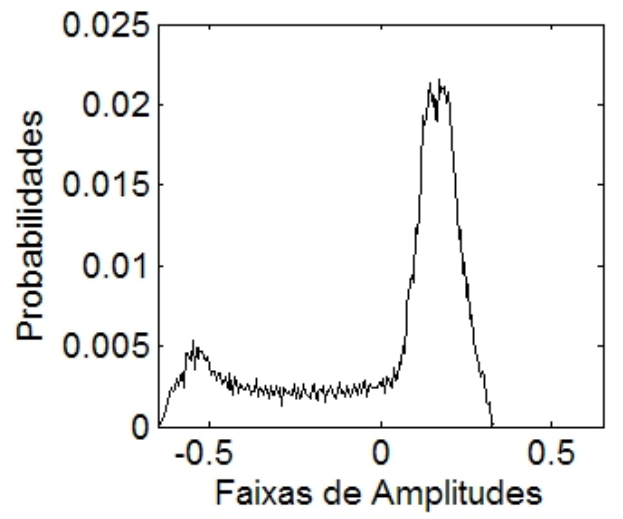

(f)

Figura 6.13: Exemplos de trechos de erros de previsão de sinais de voz usando modelo wavelet. Em (a), (c) e (e), tem-se os erros de previsão dos sinais saudável, de nódulo e de edema de Reinke respectivamente. Em (b), (d) e (f), tem-se as respectivas PDFs desses sinais.

Ao contrário do observado na Figura 6.10 para o modelo AR, no caso do modelo wavelet, os erros de previsão dos sinais dos três grupos são bem diferentes e suas PDFs também. Percebe-se que a PDF do sinal saudável se aproxima de uma Gaussiana, 
já para os sinais patológicos, as PDFs são bem diferentes de Gaussianas, bem mais planos, portanto indicando a sua falta de previsibilidade pelo modelo.

Os valores de PP obtidos para o ensaio usando modelagem baseada em decomposição wavelet para os sinais de voz dos três grupos estudados são apresentados na Figura 6.14. Na Figura 6.15, apresentam-se os resultados consolidados para os três grupos.

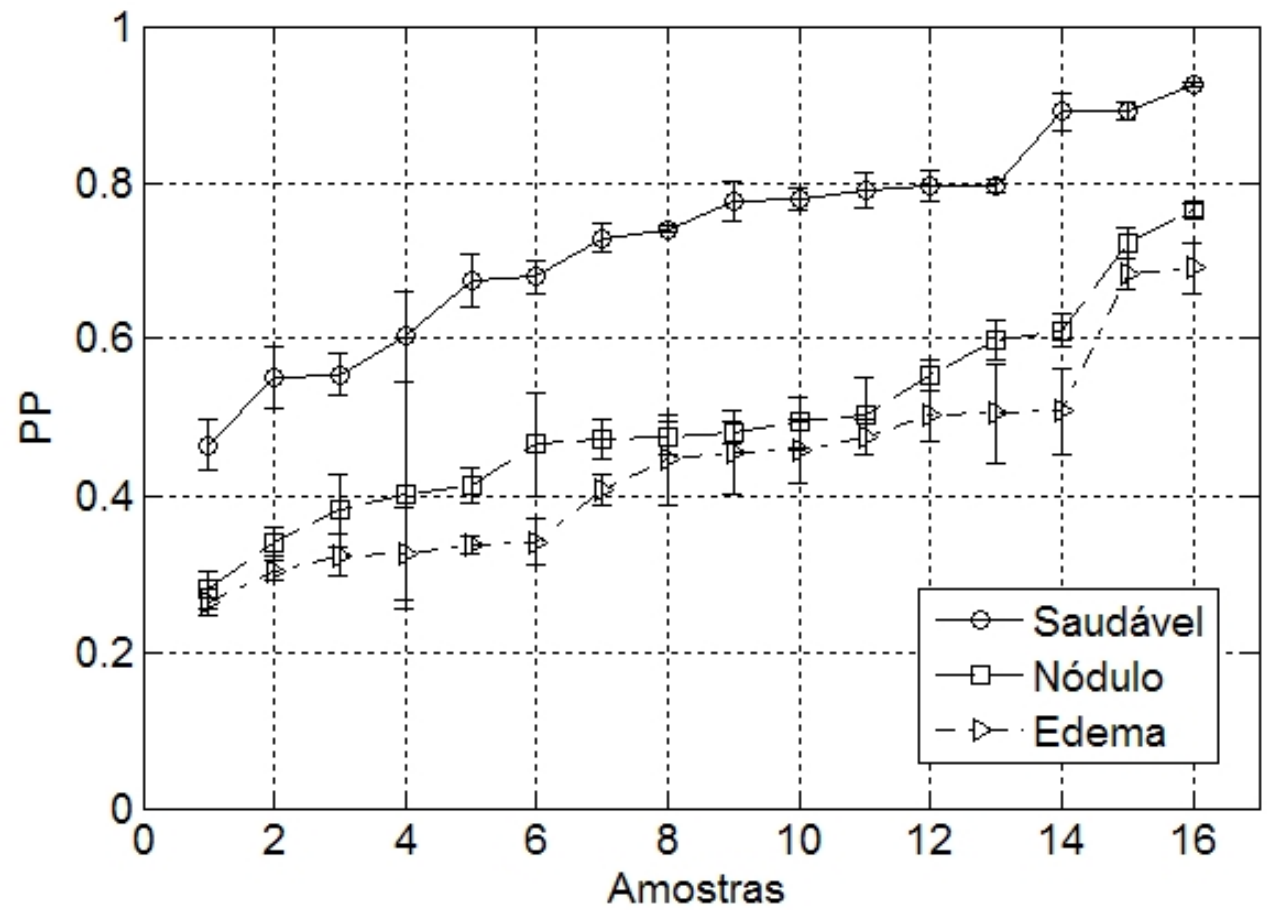

Figura 6.14: Valores médios e desvios padrões de PP, usando modelo baseado em decomposição por wavelets, dos sinais dos três grupos estudados: saudável, nódulo e edema de Reinke.

Na Figura 6.14, percebe-se uma diferenciação dos valores de PP para os sinais saudáveis, porém, pela análise de Figura 6.15, pode-se ver que a PP dos sinais saudáveis é significativamente maior do que as dos grupos patológicos. Assim, pelo menos para esses sinais analisados e usando o modelo wavelet, mostra-se que os sinais saudáveis possuem maior previsibilidade do os patológicos (nódulo e edema de Reinke), conforme esperado.

Mesmo com esse resultado positivo, apresentam-se, na próxima seção, os ensaios usando a PrCA diretamente nos sinais de voz e, também, nas suas representações tridimensionais. 


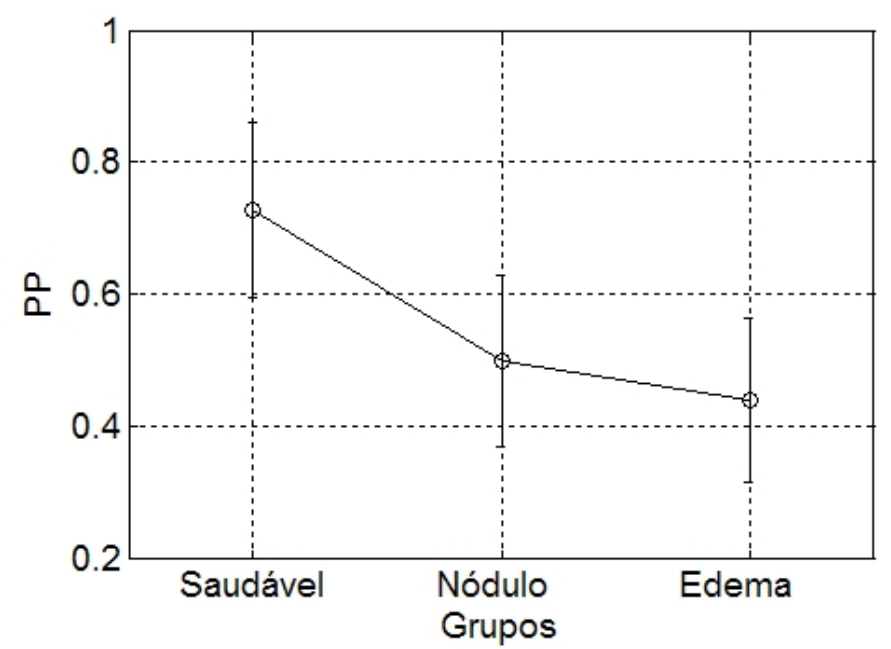

Figura 6.15: Resultados consolidados, para os três grupos analisados, do ensaio de PP usando modelo baseado em decomposição por wavelets.

\subsection{Ensaios de PrCA}

Nesta seção, mostram-se os resultados dos ensaios de PrCA dos sinais de voz dos três grupos: saudável, nódulo e edema de Reike. Conforme apresentado na Seção 5.3, realizam-se dois tipos de ensaios com PrCA, inicialmente, aplica-se a análise diretamente nos sinais temporais; em seguida, aplica-se na representação tridimensional dos sinais.

No primeiro caso, para sinais temporais, pode-se modelar esses sinais usando AR ou modelo por wavelets. Os ensaios com esses modelos serão apresentados nas próximas duas subseções. Já para a representação tridimensional, usa-se o modelo AR multidimensional, sendo os ensaios desse tipo discutidos na Subseção 6.3.3.

\subsubsection{Análise Temporal usando Modelo AR}

Para o ensaio de PrCA diretamente nos sinais de voz com o modelo AR(26), usa-se o algoritmo apresentado na Tabela 5.10. Após decompor os sinais nos componentes previsíveis, esses são reconstruídos usando somente os componentes mais previsíveis, ou seja, aqueles que possuem os menores valores associados de variância de erro normalizada. 
Essa seleção é ilustrada para um sinal simulado na Figura 5.40, escolhe-se os componentes cuja $\gamma$ for menor do que $10 \%$ do máximo dos $\gamma_{k}$. Esse procedimento é realizado para cada sinal analisado, assim, o número de componentes da reconstrução é variável. Dessa forma, obtém-se versões mais previsíveis dos sinais analisados, as quais são usadas como previsões desses sinais, chegando-se a erros de previsão também. Assim, estimam-se os valores de PP usando-se a PrCA como previsor dos sinais.

Portanto, analisam-se os 16 sinais de voz de cada um dos três grupos estudados, lembrando que cada sinal é dividido em cinco partes de 4.000 amostras para obtenção de valores médios e desvios padrões das PP. Os resultados desse ensaio são apresentados na Figura 6.16, onde se observa uma boa separação dos grupos patológicos do grupo de sinais saudáveis.

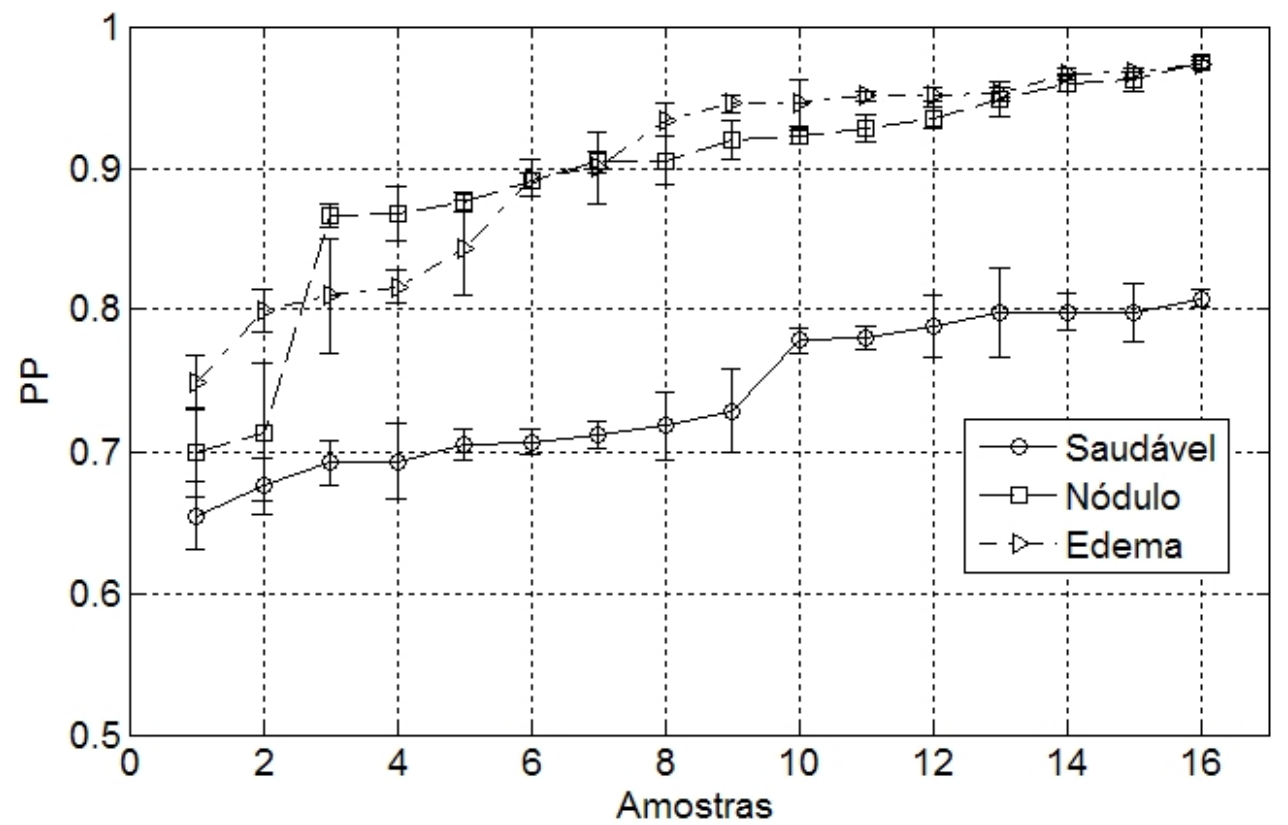

Figura 6.16: Valores médios e desvios padrões de PP para aplicação de PrCA com modelo AR(26) diretamente nos sinais de voz dos três grupos estudados: saudável, nódulo e edema de Reinke. Utilizam-se os sinais reconstruídos com os componentes mais previsíveis como estimativa dos sinais analisados.

A Figura 6.17 apresenta os resultados consolidados de PP para os três grupos de sinais. Com essa figura, percebe-se melhor a separação dos grupos patológicos e saudável, entretanto, ao contrário do esperado, a PP do grupo saudável é menor, indicando que, do ponto de vista da PrCA com modelo AR, os sinais saudáveis apresentam menor previsibilidade do que os sinais patológicos. Essa análise dos resultados será retomada após a apresentação do ensaio com modelo wavelets na próxima subseção. 


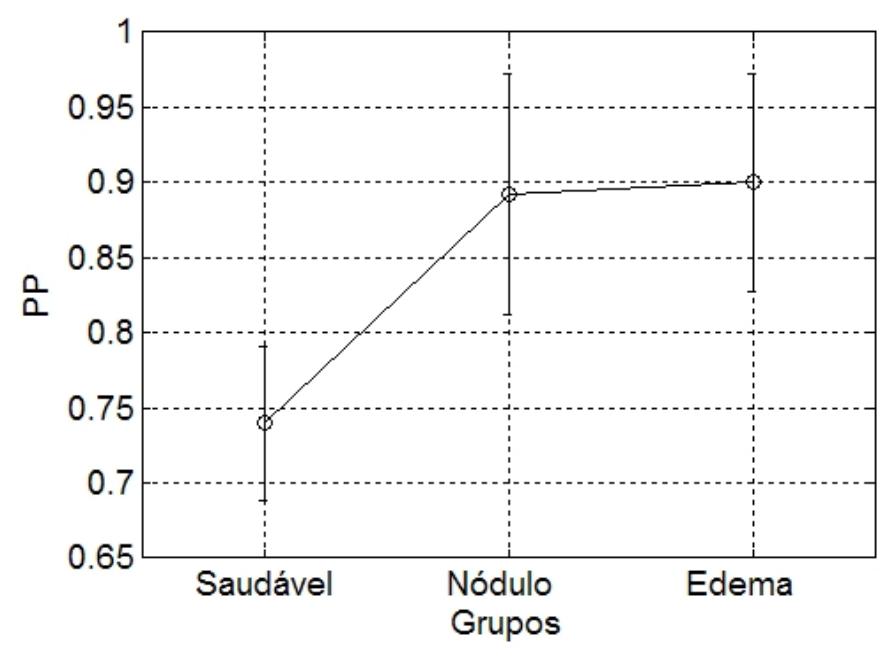

Figura 6.17: Resultados consolidados, para os três grupos analisados, do ensaio de PP usando PrCA com modelo AR(26) diretamente nos sinais de voz.

\subsubsection{Análise Temporal usando Modelo Wavelet}

Para os ensaios de PrCA diretamente nos sinais de voz com o modelo baseado em decomposição por wavelets também se utiliza o algoritmo da Tabela 5.10, modificandose somente o modelo de previsão para obtenção dos componentes previsíveis. Da mesma forma que para o modelo AR, usam-se os sinais reconstruídos com os componentes mais previsíveis para como previsão dos sinais de voz, sendo o erro de previsão usado para estimativa da PP. Novamente, utiliza-se o critério de $10 \%$ da variância de erro normalizada para seleção desses componentes.

Usa-se a mesma configuração dos sinais de voz para este ensaio, assim, os valores médios e desvios padrões de PP para os sinais dos três grupos são apresentados na Figura 6.18. Os valores consolidados desse ensaio para cada grupo são mostrados na Figura 6.19.

Novamente, observa-se uma boa separação entre os sinais saudáveis e os patológicos. Porém, ao contrário da PrCA com modelo AR, neste caso, os sinais saudáveis mostraram valores de PP maiores do que os outros. Isso indica que, perante a PrCA com modelo wavelet, esse tipo de sinal possui maior previsibilidade. 


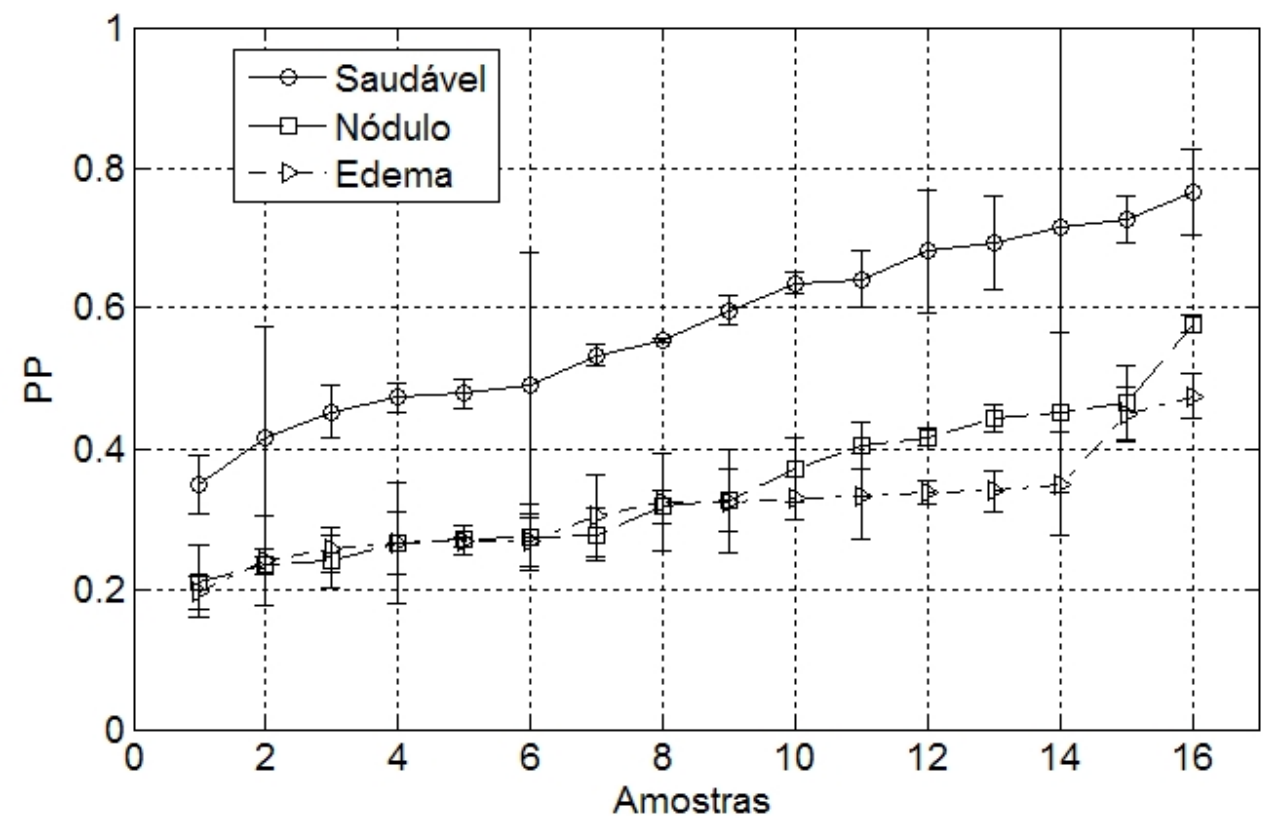

Figura 6.18: Valores médios e desvios padrões de PP para aplicação de PrCA com modelo baseado em decomposição por wavelets diretamente nos sinais de voz dos três grupos estudados: saudável, nódulo e edema de Reinke. Utilizam-se os sinais reconstruídos com os componentes mais previsíveis como estimativa dos sinais analisados.

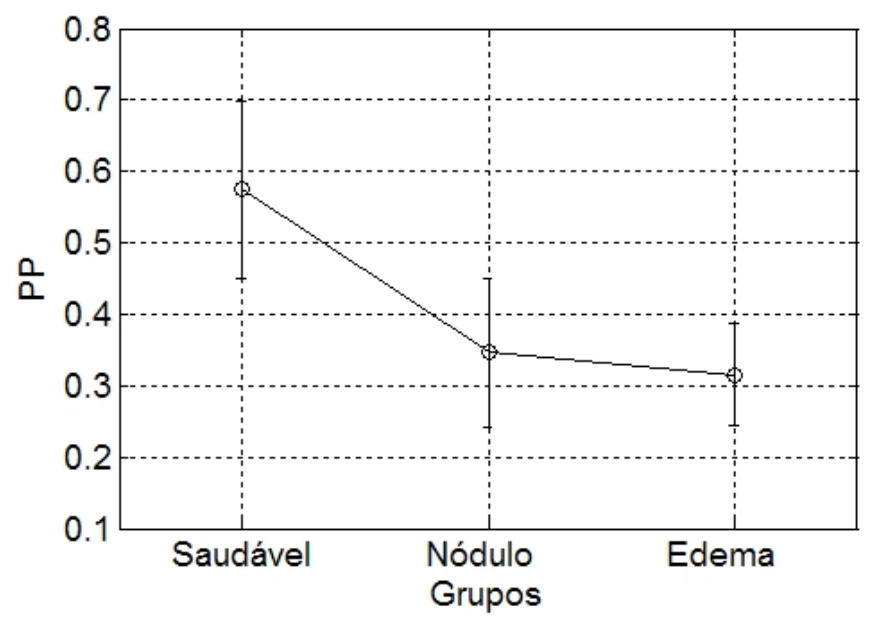

Figura 6.19: Resultados consolidados, para os três grupos analisados, do ensaio de PP usando PrCA com modelo wavelet diretamente nos sinais de voz. 
Dessa forma, para uma melhor análise desse diferença, apresenta-se a comparação da Figura 6.20. Nessa figura, mostram-se seis PDFs do erro de previsão de sinais de voz dos três grupos estudados, sendo a previsão igual ao sinal reconstruído usando os componentes mais previsíveis da PrCA. As partes (a), (c) e (e) são os erros de previsão usando PrCA com modelo AR(26) diretamente em sinais saudável, nódulo e edema de Reike respectivamente. Já nas partes (b), (d) e (f), tem-se os erros de previsão usando PrCA com modelo wavelet nos mesmos sinais respectivamente.

Como se pode ver, as PDFs dos erros de previsão são bem diferentes entre os modelos usados. Com o uso do AR(26), conforme já mencionado, as PDFs são próximas de Gaussianas, por causa da natureza de mínimos quadrados do algoritmo do modelo. Observa-se que a PDF do sinal saudável apresenta maior variância, ou seja, a curva é mais larga (considerando uma análise de uma Gaussiana aproximada), portanto, mostrando que, para esse modelo, esse tipo de sinal é menos previsível. Isso pois, as a previsibilidade é avaliada por medidas baseadas em entropia, a qual apresenta maior incerteza para PDFs mais próximas de distribuições uniforme.

Já para o modelo wavelet, os erros de previsão são bem maiores e mais espalhados do que para o modelo AR. Pode-se ver que este modelo não é muito eficiente em modelar sinais de voz, porém, ess maior faixa do erro de previsão é mais interessante para diferenciar os diversos tipos de sinais. Além disso, as PDFs dos erros dos sinais patológicos são mais planas do que a do sinal saudável, mostrando que, considerando medidas de entropia, os casos patológicos são caracterizados como menos previsíveis pelo modelo baseado em wavelets. Por causa dessa diferença, que os dois modelos, apesar de diferenciar satisfatoriamente os grupos patológicos do saudável, apresentam essa caracterização oposta da previsibilidade dos sinais saudáveis.

Na próxima subseção, mostra-se o ensaio com PrCA das representações tridimensionais dos sinais de voz usando o modelo AR multidimensional. 


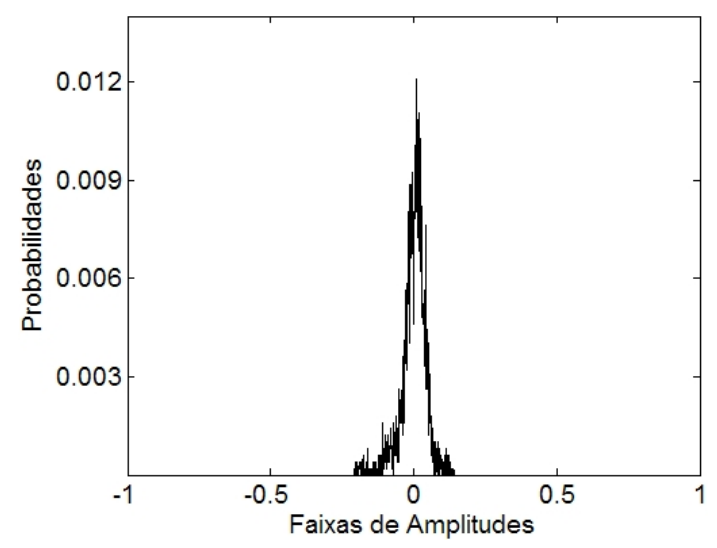

(a)

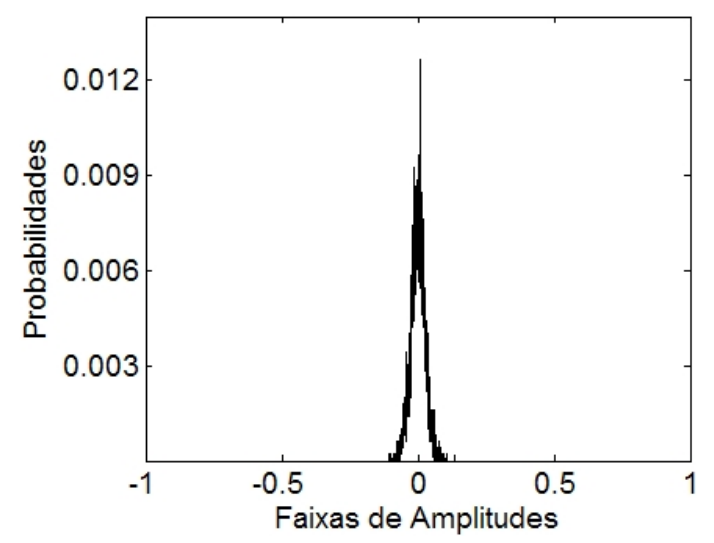

(c)

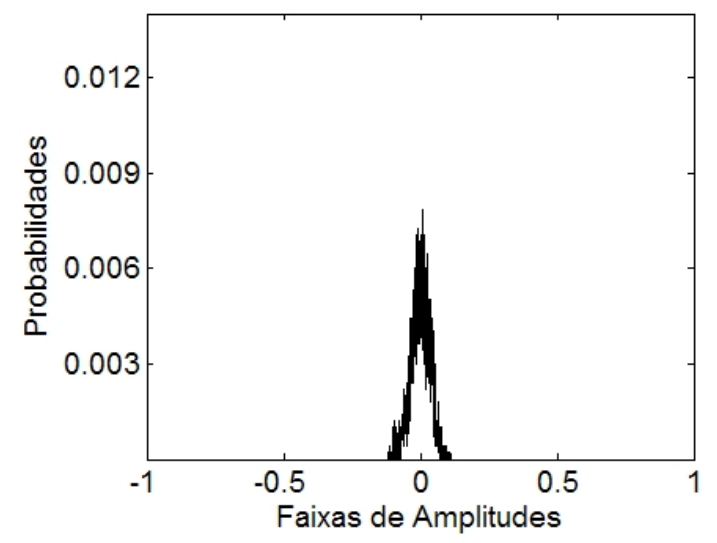

(e)

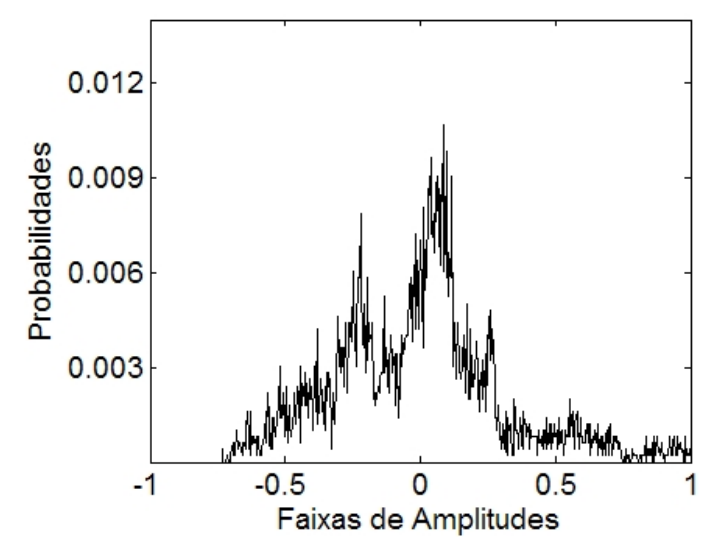

(b)

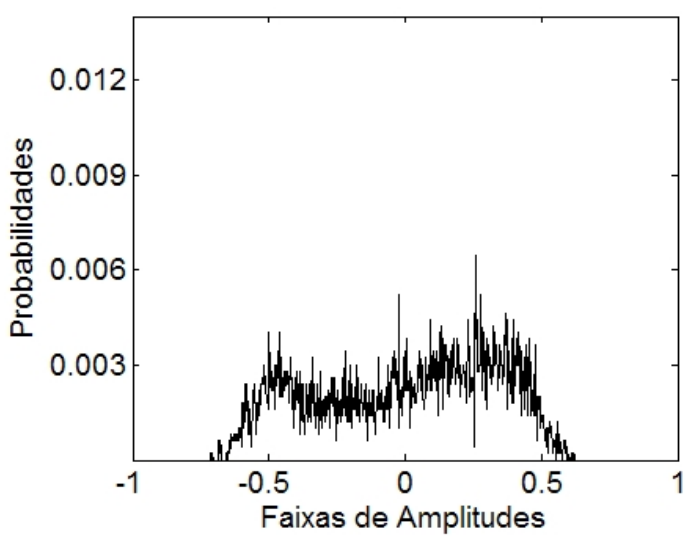

(d)

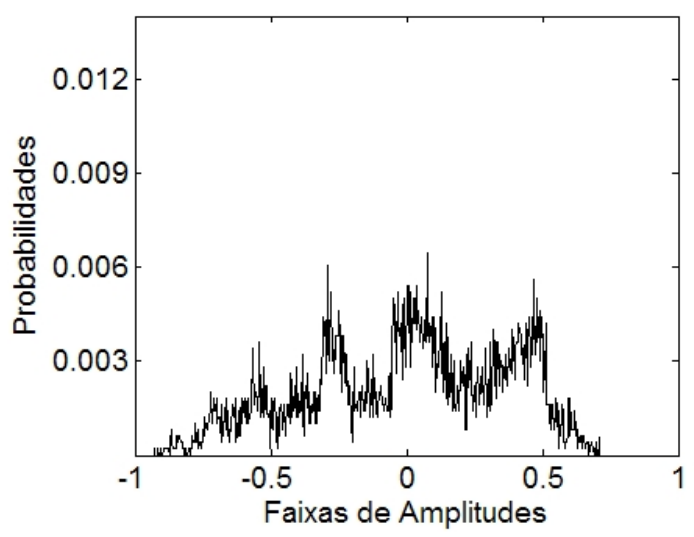

(f)

Figura 6.20: Comparação de PDFs do erro de previsão de sinais de voz dos três grupos estudados, sendo a previsão dada pelos sinais reconstruídos com os componentes mais previsíveis da PrCA obtida com os dois modelos apresentados. Nas partes (a), (c) e (e) são os erros de previsão usando PrCA com modelo $\mathrm{AR}(26)$ diretamente em sinais saudável, nódulo e edema de Reike respectivamente. Nas partes (b), (d) e (f), tem-se os erros de previsão usando PrCA com modelo wavelet nos mesmos sinais. 


\subsubsection{Análise da Representação Tridimensional}

Nesta última parte do capítulo, mostram-se os resultados do ensaio com PrCA das representações tridimensionais dos sinais de voz dos três grupos estudados. Utiliza-se o modelo AR multidimensional, conforme o algoritmo da Tabela 5.11 apresentado na Subseção 5.3.2. Os sinais de voz são divididos em cinco partes de 4.000 amostras como nos ensaios anteriores. Para cada parte dos sinais, encontra-se a representação tridimensional com atraso dado pelo mínimo da informação mútua. Usa-se o modelo AR multidimensional com ordem 26, igual ao AR usado nos sinais temporais.

Como neste ensaio, o número de componentes previsíveis é igual a 3, para a reconstrução, usam-se os dois primeiros componentes, os quais, geralmente, apresentam valores associados de variância de erro normalizada significativamente menores do que o último componente. O algoritmo de PrCA para a representação tridimensional resulta em uma representação tridimensional reconstruída e não em um sinal temporal, assim, para a obtenção de um sinal temporal reconstruído, escolhe-se a dimensão da reconstrução que apresenta a menor diferença para a representação original do sinal.

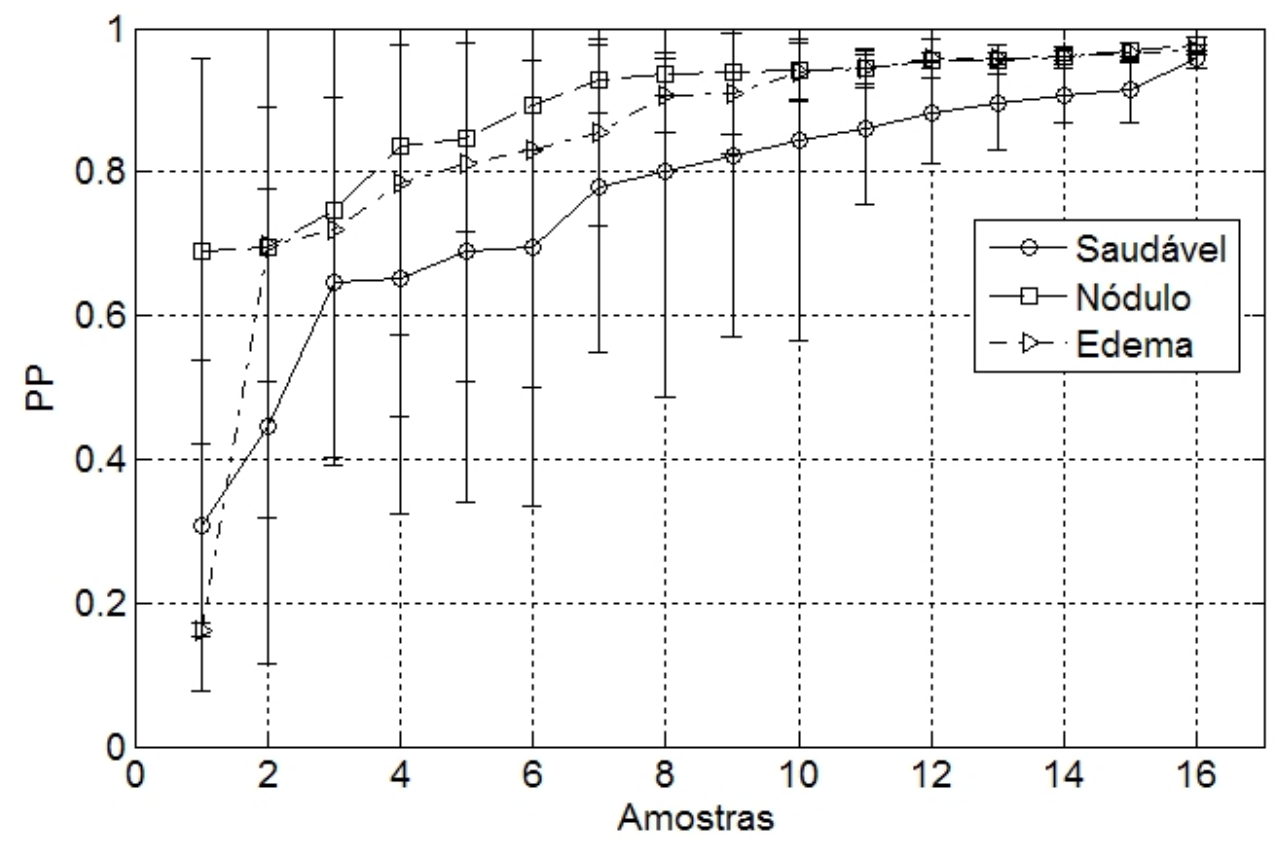

Figura 6.21: Valores médios e desvios padrões de PP para aplicação de PrCA das representações tridimensionais dos sinais de voz dos três grupos estudados: saudável, nódulo e edema de Reinke. Usa-se o modelo AR(26) multidimensional e a previsão é o sinal obtido da representação tridimensional reconstruída com menor diferença para a representação original. 
Portanto, para a estimativa da PP, usa-se esse sinal obtido da reconstrução como previsão, chegando-se a um erro de previsão pela diferença com o sinal original. $\mathrm{Na}$ Figura 6.21 apresentam-se os valores médios e desvios padrões de PP para esse ensaio de PrCA das representações tridimensionais. A Figura 6.22 apresenta os resultados consolidados de PP para os três grupos.

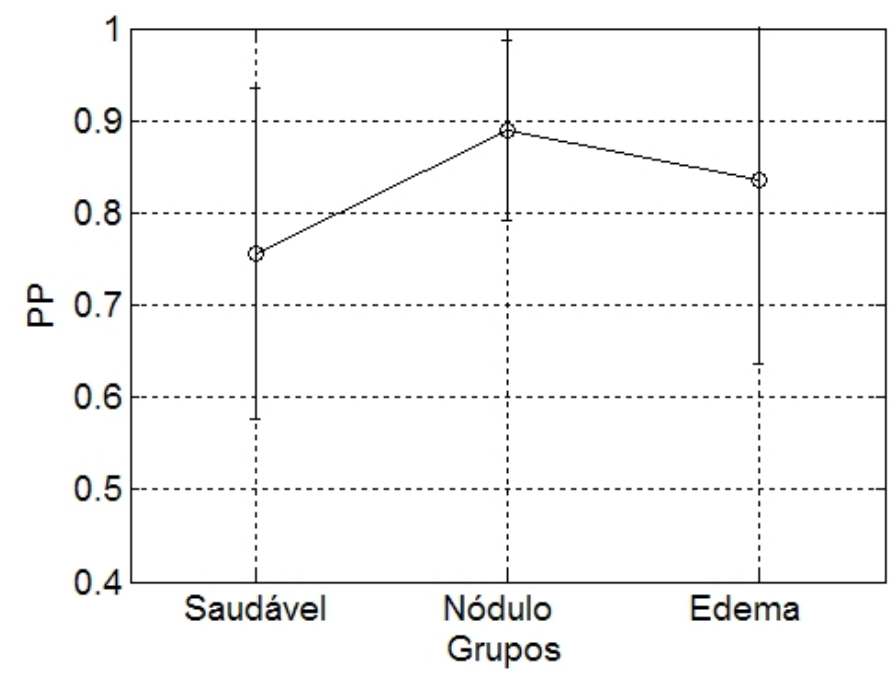

Figura 6.22: Resultados consolidados, para os três grupos analisados, do ensaio de PP usando PrCA das das representações tridimensionais. As previsões são sinais temporais obtidos das representações tridimensionais reconstruídas.

Como observado nessas figuras, tem-se grandes variações dos valores de PP para os três grupos, não sendo possível diferenciar os grupos com essa medida. Assim, ao invés de se obter um sinal temporal reconstruído para ser usado como previsão, usouse diretamente a representação tridimensional reconstruída, estimando-se o PP para as três dimensões (em relação à representação tridimensional original), chegando-se num valor médio final. Dessa forma, com essa nova abordagem, refez-se o ensaio anterior, sendo os resultados (médios e desvios padrões) apresentados nas Figuras 6.23 e 6.24.

Com essa modificação, os resultados foram melhores do que os anteriores, possuíndo menores variações de PP e apresentando uma melhor diferenciação entre os grupos patológicos e saudável. Entretanto, como observado para o ensaio de PrCA direto nos sinais de voz usando modelo AR(26), os sinais saudáveis apresentaram valores de PP menores, ou seja, sendo caracterizados como menos previsíveis pelo modelo. 
Apesar desse melhor resultado para a modificação da previsão, os ensaios de PrCA diretamente nos sinais temporais de voz apresentaram resultados melhores do que para a aplicação nas representações tridimensionais.

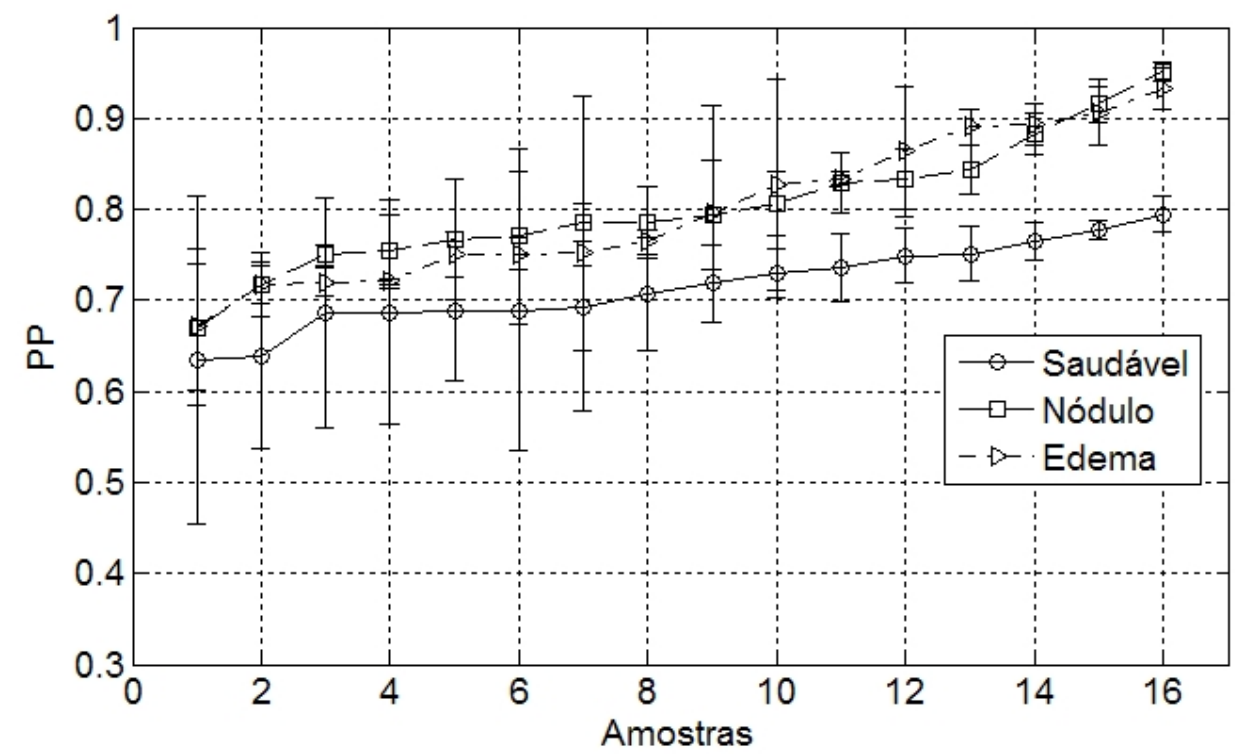

Figura 6.23: Valores médios e desvios padrões de PP para aplicação de PrCA das representações tridimensionais dos sinais de voz dos três grupos estudados: saudável, nódulo e edema de Reinke. Usa-se o modelo AR(26) multidimensional e estima-se a PP média usando a representação tridimensional reconstruída como previsão.

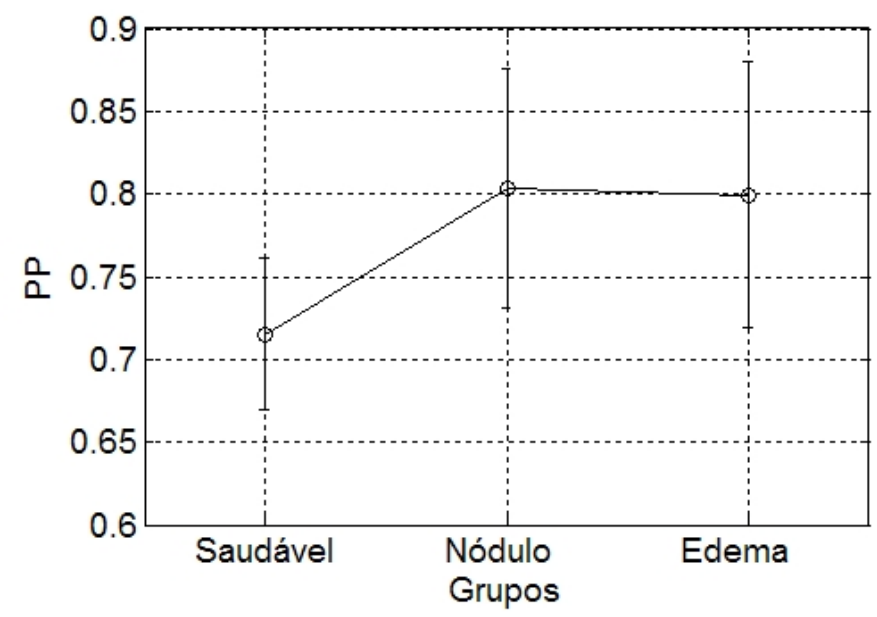

Figura 6.24: Resultados consolidados, para os três grupos analisados, do ensaio de PP usando PrCA das das representações tridimensionais. Estima-se a PP média usando a representação tridimensional reconstruída como previsão. 


\section{Capítulo 7}

\section{Discussão e Conclusões}

Neste último capítulo, apresenta-se uma discussão sobre os métodos empregados para análise da previsibilidade dos sinais de voz e os resultados obtidos. Além disso, comentam-se alguns problemas encontrados e idéais que foram aplicadas na busca da solução. Em seguida, discutem-se as contribuições científicas deste estudo enfatizando os trabalhos publicados. Por fim, apresentam-se as conclusões obtidas e os próximos passos a serem seguidos para continuar o desenvolvimento deste estudo.

\subsection{Discussão dos Métodos e Resultados}

Primeiramente, antes de se discutir os métodos e resultados das análises de previsibilidade, alguns comentários devem ser feitos a respeito do banco de vozes do LPS. Esse banco de dados foi montado nos últimos 10 anos a partir de coletas de sinais de diversas pesquisas, assim, existem muitas diferenças de métodos e sistemas de coleta, o que dificultou a seleção de um conjunto consistente de sinais. Por isso, os sinais usados na análise foram somente de pessoas dos três grupos: saudáveis, com nódulo nas pregas vocais e edema de Reinke. Foi necessário um cuidado adicional no préprocessamento dos sinais, pois alguns tinham volumes bem diferentes e inclusive nível de tensão não-nulo.

Além disso, alguns sinais possuíam grandes variações de estabilidade, tanto de amplitude como de frequiência, ocorridos durante a gravação. Portanto, escolheu-se diminuir o tamanho dos sinais para aproximadamente uns 20.000 pontos (em torno de 
$1 s$ para frequiência de amostragem de $22.050 \mathrm{~Hz}$ ). Buscava-se o trecho que possuísse a maior estabilidade e estacionaridade (sentido WSS), selecionando-se o trecho com nenhuma (ou muito pouca) variação do espectrograma. Por esses motivos, utilizou-se o pré-processamento descrito no Capítulo 4.

Também, como as medidas empregadas neste estudo são estatísticas, baseadas em aproximações das PDFs dos sinais, preferiu-se dividir esses sinais (já considerados estacionários) em cinco partes de 4.000 amostras. Dessa forma, foi possível obter valores médios, os quais tenderiam a um resultado mais correto.

Ainda sobre os sinais de voz usados neste trabalho, é interessante observar que utilizando somente as medidas acústicas apresentadas na Tabela 4.1, também no Capítulo 4, não foi possível diferenciar os sinais de voz dos três grupos estudados. Entretanto, essa medidas mostraram a grande variação dos parâmetros nos casos patológicos.

Porém, como apresentado no Capítulo 5, para os primeiros testes com os algoritmos, usaram-se sinais de voz simulados ao invés dos sinais reais do banco de dados. Para criar esses sinais, desenvolveu-se um simulador com base em um sinal de voz saudável, conforme apresentado no Apêndice A, o qual possui a capacidade de adicionar variações de nível de ruído, jitter e shimmer. Nesse desenvolvimento, encontraram-se alguns problemas para implementar a variação de jitter, entretanto os resultados foram bons, pois vários problemas, principalmente com a estimativa das PDFs e entropia, foram encontrados e corrigidos com o auxílio dos sinais simulados.

Além disso, foi possível detectar falhas na estimativa da PP com o uso do modelo AR e verificar a capacidade de modelamento de sinais de voz da decomposição por wavelets. Considerando os testes com esse modelo, o uso de sinais simulados facilitou a seleção do melhor nível de decomposição e ordem dos filtros.

Após esse breve comentário sobre os sinais usados neste trabalho, discutem-se os métodos de análise de previsibilidade e seus resultados. Inicialmente, usaram-se medidas de entropia de Shannon, as quais são abordadas a seguir. 


\subsubsection{Entropia}

Como apresentado na Seção 5.1, a entropia não é uma propriedade facilmente obtida de um sistema, pois não se conhece a PDF dos sinais gerados. Assim, faz-se necessário estimar a PDF a partir de uma quantidade finita de amostras. Discutiu-se três métodos para essa estimativa: usando uma discretização da entropia diferencial, usando passo de quantização constante, e aplicando uma equalização do histograma.

Inicialmente, tentou-se estimar a PDF de um sinal usando uma regressão spline do histograma para se encontrar uma curva mais suave, realizando uma normalização dessa curva para obtenção de área unitária, o que é uma característica das funções de probabilidade (Papoulis e Pillai, 2002). Porém, os resultados não foram bons porque pequenas variações resultavam em erros consideráveis. Somente após alguns ensaios como esse, começou-se a utilizar o método da discretização da entropia diferencial.

Mostrou-se que esse método, apesar de apresentar resultados razoáveis com sinais simulados, possui problemas quando é necessária a comparação entre dois sinais de diferentes faixas de amplitudes. Isso, pois esse algoritmo usa número de células constante para a estimativa do histograma dos sinais, assim, perde-se resolução quando a faixa de amplitude é pequena. Essa diferença é muito comum, principalmente para a estimativa da PP, a qual depende da entropia relativa do sinal e de seu erro de previsão.

Por causa disso, apresentou-se a estimativa da entropia pelo método de passo de quantização constante, o qual diminuiu esse problema, pois se mantém a resolução constante para todos os sinais analisados. Mesmo com essa melhora, apresentou-se o método de equalização do histograma para tentar diminuir problemas com a estimativa da entropia relativa quando o segundo sinal possui pequena faixa de amplitude.

Entretanto, os resultados não foram satisfatórios, apesar da equalização eficiente do primeiro sinal da estimativa da entropia relativa, o segundo não foi suficientemente equalizado. Assim, para os sinais simulados, os testes de desempenho do algoritmo obtiveram resultados similares aos do segundo método. Portanto, decidiu-se usar o método do passo de quantização constante devido a sua simplicidade (comparado ao método da equalização) e a possibilidade de manter resoluções iguais das PDFs.

Como validação desse algoritmo, para um sinal Gaussiano, compararam-se os re- 
sultados de entropia obtidos com esse método e os valores teóricos conforme deduzido no Apêndice C. A comparação é apresentada na Figura 5.7, percebe-se que o comportamento do algoritmo é igual ao esperado para variação do desvio padrão do sinal, somente os valores absolutos são diferentes, mas isso se deve à forma de estimativa. De maneira semelhante, também se realiza um teste para validar a entropia relativa entre duas distribuições Gaussianas, obtendo resultados semelhantes, Figuras 5.13 e 5.14 .

Além disso, para evitar problemas de divisões por zero na estimativa dessa entropia relativa, adicionou-se um pequeno valor na segunda PDF, ou seja, essa função foi deslocada ligeiramente para cima. No Apêndice B, mostra-se que se esse deslocamento for suficientemente pequeno, essa alteração não causa erros na estimativa da entropia relativa. Porém, como mostrado na Figura 5.13, mencionada anteriormente, evita-se uma tendência a valores muito elevados de entropia em algumas condições.

Observou-se, pelos testes com sinais simulados, que a medida de entropia dos sinais apresenta boa sensibilidade a variação de nível de ruído dos sinais, mas nem tanto para variações de jitter e shimmer, como apresentado nas Figuras 5.8 a 5.10. Para os sinais de voz dos três grupos: saudável, nódulo e edema de Reinke, a medida de entropia não foi suficiente para diferenciar esses grupos, Seção 6.1. Observando as PDFs dos sinais apresentadas na Figura 6.3, percebe-se que essas são muito parecidas, por isso, as entropias dos sinais são bem próximas.

Um ensaio semelhante é também apresentado nessa seção do Capítulo 6, o qual utiliza medidas de entropia relativa entre os sinais saudáveis e os sinais dos três grupos, incluindo os saudáveis mesmo. Com os resultados desse ensaio, Figura 6.5, nota-se uma boa diferenciação entre os grupos patológicos e o saudável, sendo que este último apresenta os menores valores de entropia relativa.

Esse comportamento era esperado, pois a voz normal possui maior regularidade (menor variação dos parâmetros acústicos), assim, como seus sinais são mais parecidos entre si mesmos, suas PDFs são mais parecidas. Apesar desse bom resultado, esse ensaio é difícil de ser realizado em uma avaliação profissional, pois, para isso, faz-se necessário possuir um banco de vozes com diagnósticos eficazes para estimativa da entropia relativa. 
Para se finalizar os ensaios com medidas de entropia, realizou-se um estudo com as curvas de crescimento da entropia. Conforme apresentado na Subseção 5.1.4, a estimativa da entropia de blocos de sinais de voz, para grandes comprimentos de bloco e sinais finitos, é inviável. Isso ocorre pois, para sinais reais, o número de possibilidades aumenta demais para comprimentos de blocos maiores.

Propôs-se um método de limitação das faixas de amplitude dos sinais para tentar conter esse crescimento fortemente exponencial das possibilidades. Porém, mesmo nos simples exemplos apresentados na seção mencionada, mostrou-se que a curva de crescimento da entropia de bloco saturava antes de atingir sua estabilização. Assim, não era possível estimar sua assíntota, portanto também não se conseguia obter as propriedades dessa reta que se relacionam a regularidade do sistema analizado.

Dessa forma, analisaram-se somente as curvas de entropia para blocos de comprimento unitário, ou seja, a curva de convergência da entropia de Shannon quando se aumenta a informação disponível (o tamanho do sinal). Os resultados desse ensaio foram apresentados nas Figuras 6.6 a 6.8, que são as curvas para os sinais saudáveis, nódulo e edema de Reinke respectivamente. Como se observou, as curvas são muito semelhantes em uma análise inicial, pelo menos para os sinais de voz usados neste trabalho.

Entretanto, nota-se a relação entre o período de pitch dos sinais e a variação apresentada pelas curvas de entropia. Portanto, futuras análises poderíam se aproveitar dessa característica para analisar os sinais a partir de sua regularidade. Mais a respeito das curvas de entropia será apresentado na Seção 7.2.

As medidas de entropia foram a primeira tentativa de análise da previsibilidade dos sinais de voz. Após essa discussão, na subseção seguinte, comentam-se as análises de PP usando os dois modelos propostos.

\subsubsection{Potência de Previsão}

Comentam-se, agora, os resultados obtidos para os ensaios de PP usando o modelo AR e o modelo baseado em decomposições por wavelets. Inicialmente, utilizou-se o AR, pois, como exposto na Seção 2.3, a literatura apresenta bons resultados da aplica- 
ção desse modelo para análise de sinais de voz devido à sua composição "somente por pólos" (all-pole).

Para a análise da previsibilidade usando medidas de PP com modelo AR, usou-se ordem igual a 26, conforme recomendação mencionada no Capítulo 4, a qual diz que uma boa ordem é 4 ou 5 unidades acima da parte inteira da freqüência de amostragem (em $k H z$ ) utilizada na aquisição dos sinais, no caso, tem-se 22 pois a aquisição foi a $22,05 \mathrm{kHz}$.

Entretanto, para a aplicação na estimativa de PP, a qual utiliza a comparação (entropia relativa) entre a PDF do sinal e a de seu erro de previsão, o modelo AR provê um sinal de erro cuja PDF é pouco sensível às variações de jitter e shimmer, os quais variam significativamente nos sinais patológicos. Essa característica foi discutida na Subseção 5.2.1, sendo apresentados ensaios com sinais simulados com variação dos parâmetros do simulador, Figuras 5.30 a 5.32, da mesma forma que para os ensaios de entropia. Por causa dessa insensibilidade, considerou-se utilizar outro modelo, baseado em decomposição por wavelets.

Considerando os sinais de voz reais, nos Capítulos 5 e 6, comparam-se diversas PDFs dos sinais, previsões e erros envolvidos nos ensaios de PP. Mostra-se que a modelagem AR de sinais de voz resulta em erro de previsão com distribuições próximas de Gaussianas, provavelmente devido ao algoritmo ser baseado em minimização quadrática. Assim, como as PDFs dos erros são sempre muito parecidas, apesar de ser um modelo que provê baixos erros de previsão, sua capacidade para diferenciar os tipos de sinais em medidas de previsibilidade fica diminuída.

Para o ensaio de PP com AR(26) para os sinais de voz dos três grupos estudados, cujos resultados são apresentados nas Figuras 6.11 e 6.12, percebe-se que os valores são muito parecidos, não sendo possível usar essa medida (com esse modelo) para a diferenciação dos grupos. Apesar disso, nota-se que o valor médio de PP para o grupo saudável é ligeiramente inferior aos dos grupos patológicos. Conforme já discutido no Capítulo 6, isso mostra que o para o modelo AR, os sinais de voz saudáveis são vistos como menos previsíveis.

Isso, provavelmente, devido a PDF mais ampla do erro de previsão do modelo conforme mostra a Figura 6.10. Além disso, como já mencionado, o modelo não percebe 
eficientemente variações de jitter e shimmer dos sinais, assim, por causa da perda de riqueza harmônica dos sinais patológicos, visualizada nas representações tridimensionais da Figura 4.3, esses são considerados mais previsíveis pelo modelo.

Dessa forma, realizaram-se ensaios com o modelo baseado em decomposição por wavelets, apresentado no Capítulo 4, sendo escolhida a família de filtros Daubechies com ordem 30 e nível de decomposição máximo igual a 5. Como já discutido, com essa configuração, aproximação reconstruída do quinto nível, $A_{5}$, contém os componentes do sinal até em torno da freqüência de $345 \mathrm{~Hz}$, o que inclui a frequiência de pitch de sinais de voz de "a" sustentado de adultos. Então, por possuir pouca informação sobre o sinal modelado, usa-se $A_{5}$ como o erro de previsão do modelo, e a soma dos detalhes reconstruídos de todos os níveis, $D_{1}$ a $D_{5}$, como previsão do sinal, conforme ilustrado na Figura 4.19. Assim, variações do pitch, ou seja, jitter, seriam melhor capturados pelo sinal de erro.

Novamente, iniciou-se a análise por ensaios com sinais simulados variando-se os parâmetros do simulador. Desta vez, ao contrário do que ocorreu para o modelo AR, os valores de PP refletiram essas variações, conforme apresentado nas Figuras 5.35 a 5.37. Assim, conforme se aumentava a desorganização dos sinais, diminuia-se a PP, ou seja, perante o modelo por wavelets, os sinais ficavam menos previsíveis.

O motivo dessa mudança frente ao modelo AR, pode ser visto na Figura 5.34, a qual mostra que a PDF do erro de previsão não se parece com uma Gaussiana. Também, na Figura 5.38, comparam-se as PDFs dos erros para sinais com parâmetros diferentes do simulador, mostrando um maior achatamento das PDFs para os casos alterados. Portanto, esse modelo não apresenta os problemas de insensibilidade a variações de jitter e shimmer do modelo AR.

O resultado do ensaio de PP com o modelo wavelet para os sinais de voz dos três grupos estudados é apresentado nas Figuras 6.14 e 6.15. Tem-se que o grupo de sinais saudáveis possui valores de PP significativamente maiores do que os dos grupos patológicos, indicando que, perante o modelo wavelet, os sinais saudáveis são mais previsíveis.

Isso é confirmado pela análise da Figura 6.13, a qual mostra as PDFs dos erros de previsão para exemplos de cada grupo, percebe-se que as PDFs dos erros dos sinais 
patológicos são as que apresentam maior desvio da Gaussiana. Espera-se que o erro possua distribuição Gaussiana, como no modelo $A R$, assim, essa variação é suficiente para caracterizar os grupos.

Em seguida, discutem-se os resultados obtidos para os ensaios de PrCA tanto diretamente aplicada aos sinais de voz quanto nas suas representações multidimensionais.

\subsubsection{Análise de Componentes Previsíveis}

Como apresentado no Capítulo 3, a PrCa é uma ferramenta interessante para analisar a previsibilidade de sistemas multivariáveis. Essa análise foi realizada diretamente nos sinais de voz, criando-se um sistema multidimensional com versões atrasadas de uma unidade dos sinais temporais. Além disso, aplicou-se a PrCA nas representações tridimensionais apresentadas na Subseção 4.2.3, as quais são criadas a partir de versões atrasadas do sinal usando um valor de atraso obtido do primeiro mínimo local da função de informação mútua. Mostrou-se que para realizar previsões nessa representação, usa-se o modelo AR multidimensional.

Com essa ferramenta, decompõe-se o sinal estudado em componentes previsíveis que são ordenados pelas suas variância de erro normalizadas, as quais são inversamente proporcionais a previsibilidade dos componentes. Assim, pode-se retirar os componentes menos previsíveis e se reconstruir os sinais para obtenção de uma versão mais previsível do mesmo. Portanto, usaram-se essas versões como previsões dos sinais, obtendo-se valores de PP da mesma forma que estimado anteriormente.

Para ensaios com sinais simulados como nos casos anteriores, usando o modelo AR(26) para execução do algoritmo da PrCA, os resultados foram apresentados nas Figuras 5.43 a 5.45. Tem-se que o método demonstra comportamento esperado para variação de nível de ruído, ou seja, diminui-se a PP para o aumento do ruído. Já para as variações de jitter e shimmer, tem-se insensibilidade do método, como ocorrido para o modelo AR aplicado na estimativa de PP.

Com o uso de modelo wavelet na PrCA, os resultados para sinais simulados são apresentados nas Figuras 5.46 a 5.48. De maneira similar, os ensaios mostraram com-

portamento igual ao obtido para estimativa de PP com modelo wavelet, porém, com 
algumas pequenas irregularidades nas curvas das figuras.

Para a PrCA aplicada na representação tridimensional, com modelo AR(26) multidimensional como previsor, os resultados do ensaio com sinais simulados são mostrados nas Figuras 5.51 a 5.53. O comportamento médio dos valores de PP foi conforme esperado, porém se observou grandes desvios padrões de PP, os quais inviabilizam as análises dos resultados.

De qualquer forma, os ensaios com sinais simulados são feitos somente para se obter uma visão geral do comportamento dos algoritmos frente a variações dos parâmetros. Assim, para os sinais de voz dos grupos estudados, realizam-se os ensaios com PrCA diretamente nos sinais usando modelo AR(26) e wavelet, e, também, PrCA nas representações tridimensionais.

Para a aplicação direta nos sinais de voz, o resultado do ensaio de PrCA usando modelo AR é apresentado nas Figuras 6.16 e 6.17. Observa-se que o comportamento apontado anteriormente para a modelagem AR de avaliar os sinais saudáveis como menos previsíveis se mantém, entretanto, com a PrCA, o modelo AR consegue diferenciar significativamente os grupos patológicos e saudável.

Com o uso do modelo wavelet, o resultado do ensaio de PrCA é apresentado nas Figuras 6.18 e 6.19. Da mesma forma que para o modelo AR, este ensaio apresentou comportamento igual ao do ensaio de PP com modelo wavelet direto nos sinais. Entretanto, com a PrCA, foi possível diferenciar melhor os dois grupos patológicos do saudável. Novamente, perante o modelo wavelet, os sinais saudáveis são considerados mais previsíveis do que os patológicos.

A Figura 6.20 apresenta uma comparação entre as PDFs dos erros de previsão usando PrCA com modelo AR e com modelo wavelet. Como discutido anteriormente, percebe-se que essas PDFs para os sinais saudáveis, do ponto de vista de medidas de entropia, são mais previsíveis do que as outras PDFs para o modelo wavelet do que para o modelo AR.

Para o ensaio de PrCA das representações tridimensionais, os resultados são apresentados nas Figuras 6.21 e 6.22. Percebe-se que, como observado pela insensibilidade nos ensaios com sinais simulados, não foi possível diferenciar os grupos de vozes com essa análise. Mas, nota-se que, na média, a PP dos sinais saudáveis são menores do que 
para os sinais patológicos, comportamento, devido, provavelmente, ao uso do modelo AR multidimensional.

Porém, como apresentado no Capítulo 6, chegaram-se aos resultados anteriores usando-se, como previsão, um sinal temporal obtido da representação tridimensional reconstruída. Porém, como os resultados não foram bons, estimou-se a PP usando diretamente essa reconstrução, obtendo um valor médio. Assim, os resultados são os apresentados nas Figuras 6.23 e 6.24. Com essa modificação, a diferenciação dos grupos patológicos e saudável foi melhor do que para o caso anterior, porém não tão bom quanto a obtida para a PrCA direta no sinal de voz usando AR.

Após essas discussões dos métodos de previsibilidade usados e os resultados obtidos, apresenta-se a contribuição científica do estudo, enfatizando-se os trabalhos publicados.

\subsection{Contribuição Científica}

Nesta seção, apresenta-se uma breve discussão dos resultados obtidos neste trabalho que foram publicados em periódicos e congressos da área de estudos de voz ou processamento de sinais.

No início deste trabalho, durante as análises iniciais dos sinais de voz e do modelo AR, realizou-se um estudo da variação das características dos pólos do modelo aplicados a sinais saudáveis e de pessoas com nódulo, conforme apresentado na Subseção 4.2.1. Esse estudo foi apresentado no Seventh IEEE International Symposium on Multimedia (Scalassara et al., 2005), sendo que uma versão mais completa, com resultados semelhantes ao apresentado na Figura 4.6, foi publicada no periódico Pattern Recognition Letters (Scalassara et al., 2007a). Nesse segundo trabalho, mostrou-se que os erros de estimativa das frequiências centrais dos picos da PSD dos sinais patológicos (nódulo) eram maiores do que os dos sinais saudáveis, provavelmente devido ao maior jitter desses sinais.

Um dos primeiros ensaios de PP realizados no desenvolvimento deste estudo foi a utilização dos sinais simulados para avaliação dos algoritmos de previsibilidade. Esses ensaios, com versões iniciais dos algoritmos de estimativa de PP usando o método 
de discretização da entropia diferencial, foram apresentados no $6^{o}$ Congresso Temático de Dinâmica, Controle e Aplicações (Scalassara et al., 2007b). Nesse trabalho, mostrou-se como a PP diminuia com a variação dos parâmetros do simulador, inclusive apresentando algumas análises da representação tridimensional desses sinais.

Em seguida, concentrando-se na análise da entropia de Shannon dos sinais, realizouse um estudo dos valores dessa medida para os sinais saudáveis e de pessoas com nódulo nas pregas vocais. Conforme apresentado na Figura 6.1, a entropia dos sinais de nódulo são maiores do que dos sinais saudáveis na média. Esse resultado foi apresentado no International Conference on Bio-inspired Systems and Signal Processing (Scalassara et al., 2008a). Entretanto, utilizou-se uma alteração do algoritmo de estimativa da entropia, sendo retificadas as amplitudes dos sinais analisados, conforme será discutido na Seção 7.4. Essa modificação resultou em uma melhora na separação dos dois grupos pelo uso da entropia dos sinais.

Ainda usando essa modificação, realizaram-se outros ensaios com entropia relativa entre os sinais, porém, desta vez, foram adicionados sinais de pessoas com edema de Reinke. Os resultados obtidos foram semelhantes aos apresentados na Figura 6.4, mostrando a diferenciação dos grupos patológicos do saudável. Esse resultado foi publicado no periódico Applied Mathematics and Computation (Scalassara et al., 2009a). Como se demonstrou que essa modificação do algoritmo, quando usada para entropia relativa, não apresentou melhora significativa da diferenciação dos grupos, essa não foi mais utilizada. Além disso, os resultados de entropia relativa foram comparados com os valores dos parâmetros acústicos dos sinais, os quais foram apresentados na Tabela 4.1.

Nesses dois estudos anteriores, apresentaram-se análises das representações tridimensionais das vozes, conforme discutido na Seção 4.1, comentaram-se sobre as diferenças dessas representações para os grupos de sinais estudados, mostrando as irregularidades e mudanças das trajetórias causadas pelas patologias.

Após esses ensaios, utilizaram-se medidas de entropia, usando o método do passo de quantização constante, para ensaios com curvas de crescimento de entropia para blocos de comprimento unitário, conforme apresentados nos Capítulos 5 e 6 . Inicialmente, analisaram-se somente os sinais saudáveis e de nódulo, resultando em curvas 
semelhantes as das Figuras 6.6 e 6.7. Entretanto, ao contrário do que foi feito para obtenção das figuras mencionadas anteriormente, usaram-se somente os casos avançados de nódulo e os sinais saudáveis considerados sem variações. Com isso, mostrou-se, de forma semelhante ao apresentado em Scalassara et al. (2008a), que os sinais de nódulo apresentam valores maiores de entropia do que os sinais saudáveis, conforme apresentado na Figura 7.1. Esse estudo foi apresentado no Tenth IEEE International Symposium on Multimedia (Scalassara et al., 2008b).

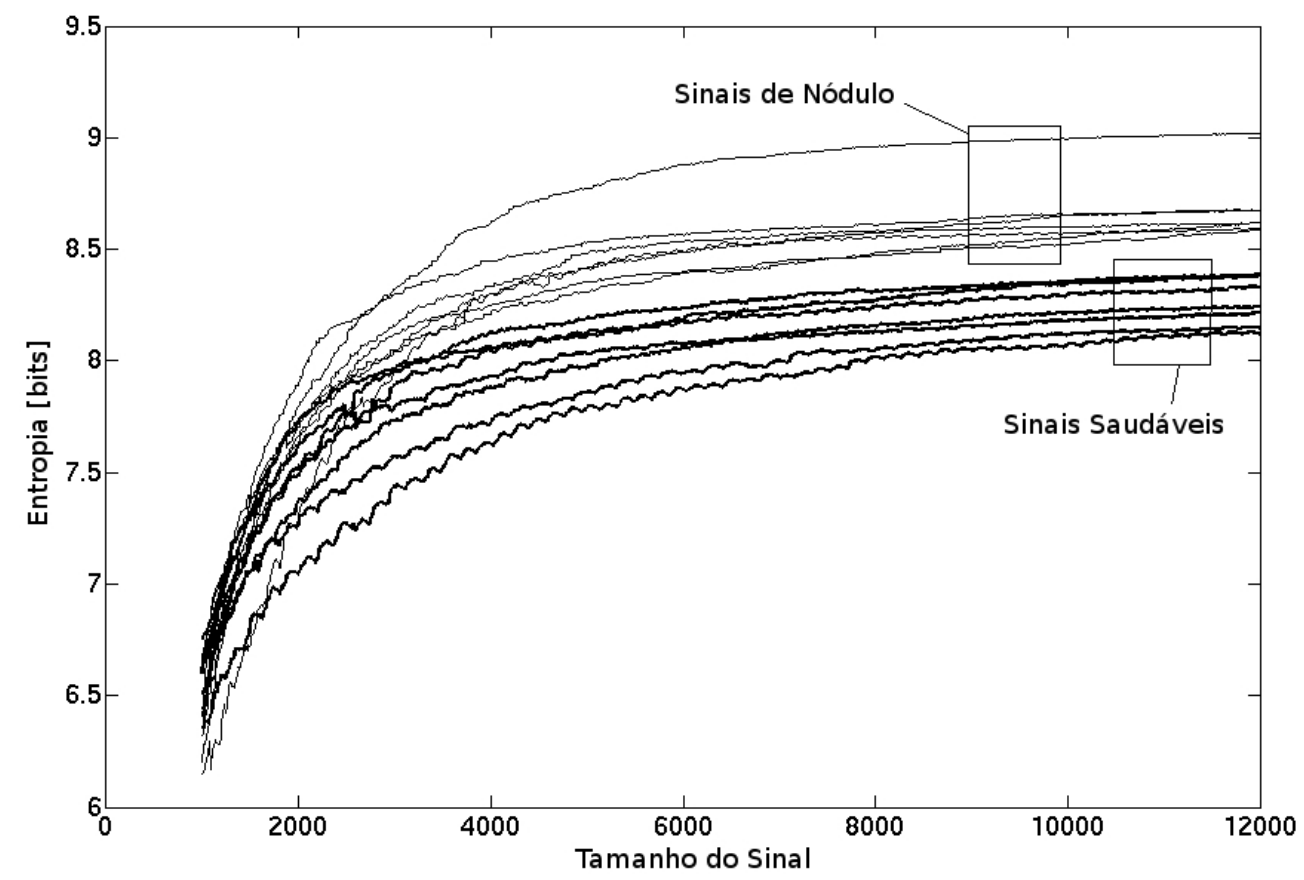

Figura 7.1: Diferenciação das curvas de convergência da entropia para alguns dos sinais de voz saudáveis e de nódulo, conforme apresentado em Scalassara et al. (2008b).

De forma semelhante ao analisado na Figura 6.9, mostrou-se a relação entre a variação da curva de convergência da entropia e o período de pitch dos sinais de voz. Além disso, como os sinais patológicos são casos avançados, foi possível visualisar diferenças entre essas variações para as curvas dos dois grupos. Percebeu-se que, para os sinais de nódulo, essas variações das curvas diminuiam mais rapidamente do que para os sinais saudáveis, como apresentado na Figura 7.2. Como essa variação está relacionada ao período de pitch dos sinais, provavelmente, essa diminuição se deve ao maior jitter dos sinais patológicos. Esse é um resultado interessante, pois relaciona a regularidade dos sinais com o comportamento de suas curvas de convergência da entropia. 


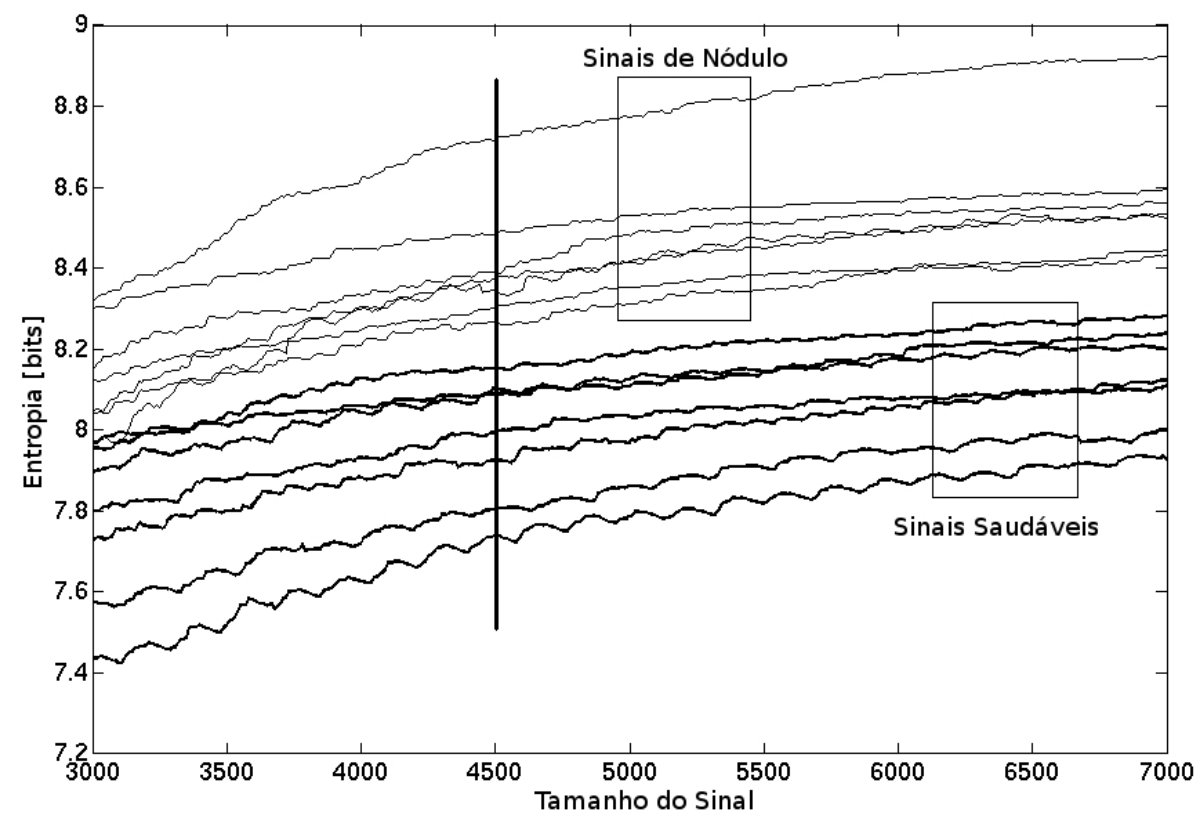

Figura 7.2: Diferença de comportamento das curvas de convergência da entropia dos sinais dos dois grupos estudados conforme apresentado em Scalassara et al. (2008b). Percebe-se que os sinais saudáveis apresentam variação maior para comprimentos maiores dos sinais.

Os problemas da estimativa da entropia de blocos e da curva de crescimento dessa entropia junto com sua assíntota é o tema do estudo apresentado no $8^{o}$. Congresso Temático de Dinâmica, Controle e Aplicações (Scalassara et al., 2009d). Da mesma forma que na Subseção 5.1.4, esses problemas foram minuciosamente discutidos no congresso, apresentando-se vários exemplos.

Ainda sobre as medidas de entropia, as discussões apresentadas na Seção 5.1 sobre três métodos para estimativa dessa medida (discretização da entropia diferencial, passo de quantização constante e equalização do histograma) foram aceitas para serem apresentadas no $20^{\text {th }}$ International Congress on Mechanical Engineering (Scalassara et al., 2009c). Nesse trabalho, discutem-se essas três técnicas apresentando exemplos de sinais compostos por ruídos Gaussianos, sinais simulados e saudáveis de voz.

Por fim, um dos trabalhos mais recentes, publicado no periódico IEEE Engineering in Medicine and Biology Magazine (Scalassara et al., 2009b), apresenta os ensaios de PP usando o modelo de decomposição por wavelets, como discutido na Subseção 6.2.2, especificamente os resultados da Figura 6.14. Mostrou-se que os sinais das duas patologias estudadas: nódulo e edema de Reinke, por serem menos previsíveis (perante o modelo usado) do que os sinais saudáveis, podem ser diferenciados pela PP. 
Após a apresentação da contribuição científica deste trabalho, apresentam-se as conclusões do estudo e os próximos passos que podem ser seguidos para continuar o trabalho.

\subsection{Conclusões Gerais}

Este trabalho visou apresentar uma discussão da aplicabilidade de algumas medidas de previsibilidade para sinais de voz, buscando usá-las para diferenciar sinais saudáveis e patológicos. Esse tipo de análise é muito usada em estudos de clima, especialmente previsões do tempo, obtendo bons resultados. Espera-se, com este estudo, abrir caminho para que esse método possa alcançar resultados interessantes também com sinais vocais. O primeiro passo foi dado, apresentar uma ligação entre previsibilidade e sinais de voz.

Com base na informação que as patologias de laringe, com suas modificações da estrutura do trato vocal e de funcionalidade dos órgãos do sistema vocálico, adicionam perturbações e componentes de ruído aos sinais de voz, mostrou-se que esses sinais se tornam menos previsíveis do que sinais saudáveis. Porém, também se demonstrou que essa relação depende do modelo usado para analisar a previsibilidade dos sinais em estudo.

De forma geral, essas modificações são interpretadas como uma adição de incerteza ao sinal, uma diminuição da informação presente em função da falta de estrutura do mesmo, causada, em especial, pelas perturbações. Essa incerteza acarreta a falta de previsibilidade dos sinais patológicos. Porém, algumas vezes, como no caso de grau avançado de nódulo nas pregas vocais, a patologia causa uma supressão de algumas das harmônicas de alta freqüência da voz, tornando-a menos rica em detalhes, o que, apesar da alta irregularidade da freqüência por exemplo, pode ser interpretado como previsibilidade do sinal. Essa interpretação depende do modelo usado pare se realizar as previsões.

Para avaliação da previsibilidade dos sinais, apresentou-se algumas medidas que podem ser usadas, como a entropia dos sinais de voz, a qual mede a incerteza das probabilidades do sinal, ou a entropia relativa entre sinais de grupos patológicos e 
saudável. Mostrou-se que a entropia dos sinais de voz usados neste estudo não foi suficiente para diferenciar esses sinais, porém pode ser usada para uma primeira análise como apresentado em Scalassara et al. (2008a).

Já a entropia relativa entre os sinais resultou em uma excelente diferenciação entre os sinais patológicos (nódulo e edema de Reinke) e saudáveis usados, conforme Scalassara et al. (2009a). Porém, tem-se limitada aplicabilidade prática, pois é necessário um banco de vozes auxiliares corretamente diagnosticados para se estimar os cruzamentos dessa entropia antes de se saber o resultado da análise da voz em estudo.

Além dessas medidas de entropia, mostrou-se a potência de previsão, a qual foi originalmente usada para análise de clima e que se baseia em comparação (por entropia relativa) entre o sinal e seu erro de previsão dado por um modelo. Usando-se o modelo AR, o qual é um dos mais usados em análise de voz, não se obteve resultado significativo dessa medida para diferenciar os grupos de vozes estudadas. Porém, com análises dos valores médios e das PDFs dos sinais envolvidos no procedimento, mostrou-se que esse modelo AR interpreta o sinal saudável, que possui maior regularidade e riqueza harmônica, como menos previsível do que os sinais patológicos.

Entretanto, usando um modelo baseado em decomposições por wavelets, os valores de PP foram significativamente maiores para os sinais saudáveis do que para os patológicos estudados. Mostrou-se, com análises semelhantes a anterior, que esse modelo interpreta os sinais saudáveis como mais previsíveis, provavelmente devido a sua maior regularidade, e menos previsíveis os sinais patológicos apesar de sua pobreza de informações espectrais.

Uma última abordagem é baseada na análise de componentes previsíveis, a qual decompõe os sinais em estudo em componentes ordenados por sua previsibilidade. Com essa ferramenta, foi possível se obter versões mais previsíveis dos sinais de voz, retirando-se os componentes menos previsíveis e reconstruíndo-se os sinais. Assim, recalcularam-se as PPs dos três grupos estudados, chegando-se a valores com maior capacidade de diferenciação entre os grupos patológicos e o saudável.

Isso foi realizado tanto com o uso do modelo AR quanto do modelo wavelet. No entanto, o modelo AR ainda avalia os sinais saudáveis como menos previsíveis do que os patológicos analisados e o modelo wavelet os avalia com mais previsíveis. Assim, 
conclui-se que a previsibilidade dos sinais de voz, pelo menos com base nos sinais e modelos analisados, depende muito da abordagem usada para análise. Porém, feita a consideração da análise, os resultados se mantém consistentes, pelo menos com a PrCA, não importando a forma de avaliação do modelo usado, foi possível diferenciar os dois grupos (saudável e patológico), mesmo sendo mais ou menos previsível do ponto de vista do modelo.

A PrCA ainda foi aplicada em uma representação tridimensional do sinais de voz, a qual é muito semelhante a reconstrução de espaço de fase, ferramenta da análise nãolinear usada para avaliar a dinâmica dos sistemas em estudo. Porém, neste trabalho, nenhuma consideração não-linear foi feita sobre essa representação, ela foi simplesmente uma diferente forma de se apresentar as informações da voz. Os valores de PP foram obtidos com o auxílio de um modelo AR multidimensional, sendo muito semelhantes aos obtidos pela PrCa com modelo AR aplicada diretamente aos sinais de voz. A capacidade de diferenciação foi menor, mas a forma de análise parece promissora, sendo necessários mais estudos para uma conclusão definitiva de sua capacidade.

Este estudo apresentou indicações que, para o caso dos sinais de voz, o grau de complexidade, ou melhor, de desorganização dos sinais varia com a presença de patologias da laringe em relação aos sinais saudáveis. Podendo, em casos iniciais, diminuir devido a perda de riqueza espectral mas sem muita adição de ruído e perturbações acústicas. Seria possivel, também, com o avanço da patologia, que essa desorganização do sinal fosse aumentando mais e mais, a ponto de ser facilmente detectada como falta de previsibilidade pelos modelos adotados para previsão do sistema.

Este estudo se baseou em poucos sinais de voz que foram coletados de pessoas com diversos graus das patologias e, mesmo para as pessoas com laringes saudáveis, os sinais possuíam várias variações de um para o outro. As características de previsibilidade medidas no trabalho mostraram grandes variações, provavelmente por esse motivo, como também é observado nas variações dos parâmetros acústicos inicialmente apresentados na análise dos sinais de voz. Por essa razão, este trabalho deve ser considerado um estudo inicial, o qual inicia um maior interesse na relação entre previsibilidade e distúrbios de voz e patologias da laringe. 


\subsection{Próximos Passos}

Como este trabalho foi uma das primeiras abordagens ao método da previsibilidade aplicada a sinais de voz, muitas coisas ainda precisam ser feitas. Algumas delas são apresentadas brevemente nesta seção.

Primeiramente, diversos outros ensaios foram realizados com as representações tridimensionais dos sinais de voz, como medidas de entropia diretamente nesse espaço ou outras formas de avaliar a PrCA, como medidas de entropia relativa entre os componentes ou reconstruções. Apesar dos resultados negativos, a análise desse tipo de representação se mostra promissora, principalmente porque as informações dinâmicas do sistema de produção vocal são refletidas nesse espaço de modo diferente ao que acontece nos sinais temporais. As medidas de entropia das representações em três ou duas dimensões apresentaram resultados ruins pois a estimativa da PDF para mais de uma dimensão sofre com a falta de resolução da estimativa, assim, os resultados para os sinais de voz foram muito semelhantes. Mesmo assim, outros métodos podem ser usados futuramente.

Uma alternativa aos algoritmos utilizados de entropia multidimensional é apresentado em Balestrino et al. (2009), aonde se utiliza o conceito de entropia de curvas para analisar o espaço de fase de sistemas dinâmicos, mostrando-se interessante para a aplicação em sinais de voz.

Considerando o ensaio da PrCA das representações tridimensionais, mostrou-se que os resultados não foram tão bons como a aplicação direta nos sinais temporais. Então, talvez com o desenvolvimento de outro modelo para fornecer previsões dessas representações, consiga-se uma melhora desse método. Uma opção seria a utilização de decomposições por wavelets também, porém, faz-se necessário desenvolver um método para isso.

Além disso, com relação ao modelo AR, realizaram-se outros ensaios não apresentados neste texto, como o uso de atrasos entre as amostras dos sinais durante a estimativa dos coeficientes do modelo. Objetivou-se diminuir a correlação entre as amostras, diminuindo a eficiência do modelo, entretanto, melhorando seu desempenho frente ao método da previsibilidade. Em testes preliminares, observou-se uma melhora 
da diferenciação dos grupos de sinais quando comparados aos obtidos com o modelo AR original. Assim, talvez, essa seja uma boa continuação dessas análises.

Uma modificação do algoritmo da PP, publicada em Scalassara et al. (2008a), é a retificação dos sinais de voz antes da análise, ou seja, refletem-se os valores negativos de amplitude para positivos. Com isso, algumas vezes, somam-se as contribuições das variações do sinal, ao invés de se cancelarem. Com essa alteração, foram obtidos bons resultados, porém, mais estudos ainda são necessários para avaliar as conseqüências dessa modificação.

Uma técnica promissora é a equalização do histograma para estimativa da entropia conforme mostrado no Capítulo 5. Porém, foram realizados somente alguns ensaios, observando-se diversos problemas com o método. Mesmo assim, a idéia por trás da utilização dessa técnica é muito interessante, ou seja, tentar diminuir o efeito das baixas amplitudes dos erros de previsão no cálculo da entropia relativa no algoritmo de PP. Assim, com mais estudo, o método poderia apresentar resultados interessantes.

Outro ponto importante, neste estudo, usaram-se poucos sinais, pois a grande maioria dos sinais do banco de dados possuíam problemas de aquisição, tinham diagnóstico duvidoso ou eram não-estacionários. Assim, para um melhor entendimento do comportamento dos métodos de previsibilidade aplicados a voz, é necessário expandir a pesquisa para mais amostras, além de aumentar os tipos de patologias. Com isso, seria possível se analisar melhor as modificações causadas pelas patologias de laringe do ponto de vista da previsibilidade.

Além dessas possíveis melhorias no método para avaliação de sinais patológicos, pode-se pensar em trabalhos futuros usando as medidas de previsibilidade em outras aplicações de áudio, como reconhecimento de fonemas ou locutor, ou ainda em codificação de áudio para melhorar a eficiência dos algoritmos já existentes. 


\section{Referências Bibliográficas}

Accardo, A., Fabbro, F., e Mumolo, E. (1992). Analysis of normal and pathological voices via short-time fractal dimension. In Proceedings of the 29th Annual International Conference of the IEEE EMBS, vol. 14, pp. 1270-1271.

Aghazadeh, B. S., Khadivi, H., e Nikkhah-Bahrami, M. (2007). Nonlinear analysis and classification of vocal disorders. In Proceedings of the Annual International Conference of the IEEE Engineering in Medicine and Biology Society, pp. 61996202 .

Akansu, A. N. e Haddad, R. A. (2001). Multiresolution Signal Decomposition: Transforms, Subbands, Wavelets. Academic Press, London, 2a ed.

Andrade, L. M. O., Vieira, J. M., Razera, D. E., Guerra, A. C., e Pereira, J. C. (2002). Medidas de perturbação da voz: um novo enfoque. Fonoaudiologia Brasil, 2(2):3946.

Araújo, S. A., Rosa, M. O., e Pereira, J. C. (2002). Normatização de medidas acústicas da voz normal. Revista Brasileira de Otorrinolaringologia, 68(4):540-544.

Atal, B. S. e Schroeder, M. R. (1967). Predictive coding of speech signals. In Proceedings of the International Conference on Speech Communications and Processing, pp. 360-361.

Awan, S. N. e Roy, N. (2005). Acoustic prediction of voice type in women with functional dysphonia. Journal of Voice, 19(2):268-282.

Baken, R. (1990). Irregularity of vocal period and amplitude: A first approach to the fractal analysis of voice. Journal of Voice, 4(3):185-197. 
Balestrino, A., Caiti, A., e Crisostomi, E. (2009). Generalised entropy of curves for the analysis and classification of dynamical systems. Entropy, 11:249-270.

Behlau, M. (2001). Voz - O Livro do Especialista, vol. 1. Revinter, São Paulo.

Beirlant, J., Dudewicz, E. J., Györfi, L., e Meulen, E. C. (1997). Nonparametric entropy estimation: An overview. International Journal of the Mathematical Statistics Sciences, 6:17-39.

Bercher, J. F. e Vignat, C. (2000). Estimating the entropy of a signal with applications. IEEE Transactions on Signal Processing, 48(6):1687-1694.

Berouti, M., Schwartz, R., e Makhoul, J. (1979). Enhancement of speech corrupted by acoustic noise. In Proceedings of the IEEE International Conference on Acoustics, Speech, and Signal Processing (ICASSP'79), vol. 4, pp. 208-211.

Bialek, W., Nemenman, I., e Tishby, N. (2001). Predictability, complexity, and learning. Neural Computation, 13:2409-2463.

Birgmeier, M., Bernhard, H., e Kubin, G. (1997). Nonlinear long-term prediction of speech signals. In IEEE International Conference on Acoustics, Speech, and Signal Processing (ICASSP'97), vol. 2, pp. 1283-1286.

Boll, S. F. (1979). Suppression of acoustic noise in speech using spectral subtraction. IEEE Transactions on Acoustics, Speech, and Signal Processing, ASSP-27(2):113120.

Bolzan, M. J. A. (2006). Transformada em ondeleta: Uma necessidade. Revista Brasileira de Ensino de Física, 28(4):563-567.

Boshoff, H. F. V. e Grotepass, M. (1991). The fractal dimension of fricative speech sounds. In Proceedings of the South African Symposium on Communications and Signal Processing (COMSIG'1991), pp. 12-16.

Branco, A. B. e Romariz, M. S. (2006). Doenças das cordas vocais e sua relação com o trabalho. Comun. Ciênc. Saúde, 17(1):37-45.

Broomhead, D. S. e King, G. P. (1986). Extracting qualitative dynamics from experimental data. Physica D: Nonlinear Phenomena, 20(2-3):217-236. 
Bélair, J. (1995). Dynamical Disease: Mathematical Analysis of Human Illness. American Institute of Physics, New York.

Cai, Z., Ruan, J., Gu, F., Tang, L., e Xu, S. (2001). Predictability analysis of the heart rate variability. In Proc. Int. J. Conf. Neural Networks (IJCNN'01), vol. 3, pp. $1642-1645$.

Cannito, P., Buder, E. H., e Chorna, L. B. (2005). Spectral amplitude measures of adductor spasmodic dysphonic speech. Journal of Voice, 19(3):391-410.

Cazares, S. (2001). Tracking poles with an autoregressive model: a confidence index for the analysis of the intrapartum cardiotocogram. Med. Eng. Physics, 23:603-614.

Ceballos, L. G. e Hansen, J. H. L. (1996). Direct speech feature estimation using an iterative em algorithm for vocal fold pathology detection. IEEE Transactions on Biomedical Engineering., 43(4):313-383.

Chaitin, G. J. (1966). On the length of programs for computing finite binary sequences. Journal of the ACM, 13:547-569.

Chen, G. e Parsa, V. (2007). Loudness pattern-based speech quality evaluation using bayesian modeling and markov chain monte carlo methods. Journal of the Acoustic Society of America, 121(2):EL77-EL83.

Cohen, A. (1998). Hidden markov models in biomedical signal processing. In Proceedings of the 20th Annual International Conference of the IEEE Engineering in Medicine and Biology Society, vol. 20, pp. 1145-1150.

Courey, M. S., Gardner, G. M., Stone, R. E., e Ossoff, R. H. (1996). Endoscopic vocal fold microflap: a three year experience. Ann. Otol. Rhinol. Laryngol., 104(4):267273.

Cover, T. M. e Thomas, J. A. (1991). Elements of Information Theory. John Wiley and Sons, Inc., New York.

Crovato, C. D. P. e Schuck, A. (2007). The use of wavelet packet transform and artificial neural networks in analysis and classification of dysphonic voices. IEEE Transactions on Biomedical Engineering., 54(10):1898-1900. 
Crutchfield, J. P., Farmer, J. D., Packard, N. H., e Shaw, R. S. (1986). Chaos. Scientifican American Magazine, 254(12):46-57.

Crutchfield, J. P. e Feldman, D. P. (2003). Regularities unseen, randomness observed: levels of entropy convergence. Chaos, 13(1):25-54.

Dajer, M. E. (2006). Padrões visuais de sinais de voz através de técnica de análise nãolinear. Dissertação de Mestrado, Programa de Pós-Graduação Interunidades Em Bioengenharia. Escola de Engenharia de São Carlos (EESC), Faculdade de Medicina de Ribeirão Preto (FMRP) e Instituto de Química de São Carlos (IQSC), Universidade de São Paulo (USP), São Carlos.

Dajer, M. E., Pereira, J. C., e Maciel, C. D. (2005). Nonlinear dynamical analysis of normal voices. In Proceedings of the Seventh IEEE International Symposium on Multimedia (ISM 2005), pp. 765-771.

Daubechies, I. (1992). Ten Lectures on Wavelets. Society for Industrial and Applied Mathematics, Philadelphia.

Davis, S. B. (1975). Preliminary results using inverse filtering of speech for automatic evaluation of laryngeal pathology. Journal of the Acoustic Society of America, 58(S1):S111-S112.

Davis, S. B. (1979). Acoustic characteristics of normal and pathological voices. In Lass, N. J. (Ed.), Speech and language: advances in basic research and practice, pp. 271-314. Academic Publishers, New York.

Dedivitis, R. A. e Barros, A. P. B. (2002). Métodos de Avaliação e Diagnóstico de Laringe e Voz. Lovise, São Paulo.

Deller, J. R. e Anderson, D. J. (1980). Automatic classification of laryngeal dysfunction using the roots of the digital inverse filter. IEEE Transactions on Biomedical Engineering., BME-27(12):714-721.

DelSole, T. (2004). Predictability and information theory. Part I: Measures of predictability. Journal of the Atmospheric Sciences, 61(20):2425-2440.

DelSole, T. (2005). Predictability and information theory. Part II: Imperfect forecasts. Journal of the Atmospheric Sciences, 62(9):3368-3381. 
DelSole, T. e Chang, P. (2003). Predictable component analysis, canonical correlation analysis, and autoregressive models. Journal of the Atmospheric Sciences, 60(2):409-416.

DelSole, T. e Tippett, M. K. (2007). Predictability: Recent insights from information theory. Rev Geophys, 45(4):RG4002.

Deng, L. e O'Shaughnessy, D. (2003). Speech Processing - A Dynamic and Optimization-Oriented Approach. Marcel Dekker, New York.

Dibazar, A. A., Berger, T. W., e Narayanan, S. S. (2006). Pathological voice assessment. In Proceedings of the 28th IEEE EMBS Annual International Conference, pp. 1669-1673.

Diniz, P. S. R., Silva, E. A. B., e Netto, S. L. (2002). Digital Signal Processing: System Analysis and Design. Cambridge University Press, Cambridge.

Duin, R. (1976). On the choice of the smoothing parameters for parzen estimators of probability density functions. IEEE Trans Comput, 25(11):1175-1179.

Déqué, M. (1998). 10-day predictability of the northern hemisphere winter 500mb height by the ECMWF operational model. Tellus, 40A:26-36.

Eadie, T. L. e Doyle, P. C. (2005). Classification of dysphonic voice: Acoustic and auditory-perceptual measures. Journal of Voice, 19(1):1-14.

Einstein, A., Penrose, R., Geroch, R., e Cassidy, D. C. (2005). Relativity: The Special and the General Theory. Pi Press, New York.

El-Jaroudi, A. e Makhoul, J. (1989). Speech analysis using discrete spectral modeling. In IEEE Proc. 32nd Midwest Symp. Circ. Syst., vol. 1, pp. 85-88.

Engel, J. (1997). The multiresolution histogram. Metrika, 46:41-57.

Epstein, E. S. (1969). Stochastic dynamic predictions. Tellus, 21:739-759.

Erdogmus, D., Hild, K. E., Principe, J. C., Lazaro, M., e Santamaria, I. (2004). Adaptive blind deconvolution of linear channels using renyi's entropy with parzen window estimation. IEEE Transactions on Signal Processing, 52(6):1489-1498. 
Erdogmus, D. e Principe, J. C. (2000). Comparison of entropy and mean square error criteria in adaptive system training using higher order statistics. In Proceedings of the Second International Workshop on Independent Component Analysis and Blind Signal Separation, pp. 75-80.

Erdogmus, D. e Principe, J. C. (2006). From linear adaptive filtering to nonlinear information processing - the design and analysis of information processing systems. IEEE Signal Processing Magazine, 23(6):14-33.

Fant, C. G. M. (1959). Acoustic analysis and synthesis of speech with applications to swedish. Ericsson Technics, 15:3-108.

Feijó, A. V. (2004). Acoustic analysis of voice in multiple sclerosis patients. Journal of Voice, 18(3):341-347.

Flanagan, J. L. (1972). Speech Analysis, Synthesis and Perception. Springer-Verlag, New York, 2a ed.

Fonseca, E. S., Guido, R. C., Scalassara, P. R., Maciel, C. D., e Pereira, J. C. (2007). Wavelet time-frequency analysis and least squares support vector machines for the identification of voice disorders. Computers in Biology and Medicine, 37(4):571578.

Fraser, A. M. e Swinney, H. L. (1986). Independent coordinates for strange attractors from mutual information. Phys. Rev. Lett., 33(2):1134-1140.

Golub, G. H. e Loan, C. F. V. (1996). Matrix computations. Johns Hopkins, Baltimore, 3a ed.

Gomez, P., Diaz, F., Lazaro, C., Murphy, K., Martinez, R., Rodellar, V., e Alvarez, A. (2005). Spectral perturbation parameters for voice pathology detection. In Proceedings of the International Symposium on Signals, Circuits and Systems, ISSCS 2005, vol. 1, pp. 299-302.

Granato, L. F. (2005). Teoria Bayesiana na Avaliação das Condições da Laringe. Tese de Doutorado, Escola de Engenharia de São Carlos (EESC), Universidade de São Paulo (USP), São Carlos. 
Granato, L. F. e Pereira, J. C. (2004). Classificador bayesiano para otimização de parâmetros acústicos no diagnóstico de condições da laringe. In Proceedings of the International Federation for Medical and Biological Engineering (Congresso Latino-Americano de Engenharia Biomédica), vol. 5, pp. 1087-1090.

Gray, A. H. e Markel, J. D. (1974). A spectral-flatness measure for studying the autocorrelation method of linear prediction of speech analysis. IEEE Transactions on Acoustics, Speech, and Signal Processing, ASSP-22(3):207-217.

Gray, S. D., Hirano, M., e Sato, K. (1993). Molecular and cellular structure of vocal fold tissue. In Titze, I. R. (Ed.), Vocal Fold Physiology, pp. 1-36. Singular Publishing Group, San Diego.

Guido, R. C., Jr, S. B., Vieira, L. S., Sanchez, F. L., Maciel, C. D., Pereira, J. C., Scalassara, P. R., e Fonseca, E. S. (2008). Introduction to the discrete shapelet transform and a new paradigm: Joint time-frequency-shape analysis. In Proceedings of the IEEE International Symposium on Circuits and Systems (ISCAS'2008), pp. 2893-2896.

Guido, R. C., Pereira, J. C., Fonseca, E. S., Maciel, C. D., Vieira, L. S., Sanchez, F. L., Guilerme, M. B. A., e Jr., S. B. (2006). Support vector machines and wavelets for voice disorder sorting. In Proceedings of the 38th Southeastern Symposium on System Theory (SSST'06), pp. 434-438.

Guido, R. C., Pereira, J. C., Fonseca, E. S., Sanchez, F. L., e Vieira, L. S. (2005). Trying different wavelets on the search for voice disorders sorting. In Proceedings of the 37th Southeastern Symposium on System Theory (SSST'05), pp. 495-499.

Halavati, R., Shouraki, S. B., e Zadeh, S. H. (2007). Recognition of human speech phonemes using a novel fuzzy approach. Applied Soft Computing, 7(3):828-839.

Hammarberg, B. (1998). Perception and acoustics of voice disorders: a combined approach. In Proceedings of the VOICEDATA98, Symposium on databases in voice quality research and education, pp. 1-6.

Hammarberg, B. (2000). Voice research and clinical needs. Folia Phoniatrica et Logopaedica, 52:93-102. 
Hawkshaw, M., Sataloff, R. T., e Bhatia, R. (1997). Chaos in voice research. In Sataloff, R. T. (Ed.), Professional Voice: The Science and Art of Clinical Care, pp. 185-189. Singular Publishing Group, San Diego, 2a ed.

Hayes, M. H. (1996). Statistical Digital Signal Processing and Modeling. John Wiley \& Sons, Inc., New York.

Haykin, S. (2001). Adaptive Filter Theory. Prentice Hall, 4a ed.

Hegger, R., Kantz, H., e Schreiber, T. (1999). Practical implementation of nonlinear time series methods: The TISEAN package. Chaos, 9(2):413-435.

Hertrich, I., Lutzenberger, W., Spieker, S., e Ackermann, H. (1997). Fractal dimension of sustained vowel productions in neurological dysphonias: An acoustic and electroglottographic analysis. Journal of the Acoustic Society of America, 102(1):652-654.

Hirano, M. (1981a). Clinical Examination of Voice. Disorders of Human Communication 5. Springer-Verlag, New York.

Hirano, M. (1981b). Structure of the vocal folds in normal and disease states: anatomical and physical studies. In Proceedings of the Conference on the Assessment of Vocal Pathology, ASHA Report 17, pp. 11-30.

Hirano, M. e Kakita, Y. (1985). Cover-body theory of vocal fold vibration. In Daniloff, R. G. (Ed.), Speech Science, pp. 1-46. College-Hill Press, San Diego.

Hirano, M. e Sato, K. (1993). Histological Color Atlas of the Human Larynx. Singular Publishing Group, San Diego.

Holmberg, E. (2001). Efficacy of a behaviorally based voice therapy protocol for vocal nodules. Journal of Voice, 15(3):395-412.

Holmberg, E. (2003). Aerodynamic and acoustic voice measurements of patients with vocal nodules: Variation in baseline and changes across voice therapy. Journal of Voice, 17(3):269-282.

Hugh-Munier, C. M., Scherer, K. R., Lehmann, W., e Scherer, U. (1997). Coping strategies, personality, and voice quality in patients with vocal fold nodules and polyps. Journal of Voice, 11(4):452-461. 
Isshiki, N. (1980). Recent advances in phonosurgery. Folia Phoniatrica et Logopaedica, 32(2):119-154.

Jiang, J. J. e Zhang, Y. (2002). Nonlinear dynamic analysis of speech from pathological subjects. Electronics Letters, 38(6):294-295.

Jiang, J. J., Zhang, Y., e McGilligan, C. (2006). Chaos in voice, from modeling to measurement. Journal of Voice, 20(1):2-17.

Jolliffe, I. T. (2002). Principal Component Analysis. Springer-Verlag, New York, 2a ed.

Kannathal, N., Choo, M. L., Acharya, U. R., e Sadasivan, P. K. (2005). Entropies for detection of epilepsy in EEG. Computer Methods and Programs in Biomedicine, 80(3):187-194.

Kantz, H. e Schreiber, T. (2004). Nonlinear Time Series Analysis. Cambridge University Press, Cambridge, 2a ed.

Kasuya, H., Ogawa, S., Mashima, K., e Ebihara, S. (1986). Normalized noise energy as an acoustic measure to evaluate pathologic voice. Journal of the Acoustic Society of America, 80(5):1329-1334.

Katagiri, S. (Ed.) (2000). Handbook of Neural Networks for Speech Processing. Artech House, Norwood, MA, USA.

Kiliç, M. A., Ögüt, F., Dursun, G., Okur, E., Yildirim, I., e Midilli, R. (2004). The effects of vowels on voice perturbation measures. Journal of Voice, 18(3):318-324.

Kleeman, R. (2002). Measuring dynamical prediction utility using relative entropy. Journal of the Atmospheric Sciences, 59(13):2057-2072.

Kleeman, R. (2007). Statistical predictability in the atmosphere and other dynamical systems. Physica D, 230:65-71.

Kleinsasser, G. (1982). Pathogenesis of vocal cord polyps. Ann. Otol. Rhinol. Laryngol., 91(4):378-381.

Koike, Y. (1969). Vowel amplitude modulations in patients with laryngeal diseases. Journal of the Acoustic Society of America, 45:839-844. 
Koike, Y. (1973). Application of some acoustic measures for the evaluation of laryngeal dysfunction. Studia Phonologica, 7:17-23.

Koike, Y. e Markel, J. D. (1975). Application of inverse filtering for detecting laryngeal pathology. Annals of Otology, Rhinology, \& Laryngology, 84:117-124.

Kolmogorov, A. N. (1965). Three approaches to the quantitative definition of information. Problems of Information Transmission, 1:4-7.

Kullback, S. (1968). Information Theory and Statistics. Dover Publications, Inc., Mineola, NY, EUA.

Kumar, A. e Mullick, S. K. (1996). Nonlinear dynamical analysis of speech. Journal of the Acoustic Society of America, 100(1):615-629.

Ladefoged, P. (1995). Elements of Acoustic Phonetics. The University of Chicago Press, Chicago, 2a ed.

Lake, D. E., Richman, J. S., Griffin, M. P., e Moorman, J. R. (2002). Sample entropy analysis of neonatal heart rate variability. Am. J. Physiol. Regul. Integr. Comp. Physiol., 283(3):R789-R797.

Levin, T. C. e Edgerton, M. E. (1999). The throat singers of tuva. Scientific American Magazine, 281(3):82-89.

Lieberman, P. (1963). Some acoustic measures of the fundamental periodicity of normal and pathologic larynges. Journal of the Acoustic Society of America, 35(3):344353.

Lieberman, P. e Blumstein, S. (1988). Speech Physiology, Speech Perception, and Acoustic Phonetics. Cambridge University Press, Cambridge.

Lim, J. S. (1990). Two-Dimensional Signal and Image Processing. Prentice Hall, Inc., Upper Saddle River, NJ, USA.

Linder, R., Albers, A. E., Hess, M., Pöppl, S. J., e Schönweiler, R. (2008). Artificial neural network-based classification to screen for dysphonia using psychoacoustic scaling of acoustic voice features. Journal of Voice, 22(2):155-163. 
Linville, S. E. (2002). Source characteristics of aged voice assessed from long-term average spectra. Journal of Voice, 16(4):472-479.

Lorenz, E. N. (1963). Deterministic nonperiodic flow. Journal of the Atmospheric Sciences, 20:130-141.

Lorenz, E. N. (1975). Climate predictability. In The Physical Basis of Climate and Climate Modelling, vol. 16 of GARP Publication Series, pp. 132-136. World Meteorological Organization.

Lumpkin, S., Bennett, S., e Bishop, S. G. (1990). Postsurgical follow-up study of patients with severe polypoid degeneration. Laryngoscope, 100(4):399-402.

Mac-Kay, A. P. M. G., Assencio-Ferreira, V. J., e Ferri-Ferreira, T. M. S. (2003). Afasias e Demências - Avaliação e Tratamento Fonoaudiológico. Santos, São Paulo.

Maciel, C. D. (2000). Análise de Espectro Singular Aplicado a Ultra-som. Tese de Doutorado, Universidade Federal do Rio de Janeiro, UFRJ, Rio de Janeiro.

Mainardi, L. T. (1995). Pole-tracking algorithms for the extraction of time-variant heart rate variability spectral parameters. IEEE Trans. Biomed. Eng., 43(3):250-259.

Majda, A., Kleeman, R., e Cai, D. (2002). A framework for predictability through relative entropy. Methods and Applications of Analysis, 9(3):425-444.

Mallat, S. (1999). A Wavelet Tour of Signal Processing. Academic Press, Cambridge, $2 \mathrm{a}$ ed.

Markel, J. D. (1972). Digital inverse filtering-a new tool for formant trajectory estimation. IEEE Transactions on Audio and Electroacoustics, 20(2):129-137.

Markel, J. D. e Gray, A. H. (1976). Linear Prediction of Speech. Springer-Verlag, Berlim.

Michelson, A. A. e Morley, E. W. (1887). On the relative motion of the earth and the luminiferous ether. American Journal of Science, 34:333-345.

Moddemeijer, R. (1989). On estimation of entropy and mutual information of continuous distributions. Signal Processing, 16(3):233-248. 
Montagnoli, A. (1998). Análise residual do sinal de voz. Dissertação de Mestrado, Escola de Engenharia de São Carlos (EESC), Universidade de São Paulo (USP), São Carlos.

Moore, C., Manickam, K., e Slevin, N. (2006). Collective spectral pattern complexity analysis of voicing in normal males and larynx cancer patients following radiotherapy. Biomedical Signal Processing and Control, 1:113-119.

Murdoch, B. E. (1997). Desenvolvimento da Fala e Distúrbios da Linguagem - Uma Abordagem Neuroanatômica e Neurofisiológica. Revinter, Rio de Janeiro.

Narayanan, S. S. e Alwan, A. A. (1995). A nonlinear dynamical systems analysis of fricative consonants. Journal of the Acoustic Society of America, 97(4):2511-2524.

Netter, F. H. (1997). Atlas of Human Anatomy. Rittenhouse Book Distributor Inc., 2a ed.

Neumaier, A. e Schneider, T. (2001). Estimation of parameters and eigenmodes of multivariate autoregressive models. ACM Trans. Math. Softw., 27(1):27-57.

Nicollas, R., Garrel, R., Ouaknine, M., Giovanni, A., Nazarian, B., e Triglia, J. M. (2008). Normal voice in children between 6 and 12 years of age: Database and nonlinear analysis. Journal of Voice, 22(6):671-675.

Niedzielska, G. (2005). Acoustic estimation of voice when incorrect resonance function of the nose takes place. Int. J. Ped. Otorhinolaryngology, 69:1065-1069.

Noll, A. M. (1966). Cepstrum pitch determination. Journal of the Acoustic Society of America, 41(2):293-309.

Nwe, T. L., Foo, S. W., e Silva, L. C. (2003). Speech emotion recognition using hidden markov models. Speech Communication, 41:603-623.

O'Leidhin, E. e Murphy, P. (2005). Analysis of spectral measures for voiced speech with varying noise and pertubation levels. In Proceedings of the IEEE International Conference on Acoustics, Speech, and Signal Processing (ICASSP'05), vol. 1, pp. 869-872. 
Oppenheim, A. V. e Schafer, R. W. (1989). Discrete-Time Signal Processing. PrenticeHall International, London.

Oppenheim, A. V., Schafer, R. W., e Buck, J. R. (1999). Discrete-Time Signal Processing. Pearson Education, New York, 2a ed.

Ott, E., Sauer, T., e Yorke, J. A. (1994). Coping with Chaos. John Wiley \& Sons, Inc., New York.

Packard, N. H., Crutchfield, J. P., Farmer, J. D., e Shaw, R. S. (1980). Geometry from a time series. Phys. Rev. Lett., 45(9):712-716.

Paninski, L. (2003). Estimation of entropy and mutual information. Neural Computation, 15:1191-1253.

Papoulis, A. e Pillai, S. U. (2002). Probability, Random Variables and Stochastic Processes. McGraw-Hill, New York, 4a ed.

Peirce, B. O. (1910). A Short Table of Integrals. Ginn \& Company, London.

Pincus, S. M. (1991). Approximate entropy as a measure of system complexity. Proceedings of the National Academy of Sciences of the United States of America, $88: 2297-2301$.

Pincus, S. M. e Goldberger, A. R. (1994). Physiological time-series analysis: what does regularity quantify? Am J Physiol, 266(4 Pt 2):H1643-H1656.

Pinho, S. e Pontes, P. (2002). Escala de avaliação perceptiva da fonte glótica: Rasat. Vox Brasilis, 8(3):11-13.

Pinson, P. (2006). Estimation of the Uncertainty in Wind Power Forecasting. Tese de Doutorado, Ecole des Mines de Paris.

Porta, A., Guzzetti, S., Montano, N., Furlan, R., Pagani, M., Malliani, A., e Cerutti, S. (2001). Entropy, entropy rate, and pattern classification as tools to typify complexity in short heart period variability series. IEEE Trans Biomed Eng, 48(11):1282-1291.

Rabiner, L. R. (1989). A tutorial on hidden markov models and selected applications in speech recognition. Proceedings of the IEEE, 77(2):257-289. 
Rabiner, L. R. e Schafer, R. W. (1978). Digital Processing of Speech Signals. Prentice Hall, Englewood Cliffs, NJ, EUA.

Rabiner, L. R. e Schafer, R. W. (2007). Introduction to digital speech processing. Foundations and Trends in Signal Processing, 1(1-2):1-194.

Renwick, J. e Wallace, J. (1995). Predictable anomally patterns and the forecast skill of northern hemisphere wintertime 500mb height fields. Monthly Weather Review, $123: 2114-2131$.

Richman, J. S. e Moorman, J. R. (2000). Physiological time-series analysis using approximate entropy and sample entropy. Am J Physiol Heart Circ Physiol, 278(6):H2039-H2049.

Ritchings, R. T., McGillion, M., e Moore, C. J. (2002). Technical note: Pathological voice quality assessment using artificial neural networks. Medical Engineering \& Physics, 24:561-564.

Rosa, M. O. (1998). Análise acústica da voz para pré-diagnóstico de patologias de laringe. Dissertação de Mestrado, Escola de Engenharia de São Carlos (EESC), Universidade de São Paulo (USP), São Carlos.

Rosa, M. O., Pereira, J. C., e Carvalho, A. C. P. L. F. (1998). Evaluation of neural classifiers using statistic methods for identification of laryngeal pathologies. In Proceedings of the 5th Brazilian Symposium on Neural Networks, pp. 220-225.

Rosa, M. O., Pereira, J. C., e Grellet, M. (2000). Adaptive estimation of residue signal for voice pathology diagnosis. IEEE Transactions on Biomedical Engineering., 47(1):96-104.

Rényi, A. (1960). On measures of information and entropy. In Proceedings of the 4th Berkeley Symposium on Mathematics, Statistics and Probability, pp. 547-561.

Santos, I. R., Dell'Acqua, R. M., Cunto, M. R., e Pereira, J. C. (2005). Parâmetros acústicos da voz relacionados à soprosidade. Revista da Sociedade Brasileira de Fonoaudiologia, 10(1):53-59. 
Scalassara, P. R. (2005). Análise de sinais de ultra-som usando decomposição autorregressiva e rastreamento de pólos. Dissertação de Mestrado, Universidade Estadual de Londrina (UEL), Londrina, PR.

Scalassara, P. R., Dajer, M. E., e Maciel, C. D. (2005). Application of autoregressive decomposition and pole tracking to pathological voice signals. In Proceedings of the Seventh IEEE International Symposium on Multimedia (ISM’2005), pp. 733-738.

Scalassara, P. R., Dajer, M. E., Maciel, C. D., Guido, R. C., e Pereira, J. C. (2009a). Relative entropy measures applied to healthy and pathological voice characterization. Applied Mathematics and Computation, 207(1):95-108.

Scalassara, P. R., Dajer, M. E., Maciel, C. D., e Pereira, J. C. (2008a). Voice signals characterization through entropy measures. In Proceedings of the International Conference on Bio-inspired Systems and Signal Processing (BIOSIGNALS'2008), vol. 2 , pp. $163-170$.

Scalassara, P. R., Dajer, M. E., Marrara, J. L., Maciel, C. D., e Pereira, J. C. (2008b). Analysis of voice pathology evolution using entropy rate. In Proceedings of the Tenth IEEE International Symposium on Multimedia (ISM'2008), pp. 580-585.

Scalassara, P. R., Maciel, C. D., Guido, R. C., Pereira, J. C., Fonseca, E. S., Montagnoli, A. N., Barbon, S., Vieira, L. S., e Sanchez, F. L. (2007a). Autoregressive decomposition and pole tracking applied to vocal fold nodule signals. Pattern Recognition Letters, 28(11):1360-1367.

Scalassara, P. R., Maciel, C. D., e Pereira, J. C. (2009b). Predictability analysis of voice signals: Analyzing healthy and pathologic samples. IEEE Engineering in Medicine and Biology Magazine, 28(5):30-34.

Scalassara, P. R., Maciel, C. D., Pereira, J. C., e Guimarães, V. F. (2007b). Initial studies of predictability applied to voice signals. In Anais do 6o. Congresso Temático de Dinâmica, Controle e Aplicações (DINCON’2007), pp. 1283-1289.

Scalassara, P. R., Maciel, C. D., Pereira, J. C., Oliveira, S., e Stewart, D. (2009c). Problems with nonparametric entropy estimation of voice signals. In Anais do 20th International Congress on Mechanical Engineering (COBEM’2009). 
Scalassara, P. R., Maciel, C. D., Pereira, J. C., Stewart, D., e Oliveira, S. (2009d). Practical problems with the entropy rate estimation. In Anais do 8o. Congresso Temático de Dinâmica, Controle e Aplicações (DINCON’2009).

Schneider, T. e Griffies, S. M. (1999). A conceptual framework for predictability studies. Journal of Climate, 12(10):3133-3155.

Schneider, T. e Neumaier, A. (2001). Algorithm 808: Arfit - a matlab package for the estimation of parameters and eigenmodes of multivariate autoregressive models. ACM Trans. Math. Softw., 27(1):58-65.

Schroeder, M. R. (1999). Computer Speech - Recognition, Compression, Synthesis. Springer-Verlag, Berlim.

Schroeder, M. R., Atal, B. S., e Hall, J. L. (1979). Optimizing digital speech coders by exploiting masking properties of the human ear. Journal of the Acoustic Society of America, 66(6):1647-1652.

Schürmann, T. e Grassberger, P. (1996). Entropy estimation of symbol sequences. Chaos, 6(3):414-427.

Sergeant, D. e Welch, G. F. (2008). Age-related changes in long-term average spectra of children's voices. Journal of Voice, 22(6):658-670.

Shannon, C. E. (1948). A mathematical theory of communication. The Bell System Technical Jounal, 27:379-423, 623-656.

Shimazaki, H. e Shinomoto, S. (2007). A method for selecting the bin size of a time histogram. Neural Computation, 19:1503-1527.

Silva, L. A. e Joaquim, M. B. (2008). Noise reduction in biomedical speech signal processing based on time and frequency kalman filtering combined with spectral subtraction. Computers and Electrical Engineering, 34:154-164.

Sleigh, J. W., Olofsen, E., Dahan, A., Goede, J., e Ross, A. S. (2001). Entropies of the EEG: the effects of general anaesthesia. In Proceedings of the Fifth International Conference on Memory, Awareness and Consciousness, New York. 
Smolíková, R., Wachowiak, M. P., e Zurada, J. M. (2004). An information-theoretic approach to estimating ultrasound backscatter characteristics. Computers in Biology and Medicine, 34(4):355-370.

Solomonoff, R. (1960). A preliminary report on a general theory of inductive inference. Technical Report V-131, Zator Co., Cambridge.

Steinecke, I. e Herzel, H. (1995). Bifurcations in an asymmetric vocal-fold model. Journal of the Acoustic Society of America, 97(3):1874-1884.

Stewart, I. (1990). Does God Play Dice? The Mathematics of Chaos. Blackwell Publishers, Cambridge.

Therrien, C. W. (1992). Discrete Random Signals and Statistical Signal Processing. Prentice Hall, Inc., Englewood Cliffs, NJ, EUA.

Tippett, M. K. e Chang, P. (2003). Some theoretical considerations on predictability of linear stochastic dynamics. Tellus A, 55(2):148-157.

Titze, I. R. (2004). What is meant by nonlinear and interactive in voice science. Journal of Singing, 60:277-278.

Titze, I. R. (2007). The human instrument. Scientifican American Magazine, 298(1):94-101.

Titze, I. R., Baken, R. J., e Herzel, H. (1993). Evidence of chaos in vocal fold vibration. In Titze, I. R. (Ed.), Vocal Fold Physiology - Frontiers in Basic Science, pp. 143-188. Singular Publishing Group, San Diego.

Tortora, G. J. e Grabowski, S. R. (2002). Princípios de Anatomia e Fisiologia. Guanabara Koogan, Rio de Janeiro, 9a ed.

Uloza, V., Saferis, V., e Uloziene, I. (2005). Perceptual and acoustic assessment of voice pathology and the efficacy of endolaryngeal phonomicrosurgery. Journal of Voice, 19(1):138-145.

Vetterli, M. e Herley, C. (1992). Wavelets and filter banks: Theory and design. IEEE Transactions on Signal Processing, 40:2207-2232. 
Viola, P., Schraudolph, N. N., e Sejnowski, T. J. (1996). Empirical entropy manipulation for real-world problems. In Proceedings of the Neural Information Processing Systems 8 (NIPS'96), pp. 851-857. MIT Press.

Wachowiak, M. P., Smolíková, R., Tourassi, G. D., e Elmaghraby, A. S. (2005). Estimating of generalized entropies with sample spacing. Pattern Anal Applic, 8:95-101.

Wallen, E. J. e Hansen, J. H. (1996). A screening test for speech pathology assessment using objective quality measures. In Proceedings of the Fourth International Conference on Spoken Language, ICSLP 96, vol. 2, pp. 776-779.

Wallis, L. (2004). Vocal fold nodule vs. vocal fold polyp: Answer from surgical pathologist and voice pathologist point of view. Journal of Voice, 18(1):125-129.

Wit, T. D. (1999). When do finite sample effects significantly affect entropy estimates? The European Physical Journal B, 11:513-516.

Wolfe, V., Long, J., Youngblood, H. C., Williford, H., e Olson, M. S. (2002). Vocal parameters of aerobic instructors with and without voice problems. Journal of Voice, 16(1):52-60.

Wong, D. Y., Markel, J. D., e Gray, A. H. (1979). Least squares glottal inverse filtering from the acoustic speech waveform. IEEE Transactions on Acoustics, Speech, and Signal Processing, ASSP-27(4):350-355.

Wyner, A. J. e Foster, D. (2003). On the lower limits of entropy estimation. Tech. Rep. Dept. Statistics, Wharton School, Univ. Pennsylvania.

Yao, W., Essex, C., Yu, P., e Davison, M. (2004). Measure of predictability. Physical Review E, 69:066121-1a13.

Yates, A. e Dedo, H. (1984). Carbon dioxide laser enucleation of polypoid vocal cords. Laryngoscope, 94(6):731-736.

Yumoto, E., Gould, W. J., e Baer, T. (1982). Harmonics-to-noise ratio as an index of the degree of hoarseness. Journal of the Acoustic Society of America, 71(6):1544-1550. 
Zhang, Y., Jiang, J. J., Biazzo, L., e Jorgensen, M. (2005a). Perturbation and nonlinear dynamic analyses of voices from patients with unilateral laryngeal paralysis. Journal of Voice, 19(4):519-528.

Zhang, Y., Jiang, J. J., Wallace, S. M., e Zhou, L. (2005b). Comparison of nonlinear dynamic methods and perturbation methods for voice analysis. Journal of the Acoustic Society of America, 118(4):2551-2560.

Zyczkowski, K. (2003). Rényi extrapolation of shannon entropy. Open Sys Information Dyn, 10:297-310. 


\section{APÊNDICE A:}

\section{Simulador de Sinais de Voz}

Neste apêndice, apresenta-se uma descrição do simulador de sinais de voz utilizado para realizar os testes inciais dos algoritmos de previsibilidade. Os sinais simulados foram usados para facilitar a interpretação dos resultados e também a correção de erros dos algoritmos.

Esse simulador desenvolvido em Matlab foi baseado em um simulador semelhante para sinais de ultra-som (Scalassara, 2005; Maciel, 2000). Para gerar um sinal simulado, utilizam-se quatro parâmetros: $N$, número de pontos do sinal; $A d$, amplitude relativa do ruído Gaussiano a ser somado no sinal (relativo à amplitude máxima do sinal); J, percentual (decimal) do jitter; e Sh, percentual (decimal) do shimmer. O número de pontos não é limitado, mas os outros parâmetros possuem valores limite. $\mathrm{O}$ $A d$ está limitado à unidade, ou seja, ruído com amplitude igual ao sinal. O jitter está limitado a $25 \%$ e o shimmer a $50 \%$.

Para a criação do sinal simulado, utiliza-se um trecho de sinal de voz real feminino de vogal "a" sustentada, com média nula e amplitude normalizada. Esse sinal de voz foi retirado do banco de vozes, possuíndo características típicas (normais) conforme análise perceptiva-auditiva de fonoaudiólogos. A Figura A.1 apresenta esse trecho de sinal.

Para a geração de sequiências de números aleatórios Gaussianos, utilizam-se novas sementes a cada uso do algoritmo de números aleatórios, as quais são baseadas no relógio do computador. Assim, evitam-se repetições de sequiências. Para aplicar o valor de jitter desejado ao sinal, utiliza-se uma dessas sequiências de números aleatórios 
Gaussianos para fornecer o número de amostras de cada período do sinal final. Isso é feito com base no jitter escolhido e no tamanho do trecho de sinal usado. Assim, tem-se o número de amostras a serem adicionadas ou subtraídas do trecho para cada período.

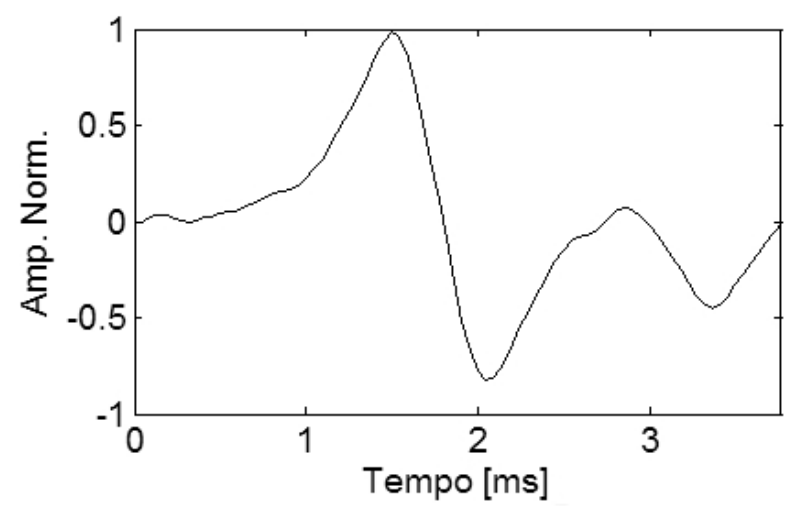

Figura A.1: Trecho de sinal de voz feminina de vogal "a" sustentada com características normais usada para criar sinais simulados.

Quando se faz necessário adicionar pontos no período, usam-se locais aleatórios do trecho, usando uma outra sequiência de números aleatórios. Os valores do sinal relacionados a esses novos pontos são obtidos pela interpolação dos pontos anterior e posterior. No caso contrário, quando se precisa retirar pontos do sinal, usam-se pontos aleatórios, substituindo o ponto anterior ao retirado pela média entre esses dois, evitando mudanças bruscas no sinal.

O shimmer também é criado utilizando-se uma sequiência de números aleatórios Gaussianos. Essa seqüência, de média nula, tem o valor de shimmer desejado como desvio padrão, sendo somada ao trecho de sinal para formar cada período. Após se criar um sinal completo com jitter e shimmer, adiciona-se o ruído Gaussiano, de média nula, conforme o valor de $A d$. Por fim, calcula-se o valor de relação sinal-ruído usando a Equação (A.1), em decibéis, sendo $\sigma_{x}$ e $\sigma_{r}$ as variâncias do sinal, antes de adicionado o ruído, e do ruído respectivamente.

$$
S N R=10 \log \left(\frac{\sigma_{x}}{\sigma_{r}}\right)
$$

Durante a formação de cada período do sinal, medem-se os jitter e shimmer efetivos, ou seja, seus valores reais no sinal. Isso é feito para se obter um valor de compa- 
ração, pois o processo de geração do sinal é aproximado, principalmente para valores dos parâmetros menores do que 1\%. A Tabela A.1 apresenta um resumo do algoritmo para gerar os sinais simulados.

Tabela A.1: Resumo do algoritmo usado para gerar sinais simulados de voz.

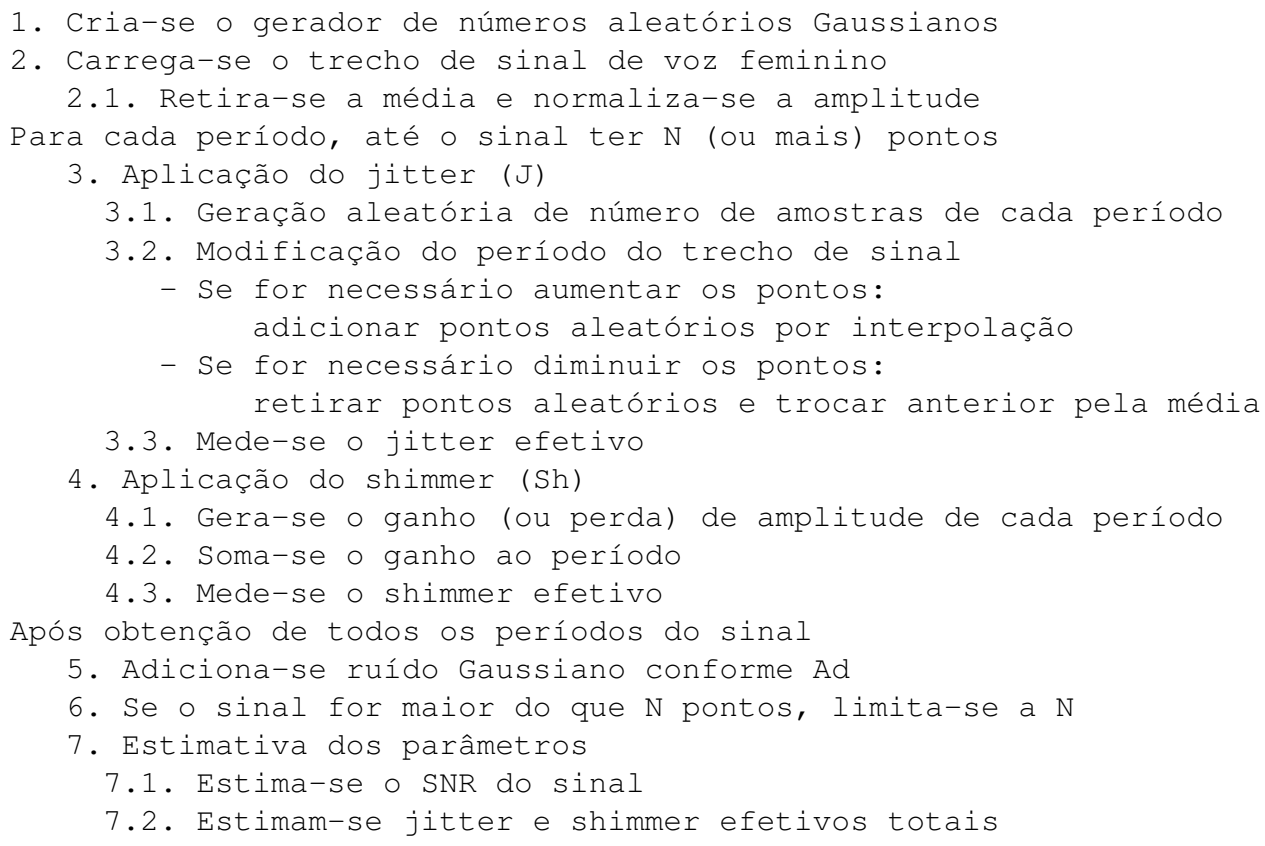

Realizaram-se alguns testes para verificar a variação dos valores especificados de jitter e shimmer. Variou-se o jitter de 0, 01 a 0, 25 em intervalos de 0,01, resultando em 25 valores. Para cada um desses valores, criaram-se 5 sinais simulados para obtenção de jitter efetivo médio. Obteve-se um erro médio de $3,12 \%$ com desvio padrão de $3,17 \%$.

Para o shimmer, fez-se algo semelhante, variando o parâmetro de 0,01 a 0,49 em intervalos de 0,02 , também criando 5 sinais simulados por valor. $\mathrm{O}$ erro médio obtido entre o shimmer especificado e o efetivo foi de $0,39 \%$ com desvio padrão de $2,68 \%$. Assim, tem-se erros dentro de uma pequena faixa de variação, podendo ser desprezados.

Além desses testes, também, analisou-se o nível de ruído. Variou-se esse parâmetro de 0,01 a 0,96 em intervalos de 0,05 , também criando 5 sinais simulados por valor. A média e o desvio padrão dos valores de SNR obtidos são apresentados na Figura A.2. Pode-se ver que o desvio padrão é mínimo e o SNR diminui gradativamente conforme o nível do ruído relativo aumenta, conforme esperado. 


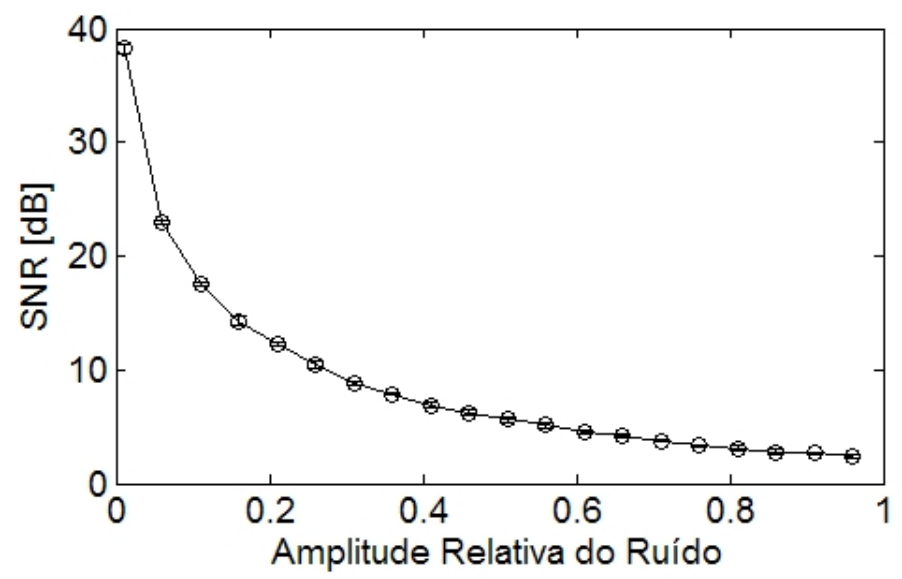

Figura A.2: Variação do nível de ruído dos sinais simulados versus o SNR do sinal resultante.

Como comparação, na Figura A.3 (a), apresenta-se o sinal de voz feminino original utilizado para se obter o período do simulador. Na parte (b), tem-se um sinal simulado com jitter e shimmer iguais a $2 \%$ e $4 \%$ respectivamente. Esses valores estão dentro da variação desses parâmetros para sinais saudáveis (Montagnoli, 1998). Além disso, o nível de ruído está em 10\%, SNR igual a 19,55 dB, valor próximo do real, dependendo da qualidade do microfone usado na aquisição da voz.

Nas partes (c) e (d) da figura, mostram-se as representações tridimensionais dos dois sinais respectivamente. Conforme apresentado no Capítulo 4, $\tau$ é o mínimo da informação mutual do sinal original. Comparando-se os sinais, tanto no tempo quanto no espaço tridimensional, percebe-se algumas diferenças, referentes aos parâmetros jitter, shimmer e nível de ruído.

Para uma melhor comparação, apresenta-se outro sinal de voz feminino de "a" sustentado na Figura A.4 apresenta essa nova comparação. Comparando-se essa figura com a anterior, percebe-se que os sinais temporais não são tão parecidos.

Entretanto, apesar dessas diferenças, o sinal simulado continua semelhante ao sinal real. Podendo ser considerado dentro da variabilidade normal dos sinais de voz saudáveis. Por outro lado, modelar sinais patológicos é algo bem complicado, pois, a patologia faz com que os sinais não se adequem aos modelos utilizados.

Assim, com base na informação de que os sinais patológicos geralmente apresentam maiores níves dos parâmetros jitter, shimmer e nível de ruído, conforme Davis (1979), utilizou-se esse enfoque nos testes para simular sinais problemáticos. Então, 


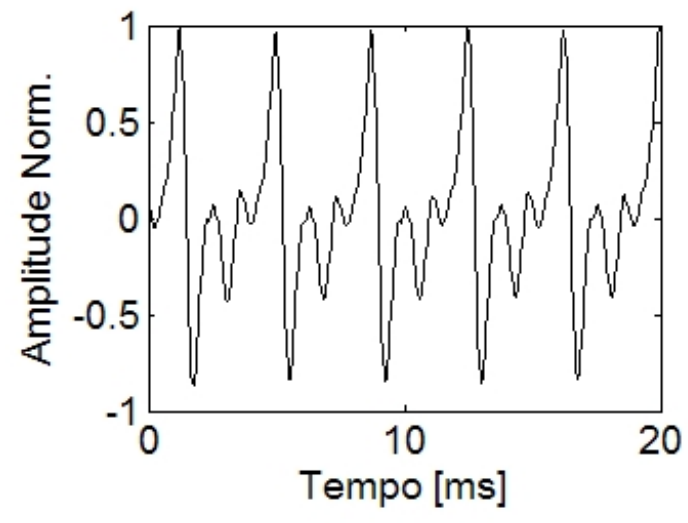

(a)

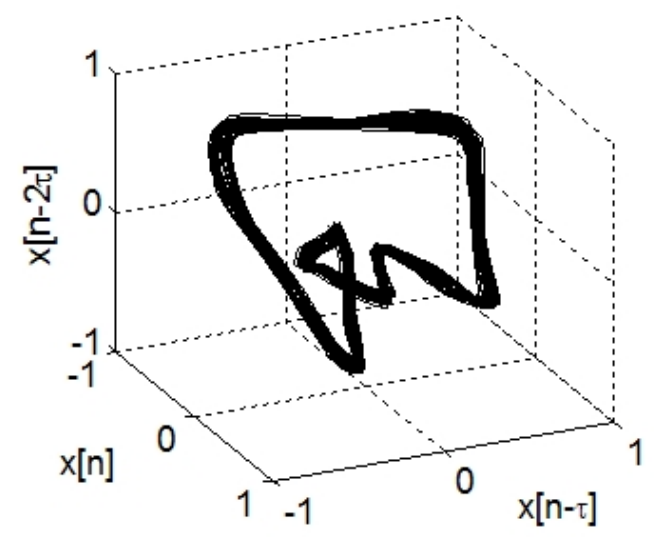

(c)

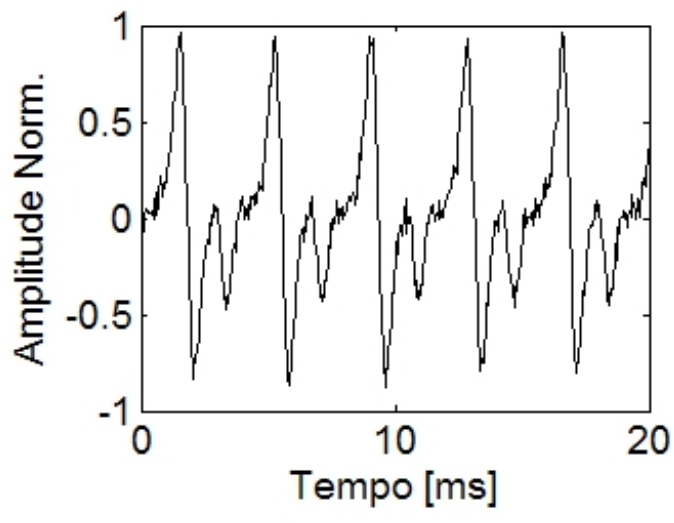

(b)

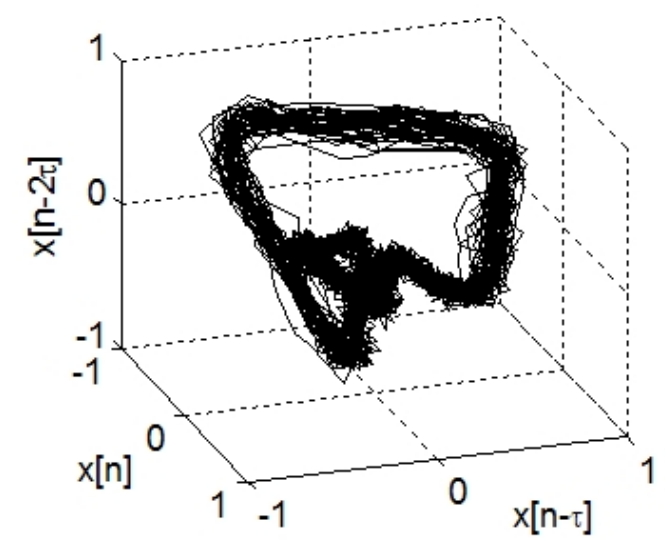

(d)

Figura A.3: (a) Trecho do sinal de voz feminino de "a" sustentado original utilizado no simulador. (b) Trecho de um sinal simulado com jitter igual a $2 \%$, shimmer igual a $4 \%$ e nível de ruído igual a 10\% (SNR de 19,55 dB). (c) Representação tridimensional do sinal original usando atraso de 10 amostras. (d) Representação tridimensional do sinal simulado usando atraso de 10 amostras.

pôde-se analisar o comportamento dos algoritmos de previsibilidade quando os sinais se tornam menos previsíveis com base nos modelos usados.

Porém, as patologias de laringe não causam somente esse tipo de modificações nos sinais de voz. Como exemplo, tem-se os sinais de voz gerados por uma pessoa com nódulos (em estágio avançado) nas pregas vocais, Figura A.5 (a), percebe-se a perda da riqueza do sinal, o qual possui menos informação harmônica. Isso também é visível na sua representação tridimensional, parte (b) da figura, a qual possui somente um laço (conforme capítulo 4).

Dessa forma, como essa e outras características não foram incorporadas no simulador, essa ferramenta é utilizada para os testes iniciais somente, objetivando analisar 


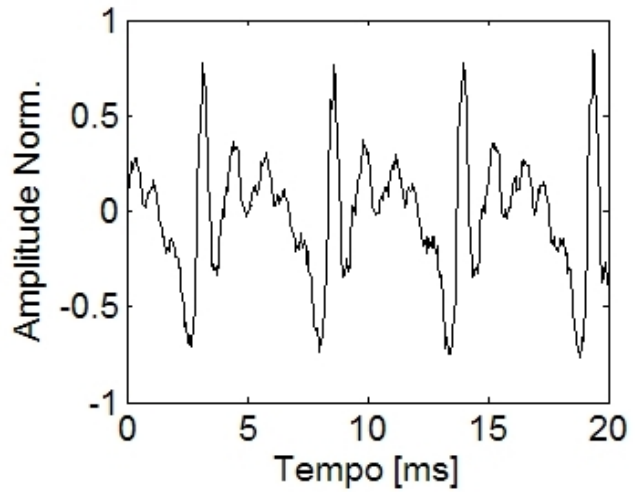

(a)

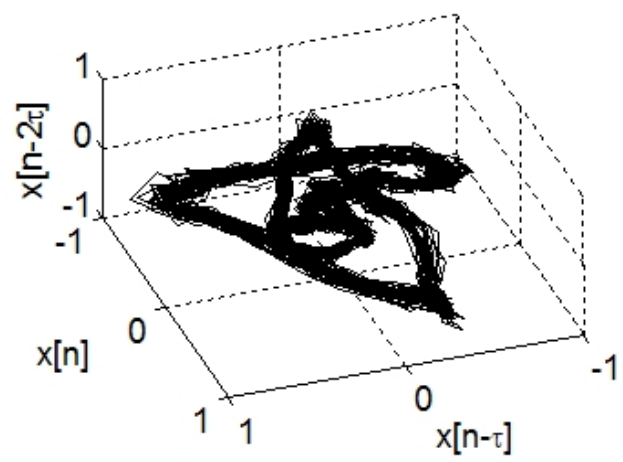

(b)

Figura A.4: (a) Trecho de outro sinal de voz feminino de "a" sustentado. (b) Representação tridimensional do sinal usando atraso de 10 amostras.

os algoritmos e eliminar erros simples.

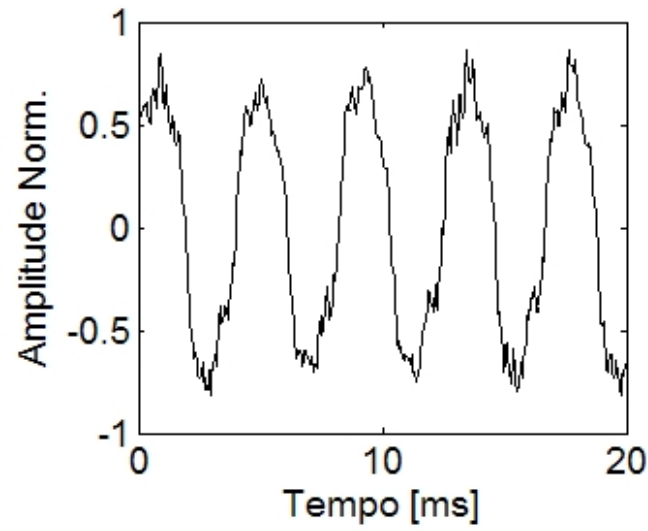

(a)

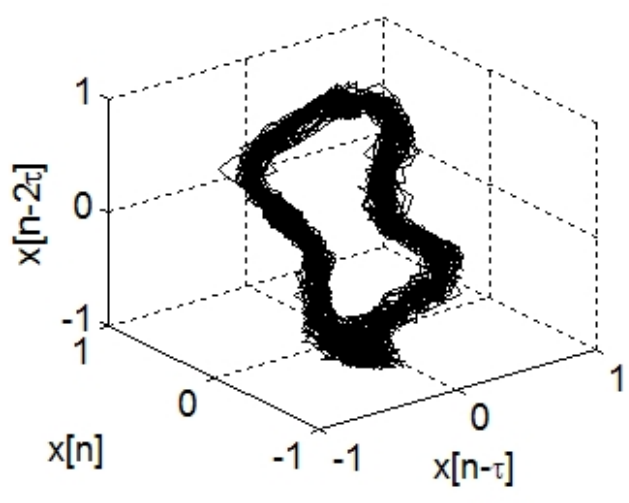

(b)

Figura A.5: (a) Exemplo de sinal de voz de pessoa com nódulo nas pregas vocais. (b) Representação tridimensional do sinal usando atraso de 10 amostras. Percebe-se a pouca informação harmônica pela falta de laços. 


\section{APÊNDICE B:}

\section{Erro da Entropia Relativa pelo}

\section{Deslocamento da PDF}

Neste apêndice, apresenta-se a dedução do erro adicionado à entropia relativa para o deslocamento da PDF da segunda distribuição usada nos cálculos. Conforme apresentado no Capítulo 5, para evitar divisões por zero no algoritmo da estimativa da entropia relativa de duas distribuições, adiciona-se um valor na PDF da segunda, a qual é o denominador da Equação (3.5), repetida como a Equação (B.1), sendo $p_{X}(x)$ e $q_{X}(x)$ as duas PDFs.

$$
D\left(p_{X} \| q_{X}\right)=\int_{-\infty}^{\infty} p_{X}(x) \log \frac{p_{X}(x)}{q_{X}(x)} d x
$$

Considerando o valor somado na segunda PDF como $e$, a nova entropia relativa passa a ser $D\left(p_{X} \| q_{X}\right)^{\prime}$, a qual é obtida usando $q_{X}(x)^{\prime}=q_{X}(x)+e$. Dessa forma, o erro desse procedimento, $E$, pode ser escrito conforme a Equação (B.2).

$$
\begin{aligned}
E & =D\left(p_{X} \| q_{X}\right)-D\left(p_{X} \| q_{X}\right)^{\prime} \\
& =\int_{-\infty}^{\infty} p_{X}(x) \log \frac{p_{X}(x)}{q_{X}(x)} d x-\int_{-\infty}^{\infty} p_{X}(x) \log \frac{p_{X}(x)}{q_{X}(x)+e} d x
\end{aligned}
$$

Expandindo-se essa equação usando as propriedades dos logaritmos e das integrais, chega-se na Equação (B.4). 


$$
\begin{aligned}
E & =\int_{-\infty}^{\infty} p_{X}(x) \log \left[q_{X}(x)+e\right]-p_{X}(x) \log q_{X}(x) d x \\
& =\int_{-\infty}^{\infty} p_{X}(x)\left\{\log \left[q_{X}(x)+e\right]-\log q_{X}(x)\right\} d x \\
& =\int_{-\infty}^{\infty} p_{X}(x) \log \left[1+\frac{e}{q_{X}(x)}\right] d x
\end{aligned}
$$

Quando o erro $e$ tende a zero, chega-se na Equação (B.4).

$$
\lim _{e \rightarrow 0} E=\lim _{e \rightarrow 0} \int_{-\infty}^{\infty} p_{X}(x) \log \left[1+\frac{e}{q_{X}(x)}\right] d x
$$

Assim, o termo $\frac{e}{q_{X}(x)}$ do logaritmo tende a zero, deixando somente $\log 1=0$, portanto, tem-se um erro nulo. Dessa forma, no algoritmo de estimativa da entropia relativa, ao se fazer o valor somado à segunda PDF suficientemente pequeno, pode-se considerar o erro desse processo desprezível. 


\section{APÊNDICE C:}

\section{Entropia de Distribuições}

\section{Gaussianas}

Neste apêndice, apresenta-se a dedução da entropia diferencial de uma distribuição Gaussiana e também a entropia relativa (diferencial) de duas distribuições Gaussianas com mesma média e desvios padrões diferentes.

\section{C.1 Entropia de Shannon de uma Distribuição Gaussiana}

Conforme apresentado no Capítulo 3, a entropia diferencial de uma variável aleatória contínua $X, \operatorname{com} \operatorname{PDF} p_{X}(x)$, é dada pela Equação (3.2), repetida na Equação (C.1).

$$
H_{D}(x)=-\int_{-\infty}^{\infty} p_{X}(x) \ln p_{X}(x) d x
$$

A PDF de uma distribuição Gaussiana de uma variável aleatória contínua é dada pela Equação (C.2), sendo $\mu$ e $\sigma$ a média e desvio padrão respectivamente.

$$
p_{X}(x)=\frac{1}{\sigma \sqrt{2 \pi}} e^{-\frac{(x-\mu)^{2}}{2 \sigma^{2}}}
$$

Assim, substituíndo (C.2) em (C.1), chega-se na Equação (C.3). A qual pode ser reescrita como (C.4). 


$$
\begin{gathered}
H_{D}(x)=-\int_{-\infty}^{\infty}\left[\frac{1}{\sigma \sqrt{2 \pi}} e^{-\frac{(x-\mu)^{2}}{2 \sigma^{2}}}\right] \ln \left[\frac{1}{\sigma \sqrt{2 \pi}} e^{-\frac{(x-\mu)^{2}}{2 \sigma^{2}}}\right] d x \\
H_{D}(x)=-\frac{1}{\sigma \sqrt{2 \pi}} \int_{-\infty}^{\infty}\left[e^{-\frac{(x-\mu)^{2}}{2 \sigma^{2}}}\right]\left\{\ln \left(\frac{1}{\sigma \sqrt{2 \pi}}\right)+\ln \left[e^{-\frac{(x-\mu)^{2}}{2 \sigma^{2}}}\right]\right\} d x(\text { C.4) }
\end{gathered}
$$

Após essas etapas, divide-se a integral anterior em duas, conforme a Equação (C.5).

$$
\begin{aligned}
H_{D}(x)= & -\frac{1}{\sigma \sqrt{2 \pi}} \int_{-\infty}^{\infty} \ln \left(\frac{1}{\sigma \sqrt{2 \pi}}\right) e^{-\frac{(x-\mu)^{2}}{2 \sigma^{2}}} d x+ \\
& +\frac{1}{\sigma \sqrt{2 \pi}} \int_{-\infty}^{\infty}\left[\frac{(x-\mu)^{2}}{2 \sigma^{2}}\right] e^{-\frac{(x-\mu)^{2}}{2 \sigma^{2}}} d x
\end{aligned}
$$

Simplificando-se essa equação, chega-se na Equação (C.6).

$$
\begin{aligned}
H_{D}(x) & =\frac{\ln (\sigma \sqrt{2 \pi})}{\sigma \sqrt{2 \pi}} \int_{-\infty}^{\infty} e^{-\frac{(x-\mu)^{2}}{2 \sigma^{2}}} d x+ \\
& +\frac{1}{\sigma \sqrt{2 \pi}} \int_{-\infty}^{\infty}\left[\frac{(x-\mu)^{2}}{2 \sigma^{2}}\right] e^{-\frac{(x-\mu)^{2}}{2 \sigma^{2}}} d x
\end{aligned}
$$

Utilizando-se o método da substituição para a resolução dessas integrais, sendo $u=\frac{(x-\mu)}{\sigma \sqrt{2}}$ e $d x=\sigma \sqrt{2} d u$, obtém-se (C.7). Como as funções integradas são simétricas, substitui-se essa equação por (C.8).

$$
\begin{aligned}
& H_{D}(x)=\frac{\ln (\sigma \sqrt{2 \pi})}{\sqrt{\pi}} \int_{-\infty}^{\infty} e^{-u^{2}} d u+\frac{1}{\sqrt{\pi}} \int_{-\infty}^{\infty} u^{2} e^{-u^{2}} d u \\
& H_{D}(x)=\frac{2 \ln (\sigma \sqrt{2 \pi})}{\sqrt{\pi}} \int_{0}^{\infty} e^{-u^{2}} d u+\frac{2}{\sqrt{\pi}} \int_{0}^{\infty} u^{2} e^{-u^{2}} d u
\end{aligned}
$$

Essas integrais são tabeladas conforme as Equações (492) e (494) retiradas de Peirce (1910), as quais são repetidas como as Equações (C.9) e (C.10), respectivamente. 


$$
\begin{gathered}
\int_{0}^{\infty} e^{-a^{2} x^{2}} d x=\frac{\sqrt{\pi}}{2 a} \\
\int_{0}^{\infty} x^{2 n} e^{-a x^{2}} d x=\frac{1 \times 3 \times 5 \times \ldots \times(2 n-1)}{2^{n+1} a^{n}} \sqrt{\frac{\pi}{a}}
\end{gathered}
$$

De posse dessas formulações, substituem-se (C.9) e (C.10) em (C.8), chegando-se na Equação (C.12).

$$
\begin{aligned}
& H_{D}(x)=\frac{2 \ln (\sigma \sqrt{2 \pi})}{\sqrt{\pi}} \frac{\sqrt{\pi}}{2}+\frac{2}{\sqrt{\pi}} \frac{\sqrt{\pi}}{4} \\
& H_{D}(x)=\ln (\sigma \sqrt{2 \pi})+\frac{1}{2}
\end{aligned}
$$

Pode-se simplificar essa última equação de forma a se obter a versão final da entropia para uma distribuição Gaussiana, Equação (C.12).

$$
H_{D}(x)=\ln (\sigma \sqrt{2 \pi e})
$$

\section{C.2 Entropia Relativa entre duas Distribuições Gaussianas}

Após a obtenção da entropia de uma distribuição Gaussiana, busca-se a entropia relativa diferencial entre duas distribuições de uma variável aleatória contínua que possuam médias iguais, $\mu$, e desvios padrões $\sigma_{1}$ e $\sigma_{2}$. As PDFs são dadas pela Equação (C.2), substituíndo-se os desvios para cada caso.

A entropia relativa entre duas PDFs é dada pela Equação (3.5), apresentada no Capítulo 3, a qual é repetida aqui como a Equação (C.13), sendo $p_{X}(x)$ e $q_{X}(x)$ essas duas PDFs.

$$
D\left(p_{X} \| q_{X}\right)=\int_{-\infty}^{\infty} p_{X}(x) \ln \frac{p_{X}(x)}{q_{X}(x)} d x
$$

Essa equação pode ser desenvolvida, chegando-se na Equação (C.14), sendo a nomenclatura modificada de $D\left(p_{X} \| q_{X}\right)$ para $D$, por questões de simplicidade. 


$$
D=\int_{-\infty}^{\infty} p_{X}(x) \ln \left[p_{X}(x)\right] d x-\int_{-\infty}^{\infty} p_{X}(x) \ln \left[q_{X}(x)\right] d x
$$

O primeiro termo do lado direito da equação é o negativo da entropia diferencial de $p_{X}(x)$, Equação (C.12), o que leva à Equação (C.15).

$$
D=-\ln \left(\sigma_{1} \sqrt{2 \pi e}\right)-\int_{-\infty}^{\infty} p_{X}(x) \ln \left[q_{X}(x)\right] d x
$$

Substituindo-se as duas PDFs Gaussianas na equação anterior, obtém-se (C.16).

$$
D=-\ln \left(\sigma_{1} \sqrt{2 \pi e}\right)-\int_{-\infty}^{\infty}\left[\frac{1}{\sigma_{1} \sqrt{2 \pi}} e^{-\frac{(x-\mu)^{2}}{2 \sigma_{1}^{2}}}\right] \ln \left[\frac{1}{\sigma_{2} \sqrt{2 \pi}} e^{-\frac{(x-\mu)^{2}}{2 \sigma_{2}^{2}}}\right] d x
$$

Dividindo-se essa integral em duas partes pela separação do logaritmo da multiplicação, como feito na seção anterior, obtém-se a Equação (C.17).

$$
\begin{aligned}
D= & -\ln \left(\sigma_{1} \sqrt{2 \pi e}\right)-\left(\frac{1}{\sigma_{1} \sqrt{2 \pi}}\right) \ln \left(\frac{1}{\sigma_{2} \sqrt{2 \pi}}\right) \int_{-\infty}^{\infty} e^{-\frac{(x-\mu)^{2}}{2 \sigma_{1}^{2}}} d x \\
& +\left(\frac{1}{\sigma_{1} \sqrt{2 \pi}}\right) \int_{-\infty}^{\infty} \frac{(x-\mu)^{2}}{2 \sigma_{2}^{2}} e^{-\frac{(x-\mu)^{2}}{2 \sigma_{1}^{2}}} d x
\end{aligned}
$$

Novamente, usando-se o método da substituição com $u=\frac{(x-\mu)}{\sigma_{1} \sqrt{2}}$ e $d x=\sigma_{1} \sqrt{2} d u$, obtém-se a Equação (C.18), sendo utilizada também a simetria das funções integradas.

$$
\begin{aligned}
D= & -\ln \left(\sigma_{1} \sqrt{2 \pi e}\right)+\frac{2 \ln \left(\sigma_{2} \sqrt{2 \pi}\right)}{\sqrt{\pi}} \int_{0}^{\infty} e^{-u^{2}} d u \\
& +\frac{2 \sigma_{1}^{2}}{\sigma_{2}^{2} \sqrt{\pi}} \int_{0}^{\infty} u^{2} e^{-u^{2}} d u
\end{aligned}
$$

Assim, usam-se as formulações (C.9) e (C.10), o que resulta na Equação (C.19).

$$
\begin{aligned}
& D=\ln \left(\sigma_{1} \sqrt{2 \pi e}\right)+\frac{2 \ln \left(\sigma_{2} \sqrt{2 \pi}\right)}{\sqrt{\pi}} \frac{\sqrt{\pi}}{2}+\frac{2 \sigma_{1}^{2}}{\sigma_{2}^{2} \sqrt{\pi}} \frac{\sqrt{\pi}}{4} \\
& D=\ln \left(\sigma_{1} \sqrt{2 \pi e}\right)+\ln \left(\sigma_{2} \sqrt{2 \pi}\right)+\frac{1}{2} \frac{\sigma_{1}^{2}}{\sigma_{2}^{2}}
\end{aligned}
$$


Após alguma manipulação matemática, obtém-se as duas formas apresentadas na Equação (C.20), as quais são duas versões da entropia relativa entre duas distribuições Gaussianas com mesma média e desvios padrões iguais a $\sigma_{1}$ e $\sigma_{2}$.

$$
\begin{aligned}
D & =\ln \left(\frac{\sigma_{2}}{\sigma_{1}} e^{\frac{\sigma_{1}^{2}-\sigma_{2}^{2}}{2 \sigma_{2}^{2}}}\right) \\
D & =\frac{\sigma_{1}^{2}-\sigma_{2}^{2}}{2 \sigma_{2}^{2}}+\ln \frac{\sigma_{2}}{\sigma_{1}}
\end{aligned}
$$

